\title{
The ecology of sponges at Palmyra Atoll: variability, introduced species and their potential direct and indirect impacts
}

\section{Ingrid Sally Sigrid Knapp}

\author{
A thesis \\ submitted to the Victoria University of Wellington \\ in fulfilment of the requirements for the degree of \\ Doctor of Philosophy in Marine Biology
}

2013

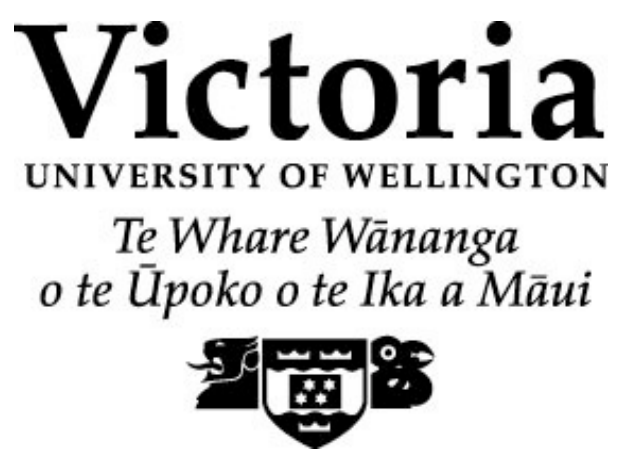


"It is that range of biodiversity that we must care for-the whole thing-rather than just one or two stars."

(David Attenborough) 


\section{Acknowledgements}

This thesis would not have been possible without the input from a number of collaborators, most of which I am fortunate enough to also call friends. Foremost, I would like to thank my primary supervisor, Dr James Bell, for his constant encouragement, advice and guidance throughout my $\mathrm{PhD}$. His proverbial door was always open, and he consistently gave constructive feedback, which shaped my thesis and the subsequent manuscripts into what it is.

All of my fieldwork was conducted at Palmyra Atoll, and I'm so very thankful and fortunate to have had the consistent support and advice from my diving partner Dr Gareth Williams, who not only showed me the ways of multivariate statistics but even took on sharks to protect me during my work in the murky lagoons. Fortunately he was resilient enough (despite some whining on his part) to put up with me and the close calls with sharks (of which there were a few) so that I managed to get all my work done of which he also helped to collect, record and hammer in. I'd also like to thank him for his support and personal investment in making my thesis what it became through his edits, methodological and logistical advice and his generous lending of zip ties.

I would also like to thank William Arlidge, a friend and Masters student who came out with us on one trip to Palmyra and helped me with my work as well as his own. He was always eager and ready to help with any task and has a good scientific mind to boot.

I'm also very grateful to the staff of The Nature Conservancy (TNC), the United States Fish and Wildlife Service (USFWS) and members of the Palmyra Atoll Research Consortium (PARC) for providing access to the refuge and logistical support, without which this work would not have been possible. In particular, the USFWS officer Dr Amanda Meyers whose bright smile, enthusiasm and thorough management of the atoll was a delight to work with, and Dr Eric Conklin for his support, advice and infectious laugh. I would also like to thank Tim Battista from the National Oceanic and Atmospheric Administration (NOAA) for his help with the GIS work at Palmyra, for producing such wonderful benthic maps and, more specifically, providing more detailed information and figures on the lagoons. 
Many thanks also have to be given to those that allowed me to bend their ears and offered their advice and assistance: Dr John Collen, Dr Scott Godwin, Dr James Maragos and my co-supervisor Dr Jonathan Gardner who also provided PC2 laboratory space and molecular equipment in New Zealand. I am also very grateful to Dr José Luis Carballo, Dr José Antonio Cruz-Barraza and Cristina Vega Juárez for taking the time and patience to identify and provide measurements of the sponge species at Palmyra.

A very special thank you also has to go to the ToBo lab, in particular my sponsor, Dr Rob Toonen, and Dr Zac Forsman, who have provided unfaltering support, advice and free reign of the lab where I conducted the vast majority of my lab work for this thesis. I am also exceptionally grateful for their help in showing me the path of understanding through the hazy cloud that was my molecular data for which I am very thankful. My knowledge of genetics was minimal before starting my thesis and I have to owe all I know to those who were willing to give their time to teach me the ways of the lab including members of the ToBo lab: Dr Chris Bird who helped me with the development of primers, Zoltan Szabo who showed me many techniques and Luke Thomas for helping me out in the labs in New Zealand.

I would also like to make a special thank you to my fellow PhD students and housemates: Abigail Powell, Mareike Sudek and Tim Jones in New Zealand who gave me the support and friendship that I needed to complete this work and to David Lin for all his advise and help. My family also were a massive contingent to the success of my $\mathrm{PhD}$ as they offered me unquestioning support and positive encouragement throughout this time.

This work was funded by Victoria University of Wellington, Air New Zealand, the Centre for Marine Environmental and Economic Research (CMEER) and the Centre for Biodiversity and Restoration Ecology (CBRE). This work was conducted under the USFWS special use permits: 12533-08004, 12533-09014 and 12533-10002.

So finally I would like to dedicate this thesis to my friends and family who without their support and help this work would not have been possible. 


\begin{abstract}
Anthropogenic pressures, direct and indirect, have left no coral reef untouched. Those that remain in a near-pristine condition are remote islands and atolls removed from the majority of direct impacts, but even these are still subjected to the pressures of global climate change to which they are demonstrating a higher resilience than those which are already severely compromised. These near-pristine systems should be protected, managed and studied to better understand how they function and hopefully ensure the future of coral reefs. Unfortunately a number of the remote atolls and islands in the Pacific were modified or used by the US military during WWII, which altered these systems in unknown ways and threatened their surrounding reefs. Palmyra Atoll in the Central Pacific for example had its lagoons dredged and blocked to create more landmass for building, along with the creation of a channel through the reef to allow boat access into the lagoons making them susceptible to introduced species. Fortunately the surrounding reefs at Palmyra are still in a near-pristine condition with high densities of scleractinian corals, however the lagoon fauna is now predominantly sponges. Sponges in high enough densities can have considerable impacts on semi-enclosed bodies of water through their high filtering capabilities and could even threaten native species through competition if they were to extend onto non-lagoon reefs. Therefore, the broad aim of this thesis was to understand the ecology of the sponges in the lagoons at Palmyra and determine their potential impacts on the atoll directly and indirectly. To answer these questions I collected sponge assemblage data across the lagoons at both shallow and deep depths and sampled those species found on the reefs, which were surprisingly entirely different from the lagoon species. I then modelled a suite of environmental predictors to ascertain whether environmental conditions might be maintaining the sponges in the lagoon. To further examine whether the sponges were capable of extending onto the reef I also looked at larval recruitment patterns and assessed the temporal stability with semi-permanent quadrats. The initial surveys revealed the presence of at least two introduced species: Haliclona caerulea (Hechtel 1965) and Gelliodes fibrosa (Wilson 1925). Molecular tools were then employed to confirm the identification and attempt to ascertain the introduction pathway of $H$. caerulea. Finally, to assess the potential impact of the sponges on the water column I calculated the filtration rates of all the morphologies in the lagoon and extrapolated to
\end{abstract}


the time required to clear all the available water in the lagoon as well as the removal rates of dissolved organic carbon and oxygen.

Overall the lagoons appear to have undergone a phase-shift from a coral to sponge dominated system. However, the direct threat of the sponges extending onto the adjacent near-pristine reef currently seems negligible as they appear to be relatively "stable" (sponge mortality and recruitment are in equilibrium) and maintained in the lagoons by the environmental conditions, despite larval production. Sponge diversity changed over depths but the total number of species was consistent with other atoll systems despite the military modifications, with the most prominent sponge being a Hawaiian endemic species: Iotrochota protea (de Laubenfels 1950). The introduction of H. caerulea, a Caribbean sponge is thought to have occurred to Palmyra via Hawai'i; however, the molecular data also revealed further cryptic speciation at both the species and order levels, suggesting greater species diversity at Palmyra than previously believed. Finally, the indirect impacts of the sponges on the water column also appear to be small and with limited future risks to the reef organisms, as recruitment and mortality are currently in equilibrium and therefore unlikely to increase dramatically in percentage cover.

Globally sponges can play important functional roles in semi-enclosed bodies of water and in summary, despite the sponges being the most dominant fauna on the hard substrate in the lagoons, they appear to pose little threat to the atoll and the adjacent reefs either directly or indirectly despite the confirmed introduction of non-endemic species. However, it must be noted that the time since the modification (70 years) is not that long in an evolutionary sense, so the sponges may still have the potential to extend onto the reef, particularly if there are any dramatic changes to the environmental conditions on the outer reefs. Therefore, to detect whether the sponges are extending onto the reef I propose, as a future management tool, the use of I. protea as an indicator species. The use of multidisciplinary approaches to answer important ecological questions with respect to the potential for sponges to have negative impacts on the nonlagoon reefs proved to be essential in understanding whether the modifications to the lagoons and the subsequent dominance of sponges could be threatening one of the last few remaining near-pristine reef systems in the world. 


\section{List of abbreviations}

$\mathbf{A I C} \mathbf{c}=$ corrected Akaike's information criterion

$\mathbf{b p}=$ base pairs

$\mathbf{B I}=$ Bayesian inference

BLAST $=$ basic local alignment search tool

BSA $=$ bovine serum albumin

$\mathbf{C A P}=$ canonical analysis of principal coordinates

CO1 $=$ cytochrome oxidase subunit 1

$\mathbf{C P C e}=$ coral point count with excel extensions

DOC $=$ dissolved organic carbon

dbRDA = distance-based redundancy analysis

DistLM $=$ distance-based multivariate analysis for a linear model

DMSO = dimethyl sulfoxide

ENSO $=$ El Niño-southern oscillation

$\mathbf{G}=$ gamma rates

$\mathbf{G T R}=$ general time reversible model

ITS $=$ internal transcribed spacer

MCMC = Markov chain Monte Carlo

$\mathbf{M L}=$ maximum likelihood

mtDNA = mitochondrial deoxyribonucleic acid

nDNA $=$ nuclear deoxyribonucleic acid

$\mathbf{N J}=$ neighbour joining

$\mathbf{n M D S}$ or $\mathbf{M D S}=$ non-metric multidimensional scaling

$\mathbf{N N I}=$ nearest-neighbour interchange

NOAA $=$ National Oceanic and Atmospheric Administration 
PCA $=$ principle component analysis

$\mathbf{P C O M}=$ percentage organic matter

PERMANOVA = permutational analysis of variance

POC $=$ particulate organic carbon

$\mathbf{P O M}=$ particulate organic matter

PRIA's = Pacific Remote Island Areas

NIS $=$ non-indigenous species

rDNA = ribosomal deoxyribonucleic acid

RNA = ribonucleic acid

SD $=$ standard deviation

$\mathbf{T I M}=$ transitional model

TOC $=$ total organic carbon

$\mathbf{T N C}=$ The Nature Conservancy

$\mathbf{T P M}=$ total particulate matter

$\mathbf{T V M}=$ transversion model

USFWS $=$ United States Fish and Wildlife Service

WWII $=$ World War Two 


\section{Contributions and Publications}

This thesis is compiled as a series of published, submitted or in prep manuscripts under the guidance of my primary supervisor Dr James Bell who provided editorial comments and advice on methodologies and analysis. Therefore there is an aspect of repetition across the chapters, particularly with the introductions. All underwater SCUBA fieldwork was conducted with Dr Gareth Williams but the subsequent processing, lab work and writing were completed by the author with the following additional contributions from co-authors:

\section{Chapter 2: Environmental drivers of sponge diversity, cover and assemblage composition in the lagoons at Palmyra Atoll, Central Pacific}

Publication status: in press at Marine Pollution Bulletin

Knapp ISS, Williams GJ, Carballo JL, Cruz-Barassa JA, Gardner JPA, Bell JJ. (in press) Reduced environmental quality supports extensive sponge assemblages in an atoll lagoon.

\section{Co-authors contribution:}

Gareth J. Williams- statistical advice and editorial comments

José Luis Carballo- editorial comments, sponge species identification

José Antonio Cruz-Barraza- sponge species identification

Jonathan P. A. Gardner- editorial comments

Chapter 3: Temporal variability and recruitment of sponges in an altered atoll lagoon; assessing their potential to extend on to an adjacent near-pristine coral reef

Publication status: submitted to Coral Reefs

Knapp ISS, Williams GJ, Bell JJ. (in prep) Evidence for a phase shift from a coral to sponge dominated community in a Central Pacific atoll lagoon as a result of environmental degradation.

\section{Co-authors contribution:}

Gareth J. Williams: methodological advice, editorial comments 
Chapter 4: Filtering capability of sponges in an altered atoll lagoon and their potential impact on an adjacent near-pristine reef.

Publication status: submitted to PLoS one

Knapp ISS, Jones TT, Williams GJ, Bell JJ. (in prep) Estimating sponge water column interactions in an atoll lagoon

Co-authors contribution:

Timothy T. Jones: analysis development and advice, editorial comments

Gareth J. Williams: methodological advice, editorial comments

Tim A. Battista: GIS analyst, produced bathymetric maps (Figure 4.4)

Chapter 5: The origins of an invasive sponge to Palmyra atoll (Haliclona caerulea, family: Haplosclerida) are obscured by cryptic diversity

Publication status: in preparation

Knapp ISS, Forsman ZH, Williams GJ, Toonen RJ, Bell JJ. (in prep) Origins of an invasive sponge to Palmyra atoll (Haliclona caerulea, family: Haplosclerida) are obscured by cryptic diversity.

\section{Co-authors contribution:}

Zac H. Forsman: methodological and statistical advice, editorial comments

Robert J. Toonen: sample acquisition, methodological advice, editorial comments

Gareth J. Williams: editorial comments

\section{Additional first author publications (Appendix I and II):}

Knapp ISS, Godwin LS, Smith JE, Williams GJ, Bell JJ. (2011). Records of marine non-native species at Palmyra Atoll in the U.S. Line Islands. Marine Biodiversity Records, 4: 1-7.

Knapp ISS and Bell JJ. (2010). Effect of depth on sponge assemblage structure at Palmyra Atoll, Central Pacific. Open Marine Biology Journal, 4: 26-30. 


\section{Table of Contents}

\section{Chapter 1}

General Introduction.

1

1.1 Sponges: function, ecology and anatomy ….............................................. 1

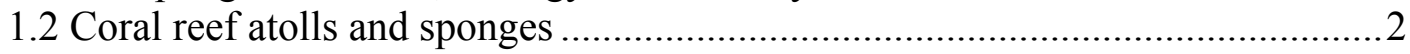

1.3 Roles in atoll ecosystems: Palmyra Atoll ......................................................... 3

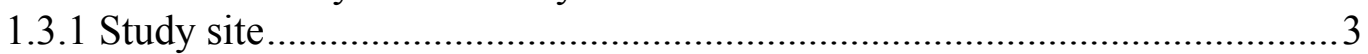

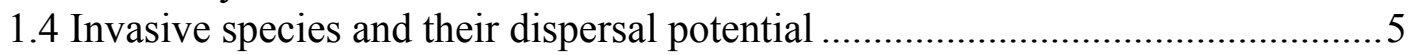

1.5 Sponges and genetics: a tool for understanding the process of invasion............ 9

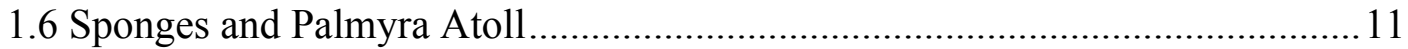

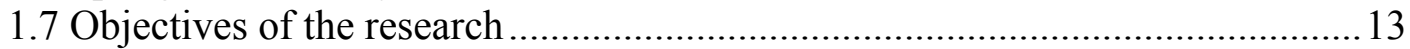

\section{Chapter 2}

Environmental drivers of sponge diversity, cover and assemblage composition in the lagoons at Palmyra Atoll, Central Pacific

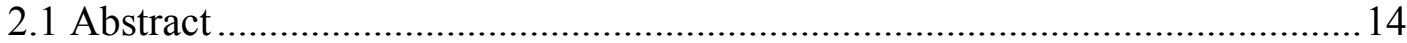

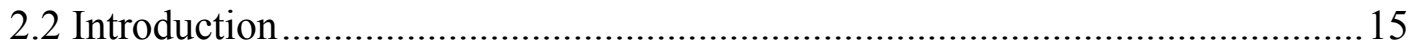

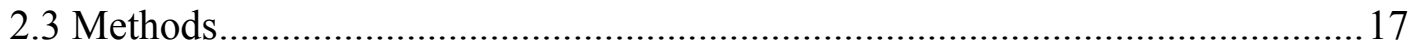

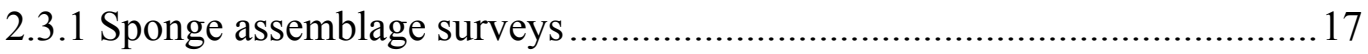

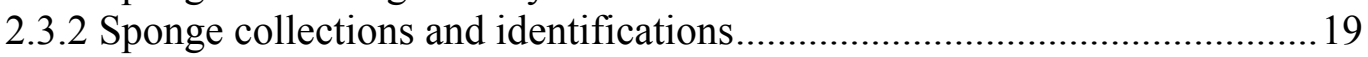

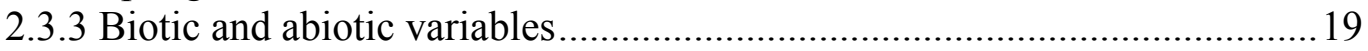

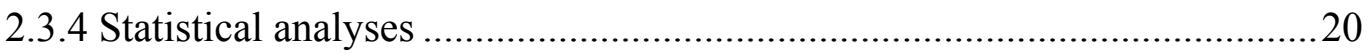

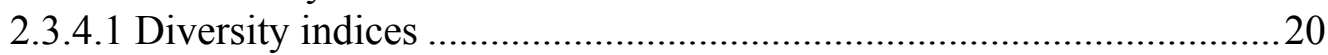

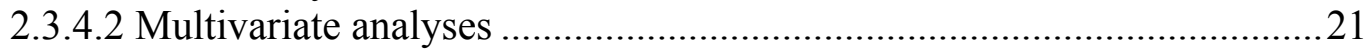

2.3.4.3 Environmental associations with sponge cover and assemblages ...........22

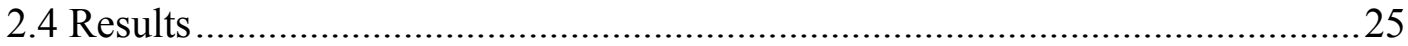

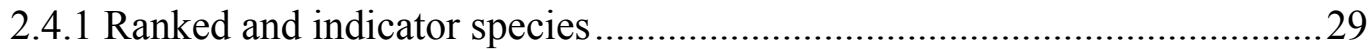

2.4.2 Changes in the abundance of Haliclona caerulea, Gelliodes fibrosa and

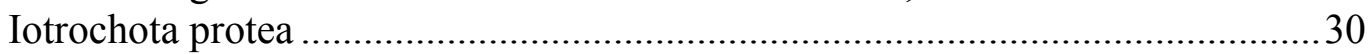

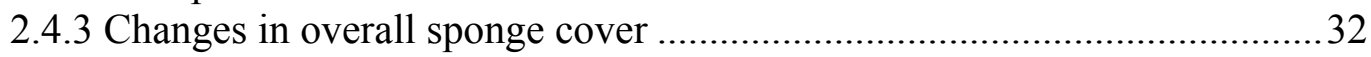

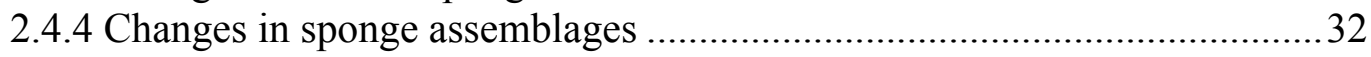

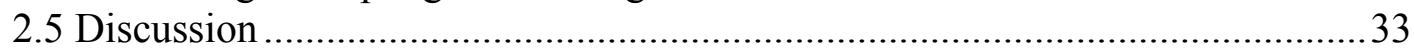

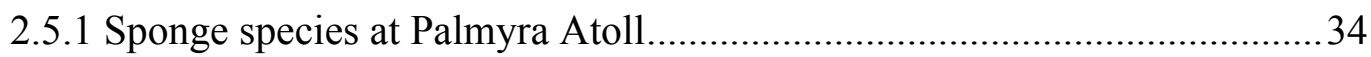

2.5.2 Distributions of likely NIS sponge species in the lagoons .........................35

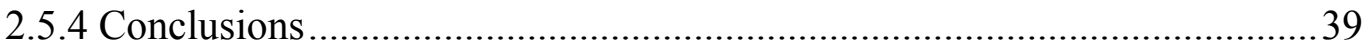

\section{Chapter 3}

Temporal variability and recruitment of sponges in an altered atoll lagoon; assessing their potential to extend on to an adjacent near-pristine coral reef .

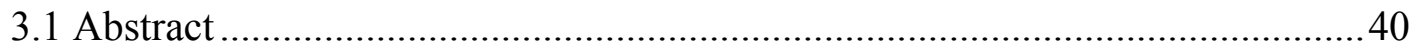

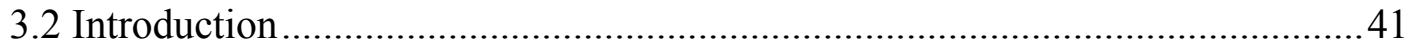

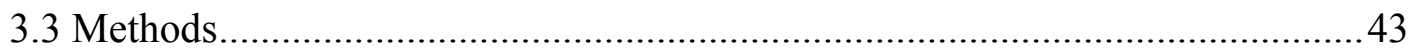

3.3.1 Evidence to suggest the condition of Palmyra's lagoons before WWII .....43

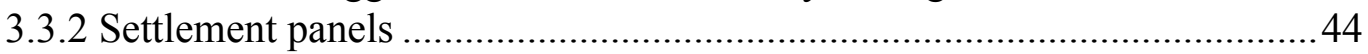

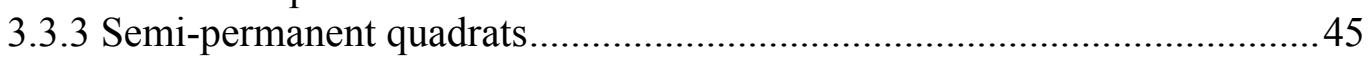

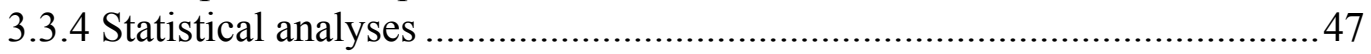

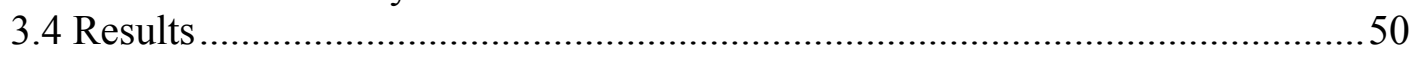

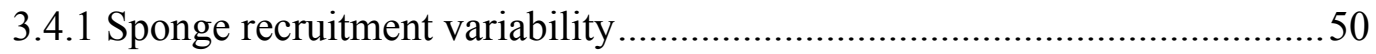




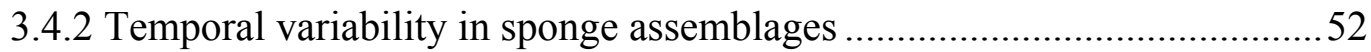

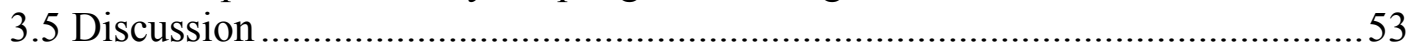

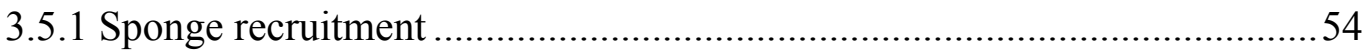

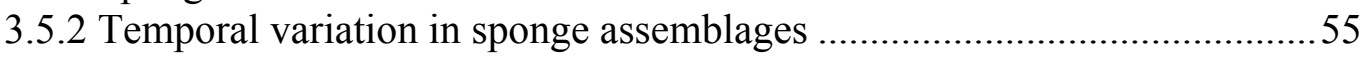

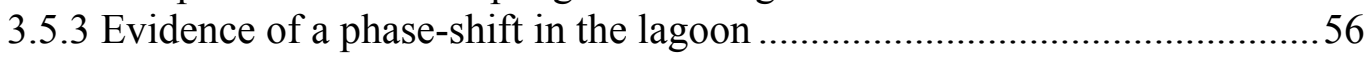

\section{Chapter 4}

Filtering capability of sponges in an altered atoll lagoon and their potential impact on an adjacent near pristine reef.

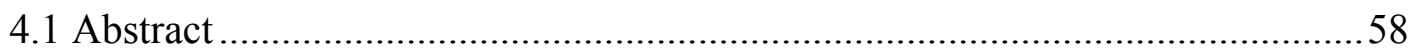

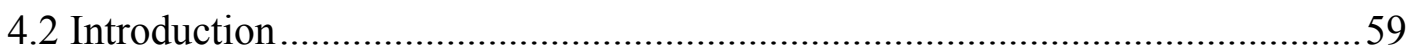

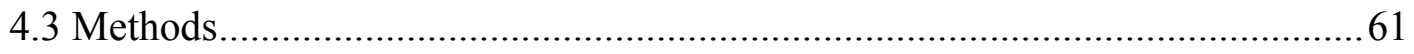

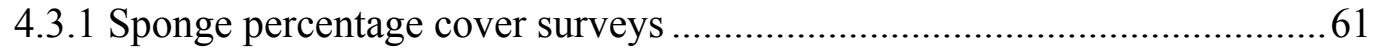

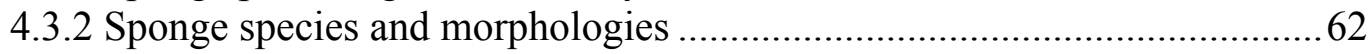

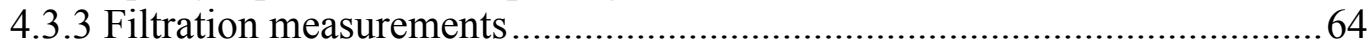

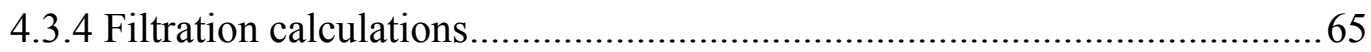

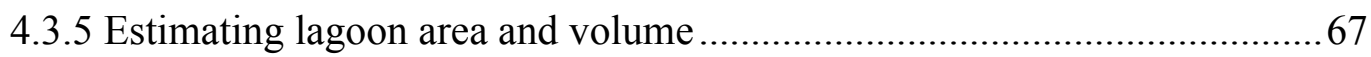

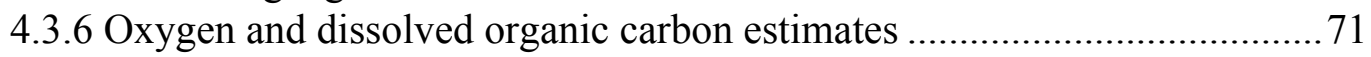

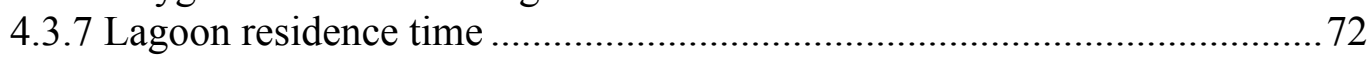

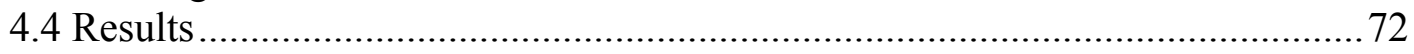

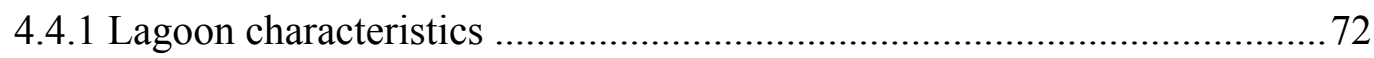

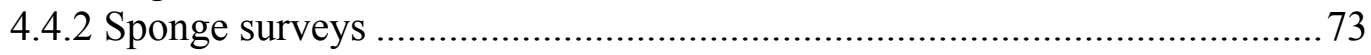

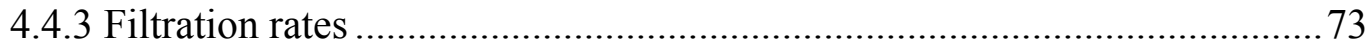

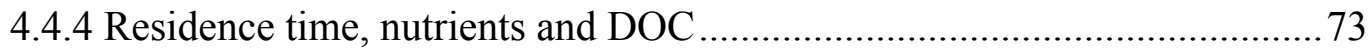

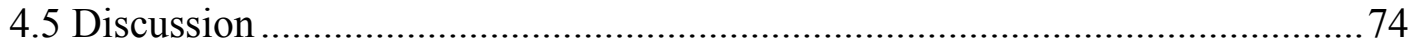

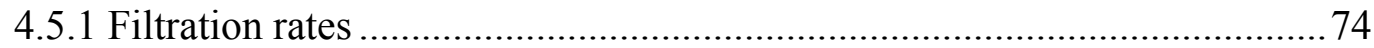

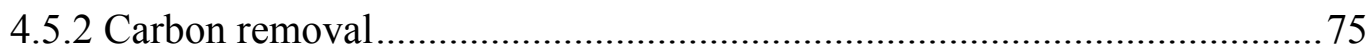

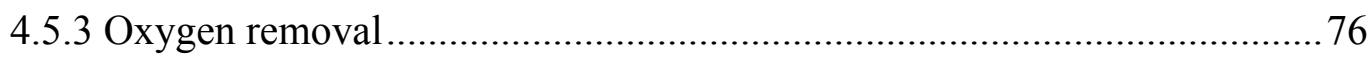

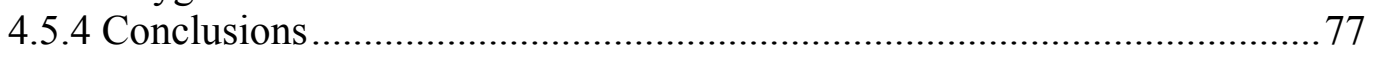

\section{Chapter 5}

Origins of an invasive sponge to Palmyra Atoll (Haliclona caerulea), (order: Haplosclerida) are obscured by cryptic speciation

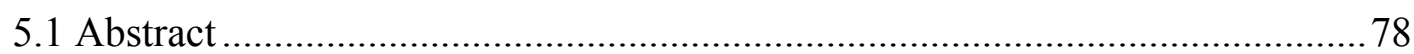

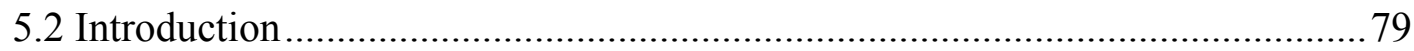

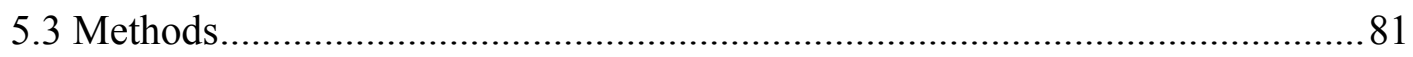

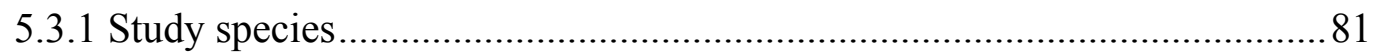

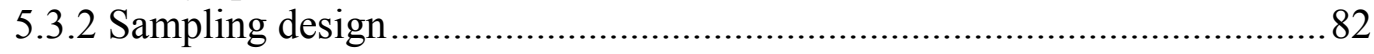

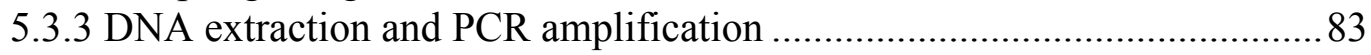

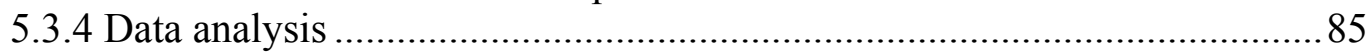

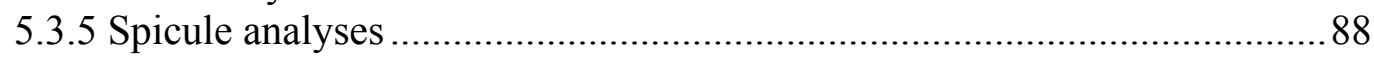

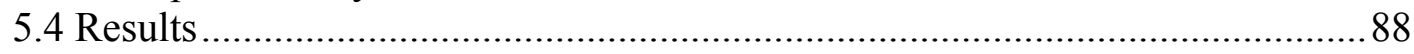

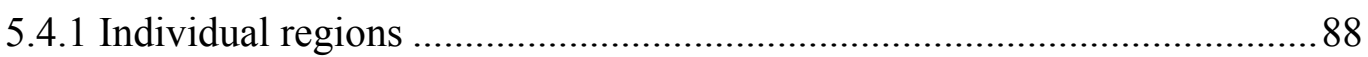

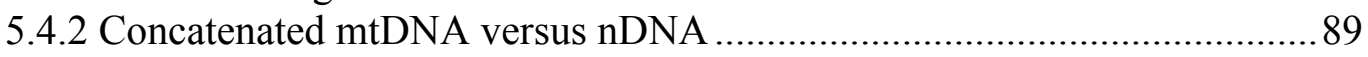

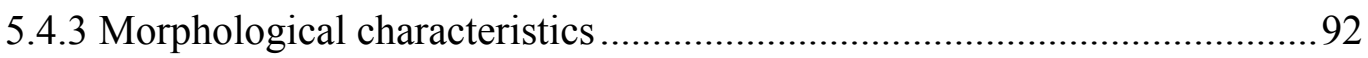

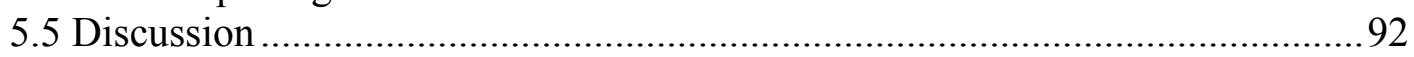

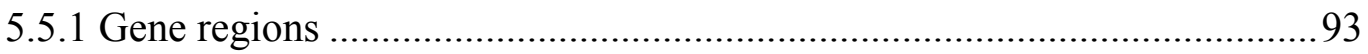

5.5.2 Cryptic speciation within H. caerulea ................................................... 95

5.5.3 Using morphological characteristics to identify H. caerulea ......................96

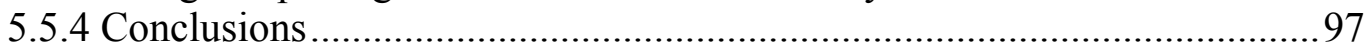




\section{Chapter 6}

General Discussion

6.1 Sponges: Wealth of benefits, paucity of knowledge....................................... 98

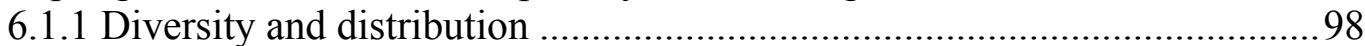

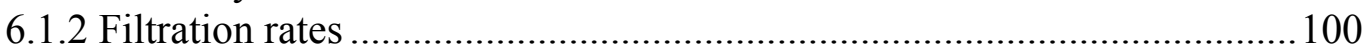

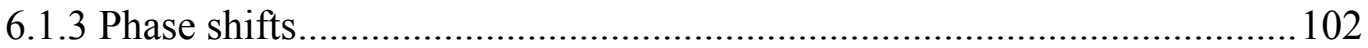

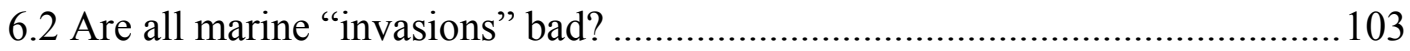

6.3 The future for Palmyra's lagoons and sponges ............................................... 106

6.3.1 Planned removal of the north-south causeway .......................................106

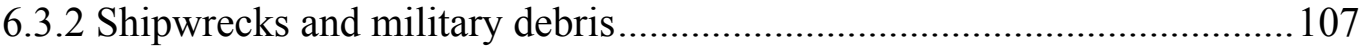

6.3.3 Future identification of sponge extension on to the reefs ........................108

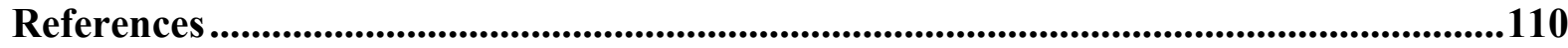

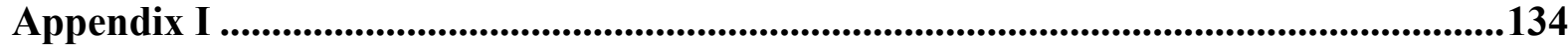

Published manuscript: Records of non-indigenous marine species at Palmyra Atoll in the US Line Islands

Appendix II.

Published manuscript: Effect of depth on sponge assemblage structure at Palmyra Atoll, Central Pacific

Appendix III

Photographs of collected and identified sponges from the lagoons and reefs at Palmyra Atoll

\section{Appendix IV}

Further ecological and morphological information for the Palmyra Atoll sponge species in Table 2.2

\section{Appendix V}

Taxonomic histories of Gelliodes fibrosa (Wilson 1925) and Iotrochota protea (de Laubenfels, 1950)

\section{Appendix VI}

Fish predation trial experiment 


\section{List of Figures}

Figure 1.1 Location of Palmyra Atoll and its lagoons, within the Central Pacific. 1 = excavated entrance channel, 2 = the airstrip made of dredge spoil and coral rubble and $3=$ the north-south causeway, specifically the cut allowing boat access between Center and East Lagoons.

Figure 2.1 Location of the 11 survey sites within the 4 lagoons: Sand Island (Sa); Strawn Island (St); Ripple Wharf (RW); Paradise Island (P); The Dolphins (D); The Cut (C); South of the Cut (S.C); Quail Island (Q); Eastern Island (E); Central East (C.E); Turtle Pool (TP) across the 4 lagoons. The black arrows indicate locations of military modifications; $1=$ excavated entrance channel, 2 = the airstrip made of dredge spoil and coral rubble and 3 = the north-south causeway, specifically the cut allowing boat access between the Center and East Lagoons.

Figure 2.2 Measures of overall \% cover, number of species, Hill's numbers N1, N2 and N21' across all sites (means \pm SD). Lagoons are indicated as blue $=$ West, yellow $=$ Center, green $=$ East and red $=$ Turtle Pool.

Figure 2.3 Canonical analysis of principal coordinates (CAP) bi-plot ordination showing the indicator sponge species across sites and lagoons. Where Sand Island (Sa); Strawn Island (St); Ripple Wharf (RW); Paradise Island (P); The Dolphins (D); The Cut (C); South of the Cut (S.C); Quail Island (Q); Eastern Island (E); Central East (C.E); Turtle Pool (TP) across lagoons West (W); Center (C); East (E) and Far East (F.E). Based upon a zero-adjusted Bray-Curtis similarity matrix with a dispersion weighting pre-treatment on sponge area cover data, which are pre-adjusted to the amount of available substrate. The analyses were based on 9999 random permutations. A Pearson's correlation coefficient of $\geq 0.5$ was used to indicate these vectors.

Figure 2.4 Ranked abundances of sponge species in the lagoons at Palmyra. Bars are stacked and indicate the mean average per lagoon, but not the total mean across all lagoons where $\mathrm{W} / \mathrm{blue}=\mathrm{West}, \mathrm{C} /$ yellow $=$ Center, E/green $=$ East and TP/red $=$ Turtle Pool. $(\star)$ marks the indicator species in Figure 2.3. The letters in brackets refer to the ID codes in Table 2.2.

Figure 2.5 Distance-based redundancy analysis (dbRDA) visualising the similarity in sponge assemblages and the correlated change in environmental conditions among the 11 lagoon sites (Fig 2.1) for mean percentage area cover (a) and sponge assemblages (b).

Figure 2.6 Underwater photos of Palmyra reef, lagoon and sponges. A) Current day conditions in the lagoon (left) versus the reef (right). B) Sponges and sediment; different strategies to deal with sedimentation. From left to right: Iotrochota protea (U), no sediment on oscular or veins; Dysidea sp.2 (C), sediment accumulates primarily on the protruding 
spikes, raised oscular; Spirastrella sp. (E), extended oscular. All letters in brackets relate to the species ID in Table 2.2.

Figure 3.1 Location of the recruitment panels in the lagoons at Palmyra Atoll: Strawn Island (St), The Dolphins (D) and Quail (Q) and semipermanent quadrats (D). The arrows indicate the location of military modifications; 1 = excavated entrance channel, 2 = the airstrip made of dredge spoil and coral rubble and $3=$ the north-south causeway, specifically the cut allowing boat access between the Center and East Lagoons. CI = Cooper Island.

Figure 3.2 Canonical analysis of Principal components (CAP) ordination visualising sponge assemblage differences over years showing a) and b) non-significant differences in the semi-permanent quadrat densities and cover, respectively and $c)$ significant differences $(p<0.001)$ in sponge densities on recruitment panels based upon a zero-adjusted Bray-Curtis similarity matrix with a dispersion weighting pre-treatment.

Figure 3.3 Mean ( \pm SD) sponge species diversity in the semi-permanent quadrats over 3 years; based on the Hills N1 index (exponential of the Shannon Wiener function).

Figure 3.4 Mean ( \pm SD) of sponge abundance (no. of individuals) across sites, panel side and year for all species (a), non-indigenous species (b and c), and the dominant species (d) in the lagoons at Palmyra.

Figure 4.1 Location of the 10 survey sites within the 3 lagoons: Sand Island (Sa); Strawn Island (St); Ripple Wharf (RW); Paradise Island (P); The Dolphins (D); The Cut (C); South of the Cut (S.C); Quail Island (Q); Eastern Island (E) and Central East (C.E). The black arrows indicate locations of military modifications; 1 = excavated entrance channel, $2=$ the north-south causeway, specifically the cut allowing boat access between the Center and East Lagoons.

Figure 4.2 Photos of the 6 species filtration rates were calculated for in situ in the West and East lagoons. a) Clathria sp. (thinly encrusting); b) Chondropsidae sp. and c) Spirastrella sp. (thickly encrusting); d) Dysidea sp. (with dye stream) and e) Haliclona (Sigmadocia) caerulea (massive) and f) Halichondria sp.1 sp. (digitate).

Figure 4.3 The site values and groupings based on the PERMANOVA analyses from Table 5.3 (similarity in percentage cover of encrusting and massive species and available hard substrate). Sites names: Sand Island (Sa); Strawn Island (St); Ripple Wharf (RW); Paradise Island (P); The Dolphins (D); The Cut (C); South of the Cut (S.C); Quail Island (Q); Eastern Island (E) and Central East (C.E).

Figure 4.4 Bathymetric maps indicating a) the depth gradient and b) the depth contours for the lagoons at Palmyra, Central Pacific. Area and volume estimates for GIS analysis were based on the outlines (of the 3 largest lagoons) as indicated in this figure. 
Figure 5.1 Map of the sampling locations for Haliclona caerulea in the Caribbean and Pacific along with the individual collection sites on $\mathrm{O}^{\prime} \mathrm{ahu}$, Hawai'i: Ke'ehi Bay (Ke), Ala Moana (Am) and Kāne'ohe Bay (Kan).

Figure 5.2 Neighbour Joining phylograms of the 56 sequenced Haliclona caerulea samples along with the outgroup species Amphimedon queenslandica with mitochondrial gene region $\mathrm{CO} 1, \mathrm{CO} 1$ extension (ext) and $r n l$. with branch support from Neighbour Joining (NJ), Maximum Likelihood (ML) and Bayesian Inference (BI) analyses. Regional names (Hawai'i, Palmyra and Caribbean) are followed by site names: Ke'ehi Bay (Ke), Ala Moana (Am) and Kāne'ohe Bay (Kan), St James Island (StJ), St Thomas Island (StT) and Puerto Rico (PR) and then the sample number per region. The two clades are divided into $\mathrm{A}$ and $\mathrm{B}$ with all subclades numbered separately for each tree. Support values indicated as 100 represent identical support from each analysis (i.e. 100/100/1.0). Scale bar $=0.02$ substitutions per 100 sites.

Figure 5.3 Neighbour joining phylograms of the 56 sequenced 'Haliclona caerulea' samples along with the outgroup species Amphimedon queenslandica with the concatenated total evidence mtDNA tree and the 18s nDNA trees with branch support from Neighbour Joining (NJ), Maximum Likelihood (ML) and Bayesian Inference (BI) analyses. Regional names (Hawai'i, Palmyra and Caribbean) are followed by site names: Ke'ehi Bay (Ke), Ala Moana (Am) and Kāne'ohe Bay (Kan), St James Island (StJ), St Thomas Island (StT) and Puerto Rico (PR) and then the sample number per region. Overlaid on the mtDNA and nDNA trees are the oxea length groups for each sample from Hawai'i and Palmyra. The two clades are divided into A (Halichondrida) and B (Haplosclerida) with all subclades numbered separately for each tree. Support values indicated as 100 represent identical support from each analysis (i.e. 100/100/1.0). Scale bar $=0.02$ substitutions per 100 sites. \% values represent the lowest sequence divergence values between subclades and clades.

Figure 5.4 Non-metric multidimensional scaling (nMDS) ordination visualising grouped sponge oxea lengths $(\mu \mathrm{m})$ over sites Ke'ehi Bay $(\mathrm{Ke})$, Ala Moana (Am) and Kāne'ohe Bay (Kan) from Hawai'i and from Palmyra Atoll (PA) based upon a zero-adjusted Bray-Curtis similarity matrix.

Figure 6.1 Map indicating the global diversity of sponges in each of the 232 marine ecoregions of the world highlighting the Line Islands where Palmyra is located and Hawai ' $i$, in the Central Pacific. Modified from van Soest et al. (2012). 


\section{List of Tables}

Table 2.1 Table of environmental (Env.), biological (Biol.) and categorical (Cate.) predictor variables and mean sponge cover for all species and target species used in the DistLM analysis. * = colineating variables not included in the final model. Values in bold denote the maximum or minimum mean values. Minimum numbers are not in bold if more than one site has the same value. $\mathrm{n} / \mathrm{a}=$ not applicable, var. = variability (+ $1 \mathrm{SD})$ and Av. = availability.

Table 2.2 Species found within the lagoons and on the reefs at Palmyra Atoll, see Appendix III for photographs. A-X samples are those species found within the quadrats. AA-AL are those species found outside the quadrats or are excavating species in the lagoons and BA-BO are those species found on the reefs. ${ }^{c}=$ calcareous sponge. $^{2}$

Table 2.3 Results from CAP analyses examining sponge assemblage variability in cover between sites and lagoons. Sa, Sand Island; St, Strawn Island; Rw, Ripple Wharf; P, Paradise Island; D, the dolphins; C, the cut; S.C, south of the cut; Q, Quail Island; E.I, Eastern Island; C.E, Center East; TP, Turtle pool; W, West Lagoon; C, Center Lagoon; E, East Lagoon; TP, Turtle pool. Where $m$ is the number of principal coordinate (PCO) axes used in the analyses, \% Var the percentage of the total variation explained by the first $m$ PCO axes, $\delta^{2}$ the squared canonical correlation and allocation success values the percentage of samples correctly allocated into their corresponding groups using the first $m$ PCO axes from the model.

Table 2.4 Results of the distance-based permutational multiple regression analysis (DistLM) for overall mean \% cover, sponge species assemblages, non-indigenous species and dominant species. Only the optimal variables of spatial change in sponge assemblages are shown along with the proportion of variability they explain. Model selection was based on Akaike's Information Criterion with a second-order bias correction applied (AICc), with the total variation explained $\left(r^{2}\right)$ by each best-fit model shown (\% total) based on 9999 random permutations of the raw data. Variables were normalized and fitted in a step-wise manner.

Table 3.1 List of species found in the semi-permanent quadrats (Q) and on the recruitment panels $(\mathrm{P})$ as marked by ticks. The ID letter refers to those given in Chapter 2.

Table 3.2 Results from the permutational multivariate analysis of variance (PERMANOVA) for total cover (univariate), assemblages (multivariate), individual species (univariate) and diversity (Hills N1) (semi-permanent quadrats only) for the semi-permanent quadrat sponge densities (a) and cover (b) over time (seasons and years) and recruitment panel densities (c) between sites, years and sides (top or underside) with $\mathrm{p}$ values followed by Pseudo- $F$ values in brackets. Figures in bold indicate significant differences. ${ }^{a}$ Term has one or more empty cells. 
Table 4.1 Pairwise post-hoc test results indicating significant differences between encrusting and massive/digitate species. a) Clathria sp. (thin encrusting); b) Spirastrella sp. and c) Chondropsidae sp. (thick encrusting); d) Dysidea sp. and e) Haliclona (Sigmadocia) caerulea (massive) and f) Halichondria sp.1 sp. (digitate).

Table 4.2 Species mean and standard deviation values used to calculate the volume flux per unit area and per unit volume of sponge $\left(\mathrm{cm}^{3}\right)$. Where $\mathrm{n}=$ number of individuals, $\mathrm{VF}=$ volume flux.

Table 4.3 Pairwise post-hoc test results indicating site differences in a) percentage encrusting species cover $b$ ) percentage massive species cover and c) percentage available hard substrate. Those sites with no significant differences for all variables were grouped together for subsequent analyses. Sites names: Sand Island (Sa); Strawn Island (St); Ripple Wharf (RW); Paradise Island (P); The Dolphins (D); The Cut (C); South of the Cut (S.C); Quail Island (Q); Eastern Island (E) and Central East (C.E).

Table 4.4 Approximate lagoon area cover (sand and boulders) $\left(\mathrm{km}^{2}\right)$ and volume $\left(\mathrm{km}^{3}\right)$. Measurements made using ArcGIS. *Actual maximum depth across all lagoons is $52 \mathrm{~m}$. In bold are overall total values for the lagoons.

Table 5.1 Location, code IDs and numbers of sequences included in the final analyses of 'Haliclona caerulea' samples.

Table 5.2 Primers used in the PCR and sequencing of 'Haliclona caerulea' samples.

Table 5.3 Total number of base pairs (bp), samples (n), haplotypes (H) and pairwise per site, per alignment percentage sequence differences $(\mathrm{P})$ for each sampling location and across all samples. ext $=$ extension region. 


\section{Chapter 1}

\section{General Introduction}

\subsection{Sponges: function, ecology and anatomy}

Sponges (phylum Porifera) are the simplest and oldest multicellular organisms still extant today and are considered the evolutionary link between protozoans and metazoans, with cnidarians being their closest relatives (Müller 1995, Watkins \& Beckenbach 1999, Muller et al. 2003). They are benthic sessile invertebrates which have been extant for approximately 580 million years, long before the notable 'Cambrian explosion', which occurred 540 MYA (Li et al. 1998, Budd 2008). Sponges can be found inhabiting marine ( $80 \%$ of species), freshwater and brackish environments (de Laubenfels 1936, 1947, Penney \& Racek 1968, Hooper \& van Soest 2002), in temperate, tropical and polar environments, from shallow water to the deep seas (Hoppe \& Reichert 1987, Roberts \& Davis 1996, Witte 1996, Bell \& Barnes 2000a, McClintock et al. 2005).

Throughout this time and expansion, their body plan and mode of feeding has changed little, maintaining the principal organisational feature defining this phylum; an aquiferous system comprised of a network of water-conducting chambers and canals (Bergquist 1978, Brusca \& Brusca 1990). The chambers and canals are lined with flagellated choanocyte (collar) cells, which create a flow of water into the ostia (pores) and over the microvilli and remove nutrients and food particles and expelling waste products out through the oscula/osculum.

Sponges can filter large volumes of water; up to $24,000 \mathrm{~L} \mathrm{~kg}^{-1}$ of sponge (Vogel 1977). They primarily feed on ultraplankton $(<20 \mu \mathrm{m})$ and picoplankton $(<2 \mu \mathrm{m})$ (Reiswig 1971a, 1974, Pile et al. 1996, Ribes et al. 1999), as well as bacteria (1-10 $\mu \mathrm{m})$ (Reiswig 1975, Frost 1978) and possibly viruses (0.03-0.1 $\mu \mathrm{m})$ (Hadas et al. 2006). Picoplankton and bacteria are important sources of carbon and nutrients on coral reefs (Ribes et al. 2005) with roughly over $80 \%$ of the particles removed less than $10 \mu \mathrm{m}$ in size (Yahel et al. 1998, Ribes et al. 2003). Retention rates of food particles by sponges are high, ranging from 58 to 99\% (Pile et al. 1997, Lesser 2006, de Goeij et al. 2008), making them very important in linking primary and secondary production (Gili \& Coma 1998). 
The choanocyte cells filter and phagocytose food particles and metabolites from the passing water. Nutrients are then passed to the middle layer of the sponge; the mesohyl (mesenchyme). Archaeocyte cells (amoebocytes) then distribute the nutrients to other sponge cells as well as carry any waste products back to the choanocyte cells. Many of the cells within a sponge, including the archaeocytes and choanocytes are highly plastic and can differentiate into other, more specialized, cells such as spermatocytes and/or oocytes (Galtsoff 1923, 1925, Buscema et al. 1980, Bond 1992, Anakina \& Drozdov 2001).

There are 3 sponge classes: Calcarea, Demosongiae, and Hexactinellida. The majority of these secrete supportive proteinaceous fibres; spongin, and/or mineral (calcareous or siliceous) skeletal structures known as spicules (Uriz et al. 2003). The skeletal structures of each class, along with genetic analysis, can be distinctive enough to separate species and allow the reconstruction of evolutionary relationships (Chombard et al. 1998, Schutze et al. 1999, Uriz \& Carballo 2001). Overall, sponges are a highly diverse as well as ecologically and economically important marine invertebrate taxon, but are vastly and notoriously understudied (Hooper \& van Soest 2002, Becerro 2008), despite the fact that on some reefs sponges can even exceed the species diversity and biomass of the scleractinian corals (Wulff 2001, Wulff 2011).

\subsection{Coral reef atolls and sponges}

Coral reef atolls are found only in tropical and sub tropical waters and consist of an annular reef encircling a lagoon system. Most, but not all also have areas of land above sea level. Coral reefs are one of the most productive and diverse ecosystems in the world (Grigg 1984, Crossland et al. 1991, Hughes et al. 2003). Sponges when present perform important functional roles in reef ecosystems (Wulff 2001, Bell 2008a) including erosion and consolidation of reefs (Rützler 1975, Wulff 1984), benthopelagic coupling (Lesser 2006), nutrient recycling (Diaz \& Ward 1997), and facilitating primary production through symbiosis (Wilkinson 1983), as well as providing microhabitats, affecting of near-boundary flow systems (Gili \& Coma 1998), and being food sources for other organisms (Wulff 1994) and important spatial competitors. Therefore, reduced sponge abundance could result in some of these functions not being performed and also lead to the acceleration of a reefs decline (Wulff 2001). A lot of notable work carried out on Caribbean reefs has shown that sponges can benefit a reef by binding corals to the substrate, which is particularly important when environmental 
conditions would otherwise dislodge them (Wulff \& Buss 1979), as well as shielding them from other reef excavating species (Goreau \& Hartman 1966). Sponges can also aid in the regeneration of reefs via the stabilization of coral fragments allowing recruitment of coral larvae (Wulff 1984).

Coral reef atolls, unlike most coastal reefs, have central lagoons, which are a remnant of the oceanic volcano that formed them (Delesalle \& Sournia 1992, Kench 1998). Lagoons are generally considered low-current systems, which act as sediment 'sinks' and therefore experience high levels of sedimentation (Ilan \& Abelson 1995). Generally, excessive sedimentation is considered detrimental to coral reef ecosystems affecting both the structure and functioning by smothering the reef organisms and reducing light penetration (Rogers 1990). Perhaps surprisingly, sponges have been commonly documented inhabiting areas of high sedimentation (Ilan \& Abelson 1995, Bell \& Barnes 2000a, Bell 2004, Bell \& Smith 2004, Carballo 2006). Hiscock et al. (1983) noted that mechanisms to minimise sediment clogging are beneficial for organisms in highly sedimented habitats and it has been observed that many mechanisms exist allowing sponges to survive in such conditions (Bell 2004), including water flow reversal (Simpson 1984), and the production of a mucus layer, which the sponge then sheds to remove any settled sediment (Barthel \& Tendal 1993). Sponges also exhibit micro and macro morphological acclimation to survive habitat disparities (Palumbi 1984, 1986, Bell \& Turner 2000, Bell et al. 2002). These mechanisms are especially important in low current systems, such as lagoons, as the high levels of sediment can clog the delicate filtering apparatus of sponges (Bell 2004).

\subsection{Roles in atoll ecosystems: Palmyra Atoll}

\subsubsection{Study site}

Palmyra Atoll is located 1,930 km south West of Hawai 'i $\left(5^{\circ} 53^{\prime} \mathrm{N}, 162^{\circ} 05^{\prime} \mathrm{W}\right)$ and lies toward the northern end of the Line Islands in the north Central Pacific (Fig 1.1). Palmyra is a U.S. National Wildlife Refuge (USFWS) and part of the Pacific Remote Islands Marine National Monument (proclamation 8336) established in 2009. Together with neighbouring Kingman Reef, Palmyra represents a biodiversity hotspot in the Central Pacific (Maragos \& Williams 2011b). The atoll is approximately $12 \mathrm{~km}$ long, comprised of 50 islets with 4 lagoons (Collen et al. 2009) and a surrounding nearpristine reef system (Sandin et al. 2008). Palmyra has remained essentially uninhabited throughout its history, with the exception of the U.S. naval presence during WWII, and 
is now co-owned by The Nature Conservancy (TNC) and the United States Fish and Wildlife Service (USFWS). The only inhabited island is Cooper Island (Fig 1.1), which is also the location of the field station.

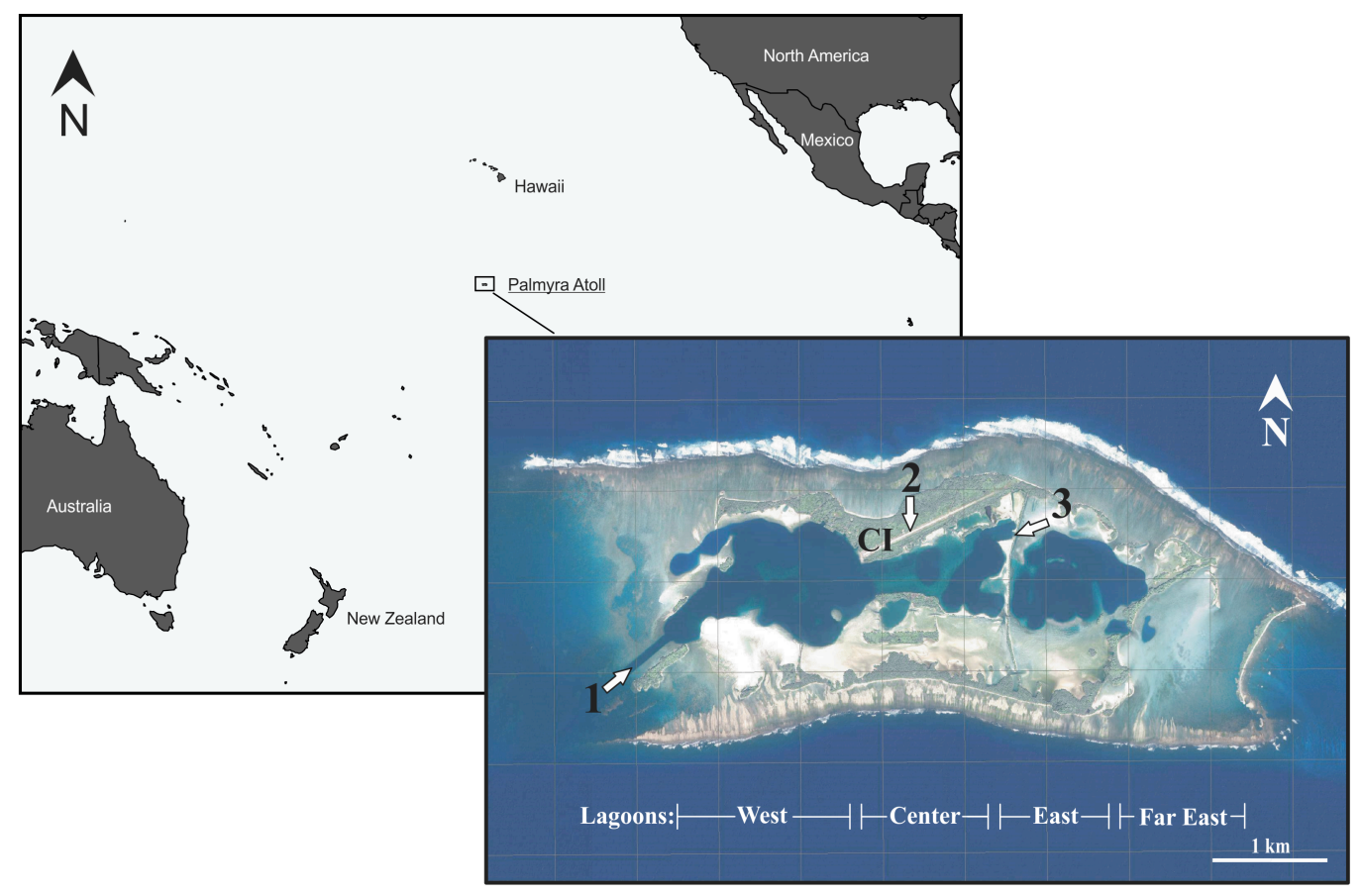

Figure 1.1 Location of Palmyra Atoll and its lagoons, within the Central Pacific. $1=$ excavated entrance channel, 2 = the airstrip made of dredge spoil and coral rubble and 3 $=$ the north-south causeway, specifically the cut allowing boat access between Center and East Lagoons.

Palmyra's lagoons are characterised by high sedimentation and low water flow with the substrate composed largely of fine/coarse sediment $(63 \mu \mathrm{m}-2.8 \mathrm{~mm})$ and boulders $\left(<0.5 \mathrm{~m}^{2}\right)$ (see Chapter 2) with low hard coral diversity and cover (Williams et al. 2008). The current flow moves from east to west (Gardner et al. 2011) at an average rate of $0.0102 \mathrm{~m} \mathrm{sec}^{-1}( \pm 0.0143)$ (see Chapter 2). Water also tidally comes in through the breaks in the islets, and flows in and out of the boat channel and Western flats (See Collen et al. 2009). The present conditions are likely due to the modifications made by the U.S. Navy to the atoll to construct a naval air station during WWII, which included extensive dredging of the lagoons to deepen them for boats, using the spoil to build-up and connect the islets, building large iron wharfs and docks and excavating a channel through the western reef terrace to allow boat access (Dawson 1959, Maragos 1993) (Fig 1.1). The military presence is still clearly visible today with iron structures in and around the lagoons. The north-south causeway has almost completely blocked 
the flow of water between the lagoons, but between 1958 and 1979 it breached, and it now has cuts in several places returning some movement between the lagoons (Maragos 1993). Dawson (1959) noted that soon after the military modifications the lagoons were essentially dead with "no living coral worth mentioning", and the east lagoon was filled with sediment, was stagnant and often smelt of hydrogen sulphide. To increase the flow of water across the lagoons in 2008, USFWS even outlined a proposal to remove a section of the causeway to relieve the sediment stress on the eastern backreefs (Williams et al. 2011c).

Palmyra Atoll is an unusual atoll system; the outer reefs are considered near 'pristine' due to minimal human impacts (Sandin et al. 2008), however the lagoon system has been vastly altered (Collen et al. 2009). Unlike other reefs e.g. in the IndoPacific or Caribbean, there are few sponges on the main reef at Palmyra (authors pers. obs.), however in the lagoons the sponges are the dominant fauna (Bell \& Carballo 2008). This may potentially be as a result of the extensive alterations made to the atoll during the U.S Naval occupation during WWII. Alterations and modifications of environments are likely to change the structure and function of an ecosystem (Vitousek et al. 1997), as well as composition of the biotic community by making the habitat more susceptible to invasions by non-indigenous species (NIS) (Mooney \& Cleland 2001).

\subsection{Invasive species and their dispersal potential}

Globally, invasive species result in substantial ecological and economic damage, with the estimated cost being US\$ 1.4 trillion a year (5\% global GDP) (Pimentel et al. 2001, Pimentel et al. 2005), and once NIS have established they are almost impossible to remove (Kolar \& Lodge 2001). The arrival of NIS is a global phenomenon with examples found in all ecosystems. NIS can be ecologically damaging to the host habitat by displacing indigenous species, and altering community structure and food webs, as well as other important biological processes, such as nutrient cycling and sedimentation (Molnar et al. 2008).

Although transportation of a species to an ecosystem outside of its natural range can potentially occur via natural dispersal mechanisms, there has been a notable increase in invasion events with the advent of global trade (Ruiz et al. 1997, Vitousek et al. 1997). Aquaculture, agriculture, trading and recreation, as well as other human activities have exacerbated the transportation of species across great biogeographic barriers, something which was historically unlikely, but is now an everyday occurrence 
(Mooney \& Cleland 2001). However, it is important to note that despite the high number of NIS transported everyday, only a small fraction of species manage to establish themselves permanently in new locations (Mack et al. 2000); nevertheless the impacts of these few successful species can still be considerable (Molnar et al. 2008). For example, the global expansion of the green shore crab (Carcinus maenas) from Europe to the United States of America, Canada, South Africa and Australia (Lafferty \& Kuris 1996) has had major impacts. C. maenas is a voracious predator of many benthic marine invertebrates and can have a considerable impact on native intertidal fauna (Cohen et al. 1995) as well as devastating shellfish fisheries (Walton et al. 2002, Behrens Yamada \& Gillespie 2008).

The variability in success rate of NIS establishment can often depend on the propagule pressure or 'introduction effort', a measure which is dependent on the number of release events (propagule number) and the number of individuals released per event (propagule size); as the number of either of these two factors increases so does the propagation pressure (Lockwood et al. 2005). The invasion process is complex and not predictable in its outcome. There are a range of scenarios resulting in successful invasions; from the introduction of one large population in a single event or multiple smaller incursions (Lockwood et al. 2005). Understanding the process of invasion is important from a management perspective as this information can vastly alter how manager might deal with NIS populations; whether to stem the source population or tackle the resultant invasive population.

Islands are particularly at risk from NIS and have a higher proportion of invaders than mainland biota (Mooney \& Cleland 2001). It is thought that this may be because, in comparison to the mainland, species complexity and competition on islands is lower leaving niche gaps, which are more prone to invasion (Elton 1958). Paleobiological reconstructions (Vermeij 1991) of the direction of invasions show historically that a higher percentage of species from more speciose communities will establish in less speciose communities, than in the opposite direction. Therefore it has been hypothesised that highly speciose communities (mainland biota) are more resistant to invasion, because they have fewer niche gaps, and are more likely to successfully colonise lower speciose communities (island biota) (Lodge 1993).

In Hawai' $i, 20-40 \%$ of species across all taxa are thought to be non-indigenous (DeFelice et al. 2001, Molnar et al. 2008). Invasive marine and brackish invertebrates alone total nearly $7 \%$ of local fauna (DeFelice et al. 2001). The non-indigenous 
invertebrates appear to mostly originate from the Indo-Pacific and Philippines, as well as the Western Atlantic and Caribbean (DeFelice et al. 2001). The key pathway of invasion of NIS to Hawai'i is shipping, with $68 \%$ of harmful species having been imported in this manner (Molnar et al. 2008).

There are many factors leading to a successful invasion of an NIS including the attributes of the donor region, the potential disperser species, and the route, means and conditions of transport (Vermeij 1996). The process of invasion can essentially be split into 3 successive phases: arrival (successful transportation to the recipient biota), establishment (development through local reproduction and recruitment), and integration (spreading and forging new ecological links with recipient biota and evolving to the new selective regime) (Vermeij 1996, Puth \& Post 2005).

Non-indigenous marine species (NIMS) can be transported via commercial or even recreational boats, hull fouling, ballast water, sediments and sea chests (Carlton \& Geller 1993, Coutts et al. 2003, Ruiz \& Carlton 2003). Maritime traffic between ports has been reported as the primary mechanism for transporting larval NIMS around the world (Lafferty \& Kuris 1996, Godwin 2003b, Levine \& D'Antonio 2003).Oceanic vessels can be viewed as 'biological islands' providing settlement substrata, in protected recesses and enclosed bodies of water, for mobile and sessile organisms to inhabit (Wonham et al. 2000, Godwin 2003b). The majority of marine NIS arrive as larvae and as such are introduced to the recipient biota without many natural enemies (parasitic castrators, specialized predators and pathogens of adults), which might normally control their numbers in their native regions (Lafferty \& Kuris 1996). Hull fouling is also an important vector transporting numerous organisms around the world including algae, sponges, cnidarians, annelids, molluscs, crustaceans, bryozoans and chordates (Godwin 2003b). These organisms tend to proliferate in sheltered areas of the hull e.g. sea chests, and areas where the antifouling paint is compromised e.g. weld seems (Coutts et al. 2003, Godwin 2003b).

A number of factors allow the introduction and proliferation of invasive species in a new environment including: a lack of natural enemies, high adaptability, new parasitic hosts available, exploitation of resources in novel ways, presence of artificial or disturbed habitats, and/or effective predatory skills or defences suited to the new environment (Bax et al. 2001, Pimentel et al. 2001, Callaway \& Ridenour 2004). The NIMS can then direct more resources towards growth or reproduction (Bax et al. 2001) resulting in high NIMS population densities that can then effectively compete with the 
native species or even impact the recipient ecosystem (Lafferty \& Kuris 1996, Vitousek et al. 1997).

It is important to ascertain the process of invasion to understand and manage the affects that NIS can have on community assemblages (Webb et al. 2002). It is also important to understand the establishment and interaction of metapopulations of invasive species (Leibold et al. 2004). Metapopulations can establish as a result of continual re-introductions of non-indigenous individuals to an established NIS 'population' in a recipient biota (Grosholz \& Ruiz 1996, Jansen \& Vitalis 2007, Dlugosch \& Parker 2008). From a management perspective it would be prudent to focus on isolated introductions before an NIS is able to adapt and integrate to the host biota and develop novel invasive behaviours such as predator avoidance or even phenotypic plasticity (Dlugosch \& Parker 2008). These rapid adaptive behaviours can often develop on time scales of years to decades, and are often associated with the impacts of anthropogenic factors such as habitat degradation, fragmentation, over harvesting and the introduction of NIS (Stockwell et al. 2003, Stockwell \& Ashley 2004).

Sponges have long been transported around the world; for example, Mycale armata (Thiele, 1903), which is now found in Hawai' $i$, originated in the Indo-Pacific (DeFelice et al. 2001) or Crambe crambe (Schmidt, 1862), which extended its range from the Mediterranean to the Micronesian islands via hull fouling, ballast water or natural rafts (Duran et al. 2004a). Generally, sponges are highly effective spatial competitors (Jackson \& Buss 1975) and therefore can significantly impact the environment where they are abundant (Reiswig 1974, Coles 2007) particularly on oceanic islands and in lakes (Vermeij 1996), because in shallow locations high sponge biomass can potentially remove large quantities of nutrients and oxygen from the water column (Reiswig 1971b, 1974).

Sponges are unlikely to become invasive over large biogeographical barriers without human-mediated transportation because of their limited dispersal mechanisms and capabilities (Zea 2001, Maldonado 2006). Therefore they make an interesting model system to look at anthropogenic mediated dispersal. Sponges are hermaphrodites and can reproduce asexually via budding, gemmule formation and fragmentation (Fell 1974, Simpson 1984) or sexually via larval production. As is common with most sessile marine organisms, sponges are indirect developers with the embryos developing into larvae before metamorphosing into the adult form (Maldonado 2006). Sexual 
reproductive modes in sponges include oviparity (Fromont \& Bergquist 1994, Corriero et al. 1996) (external fertilization of the ova) and viviparity (Ilan 1995, Whalan et al. 2005) (internal fertilization). A number of marine invertebrates with a planktonic phase in their life cycle have been transported via ballast water (Carlton \& Geller 1993). However dispersal distance via asexual reproduction is thought to be low in sponges (Bergquist et al. 1970, Ayling 1980, Wulff 1985, Wulff 1991) and their larvae only remain in the water column for a limited period (days at most) before settling on the sea floor and metamorphosing into their sessile adult form (Uriz et al. 1998, Maldonado 2006). Therefore the global transport of these species is unlikely to be via ocean currents but by fouling on ships, which can maintain the adult forms at sea for weeks or even months (Godwin 2003b). For example the sponge Gelliodes fibrosa (Wilson, 1925) (grey encrusting sponge), an established Hawaiian NIMS, was documented in 1992 to foul the hull of a floating dry dock brought to Pearl Harbour from Subic Bay in the Philippines, its country of origin (Godwin 2003b). Slow moving vessels e.g. barges, towed vessels or floating dry docks are particularly high risk to fouling organisms as they have long residence times in ports giving time for organisms to establish in the port away from the vessel (Godwin 2003b).

\subsection{Sponges and genetics: a tool for understanding the process of invasion}

To conserve and manage marine ecosystems effectively, a better understanding of the global demographic connectivity between populations of NIS and their distribution patterns is needed (Palumbi 2004, Hoshino et al. 2008, Wörheide et al. 2008). The genetic 'tools' currently available potentially allow us to determine the amount of genetic connectivity between and within populations, and with that knowledge we can improve our understanding of the ecological and evolutionary relationships of invasive species (Wörheide et al. 2005).

Sponge phylogenetics has become increasingly popular since the 1980's (Wörheide et al. 2005, Hoshino et al. 2008) and with this enhanced knowledge comes the understanding that biogeographic studies should not be based solely on morphometric data (Wörheide et al. 2008). The plastic and cryptic nature of some species makes it difficult to clearly identify individual species and therefore distribution patterns of populations (Stockman \& Bond 2007). Sponge species that previously appeared to be morphologically homogenous, when later analysed using molecular techniques have often been found to have high genetic divergence between groups and 
even within 'species'(e.g. Solé-Cava \& Thorpe 1986, Muricy et al. 1996, Klautau et al. 1999). For example, the sponge species, Chondrilla nucula (Schmidt, 1862), Plakina trilopha (Schulze, 1880) and Suberites ficus (Johnston, 1842) were initially identified as having wide distribution patterns with different colour morphotypes, but further genetic analysis indicated a high rate of cryptic divergence and speciation within each of these species. The difficulty associated with identifying species using morphological characters therefore led to an initial overestimation of distribution ranges and underestimation of biodiversity (e.g. Klautau et al. 1999, Xavier et al. 2010).

One of the difficulties of working with marine species is that the nature of the environment makes it difficult to delineate a species' range due to the high dispersal potential associated with ocean current flow systems (Wörheide et al. 2008). Clear habitat fragmentation is particularly difficult to observe in marine environments, unlike freshwater and terrestrial ecosystems (Hoshino et al. 2008). The small size of pelagic larvae also makes it difficult to directly track their movement in situ (Graham \& Sebens 1996). Molecular tools are therefore increasingly being employed to investigate species taxonomy and phylogeography. The results from molecular data have significantly aided in our understanding of sponge systematics and in reconstructing metazoan evolutionary relationships (Wörheide et al. 2008), as well as helping to understand the phylogeographic distributions of NIS (Le Roux \& Wieczorek 2009). Molecular phylogeography uses genetic techniques to help trace the evolutionary history of populations. It aids in unravelling the genomic genealogical patterns developed due to historical genetic subdivisions (Avise 2000b). Dissecting the relative relatedness and age of alleles and placing them in a geographical context aids in examining the ongoing gene flow in a population (Hare 2001). Understanding this gene flow can provide clues to the ecological history that has led to a species current taxonomic status (Stockman \& Bond 2007).

Anthropogenic dispersal of NIS often leads to only a fraction of the genetic variability being transferred from the host to recipient biota (Nei et al. 1975, Dlugosch $\&$ Parker 2008). This can lead to the development of founder events, such as vicariance, population bottlenecks and range fluctuations, a product of the reduced genetic diversity and these events are usually detectable with molecular tools (e.g. Tarjuelo et al. 2001, Duran et al. 2004a, Wörheide et al. 2008). Molecular analyses indicate the original source population as the most genetically divergent population, because when species are transported to a recipient biota only a fraction of the genetic diversity is 
transferred (Tsutsui et al. 2000). From a management perspective, knowing the origins of an NIS is very important as this is the stage of initial dispersal from which the invasion starts and this is the area easiest to prevent further invasions by stemming the flow of genetic diversity to invasive populations (Puth \& Post 2005).

\subsection{Sponges and Palmyra Atoll}

Palmyra Atoll may not be as heavily inhabited as the nearby Hawaiian archipelago, but as an altered ecosystem it was potentially very susceptible to invasion after the lagoon dredging, military inhabitation and maritime traffic during WWII. The main biota on the hard substrates in the lagoons is now sponges, including possible introduced species. Therefore, from a management perspective it is important to establish the level of diversity and abundance of the sponges (Coles \& Bolick 2007) in the lagoon and their potential direct and indirect impacts on the atoll system.

The hypothesis that islands are more susceptible to invasions (Elton 1958, Mooney \& Cleland 2001) is difficult to test (Yiming et al. 2006). Therefore future research should investigate island invasions to better understand the impact that invasive species can have on these low diversity communities (Lodge 1993), particularly those under protection with little experience of human intervention, such as marine reserves and remote islands/atolls like Palmyra (Bax et al. 2003). Despite its remoteness the history of Palmyra makes it vulnerable to the 3 phases of successful invasion.

The most likely source for invasive species to Palmyra is the nearest large port Hawai' $\mathrm{i}$, which has been host to NIS for more than 1000 years (Mooney \& Cleland 2001), is an important vector pathway for NIS, and had notably higher introduction rates during the wartime period (Coles et al. 1999). Naval ships during this time were also the cause of other introductions to remote Pacific islands (e.g. Coles et al. 1999, Paulay et al. 2002). Ships were transporting equipment, goods and building materials to Palmyra from Hawai'i in high intensity from 1940 to 1945 and amongst the ships were often slow moving barges, allowing for higher survival rates of fouling organisms (Coutts et al. 2003, Godwin 2003b). In addition to this, the ship owners at this time were most likely less well informed of the impacts of invasive species and therefore ballast water and ships hulls were most likely only cleaned when fouling impacted the ships performance (Townsin 2003, Duggan et al. 2005). 
After the lagoons were extensively scoured, potentially little of the native biota remained leaving the establishment of NIS relatively unchallenged. The alterations may also have inadvertently created conditions more suitable for the NIS than the recipient biota (Vitousek et al. 1997). Many of the invasive marine invertebrate species of the Hawaiian Islands have been found to survive and proliferate in the high sediment conditions of harbours, presumably an environment they are better adjusted to than the adjacent reefs (Coles et al. 1997), or perhaps predation levels are higher on the reefs (Pawlik 1998). If native species densities remained low after the dredging, invasive species, namely the sponges, may have been able to proliferate within the lagoon system and adjust to the new selective regimes. Unfortunately, Palmyra was subjected to both environmental changes and introduced species, potentially leaving it susceptible to great biotic change (Ruiz \& Carlton 2003). The impact on the lagoon environment and biota may consequently have lasting affects on the adjacent 'near pristine' reef as the water flows out across the reef systems (e.g. Sultan \& Ahmad 1990), because the lagoon areas are very shallow in places and the high sponge biomass could potentially remove large quantities of nutrients and oxygen from the water column (Reiswig 1974).

It is therefore important to ascertain the process of invasion to understand and manage the impacts that NIS can potentially have on communities or even directly on the ecosystem (Lafferty \& Kuris 1996, Vitousek 1997, Webb et al. 2002). Further research should examine the potential impacts that these changes have had on such an altered system and whether they will impact not only the lagoon system, but on the surrounding reef as well. Firstly, the species need to be identified, particularly any nonindigenous sponge species (NISS). The origins of these species need to be established, as well as the number of potential invasion events i.e. whether the NISS were transported to Palmyra during the war alone or whether they are continually being brought to the atoll via other vessels. This will help establish whether preventative measures need to be taken to avoid further invasions, by the same or different species. Temporal changes in sponge species assemblages and spatial distribution patterns also need to be observed to look at rates of change and potentially ascertain whether they have the ability to cover the lagoons and extend onto the reef or whether the assemblages are relatively stable and confined within the lagoon. The potential that NISS have to invade new locations must also be considered to determine the rate at which invasive species can inhabit new locations if there is available substrate. Also, the impacts that the sponges could have on the water column are important to assess, as 
the lagoon water flows out over the adjacent near-pristine reef. This information can be used to understand the potential impact the sponge fauna within the lagoons may have on the atoll system at Palmyra. This research will also improve our understanding of the potential direct and indirect impacts that sponges in high densities (particularly introduced species) can have on the water column in other semi-enclosed systems such as other atolls, harbours and bays, and their direct threat of expanding beyond these introduction sites to more unaltered systems.

Overall the aims of this thesis were to a) identify the sponges at Palmyra, particularly any non-indigenous species b) establish whether the sponges are maintained within the lagoons or have the potential to extend onto the adjacent reef c) confirm the introduction of non-indigenous species to Palmyra and d) establish whether the sponges are impacting the water column in the lagoons sufficiently to affect the water which flows out over the adjacent near-pristine reef.

\subsection{Objectives of the research}

This research examined the ecology of sponge assemblages at Palmyra Atoll in the Central Pacific to determine the potential direct and indirect impacts of sponge assemblages on this semi-enclosed body of water. The specific aims of my thesis were to:

a) Quantify the abundance and distribution patterns of sponges at Palmyra Atoll and determine the factors influencing these distribution patterns.

b) Identify potential sponge species that have been introduced to Palmyra.

c) Measure the growth and recruitment of sponge species to determine if there is any potential for sponges in the lagoon to colonise the adjacent reef.

d) Measure the ecological impacts of sponges on the water column at the atoll. 


\section{Chapter 2}

\section{Environmental drivers of sponge diversity, cover and assemblage composition in the lagoons at Palmyra Atoll, Central Pacific}

\subsection{Abstract}

Heavy disturbance usually leads to changes in local-scale environmental conditions, which may have subsequent effects on the associated biota and leave communities with a reduced ability to resist invasive species. Palmyra Atoll in the Central Pacific was subject to major military modifications across its lagoon system and islets during WWII and now the dominant fauna on the remaining hard substrate are sponges. Given the limited dispersal capacity of sponges and isolation of Palmyra, it is likely that many of the sponge species currently found in the atoll lagoons are nonindigenous. In this study, I quantified the physical and biological factors explaining the variation in sponge distribution patterns across 11 sites to determine the potential for the sponges in the lagoon at Palmyra to invade the surrounding reef systems if nonlagoon environmental quality changes in the future. Significant differences in sponge assemblages were found between all but three sites. Overall, $40 \%$ and $96 \%$ of the variability in sponge assemblages and mean sponge cover was explained by the biotic and abiotic variables measured, respectively. The main factors explaining the variability in total sponge cover were turbidity, percentage of hard substrate, variability in water flow and percentage of coarse sand. Substrate angle, variability in chlorophyll$a$ and percentage of hard substrate were the top three variables explaining the variability in sponge assemblages, although no single factor explained more than $8 \%$ of the total variation. The findings suggest that the lagoon sponges at Palmyra are likely to be restricted to these environments where they are particularly associated with conditions resulting from the earlier heavy disturbance, and are therefore unlikely to spread to the outer reefs unless there is a dramatic decline in environmental quality. Therefore, any occurrence of lagoon-inhabiting sponges on outer atoll reef systems in the future may indicate a decline in environmental quality. 


\subsection{Introduction}

Coral reefs are highly diverse ecosystems providing numerous ecological and economic benefits (Moberg \& Folke 1999, Barbier et al. 2011). However, despite their importance, coral reefs are experiencing major anthropogenic pressure (Pandolfi et al. 2003, Bellwood et al. 2004, Hoegh-Guldberg 2011) to the extent that no remaining reefs can be considered pristine (Jackson 1997). Alterations and modifications to marine environments, such as coral reefs, change the structure and function of the receiving ecosystem by reducing diversity, lowering light levels and available substrate, and increasing sediment loading and nutrient pollution (Rogers 1990, Cranfield et al. 2004, Fabricius 2005). When such disturbances are extreme, complex ecosystems can be rapidly transformed to simple ones and become characterised by reduced diversity (Rapport \& Whitford 1999). Furthermore, modifications and the removal of native fauna often make habitats more susceptible to colonisation by non-indigenous species (NIS) (Mooney \& Cleland 2001), as well as inadvertently create conditions and provide substrate that are preferential to the NIS over the existing biota (Byers 2002, Tyrrell \& Byers 2007).

There are a large number of atolls in the Central Pacific, most which have a long history of human colonisation, and which are typically characterised by degraded lagoon systems with low levels of water exchange and high levels of turbidity (Sandin et al. 2008). These environments appear to have gone through major changes compared to their original state and many such lagoons support a large number of non-indigenous species (see Appendix I). Given that many of these introductions are thought to have occurred in recent human history (past 50-100 years) because of shipping traffic, there is concern that these relatively recent introductions to lagoon systems as the point of incursion may lead to a later invasion of outer atoll reef systems. While such invasions have not yet been widely reported (but see Appendix I), it is possible that such species are still in an establishment phase. Therefore, it is important to understand the factors influencing the distribution patterns of species within degraded lagoons to determine their potential to invade outer reef systems.

Palmyra Atoll, situated 1,930 km south of the Hawaiian archipelago, is considered a near-pristine atoll system and represents a biodiversity hotspot in the Central Pacific (Maragos \& Williams 2011a). However, although the outer reefs at Palmyra are characterized by a high cover of calcifying organisms and abundant predatory fish (Sandin et al. 2008), the prominent benthic fauna on the hard substrate in 
the lagoons, where extensive habitat modifications occurred (Collen et al. 2009), are sponges. The lagoons at Palmyra were subject to a number of military modifications during WWII (Dawson 1959) including extensive dredging and construction that removed endemic fauna, including corals from the lagoons (Anon. 1947), and altered the environmental conditions by stemming the flow of water between lagoons (Dawson 1959, Maragos 1993, Collen et al. 2009). It has been proposed, because of its shape, that the pre-war lagoon at Palmyra might have been similar to Millennium Atoll's lagoons (pers. comms. Jim Maragos), which is dominated by Acropora spp., but also characterised by high crustose coralline algal cover, turfing algae and the giant clam Tridacna maxima (Barott et al. 2010). A large number of old T. maxima shells remain in Palmyra's lagoon supporting this suggestion. The military modifications at Palmyra therefore most likely resulted in a major decline in species diversity, and potentially made the lagoon system more vulnerable to NIS and led to the current environmental conditions, where sponges are the dominant benthic fauna on hard substrates.

Sponges are often understudied and overlooked despite performing a range of important functional roles in coral reef ecosystems, particularly resulting from their filtering activities, competitive ability and complex relationships with other organisms (Wulff 2001, Bell 2008a). Furthermore, where sponges occur in high enough densities they can have considerable impacts on benthic and pelagic ecosystems (e.g. Peterson et al. 2006). It is currently unknown how many of the sponge species in the lagoons at Palmyra are native to the atoll; however two non-indigenous sponge species have already been reported (see Appendix I). Given the generally limited dispersal potential of sponges (Maldonado \& Young 1996) and the isolated nature of the atoll, it is likely that many of the sponges found in this disturbed environmental are non-native to the Palmyra system.

Several features of the sponges at Palmyra are of particular concern from a conservation and management perspective, and are potentially problems for other atoll systems where sponges are an abundant component of lagoon fauna. Firstly, sponges are usually top spatial competitors and have the ability to overgrow other reef organisms (Bell 2008a). Secondly, the filtering activity of sponges has the potential to impact the water column (e.g. nutrient removal). Therefore changes to sponge abundance in the lagoon or an increase in the distribution range of sponges at Palmyra, has the potential to alter overall community structure and ecosystem functioning (Bell 2008a). However, recent surveys have found no common sponge species between the 
lagoon and outer atoll reefs where sponges are rare suggesting abiotic and biotic factors might be restricting the sponges to the lagoons. Despite this, given that the establishment of the sponge assemblage is likely to be relatively recent (last 60 years since major military occupation) compared to the likely age of the atoll colonisation, this needs further investigation as sponges might still be in an establishment phase.

In general there is a paucity of studies that have examined sponge assemblage diversity and abundance in the Central Pacific (e.g. Bell \& Carballo 2008 and Appendix II), with little known about the environmental parameters shaping the sponge assemblages in these coral reef ecosystems. Previous studies have shown that spatial variation in sponge distribution patterns and abundance depend on a number of environmental and biological factors, including depth (see Appendix II), water flow (Bell \& Barnes 2003a), sedimentation (Carballo 2006, de Voogd \& Cleary 2007), predation (Dunlap \& Pawlik 1996), salinity (Roberts et al. 2006), nutrient levels (Wilkinson \& Cheshire 1989), light levels (Cheshire \& Wilkinson 1991), substrate type and angle (Bell \& Barnes 2000a, Powell et al. 2010), turbidity (Zea 1994), and larval dispersal and recruitment (Maldonado \& Young 1996).

In this study, Palmyra Atoll was used as a model atoll system to examine the factors explaining the variation in sponge abundance and distribution patterns to assess any potential for sponges to spread from the lagoon to the outer reefs systems in the future. The aims of this study were: 1) to identify the sponge species distribution patterns across the lagoons; 2) to determine the variables that best explain the variation in sponge assemblage patterns and overall sponge percentage cover in the lagoons; and 3) to explore the potential for the lagoon inhabiting sponges to extend on to the adjacent reef systems in the future.

\subsection{Methods}

\subsubsection{Sponge assemblage surveys}

Between June to November 2008 sponge assemblages were surveyed across the four lagoons at 11 sites (Fig 2.1) at depths between 5-8 $\mathrm{m}$. The site selection criterion was based on achieving representative sampling across the lagoons. These observations focused on sponges found on the surface of the boulders rather than those underneath boulders (See Bell \& Carballo 2008). Excavating (bioeroding) species were not included because accurate estimates of area cover were not possible. At each site, ten 1 $\mathrm{m}^{2}$ quadrats (divided into twenty five $40 \mathrm{~cm}^{2}$ sub-sections) were haphazardly placed on 
boulder patches at each site. In total, $110 \mathrm{~m}^{2}$ of substrate were surveyed across the lagoons at Palmyra. Within each quadrat sub-section, the percentage cover of each sponge species was estimated along with the area of available hard substrate. If a sponge extended beyond the quadrat only the area in the sub-section was estimated and if a sponge extended into an adjacent sub-section the area cover was estimated independently in each. Sponge cover was standardised against available hard substrate between quadrats to enable direct comparisons between sites by accounting for the variability in overall boulder densities:

$$
=(c \times 4) \div(b \div 100) \div 100
$$

where $c$ is the cover of sponges (per species) $\left(\mathrm{cm}^{2}\right)$, which was multiplied by 4 because each of the 25 sub-sections equates to $4 \%$ of the total quadrat and $b$ is the average $\%$ of available substrate per quadrat. Then to get the average $\%$ area cover of sponge per available substrate the sum of both brackets was \% by 100 .

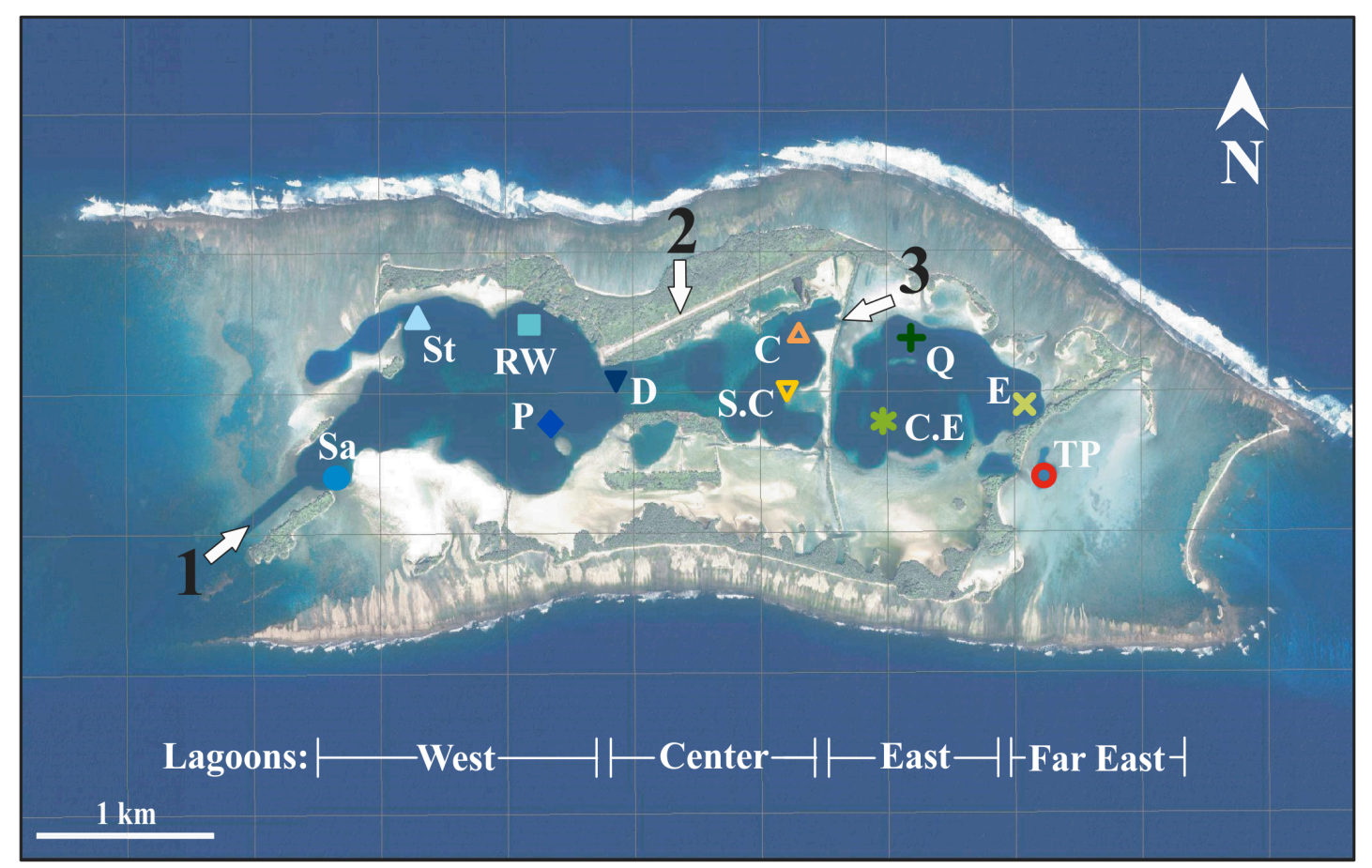

Figure 2.1 Location of the 11 survey sites within the 4 lagoons: Sand Island (Sa); Strawn Island (St); Ripple Wharf (RW); Paradise Island (P); The Dolphins (D); The Cut (C); South of the Cut (S.C); Quail Island (Q); Eastern Island (E); Central East (C.E); Turtle Pool (TP) across the 4 lagoons. The white arrows indicate locations of military modifications: 1 = excavated entrance channel, 2 = the airstrip made of dredge spoil and coral rubble and $3=$ the north-south causeway, specifically the cut allowing boat access between the Centre and East Lagoons. 


\subsubsection{Sponge collections and identifications}

Sponge samples were collected from all unidentified species inside and outside of the quadrats. Where possible, three samples of each species were collected and stored in $>95 \%$ ethanol. All samples were identified by examining phenotypic characteristics, spicule preparations and sections.

\subsubsection{Biotic and abiotic variables}

A suite of variables was collected at each site at depths of 5-8 m from 2008 to 2010. All individual variables were collected simultaneously to ensure comparability across sites. Temperature $\left({ }^{\circ} \mathrm{C}\right)$ data were collected using pendant $\mathrm{HOBO}^{\circledR}$ temperature

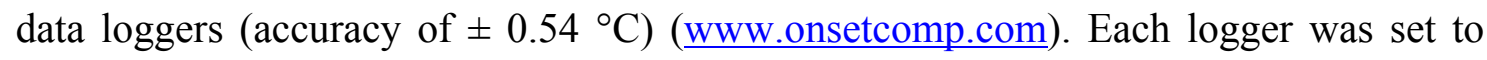
record once every 2 minutes between June-July 2010. RBR ${ }^{\circledR}$ XR-420 data loggers (www.rbr-global.com), recording once every minute between June-November 2008 and June-July 2010, measured salinity, turbidity (as a proxy for sediment load), chlorophyll- $a$ and additional temperature data. Chlorophyll- $a$ is used here as an approximation of food availability because it is a measure of the available phytoplankton in the water and generally correlates positively with bacteria levels (Cole et al. 1988), which are a major food source for sponges (Reiswig 1971b, 1975, Pile et al. 1996). Unfortunately, the remote nature of Palmyra Atoll made it impossible to collect water samples for complete food particle analysis (e.g. with flow cytometry).

Water flow was recorded once every 10 seconds using a Valeport ${ }^{\circledR}$ Model 106 Current Meter (www.valeport.co.uk) deployed between June-November 2008 and June-July 2010 for approximately two days at each site. Percentage organic matter (\%) (PCOM) and total particulate matter $\left(\mathrm{mg} \mathrm{m}^{-2} \mathrm{~d}^{-1}\right)$ (TPM) in settled sediment were measured 2-5 times between June-November 2008 and 2009 using PVC sediment traps (See Bloesch 1994). The traps were $50 \mathrm{~cm}$ long with an internal diameter of $5.1 \mathrm{~cm}$ and placed $30 \mathrm{~cm}$ above the substrate. Upon collection, the trap contents were filtered through grade 114 wet strengthened Whatman ${ }^{\circledR}$ filter papers and put into a drying oven at $60^{\circ} \mathrm{C}$ to desiccate until they reached a constant weight. The dry weight and number of days the trap remained in the water were used to calculate TPM. The samples were then placed into a muffle furnace at $500{ }^{\circ} \mathrm{C}$ for 24 hours to obtain the ash-free dry weight. Weight loss on combustion was used to calculate the Particulate Organic Matter (POM) matter $\left(\mathrm{mg} \mathrm{m}^{-2} \mathrm{~d}^{-1}\right)$. PCOM was calculated as POM/TPM x 100 (Craft et al. 1991). 
Percentage hard and soft substrate (boulders and sand) were quantified using 10 x $1 \mathrm{~m}^{2}$ photoquadrats taken at each site. Estimates of benthic cover were collected independently from the sponge cover surveys because boulders were targeted for this portion of the survey and would give a biased representation for each site. In order to obtain random sampling when characterising the habitats, a $30 \mathrm{~m}$ transect was laid at 5$8 \mathrm{~m}$ depth and a $1 \mathrm{~m}^{2}$ quadrat placed on either side of the transect at $5 \mathrm{~m}$ intervals $(\mathrm{n}=$ 10) from $5 \mathrm{~m}$ to $25 \mathrm{~m}$. By not placing the quadrats at either $0 \mathrm{~m}$ or $30 \mathrm{~m}$, the likelihood of observer bias was removed when laying the transect tape. Substrate percentage cover values were calculated using Coral Point Count with excel extensions (CPCe) software (Kohler \& Gill 2006). One hundred randomly assigned points were placed over each 1 $\mathrm{m}^{2}$, equalling 1000 points per site and 11,000 points across the atoll, covering a total of $110 \mathrm{~m}^{2}$.

Grain size composition of the sediment was examined by collecting in situ bulk sediment samples from the beginning and end of the quadrat transects. Each sample was then separated using standard brass sieves (USA Standard Testing Sieve- ASTM. E-11 specifications) into the fractions: rubble $(>2.8 \mathrm{~mm})$, coarse sand $(500 \mu \mathrm{m}-2.8$ $\mathrm{mm})$, medium sand $(250-500 \mu \mathrm{m})$, fine sand $(63-250 \mu \mathrm{m})$ and silt/clay $(<63 \mu \mathrm{m})$ in accordance with the Wentworth scale (Folk 1974). The largest grain size class $(>2.8$ $\mathrm{mm}$ ) was subsequently discarded because there is no upper size limit and it would therefore skew the results. The four remaining fractions were poured into and drained through pre-weighed grade 114 wet strengthened Whatman ${ }^{\circledR}$ filter papers and dried in an incubator for 2 days at $60{ }^{\circ} \mathrm{C}$. Samples were allowed to cool to room temperature, weighed and then dried for additional $24 \mathrm{~h}$ periods until a constant weight was achieved. Proportions (\%) for each size class were calculated as 100/total weight $\mathrm{x}$ class weight. The final variable included in the model was substrate slope /angle, which was categorical and sites where either classed as (1) sloping $\approx 40-50^{\circ}$ or (2) horizontal $\approx 0^{\circ}$.

\subsubsection{Statistical analyses}

\subsubsection{Diversity indices}

Across sites, I characterised and compared sponge assemblages using a number of diversity indices: number of species (S), Hill's numbers N1 and N2 and the modified Hill's ratio (N21'). Hill's numbers $\mathrm{N} 1$ and $\mathrm{N} 2$ indicate the influence of rare and 
dominant species, respectively, and Hill's ratio examines species equitability (evenness) without any dependency on the number of species (Rogers et al. 1999).

\subsubsection{Multivariate analyses}

All assemblage data, prior to the analyses, were dispersion weighted (based on 1000 permutations), which differentially weights species depending on their observed variability between samples (Clarke et al. 2006a) and is suitable for species prone to spatial clustering, such as sponges. Similarity matrices were based on zero-adjusted Bray-Curtis coefficients and accounted for denuded data (Clarke et al. 2006b), which were characteristic of a number of sites.

A permutational multivariate analysis of variance (PERMANOVA) (based on 9999 permutations) (Anderson 2001, Clarke et al. 2006b) and pairwise post-hoc tests were used to examine differences in sponge cover at two separate factor levels: lagoon (West, Center, East and Turtle pool) and site (all 11 sites) (Fig 2.1). To visualise the PERMANOVA results, non-metric multi-dimensional scaling (nMDS) and canonical analysis of principal coordinates (CAP) plots (using 9999 permutations), with allocation success values, were examined (Anderson \& Willis 2003). Allocation success values (\%) were calculated using the leave-one-out procedure of the CAP analysis (Anderson \& Willis 2003) and indicated the relative distinctness between assemblages. Allocation values greater than 25\% (for the 4 lagoons) and $9.09 \%$ (for the 11 sites) were considered to indicate more distinct assemblages than those expected by chance alone. Indicator species, i.e. those which most characterise a site (Dufrêne \& Legendre 1997) and were responsible for the observed differences between assemblage patterns in the CAP plot, were examined by calculating Pearson's product-moment correlations of canonical ordinations axes with the original sponge percentage cover data (Anderson 2004). Those species identified as indicator species (defined as $\geq 0.5$ in this study) were graphically displayed as vectors on a bi-plot.

Ranked species abundances were calculated by separately totalling sponge cover data per species and ranking them from the most to the least abundant, indicating how common or rare a sponge species ranked relative to all other sponges across the lagoons. 


\subsubsection{Environmental associations with sponge cover and assemblages}

Analysis and modelling of the univariate and multivariate sponge data with the environmental, biological and categorical predictor variables were conducted using a distance-based linear model (DistLM) (McArdle \& Anderson 2001). Three important species were also examined individually, two potentially introduced species and the most dominant sponge in the lagoons. Haliclona caerulea (Hechtel 1965) (also known as Haliclona (Gellius) caerulea, Haliclona (Soestella) caerulea or Sigmadocia caerulea) are two confirmed non-indigenous species introduced to Palmyra (see Appendix I) and Hawai'i (DeFelice et al. 2001) from the Caribbean and the Philippines, respectively. Iotrochota protea (de Laubenfels 1950) (purple staining sponge), the dominant species in the lagoons at Palmyra, is native to Hawai' $i$, but it is unknown whether it was found on Palmyra prior to military occupation. For further information on these highlighted species please see Chapter 5 and Appendices I and V. The DistLM routine conducts a multivariate multiple regression to quantitatively explain how much variation in the sponge assemblage data can be explained by the biotic and abiotic variables. Twenty-one environmental and biological variables were initially measured (Table 2.1), seven of which were one standard deviation (+1SD) values, which represent the variability of the factor at an individual site. To examine colineation between the variables, I examined draftsman plots and Principal Component Analysis (PCA) ordinations. Inter-correlation values $>0.75$ (lower than the recommended 0.95 cut-off (Anderson et al. 2008) between two variables were considered for removal but were first examined further using PCA plots. Those factors removed from the model lay in the same direction and length as one or more of the other colineating variables in the PCA plots and were therefore redundant as variables. The following variables were removed from the final model: Temperature, chlorophyll$a$, turbidity (+1SD), water flow, total particulate matter (TPM), TPM (+1SD), and medium and fine sediment, resulting in the inclusion of thirteen predictor variables into the DistLM model (see Table 2.1). The routine was run using the 'best' selection procedure, based on 9999 permutations of the residuals under the reduced model. The model selection criteria were determined using Akaike's information criterion (Akaike 1973) with a second-order bias correction applied (AICc) (Burnham \& Anderson 2002). The most parsimonious model with the highest $R^{2}$ value and lowest AICc value was selected. In this study, each site (Fig 2.1), consisting of $10 \times 1 \mathrm{~m}^{2}$ quadrats, was considered an independent observation with independent variables collected for each of 
the 11 locations. Distance-based redundancy analyses (dbRDA) were used to visualise and interpret the optimal models (McArdle \& Anderson 2001). Sites are displayed by a group centroid: centroids closer together represent more similar sponge assemblages. The length and direction of each vector line indicates the strength and sign (+ve or -ve) of the relationship between the predictor variables and the sites. Sites in the opposite direction of the line are negative or lower values of the variable. All analyses were conducted using PRIMER v6 (Clarke \& Gorley 2006) and the PERMANOVA+ add-on package (Anderson et al. 2008). 


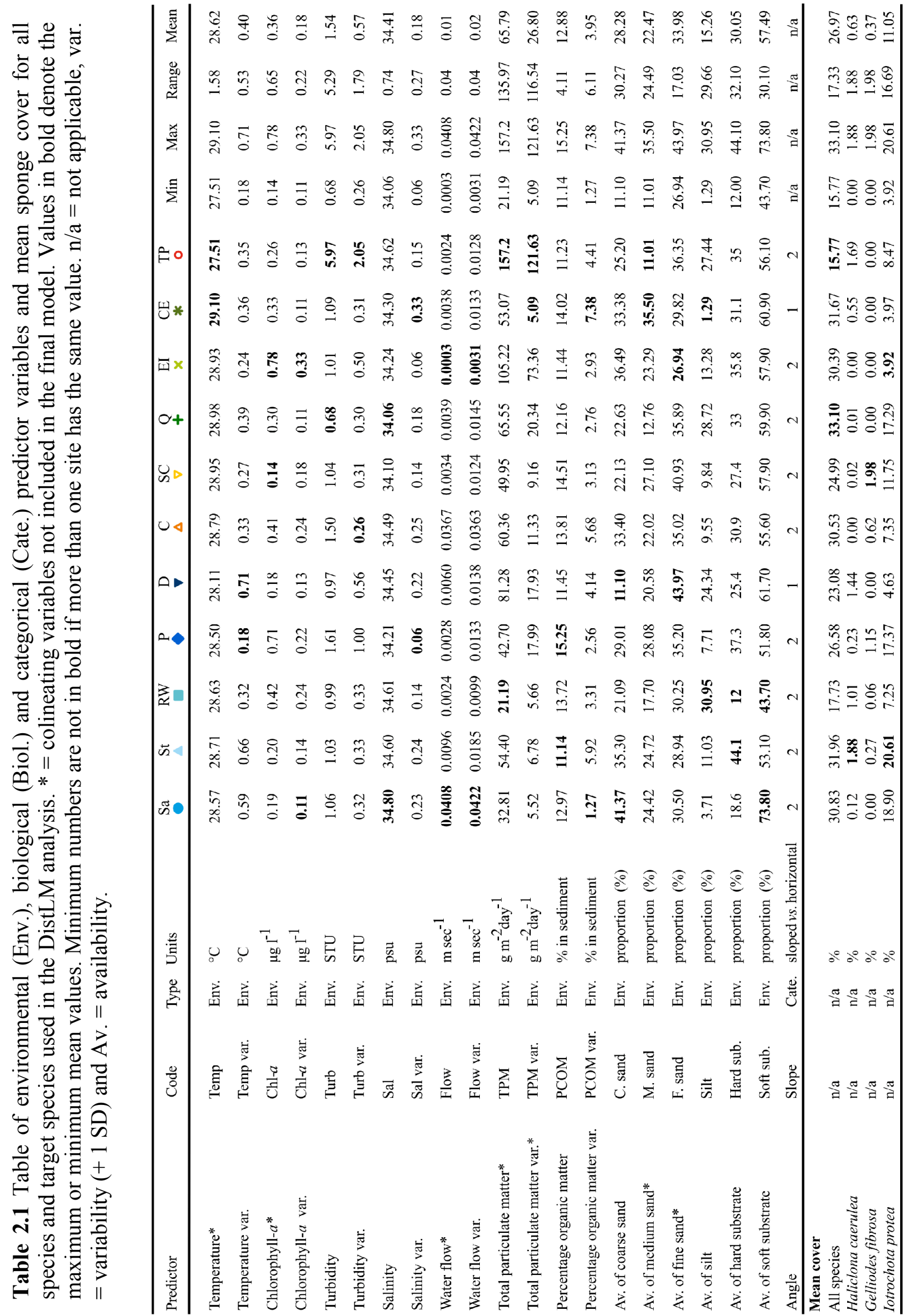




\subsection{Results}

A total of 36 sponge species were recorded across the lagoons at Palmyra Atoll (Table 2.2; Appendix III). Twenty-four of these were collected during the quadrat surveys in 2008 and the remainder were rare species and observed outside of the quadrats, found deeper than $8 \mathrm{~m}$ or were excluded because they were excavating species. On the non-lagoon reefs, we found 15 sponge species, therefore across the atoll in total, we found 51 species and importantly no species were found in both the lagoons and on the outer reefs. Overall there were 16 genera, 13 families and 7 orders of sponges observed in the lagoons and 9 genera, 11 families and 8 orders on the reefs.

Excluding excavating species, four morphological groups were represented in the lagoon: encrusting, cushion, massive and digitate. The Ripple Wharf in the West Lagoon had the lowest number of species $(S=8)$ and the Cut in the Center Lagoon and Quail Island in East Lagoon the highest $(S=17)$, with an overall average of 15 ( \pm 2.6) sponge species per site (Fig 2.2b). Both Hill numbers N1 and N2 indicated similar patterns across sites with the highest measure of diversity and evenness (Fig 2.2c) found at the Dolphins (N1 and N2) and the Ripple Wharf (N21') (Fig 2.2d), respectively, and the lowest at Strawn Island for all indices. 
Table 2.2 Species found within the lagoons and on the reefs at Palmyra Atoll, see Appendix III for photographs. A-X samples are those species found within the quadrats. AA-AL are those species found outside the quadrats or are excavating species in the lagoons and BA-BO are those species found on the reefs. ${ }^{c}=$ calcareous sponge. For further information on the ecological and morphological characteristics of the sponges in this list please refer to Appendix IV.

\begin{tabular}{|c|c|c|c|c|c|}
\hline ID List & Genus & Family & Suborder & Order & Reference \\
\hline A cf. Aplysilla rosea & Aplysilla & Darwinellidae & $\mathrm{n} / \mathrm{a}$ & Dendroceratida & Barrois, 1876 \\
\hline B Dysidea sp.1 & Dysidea & Dysideidae & $\mathrm{n} / \mathrm{a}$ & Dictyoceratida & Johnston, 1842 \\
\hline C Dysidea sp. 2 cf. etherea & Dysidea & Dysideidae & $\mathrm{n} / \mathrm{a}$ & Dictyoceratida & Johnston, 1842 \\
\hline D Spirastrella sp. & Spirastrella & Spirastrellidae & $\mathrm{n} / \mathrm{a}$ & Hadromerida & Schmidt, 1868 \\
\hline E Scopalina sp. & Scopalina & Dictyonellidae & $\mathrm{n} / \mathrm{a}$ & Halichondrida & Schmidt, 1862 \\
\hline F Halichondria sp.1 & Halichondria & Halichondriidae & $\mathrm{n} / \mathrm{a}$ & Halichondrida & Fleming, 1828 \\
\hline G Halichondria sp.2 & Halichondria & Halichondriidae & $\mathrm{n} / \mathrm{a}$ & Halichondrida & Fleming, 1828 \\
\hline H Hymeniacidon sp.1 & Hymeniacidon & Halichondriidae & $\mathrm{n} / \mathrm{a}$ & Halichondrida & Bowerbank, 1858 \\
\hline I Halichondriidae sp. 1 & unknown & Halichondriidae & $\mathrm{n} / \mathrm{a}$ & Halichondrida & Gray, 1867 \\
\hline J Halichondriidae sp.2 & unknown & Halichondriidae & $\mathrm{n} / \mathrm{a}$ & Halichondrida & Gray, 1867 \\
\hline $\mathrm{K}$ Chalinula sp. & Chalinula & Chalinidae & Haplosclerina & Haplosclerida & Schmidt, 1868 \\
\hline L Haliclona (Gellius) caerulea & Haliclona & Chalinidae & Haplosclerina & Haplosclerida & Hechtel, 1965 \\
\hline M Haliclona sp.1 & Haliclona & Chalinidae & Haplosclerina & Haplosclerida & Grant, 1836 \\
\hline N Challyspongiidae sp. & unknown & Challyspongiidae & Haplosclerina & Haplosclerida & de Laubenfels, 1936 \\
\hline O Gelliodes fibrosa & Gelliodes & Niphatidae & Haplosclerina & Haplosclerida & Wilson, 1925 \\
\hline P Niphatidae sp.1 & unknown & Niphatidae & Haplosclerina & Haplosclerida & Van Soest, 1980 \\
\hline Q Haplosclerida sp. & unknown & unknown & unknown & Haplosclerida & Topsent, 1928 \\
\hline $\mathrm{R}$ Acarnus sp.1 & Acarnus & Acarnidae & Microcionina & Poecilosclerida & Gray, 1867 \\
\hline $\mathrm{S}$ Acarnus sp.2 & Acarnus & Acarnidae & Microcionina & Poecilosclerida & Gray, 1867 \\
\hline $\mathrm{T}$ Chondropsidae sp. & unknown & Chondropsidae & Myxillina & Poecilosclerida & Carter, 1886 \\
\hline U Iotrochota protea & Iotrochota & Iotrochotidae & Myxillina & Poecilosclerida & Ridley, 1884 \\
\hline $\mathrm{V}$ Iotrochotidae sp. & unknown & Iotrochotidae & Myxillina & Poecilosclerida & Dendy, 1922 \\
\hline W Clathria sp. & Clathria. & Microcionidae & Microcionina & Poecilosclerida & Schmidt, 1862 \\
\hline X Hexadella sp. & Hexadella & Ianthellidae & $\mathrm{n} / \mathrm{a}$ & Verongida & Topsent, 1896 \\
\hline AA Darwinellidae sp. & unknown & unknown & Darwinellidae & Dendroceratida & Merejkowsky, 1879 \\
\hline AB Cliona sp. 1 & Cliona & Clionaidae & $\mathrm{n} / \mathrm{a}$ & Hadromerida & Grant, 1826 \\
\hline AC Cliona $\mathrm{sp} .2$ & Cliona & Clionaidae & $\mathrm{n} / \mathrm{a}$ & Hadromerida & Grant, 1826 \\
\hline AD Suberitidae sp.1 & unknown & Suberitidae & $\mathrm{n} / \mathrm{a}$ & Hadromerida & Schmidt, 1870 \\
\hline AE Suberitidae sp. 2 & unknown & Suberitidae & $\mathrm{n} / \mathrm{a}$ & Hadromerida & Schmidt, 1870 \\
\hline AF Hymeniacidon sp. & Hymeniacidon & Halichondriidae & $\mathrm{n} / \mathrm{a}$ & Halichondrida & Bowerbank, 1858 \\
\hline AG Halichondriidae sp. 3 & unknown & Halichondriidae & $\mathrm{n} / \mathrm{a}$ & Halichondrida & Bowerbank, 1858 \\
\hline AH Haliclona $\mathrm{sp} .2$ & Haliclona & Chalinidae & Haplosclerina & Haplosclerida & Grant, 1836 \\
\hline AI Niphatidae sp.2 & unknown & Niphatidae & Haplosclerina & Haplosclerida & Van Soest, 1980 \\
\hline AJ Microcionidae sp. & unknown & Microcionidae & Microcionina & Poecilosclerida & Carter, 1875 \\
\hline AK Myxillidae sp. & unknown & Myxillidae & Myxillina & Poecilosclerida & Dendy, 1922 \\
\hline AL Poecilosclerida sp. & unknown & unknown & unknown & Poecilosclerida & Topsent, 1928 \\
\hline BA Astrophorida sp. & unknown & unknown & unknown & Astrophorida & Sollas, 1887 \\
\hline BB Jaspis sp. & Jaspis & Ancorinidae & $\mathrm{n} / \mathrm{a}$ & Astrophorida & Gray, 1867 \\
\hline BC Halisarca sp. & Halisarca & Halisarcidae & $\mathrm{n} / \mathrm{a}$ & Chondrosida & Johnston, 1842 \\
\hline BD Clathrina sp. & Clathrina & Clathrinidae & $\mathrm{n} / \mathrm{a}$ & Clathrinida & Gray, 1867 \\
\hline BE Hyatella sp. & Hyatella & Spongiidae & $\mathrm{n} / \mathrm{a}$ & Dictyoceratida & Lamarck, 1814 \\
\hline BF Cliona sp. 3 & Cliona & Clionaidae & $\mathrm{n} / \mathrm{a}$ & Hadromerida & Grant, 1826 \\
\hline BG Tethya sp. & Tethya & Tethyidae & $\mathrm{n} / \mathrm{a}$ & Hadromerida & Lamarck, 1815 \\
\hline BH Callyspongia sp. & Callyspongia & Callyspongiidae & Haplosclerina & Haplosclerida & Duchassaing \& Michelotti, 1864 \\
\hline BI cf. Chalinidae sp. & unknown & Chalinidae & Haplosclerina & Haplosclerida & Gray, 1867 \\
\hline BJ Haliclona sp. 4 & Haliclona & Chalinidae & Haplosclerina & Haplosclerida & Grant, 1836 \\
\hline BK Haliclona sp.3 & Haliclona & Chalinidae & Haplosclerina & Haplosclerida & Grant, 1836 \\
\hline BL Niphatidae sp. & unknown & Niphatidae & Haplosclerina & Haplosclerida & Van Soest, 1980 \\
\hline BM Plakinidae sp. & unknown & Plakinidae & $\mathrm{n} / \mathrm{a}$ & Homosclerophorida & Schulze, 1880 \\
\hline BN Crella (Crella) sp.1 & Crella & Crellidae & Myxillina & Poecilosclerida & Gray, 1867 \\
\hline BO Crella (Crella) sp. 2 & Crella & Crellidae & Myxillina & Poecilosclerida & Gray, 1867 \\
\hline
\end{tabular}



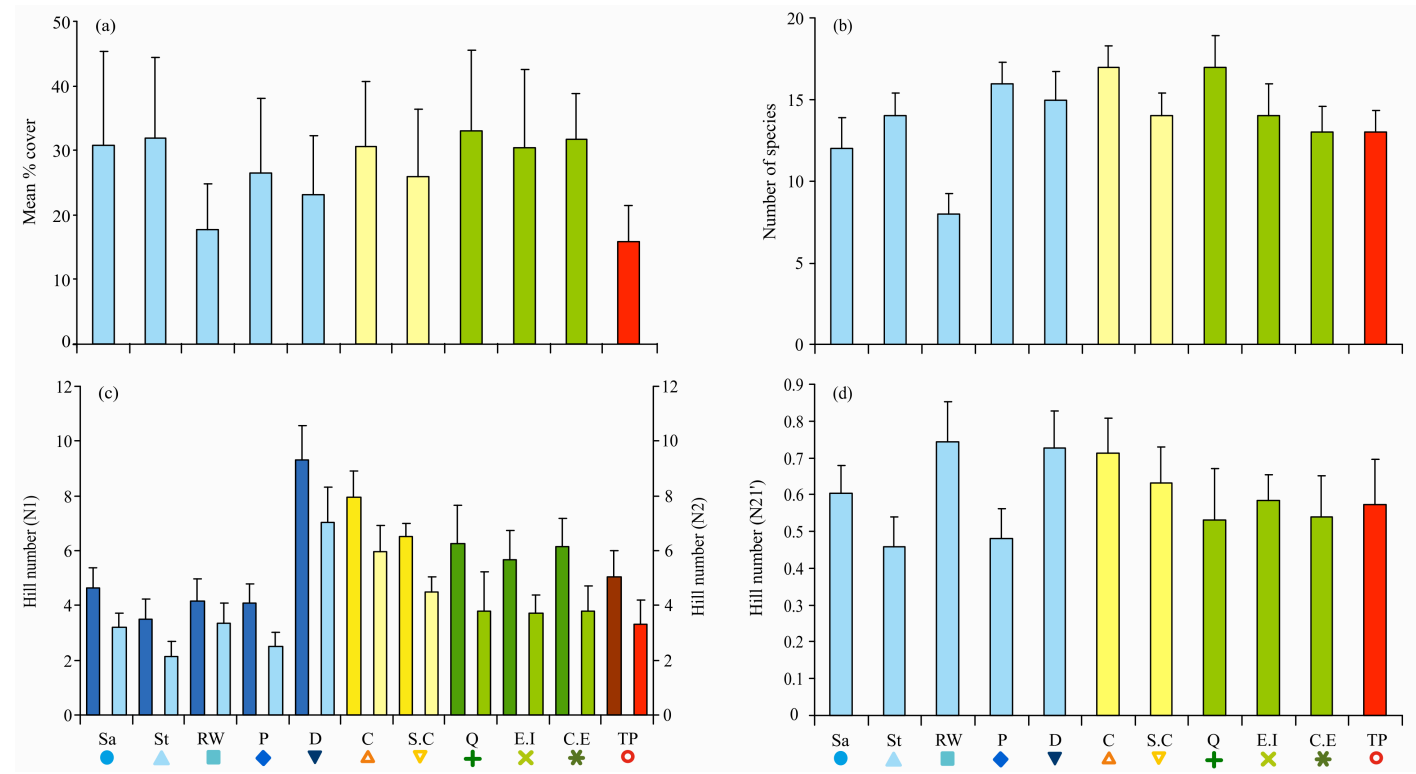

Figure 2.2 Measures of overall \% cover, number of species, Hill's numbers N1, N2 and $\mathrm{N} 21$ ' across all sites (means $\pm \mathrm{SD}$ ). Lagoons are indicated as blue $=$ West, yellow $=$ Center, green $=$ East and red $=$ Turtle Pool.

Mean sponge cover varied among sites across the lagoons (Fig 2.3a) and ranged from 15.8\% $( \pm 5.7)$ at Turtle Pool, in the far East Lagoon, to 33.1\% $( \pm 12.4)$ at Quail Island, in West Lagoon (Fig 2.1), with an overall mean of 27.0\% ( \pm 11.6). Significant differences in sponge cover occurred among sites (Pseudo- $\left.F_{10,109}=6.6015, \mathrm{p}<0.001\right)$. Further pairwise tests revealed that all sites were significantly different from each other except in West Lagoon between Strawn and Paradise Islands $(t=1.25, p=0.1403)$, and Sand and Paradise Islands $(\mathrm{t}=1.36, \mathrm{p}=0.0933)$. Significant differences were also found between all four lagoons (Pseudo- $F_{3,109}=8.3042, \mathrm{p}<0.001$ ). The CAP output also identified significant differences in sponge assemblages between sites and lagoons (Fig 2.3 and Table 2.3). Each site and lagoon had higher allocation success values than would be expected by chance alone. 


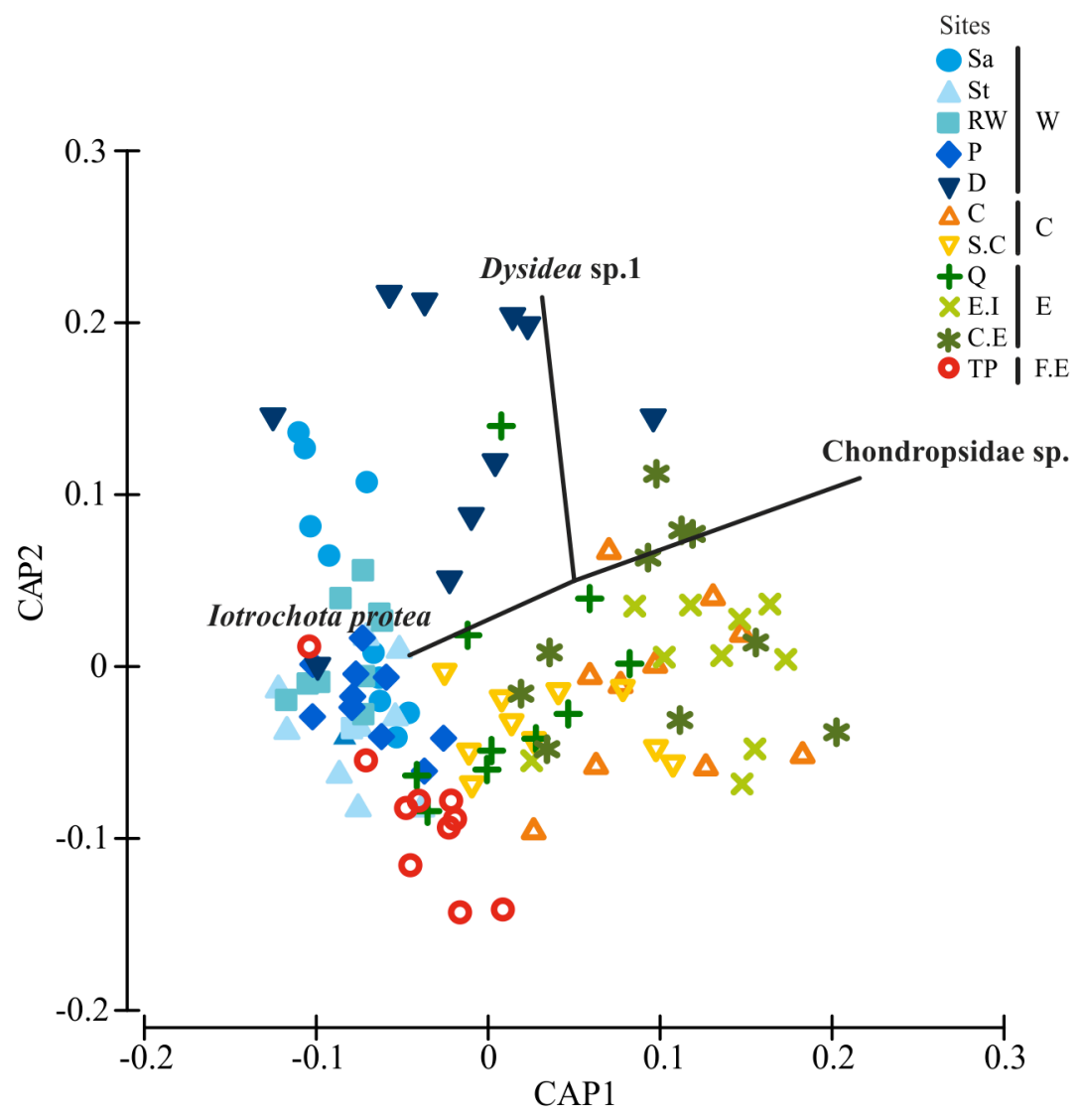

Figure 2.3 Canonical analysis of principal coordinates (CAP) bi-plot ordination showing the indicator sponge species across sites and lagoons. Sand Island (Sa); Strawn Island (St); Ripple Wharf (RW); Paradise Island (P); The Dolphins (D); The Cut (C); South of the Cut (S.C); Quail Island (Q); Eastern Island (E); Central East (C.E); Turtle Pool (TP) across lagoons West (W); Center (C); East (E) and Far East (F.E). Based upon a zero-adjusted Bray-Curtis similarity matrix with a dispersion weighting pretreatment on sponge area cover data, which are pre-adjusted to the amount of available substrate. The analyses were based on 9999 random permutations. A Pearson's correlation coefficient of $\geq 0.5$ was used to identify these vectors. 
Table 2.3 Results from CAP analyses examining sponge assemblage variability in cover between sites and lagoons. Sa, Sand Island; St, Strawn Island; Rw, Ripple Wharf; P, Paradise Island; D, the dolphins; C, the cut; S.C, south of the cut; Q, Quail Island; E.I, Eastern Island; C.E, Center East; TP, Turtle pool; W, West Lagoon; C, Center Lagoon; E, East Lagoon; TP, Turtle pool. Where $m$ is the number of principal coordinate (PCO) axes used in the analyses, \% Var the percentage of the total variation explained by the first $m$ PCO axes, $\delta^{2}$ the squared canonical correlation and allocation success values the percentage of samples correctly allocated into their corresponding groups using the first $m$ PCO axes from the model.

\begin{tabular}{|c|c|c|c|c|c|c|c|c|c|c|c|}
\hline Factor & $m$ & $\%$ Var & $\delta^{2}$ & $\mathrm{P}$ & & & & & & & \\
\hline Site & 7 & 79.1 & 0.78 & 0.0001 & & & & & & & \\
\hline Lagoon & 9 & 89.3 & 0.71 & 0.0001 & & & & & & & \\
\hline \multicolumn{12}{|c|}{ Allocation success } \\
\hline \multirow[t]{2}{*}{ Site } & $\mathrm{Sa}$ & St & RW & $P$ & D & C & S.C & Q & E.I & C.E & $\mathrm{TP}$ \\
\hline & 50 & 50 & 90 & 40 & 80 & 30 & 60 & 50 & 60 & 40 & 50 \\
\hline \multirow[t]{2}{*}{ Lagoon } & $\mathrm{W}$ & $\bar{C}$ & $\bar{E}$ & F.E & & & & & & & \\
\hline & 86 & 60 & 63 & 70 & & & & & & & \\
\hline
\end{tabular}

\subsubsection{Ranked and indicator species}

Of the 24 species identified within the survey quadrats three were characteristic of different sites (Fig 2.3): Iotrochota protea (U) for the majority of the West Lagoon sites, Dysidea sp. 1 (B) (Johnston, 1842) for The Dolphins and Chondropsidae sp. (T) (Carter, 1886) for Center and East Lagoons. The ranked abundance data (Fig 2.4) indicated the dominance of a few common species and a large number of 'rare' species in the Palmyra system resulting in low evenness. The two species with the highest cover across all lagoons were Iotrochota protea and Chondropsidae sp. (Fig 2.3). Iotrochota protea had the highest percentage mean cover for all lagoons, except East Lagoon (Fig 2.4), with the greatest abundance (14.17\% \pm 8.2) in West Lagoon. 


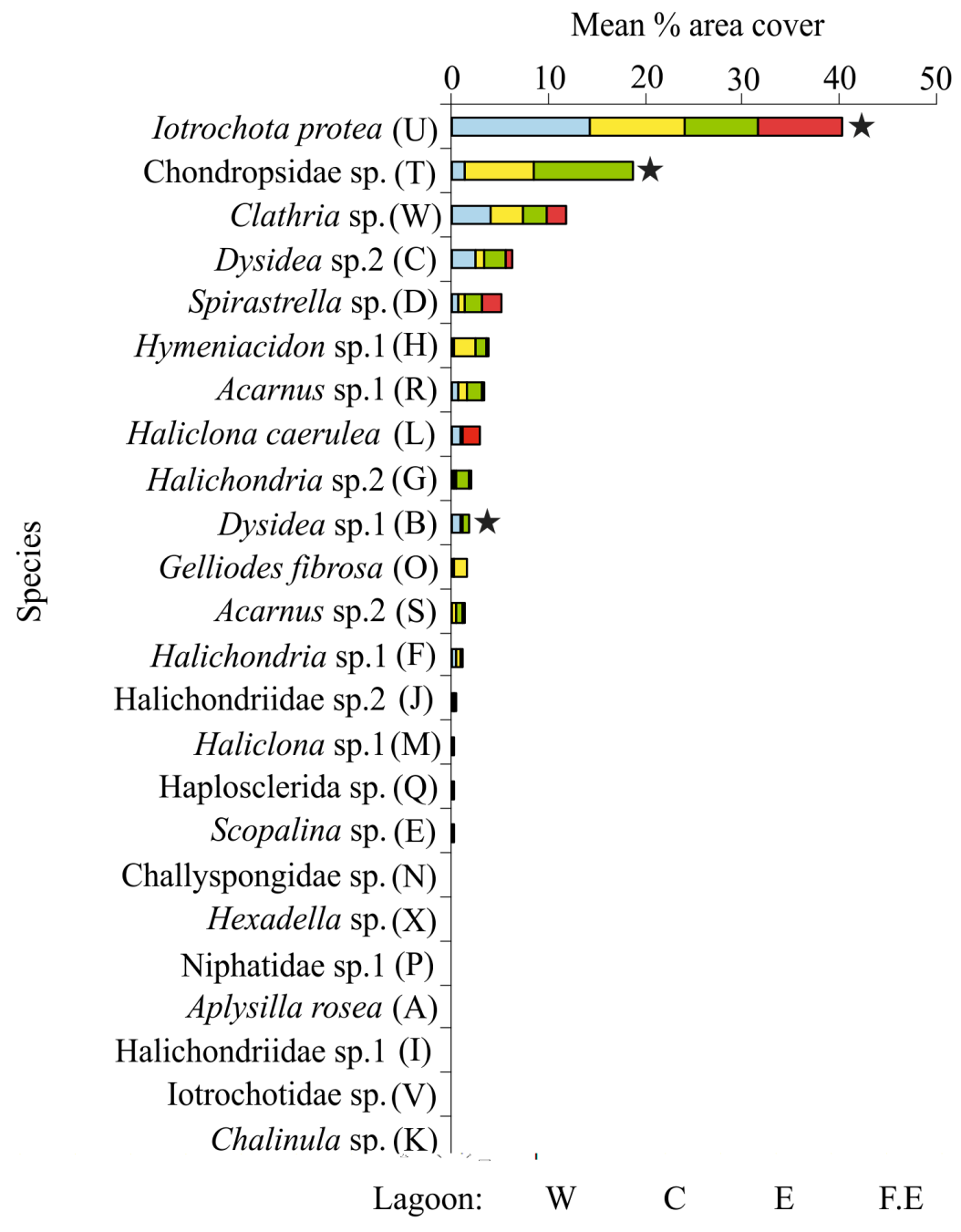

Figure 2.4 Ranked abundances of sponge species in the lagoons at Palmyra. Bars are stacked and indicate the mean average per lagoon, but not the total mean across all lagoons where $\mathrm{W} /$ blue $=$ West, C/yellow $=$ Center, E/green $=$ East and F.E $/$ red $=$ Far East. ( $\star$ ) marks the indicator species in Figure 2.3. The letters in brackets refer to the ID codes in Table 2.2.

2.4.2 Changes in the abundance of Haliclona caerulea, Gelliodes fibrosa and Iotrochota protea

The abundance of these three species was all correlated with different environmental variables. Salinity levels had a positive relationship with Haliclona caerulea (blue Caribbean sponge), explaining $25.2 \%$ of the variability in its abundance (see Table 2.4). Haliclona caerulea was most abundant in West Lagoon at Strawn Island, The Dolphins and Turtle Pool where salinity levels were $>36.45$ psu (Table 2.1). At those sites where Gelliodes fibrosa was recorded, cover was positively correlated with Percentage Organic Matter (PCOM), which explained 29.0\% of the 
variability. The second highest PCOM value and highest G. fibrosa cover was at South Cut with $15.3 \%$ and $1.98 \%$, respectively. The Ripple Wharf and Strawn had the lowest cover of G. fibrosa (0.06 and $0.27 \%$, respectively) along with the lowest levels of PCOM (13.7 and 11.1\%, respectively). The abundance of Iotrochota protea, the species with the highest cover across the majority of the lagoons, was correlated with substrate angle and variability in chlorophyll- $a$, which explained $34.0 \%$ and $34.2 \%$ of the variation, respectively. Sloped sites, with the exception of Eastern Island, had the highest I. protea cover ranging from $7.3 \%$ to $20.6 \%$. Central East, The Dolphins (horizontal sites) and Eastern Island had the lowest cover (3.97, 4.63 and 3.92\%, respectively). Variability in chlorophyll- $a$ had a weak negative relationship with $I$. protea abundance, with the lowest cover and highest standard deviation in chlorophyll$a$ levels $\left(1.30 \%\right.$ and $\left.0.33 \mu \mathrm{g}^{-1}\right)$ both at the Eastern Island site.

Table 2.4 Results of the distance-based permutational multiple regression analysis (DistLM) for overall mean \% cover, sponge species assemblage and the introduced and potentially introduced species. Only the optimal variables of spatial change in sponge assemblages are shown along with the proportion of variability they explain. Model selection was based on Akaike's Information Criterion with a second-order bias correction applied (AICc), with the total variation explained $\left(\mathrm{r}^{2}\right)$ by each best-fit model shown (\% total) based on 9999 random permutations of the raw data. Variables were normalized and fitted in a step-wise manner.

\begin{tabular}{lllccc}
\hline Model & AICc & Predictor & Pseudo-F & p & \%Var \\
\hline Mean \% cover & \multirow{2}{*}{41.26} & Turb & 5.71 & 0.0499 & 38.83 \\
& & Hard_cov & 10.02 & 0.0168 & 34.02 \\
& & Flow_1SD & 11.87 & 0.0104 & 17.08 \\
& & C. Sand & 8.26 & 0.0183 & 5.83 \\
& & Total & & & $\mathbf{9 5 . 7 6}$ \\
Species & \multirow{2}{*}{793.14} & Angle & 8.72 & 0.0001 & 7.47 \\
assemblages & & Chl-a_1SD & 7.79 & 0.0001 & 6.28 \\
& & Hard_cov & 6.07 & 0.0001 & 4.67 \\
& & Turb & 5.70 & 0.0001 & 4.20 \\
& & Silt_ & 5.60 & 0.0001 & 3.40 \\
& & Sal_1SD & 5.00 & 0.0001 & 3.31 \\
& & Soft_cov & 4.60 & 0.0001 & 3.28 \\
& & PCOM_1SD & 4.76 & 0.0001 & 3.27 \\
& & Flow_1SD & 3.57 & 0.0003 & 2.31 \\
& & C. Sand & 2.87 & 0.0020 & 1.82 \\
Haliclona caerulea & \multirow{2}{*}{89.58} & Total & & & $\mathbf{4 0 . 0 1}$ \\
\hline \multirow{2}{*}{ Gelliodes fibrosa } & \multirow{2}{*}{88.43} & Sal & 2.27 & 0.1211 & $\mathbf{2 5 . 2 1}$ \\
& & PCOM & 2.88 & 0.0757 & $\mathbf{2 8 . 9 7}$ \\
Iotrochota protea & \multirow{2}{*}{69.22} & Angle & 4.64 & 0.0541 & 34.01 \\
& & Chl-a_1SD & 8.59 & 0.0125 & 34.17 \\
& & Total & & & $\mathbf{6 8 . 1 8}$ \\
\hline
\end{tabular}




\subsubsection{Changes in overall sponge cover}

Out of 13 variables (Table 2.1), 95.8\% of the variation in overall sponge cover between sites was explained by four factors: turbidity $(38.8 \%)$, percentage hard substrate $(34.0 \%)$, flow rate variability (1SD) (17.1\%) and percentage cover of coarse sand (5.8\%) (see Table 2.4). Turbidity had an overall negative relationship with sponge area cover, with Turtle Pool having the highest turbidity (5.97 STU \pm 2.05 ) and lowest sponge cover (15.8\%) (Table 2.1). Percentage hard substrate was lowest at the Ripple Wharf (12.0\%) and highest at Strawn Island (44.1\%). Turtle Pool had the fourth highest hard substrate cover (35.0\%), but the lowest area cover of sponges (15.8\%). Variability in water flow was highest at Sand Island $\left(0.0422 \mathrm{~cm}^{2} \mathrm{sec}^{-1}\right)$ and The Cut $\left(0.0363 \mathrm{~cm}^{2}\right.$ $\left.\mathrm{sec}^{-1}\right)$ and lowest at Eastern Island $\left(0.0031 \mathrm{~cm}^{2} \mathrm{sec}^{-1}\right)$ with the remaining sites between 0.0099 and $0.0185 \mathrm{~cm}^{2} \mathrm{sec}^{-1}$. Percent of coarse grain sand was positively related to percent sponge cover with the highest values at Sand Island (41.4\%) and the lowest at The Dolphins (11.1\%).

\subsubsection{Changes in sponge assemblages}

Variability in sponge assemblages among sites (Fig 2.5) primarily correlated with substrate angle, chlorophyll- $a$ variability and the percentage of hard substrate, explaining $7.5 \%, 6.3 \%$ and $4.7 \%$ of the variability, respectively (see Table 2.4 ). The total amount of variability explained by all significant environmental and biological factors was $40.0 \%$, with the top three explaining approximately half $(18.4 \%)$ of the variability. Substrate angle was negatively associated with The Dolphins (one of the two horizontal sites). Variability in chlorophyll-a concentration was positively associated with Central East, Eastern Island and The Cut. Percentage hard cover was positively associated at South Cut and Turtle Pool and negatively correlated at Sand Island and the Ripple Wharf. 


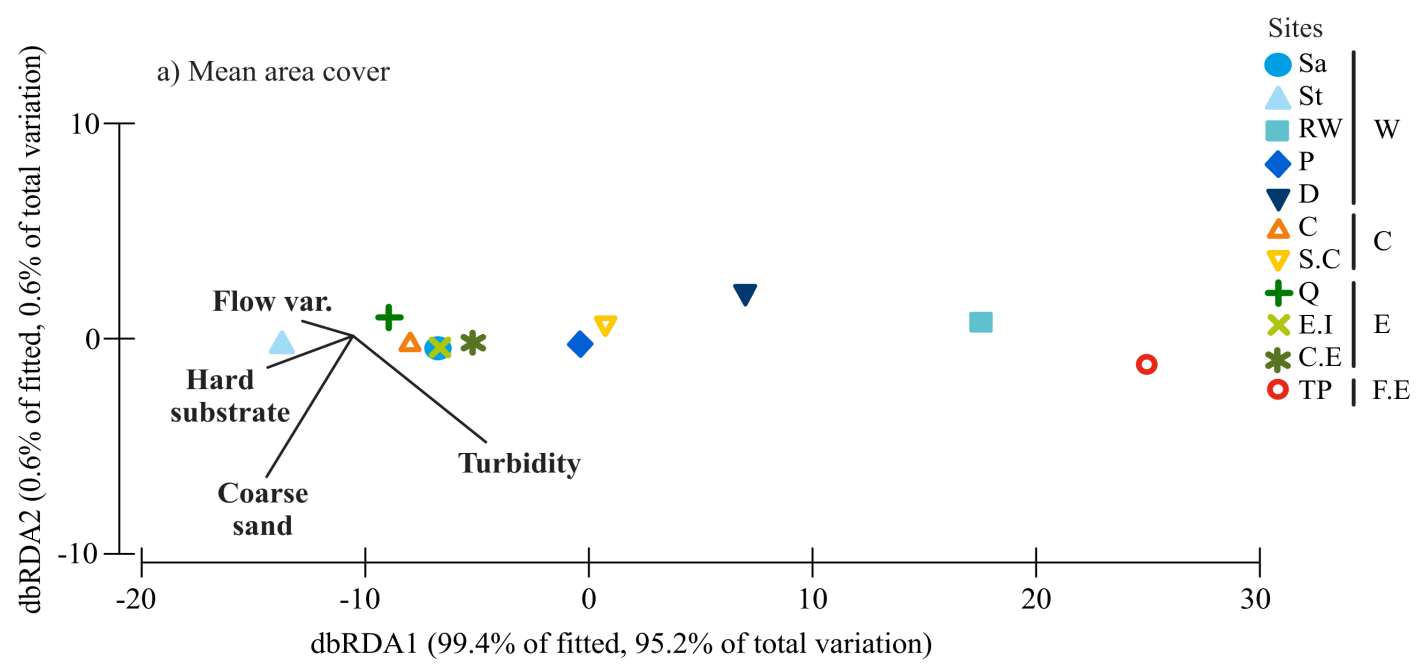

b) Species assemblages

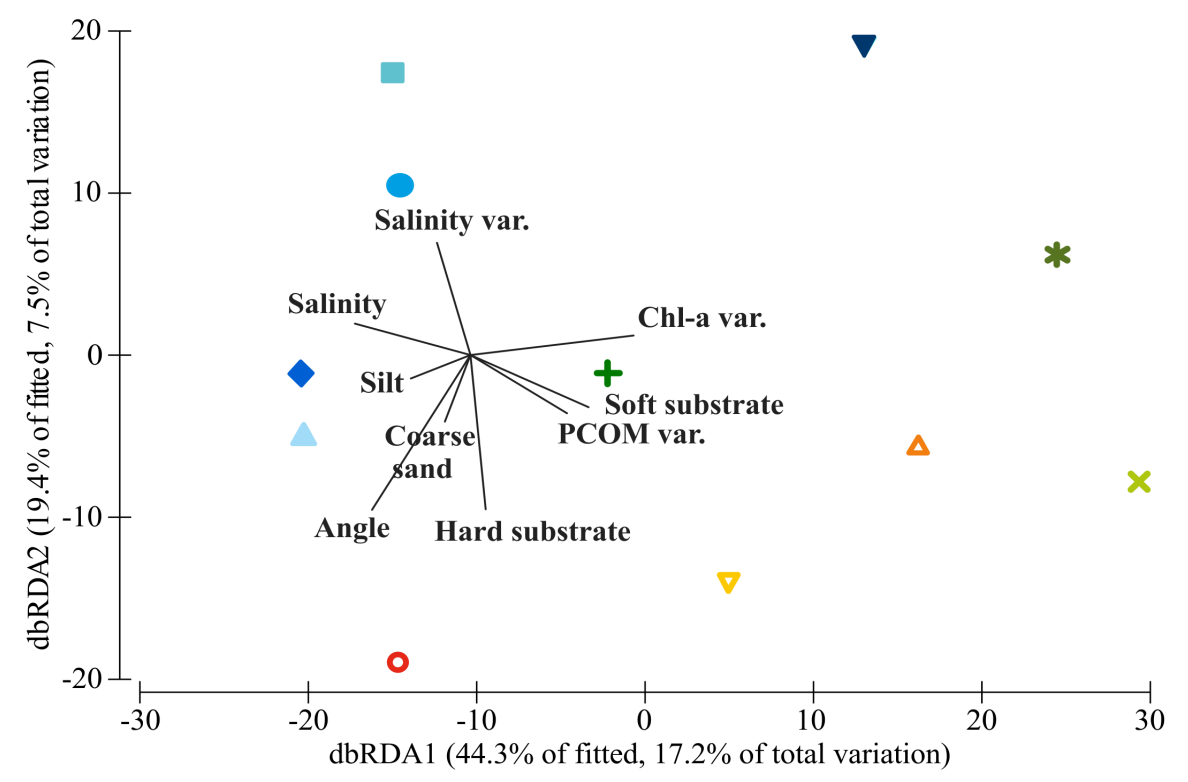

Figure 2.5 Distance-based redundancy analysis (dbRDA) visualising the similarity in sponge assemblages and the correlated change in environmental conditions among the 11 lagoon sites (Fig 2.1) for mean percentage area cover (a) and sponge assemblages (b).

\subsection{Discussion}

Many Central Pacific atolls have suffered extensive degradation of their lagoons as a result of human disturbance (Sandin et al. 2008). The habitats in the altered lagoon system at Palmyra Atoll in the Central Pacific are very different to the surrounding near-pristine coral reefs (Fig 2.6a). At Palmyra Atoll sponges dominate the hard substratum lagoon environments, which is unlikely to have been the case prior to the 
disturbance during WWII. I found that turbidity, percentage hard substrate, variability in water flow rate and percentage cover of coarse sand together explained a total of $95.76 \%$ of the variability in overall sponge cover between sites. In addition, although I found that $40 \%$ of the variability in sponge assemblage structure was explained by 10 variables, no single variable explained more than $8 \%$ of the variation. Of the 24 species observed in the quadrats, three characterised different site groups (Fig 2.3) and three of the most important species, Haliclona caerulea, Gelliodes fibrosa and Iotrochota protea, were each correlated with different variables when modelled individually. My results suggest that the sponge species within the lagoons are strongly associated with environmental and biological characteristics associated with the current lagoon environment and are unlikely to spread to the outer reefs unless there are future declines in reef environmental quality.

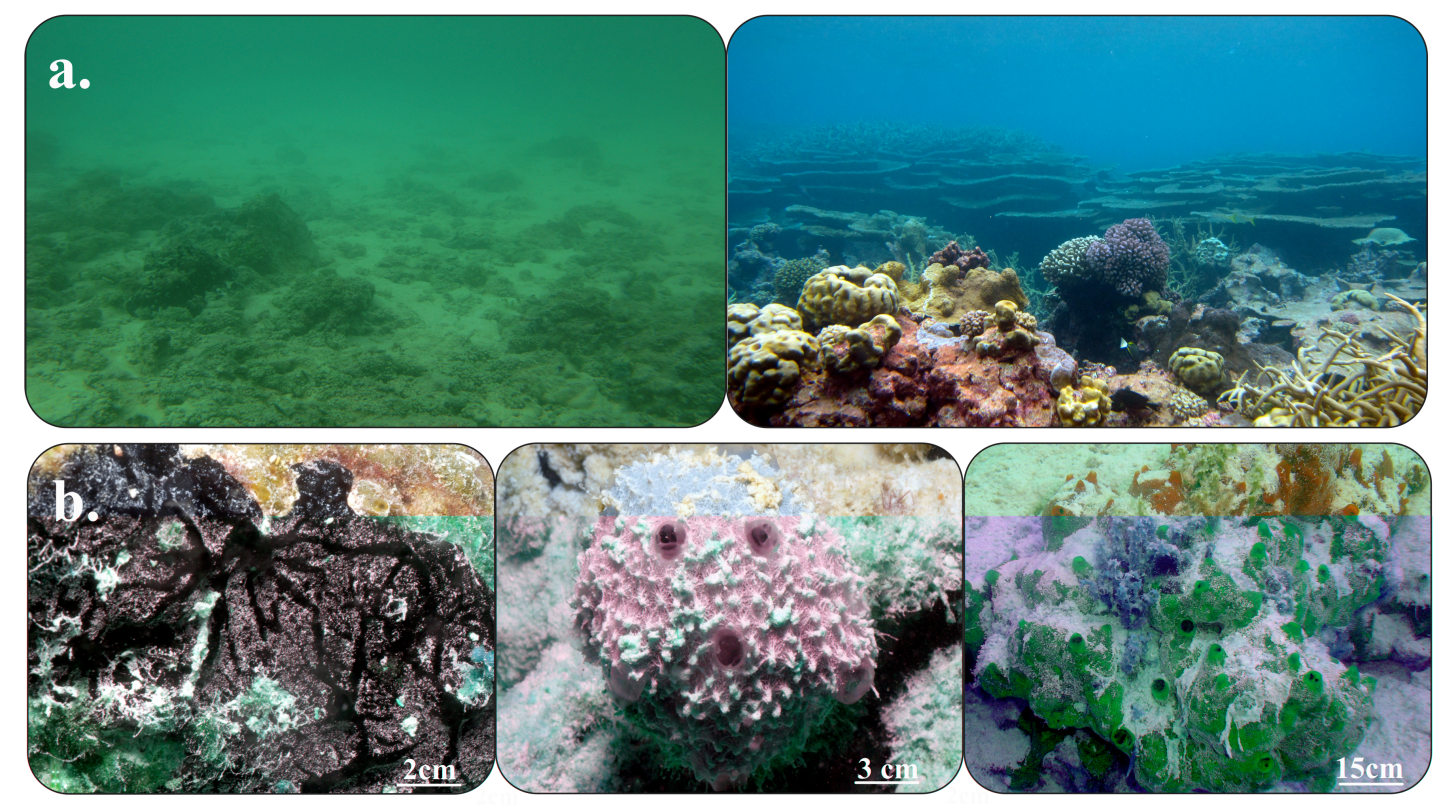

Figure 2.6 Underwater photos of Palmyra reef, lagoon and sponges. A) Current day conditions in the lagoon (left) versus the reef (right). B) Sponges and sediment; different strategies to deal with sedimentation. From left to right: Iotrochota protea (U), no sediment on oscula or veins; Dysidea sp.2 (C), sediment accumulates primarily on the protruding spikes, raised oscula; Spirastrella sp. (E), extended oscula. All letters in brackets relate to the species ID in Table 2.2.

\subsubsection{Sponge species at Palmyra Atoll}

There is a paucity of ecological research on sponge assemblages from Pacific islands, particularly in the Central Pacific region. Previous studies have shown that the 
number of species reported from Pacific islands ranges between 8 and 60 (de Laubenfels 1951, 1954, Bergquist 1965, Chiriboga et al. 2011, van Soest et al. 2011). To date, 36 sponge species have been found within the lagoons at Palmyra and at least 15 more on the reefs (Table 2.2; Appendix III), totalling 51 species units identified thus far, which is therefore similar to other Pacific islands, but much lower than other tropical areas such as Indonesia and Australia where similar sampling effort and area to the present study has detected more than 100 species (see Bell 2007).

The number of species per site at Palmyra was similar across the lagoons with the exception of the man-made Ripple Wharf in West Lagoon, which had the lowest number of species. This is probably due to the high percentage of anthropogenic debris resulting in low available hard substrate for sponges to inhabit; also some sponge species may not settle on artificial substrate because these surfaces are smoother (Knott et al. 2004). West Lagoon at Palmyra has been proposed as the location for most of the non-indigenous species introductions (see Appendix I), however this area generally had low diversity with only a few abundant species at Strawn Island and Paradise Island. Iotrochota protea accounted, on average, for half of the total sponge cover at all of the sites in West Lagoon. The Dolphins was the only exception, which was distinctly different to all other sites because it had a greater number of rare species and was actually characterised by one of the rarer species: Dysidea sp.1 (Johnston, 1842). It is possible that the high number of rare species at The Dolphins is because it was the location of a WWII boat dock resulting in high exposure to introduced species via fouling and ballast water, but many of these species have been unable to spread extensively to other areas in the lagoon.

\subsubsection{Distributions of likely NIS sponge species in the lagoons}

It is unknown how many of the sponge species found in the surveys are native to Palmyra. Across all lagoons the native Hawaiian species, I. protea, had the highest cover and was found at all sites. Little is known about I. protea except that it is found on sandy or rubble substrates in sheltered bays (Hoover 2006). I. protea is likely a NIS since like all sponge species, it has very poor dispersal ability and it seems unlikely that natural colonisation would have occurred. If it is a NIS, it is of concern as it covers approximately $13 \%$ of the boulders at the majority of sampling sites, which on average is half of the total sponge cover. However, considering I. protea is generally associated with low current conditions (Hoover 2006) this species is probably prevented from 
dispersing to the outer reef sites because of the environmental conditions associated with higher water flow rates in these environments.

The environmental parameters driving sponge distribution patterns in the lagoons at Palmyra differed between some sponge species. Cover of I. protea was negatively correlated with variability in chlorophyll- $a$ and positively correlated with inclined surfaces over horizontal ones. A negative correlation with variability in chlorophyll- $a$ indicates that those sites with higher sponge cover are likely to have more stable food sources (i.e. less variation). Substrate inclination has also long been identified as influencing the distribution of sponges because of the different physical characteristics such as sedimentation, light, and water flow correlated with an inclined versus horizontal surfaces (Wilkinson \& Evans 1989, Bell \& Barnes 2000b, Bell \& Smith 2004). However, despite the ability of I. protea to inhabit all sites in the lagoon, cover was in general higher on inclined sites compared to horizontal ones where sediment settlement will be lower.

Haliclona caerulea is believed to be an introduced species to Palmyra since it is native to the Caribbean (Hechtel 1965; Appendix I). Its abundance was positively correlated with salinity, and its cover was found to be higher in the West Lagoon and Turtle Pool (in the Far East Lagoon). At Palmyra the salinity levels are tidally driven and ranged by 0.74 psu overall with the highest values found at both ends of the atoll (West and Far East) where proximity to the surrounding seawater is the greatest (Fig 2.1) and freshwater run-off is less influential on the salinity. A decrease in salinity has the potential to reduce growth and reproductive activity of sponges. For example, Roberts et al. (2006) found a reduction in salinity by 2 psu negatively impacted a temperate reef sponge species. However, it is unknown what salinity levels (high or low) are likely to affect the growth or reproduction of $H$. caerulea and whether salinity differences prevents this species establishing on the outer reefs.

Gelliodes fibrosa is another known non-indigenous sponge species to Palmyra (see Appendix I) and its abundance was positively correlated with the percentage of organic matter (PCOM) in the sediment. A large number of the encrusting species at Palmyra, including G. fibrosa have a fine sediment layer on their surfaces (Fig 2.6b), but not on their osculum and, depending on the species, their surface veins. Concentrations of particulate and dissolved organic matter in sediments are higher than in the water column, so the lagoon sponges, and possible symbionts, have the potential to use this as a nutritional resource (Ilan \& Abelson 1995). Back reef values of PCOM 
(Williams et al. 2011c) are 4-5 times lower than in the lagoon, so if G. fibrosa distributions are determined by food availability related to PCOM levels, they are probably too low on the back reef to support this species.

\subsubsection{Drivers of sponge cover and assemblage patterns}

The composition of the sponge assemblages in the lagoons at Palmyra was significantly associated with 10 biotic and abiotic variables. However, none of the variables accounted for more than $8 \%$ of the variability and therefore individually are likely to have relatively low ecological significance, with the top 3 variables only explaining $18.4 \%$ of the total variation. The top two variables in this model were the same as the two variables for I. protea, perhaps suggesting that this species is having a large influence on the overall sponge assemblages across the lagoons (despite dispersion weighting).

The top four variables explaining overall sponge cover were turbidity, percentage hard substrate, variability in water flow and percentage coarse sediment, which explained $95.76 \%$ of the variability between sites. The current environmental conditions in the lagoons at Palmyra are that of low water flow and high sedimentation with the benthos characterised by fine/coarse sediment and boulders. Furthermore, substrate availability is low in the lagoon; boulders $\left(<0.5 \mathrm{~m}^{2}\right)$ are common but larger areas of hard surface are rare. Not surprisingly therefore, I found that percentage hard substrate had a weak positive correlation with sponge cover.

Water flow was also positively correlated with sponge cover among sites, with Sand Island in the West Lagoon and the Cut in the Center Lagoon, situated nearest to access channels, having the highest water flow levels along with the greatest percentage cover of sponge. Water flow rate is important for facultatively-active suspension feeders, like sponges, because passage into and through the sponge can be passively induced as a result of the Bernoulli principle (Vogel 1977), reducing the energy required for pumping. In addition, higher water flow will supply more food to the sponge per unit time compared to low flow. I also found a negative relationship between turbidity and sponge cover, which is most likely explained by the potential for high sediment levels to clog the delicate filtering apparatus of sponges (Bell 2004), as well as smother available hard substrate for larval settlement (Rogers 1990). Turtle Pool, in the far east lagoon, had the highest turbidity levels and lowest sponge cover, whilst Quail Island had higher than average cover and had the lowest turbidity levels. In 
contrast to my results, Bell and Smith (2004) found that percentage cover of sponges was greater on reefs experiencing higher sedimentation levels, although their study compared two coastal coral reef locations, which more than likely experience greater water flow and lower sediment loading than the most turbid site in the lagoons at Palmyra, Turtle Pool. Turtle Pool had nearly 3 times higher turbidity levels than the next most turbid site (Paradise Island, in the West Lagoon); therefore, there is a relatively large range of turbidity levels for which I have no sponge assemblage data (2-5 STU). The high turbidity levels at Turtle Pool do, however, provide an insight into how sponge cover might be affected by large increases in sedimentation, for example if the north-south military causeway (Fig 2.2) was removed as discussed by Williams et al. (2011c). If turbidity increases substantially in the lagoons there is a possibility that not only coral species will be affected, but the sponges as well.

The distribution of reef organisms can be greatly affected by increases in sedimentation because of the impact on larval settlement and survival (Hodgson 1990, Connell et al. 1997). Research on the factors controlling sponge larval settlement and recruitment is limited. However, water flow can, for some species, be positively associated with juvenile survivorship and adult abundance (Maldonado \& Young 1996) and if strong enough remove larval selection at settlement (Woodin 1986, Butman 1987). The mean water flow rate in the lagoons at depths of $5-8 \mathrm{~m}$ was $0.01 \mathrm{~m} \mathrm{sec}^{-1}( \pm$ 0.01 ) and sponge larval swimming speeds have been recorded as between $0.001-0.01 \mathrm{~m}$ $\sec ^{-1}$ (e.g. Bergquist et al. 1970, Maldonado \& Young 1996). Therefore, theoretically during slow flowing tides, the sponge larvae in the lagoons at Palmyra could swim against the prevailing westerly water flow to settle in more suitable habitats. Interestingly, I recorded both $H$. caerulea and I. protea at Turtle Pool, which is located furthest away from the West Lagoon, the suggested location for all the introduced species (see Appendix I). Therefore, because these species have managed to extend to the opposite side of the atoll over several $\mathrm{km}$, against the prevailing westward water flow (Gardner et al. 2011), it appears unlikely that the sponges will extend onto the reef unless there is a decline in environmental quality there. This hypothesis is further supported by the difference between lagoon and reef species lists, with no species common to both environments.

Other factors might also be preventing the sponges from within the lagoon establishing on the outer reefs. Specifically, fish predation has been shown to influence sponge distributions in the Caribbean (Pawlik 1998, Wulff 2000). However, a 
preliminary fish predation experiment at Palmyra by the author, where seven lagoon sponge species were transplanted onto five back reef sites on multiple occasions, were not consumed and is therefore it unlikely that predation is preventing colonisation of the outer reefs by sponges at Palmyra. For further information on this trial experiment see Appendix VI.

\subsubsection{Conclusions}

Sponge diversity at Palmyra is comparable to other Pacific islands and atolls; however, it is still unknown how many species are native to the lagoons. Species diversity, when examining Hill's N1, was on average the lowest in West Lagoon, indicating that few species dominate these habitats. An exception to this was a site known as The Dolphins, which was one of the main boat docks during WWII and had the highest species diversity atoll-wide. For all the models examined (overall sponge cover, sponge assemblages and individual notable species) the strongest environmental relationships were found for sedimentation/turbidity and food/habitat availability. The current distribution and abundance patterns of sponges, particularly for I. protea (the most abundant species in the lagoons) suggests that unless there is a dramatic decline in environmental quality on the reefs at Palmyra, particularly increased sedimentation and turbidity, the sponges will most likely remain confined to the lagoons. This information may prove useful for monitoring declines in environmental quality for Palmyra and other atoll systems, as the appearance of lagoon sponge species on outer reefs could act as an early warning of environmental degradation. 


\section{Temporal variability and recruitment of sponges in an altered atoll lagoon; assessing their potential to extend on to an adjacent near-pristine coral reef}

\subsection{Abstract}

Coral reefs support a high diversity of life making them ecologically and economically rich ecosystems; however, no reef has been left unaffected by human activities. Although some of the last remaining near-pristine reefs are in the Central Pacific, unfortunately a number of these atoll lagoons and islets were modified by the US military during WWII. Surprisingly, despite the quality of the reefs at these modified atolls, little work has examined their altered lagoons and the potential of current species, particularly non-indigenous species (NIS), to extend onto the nonlagoon reefs. This study examines the temporal variability and recruitment of the current dominant fauna (sponges) of the once (pre-WWII) coral inhabited lagoons at Palmyra Atoll to assess whether the sponges, including NIS, have the potential to extend from the altered lagoon to the adjacent near-pristine reefs. Semi-permanent sampling stations and ceramic panels were used to examine temporal variability in the sponge assemblage and larval recruitment, respectively. Over 3 years I recorded sponge densities, cover and species diversity, but only found significant inter-annual variation in species diversity. The recruitment panels, observed over 2 years, indicated that the number of recruits found on panels increased over time. The ability of the sponges to recruit to newly available substrate and the relative stability of the established sponge assemblage suggests that recruitment and mortality are in equilibrium. This study found that the sponges are unlikely to be limited to the lagoons due to recruiting capabilities and therefore could have already extended onto the reef. I also explore the possibility that the lagoon has undergone a phase-shift from a coral to sponge dominated ecosystem due to the military modifications. 


\subsection{Introduction}

Coral reefs globally are ecologically and economically important (Moberg \& Folke 1999); however, they remain under threat from direct and indirect anthropogenic pressures (Hughes et al. 2003, Pandolfi et al. 2003, Bellwood et al. 2004, HoeghGuldberg 2011). Remote and uninhabited atolls support some of the last remaining near-pristine coral reefs and therefore further research into the impacts of threats to these environments is important. Pressures on uninhabited atolls include construction, fishing, poaching, shipwrecks, coral bleaching, disease outbreaks, and non-indigenous introductions (See Maragos et al. 1996, Williams et al. 2010, Williams et al. 2011a; Appendix I).

Atoll systems, unlike most coastal reefs, have central lagoons; remnants of the oceanic volcano that formed them and depending on the structure of the islets the lagoons often connect with the adjacent coral reefs (Delesalle \& Sournia 1992, Kench 1998). Therefore, the processes and organisms inhabiting an atoll lagoon may impact the adjoining reef through introducing new non-indigenous species or through water movement loaded with higher levels of dissolved inorganic and organic carbon and nitrogen, bacterioplankton, phytoplankton and sediment, as a result of anthropogenic pressures such as nutrient inputs and construction and natural biological processes (Pastorok \& Bilyard 1985, Charpy-Roubaud et al. 1990, Torréton et al. 1997, Dufour \& Berland 1999, Suzuki \& Kawahata 2003).

Lagoons like those of Palmyra, Johnston, Midway and Wake Atolls in the Central Pacific still support a rich diversity of marine life, but were heavily altered to varying degrees during WWII due to US military occupation and construction (Maragos et al. 2008, Rooney et al. 2008). A variety of methods were used to establish military bases at each atoll, including lagoon dredging to build up the islets along with creating shipping access channels through the reef if necessary (Dawson 1959, Maragos 1993). Alterations like dredging dramatically reduce habitat complexity and species composition, diversity and richness (See Thrush \& Dayton 2002), resulting in phaseshifts (Done 1992) and often making systems more susceptible to non-indigenous species (NIS) (Mooney \& Cleland 2001, Byers 2002, Tyrrell \& Byers 2007). It is therefore likely that the introduction of NIS to these Pacific atolls occurred relatively recently $(<70-80$ years ago) because of the dredged condition of the lagoons and the increased shipping activity associated with the WWII military actions (see Appendix I). However, due to the lack of species lists prior to the alterations, it is unknown how 
many of the current species are native and whether any of the non-indigenous lagoon species could extend onto the adjacent reefs.

Environmental conditions at these atolls may be maintaining the introduced species in the lagoons (see Chapter 2) or perhaps the species are still in the establishment phase and have not yet had enough time to extend onto the reefs. While introductions of NIS have been reported for Pacific atoll lagoons such as Johnston and Palmyra (Coles et al. 2001; Appendix I), their temporal variability and potential to recruit (the introduction of new individuals to a population) to newly available substrate is mostly unknown.

The dominant fauna on the remaining hard substrate in the lagoons at Palmyra Atoll are sponges (Chapter 2). Sponges perform a large number of functional roles in reef systems (See Wulff 2001, Bell 2008a) including acting as top spatial competitors (de Voogd et al. 2004), being an important link in bentho-pelagic coupling (Lesser 2006), nutrient recycling (Diaz \& Ward 1997) and as a food source for other organisms (Duffy 1992, Wulff 1994). Therefore, it is important to ascertain whether the sponges inhabiting the lagoon at Palmyra have the potential to extend onto the reef, particularly as the non-indigenous species, Haliclona caerulea and Gelliodes fibrosa, have already been observed here, along with a native Hawaiian species; Iotrochota protea, which is the dominant species in the lagoons (see Chapter 2 and Appendix I). Currently, the sponges extend across all the lagoons at Palmyra covering $27 \%( \pm 6 \%)$ of the available hard substrate down to $8 \mathrm{~m}$ (Chapter 2) and can potentially filter all of the circulating water in the lagoons every 3-6 days (Chapter 4). Therefore, if sponge cover increases they could have an even greater impact on the lagoon and reef fauna both directly and indirectly (see Chapter 4). Predominantly sponge growth increases cover, while sponge density (abundance) increases through the production of larvae to create new sponges and asexually via fragmentation, budding and gemmule formation (Ayling 1980). Research globally has revealed variability in temporal changes in sponge cover and density assemblages. For example, in the Mediterranean and Atlantic, studies have reported fairly stable sponge assemblages (Fowler \& Laffoley 1993, Garrabou \& Zabala 2001), while in the Caribbean, Hughes (1996) found that abundances were fairly stable but assemblage composition varied over time. However, more recent research in the Atlantic, East and West Pacific and Indo-Pacific (Bell et al. 2006, Wulff 2006, Carballo et al. 2008, Berman 2012) has revealed more significant temporal changes in the sponge assemblages, including seasonal variation with periods of sponge growth 
and shrinkage (Garrabou \& Zabala 2001, Bell 2008b, Carballo et al. 2008). However, to date, no studies have examined temporal variation in sponge assemblages in the Central Pacific.

Temporal variation in the majority of sponge assemblages will also be affected by larval dispersal and fragmentation because it allows these sessile invertebrates to colonize new locations (Maldonado 2006) and is therefore the main mode by which the sponges in Palmyra's lagoon could extend onto the adjacent reef. However, sponge larvae only remain in the water column for a few minutes to a few days before settling on the sea floor and metamorphosing into their sessile adult form, therefore limiting their potential to increase their spatial distribution (Uriz et al. 1998, Maldonado 2006). Therefore movement of the sponges at Palmyra through growth or reproduction could be so limited that they have not yet progressed on to the reef, but have the potential to in the future. Alternatively if the sponges can recruit to new surfaces over short periods ( $<1$ year) and grow rapidly, then they already have the potential to extend onto the reef, but have not due to other constraints such as environmental conditions, and are therefore unlikely to do so in the future.

Distinguishing between growth and fragmentation of established sponges and new recruits is often difficult in natural environments. I therefore elected to study the temporal variability of existing sponge assemblages (annually and seasonally) and settlement panels to study the potential of sponges to successfully recruit to newly available substrate. The aims of this study were to: a) gain a greater understanding of the potential for the sponges to recruit to newly available substrate over a short period $(<1$ year) and b) determine whether the sponge assemblages change (species composition and/or percentage cover) over time and between seasons in order to c) determine whether the sponges are likely to extend from the lagoon onto the adjacent near-pristine reef.

\subsection{Methods}

\subsubsection{Evidence to suggest the condition of Palmyra's lagoons before WWII}

Due to its shape, it has been suggested that the lagoons at Palmyra, before the WWII modifications, could have been analogous to that at Millennium Atoll (pers. comms. Jim Maragos), which is dominated by Acropora spp. and characterised by high crustose coralline algal cover, turfing algae and giant clams (Tridacna maxima) (Barott et al. 2010). Supporting this hypothesis, a large number of old T. maxima shells remain 
in the Palmyra lagoons today (authors pers. obs.). Also reports of the pre-military condition of the atoll state the presence of coral reefs in the lagoon (Woodbury et al. 1946, Anon. 1947) with the serviceable runway on Cooper Island (Fig 3.1) made up of the corals removed from the lagoon (Anon. 1947).

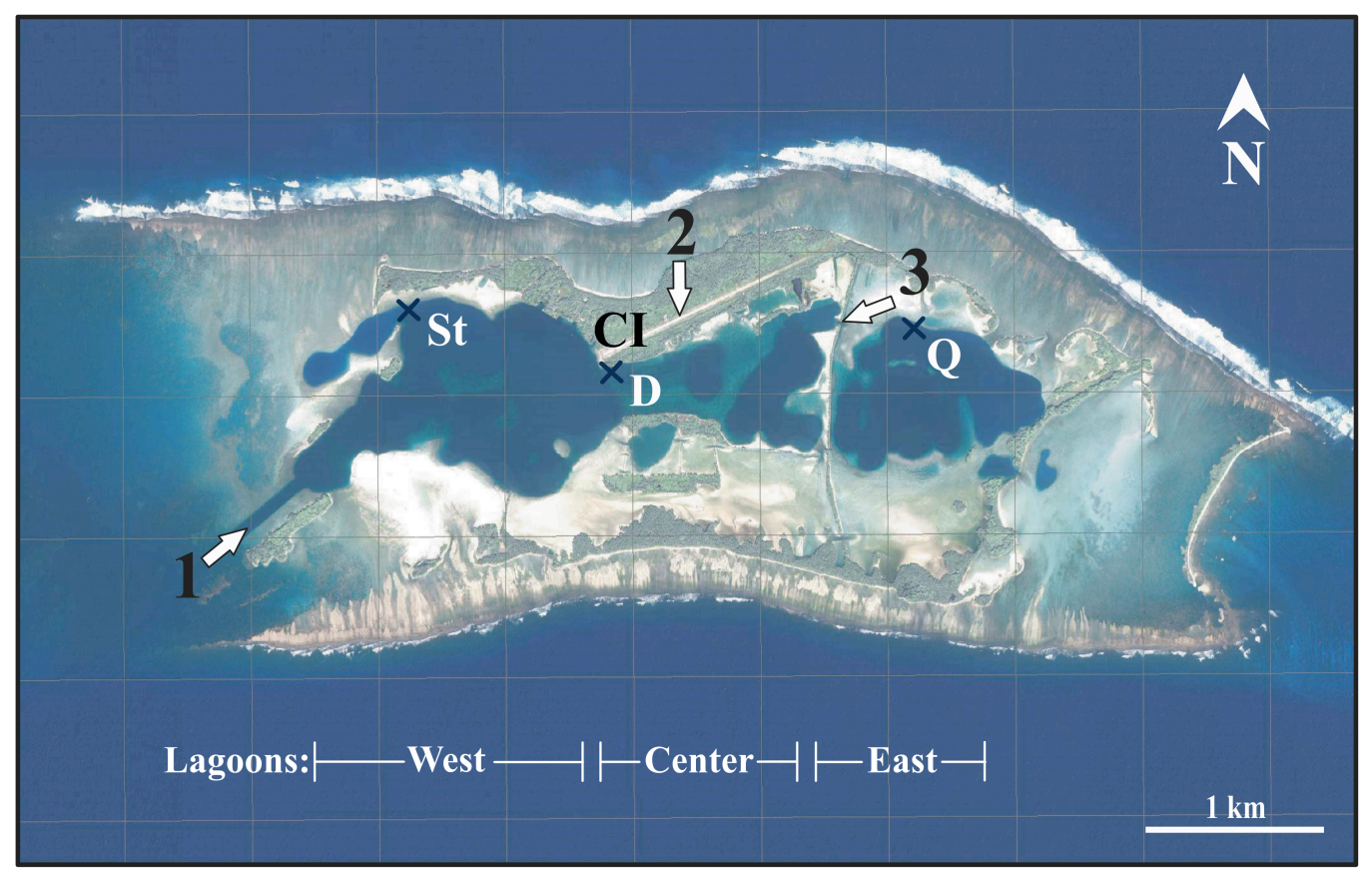

Figure 3.1 Location of the recruitment panels in the lagoons at Palmyra Atoll: Strawn Island (St), The Dolphins (D) and Quail (Q) and semi-permanent quadrats (D). The arrows indicate the location of military modifications; 1 = excavated entrance channel, $2=$ the airstrip made of dredge spoil and coral rubble and $3=$ the north-south causeway, specifically the cut allowing boat access between the Center and East Lagoons. $\mathrm{CI}=$ Cooper Island.

\subsubsection{Settlement panels}

In a preliminary trial, five ceramic settlement panels were placed at The Dolphins and three by Strawn Island in October 2008 (Fig 3.1) After observing the successful settlement of sponges, in July 2009 twelve new panels were placed at 6-8 m at The Dolphins, thirteen by Strawn Island and fourteen by Quail Island, and observed in October 2009 and July 2010. Each settlement panel was 12 x $12 \mathrm{~cm}$ with a $1 \mathrm{~cm}$ hole in the centre. The panel was placed over a stainless steel nail hammered into the hard substrate (secured with marine epoxy). A cable tie was placed around the top of the nail to secure the panel but was cut-off and replaced with each observation. This loose fixing allowed for the area under the panel to remain accessible to larvae. The top and underside surface of the panels and the substrate underneath were photographed, with 
close-up photographs taken to aid species identification. The sponge density was recorded on each side of panels, which was estimated from the photographs; sponges on the edges of the panel were not recorded. Where possible, the panel was placed in areas devoid of sponges, however this was not always possible. Therefore those species found initially under the panels were removed from the total recruits counted as they were considered as overgrowth species. Sponge identification is difficult and even more so for small newly recruited individuals on settlement panels, so those species that I could not identify to genus were grouped in an 'other' group.

\subsubsection{Semi-permanent quadrats}

Three sets of $5 \times 1 \mathrm{~m}^{2}$ semi-permanent quadrat stations were established at 6-8 $\mathrm{m}$ depth at The Dolphins in July 2008 (total area of $15 \mathrm{~m}^{2}$ ) (Fig 3.1). The quadrat stations were semi-permanent so any trace of them could be removed at the end of the study. The three stations were measured five times over three years in July 2008, October 2008, July 2009, October 2009 and July 2010. They were marked by metre long stainless steel rods hammered into the soft sediment. The rods delineated the 2 corners of where the quadrat should be placed with the bottom corner of one quadrat identifying the top of the next quadrat. The quadrat was $1 \mathrm{~m}^{2}$, subdivided into $2520 \mathrm{x}$ $20 \mathrm{~cm}$ sub-sections, and placed over the rods to estimate the sponge cover and density of each species and estimate the available hard substrate. If a sponge extended beyond the quadrat, only the area in the sub-section was included, and if a sponge extended into an adjacent sub-section the area cover was estimated independently in each. The cover and density data were subsequently adjusted to the percentage of available substrate to enable direct comparisons between sites by accounting for the variability in overall boulder densities. The observations for this study focused on species on the upper surface of the boulders as opposed to those found underneath boulders (see Bell \& Carballo 2008). Bioeroding species were not included because of difficulties making accurate estimates of area cover. Species were identified by examining phenotypic characteristics, spicule preparations and sections (Table 3.1). 


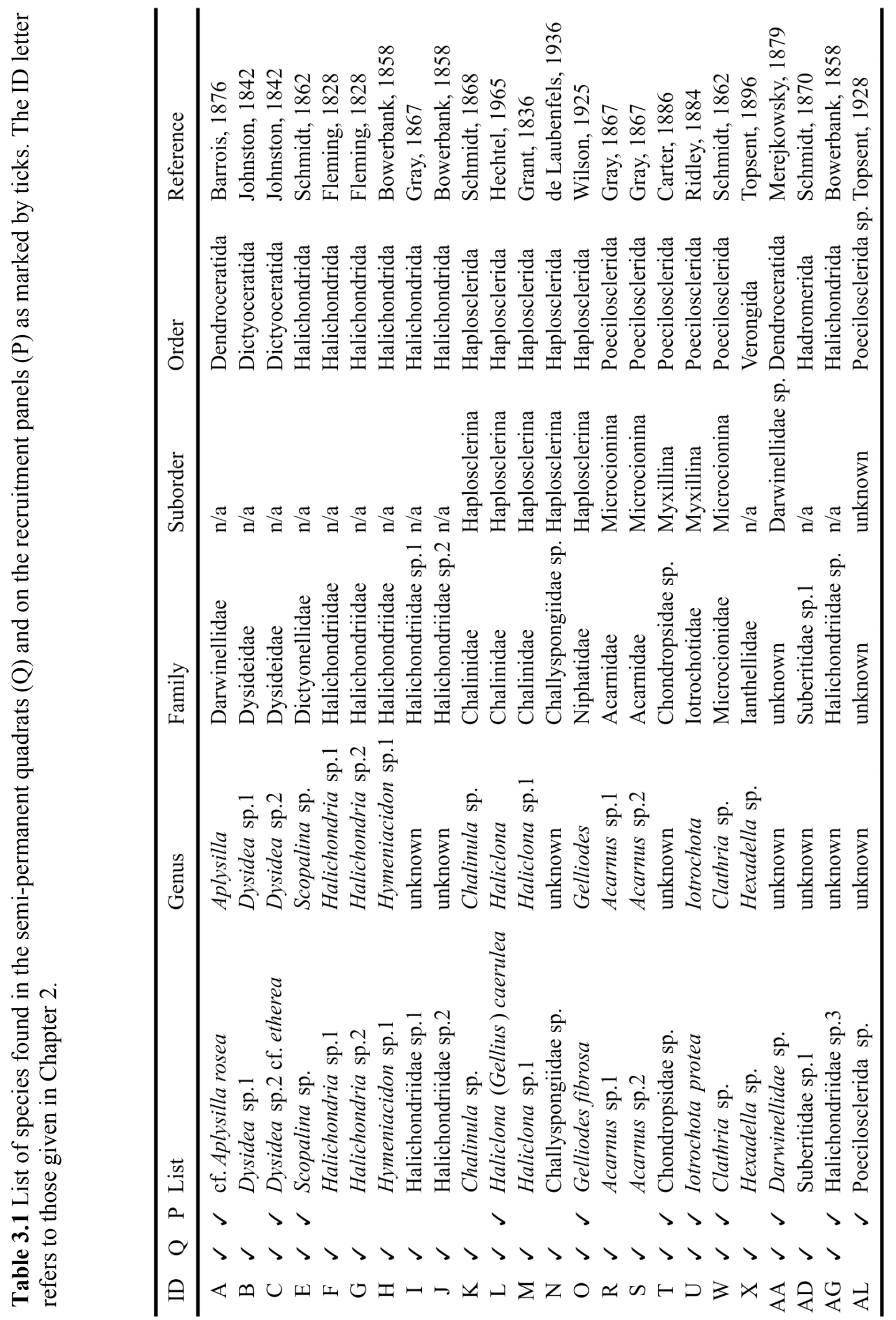




\subsubsection{Statistical analyses}

All multivariate temporal assemblage data were dispersion weighted (based on 1000 permutations), which is suitable for species prone to spatial clustering, such as sponges because it differentially weights species depending on their observed variability between samples (Clarke et al. 2006a), while the univariate total sponge cover was $\log (\mathrm{X}+1)$ transformed. Similarity matrices were based on zero-adjusted Bray-Curtis coefficients to account for denuded data (Clarke et al. 2006b), which was characteristic of a number of the quadrats and panels. Permutational multivariate analysis of variance (PERMANOVA) (based on 9999 permutations) (Anderson 2001, Clarke et al. 2006b) and pairwise post-hoc tests were used to examine differences in sponge assemblages and total cover. The PERMANOVA design for the semipermanent quadrats examined sponge densities and cover at 2 fixed factor levels: 'year' (2008, 2009 and 2010) and 'season' (July and October). The settlement panel analysis examined sponge densities with 3 fixed factors: 'year' (2009 and 2010), 'side' (top and underside) and 'site' (Dolphins, Strawn and Quail) nested in year (Table 3.2). The effect of all factors and their interactions were tested by a permutation of the residuals under a reduced model (max. 9999) with Type III (partial) sums of squares. Canonical Analysis of Principal components (CAP) were used to visualise the PERMANOVA results (Fig 3.2). 
Table 3.2 Results from the permutational multivariate analysis of variance (PERMANOVA) for total cover (univariate), assemblages (multivariate), individual species (univariate) and diversity (Hills N1) (semi-permanent quadrats only) for the semi-permanent quadrat sponge densities (a) and cover (b) over time (seasons and years) and recruitment panel densities (c) between sites, years and sides (top or underside) with $\mathrm{p}$ values followed by Pseudo- $F$ values in brackets. Figures in bold indicate significant differences. ${ }^{\mathrm{a}}$ Term has one or more empty cells.

\begin{tabular}{|c|c|c|c|c|c|c|c|c|}
\hline & Factor & $\mathrm{df}$ & Total & Assemblage & H. caerulea & G. fibrosa & I. protea & Hills N1 \\
\hline (a) & $\begin{array}{l}\text { Season } \\
\text { Year } \\
\text { Year x Season } \\
\text { Residuals } \\
\text { Total } \\
\end{array}$ & $\begin{array}{c}1 \\
2 \\
1 \\
70 \\
74 \\
\end{array}$ & $\begin{array}{l}0.1293(2.36) \\
0.1661(1.85) \\
0.5414(0.38)\end{array}$ & $\begin{array}{l}0.0908(1.77) \\
0.0332(1.89) \\
0.5806(0.80)\end{array}$ & $\begin{array}{l}0.9295(0.03) \\
0.1698(1.80) \\
0.7917(0.11)\end{array}$ & $\begin{array}{l}0.4346(0.62) \\
0.2486(1.39) \\
0.7639(0.13)\end{array}$ & $\begin{array}{l}0.9225(0.04) \\
0.9542(0.09) \\
0.9934(0.00)\end{array}$ & $\begin{array}{l}0.2637(1.26) \\
\mathbf{0 . 0 1 6 6}(\mathbf{4 . 2 9}) \\
0.4711(0.56)\end{array}$ \\
\hline (b) & $\begin{array}{l}\text { Season } \\
\text { Year } \\
\text { Year x Season } \\
\text { Residuals } \\
\text { Total } \\
\end{array}$ & $\begin{array}{c}1 \\
2 \\
1 \\
70 \\
74 \\
\end{array}$ & $\begin{array}{l}0.4353(0.62) \\
0.9919(0.024) \\
0.3965(0.75)\end{array}$ & $\begin{array}{l}0.6426(0.70) \\
0.2197(1.29) \\
0.6771(0.67)\end{array}$ & $\begin{array}{l}0.5317(0.41) \\
0.2055(1.62) \\
0.1829(1.83)\end{array}$ & $\begin{array}{r}0.7426(0.14) \\
0.505(0.70) \\
0.7866(0.10)\end{array}$ & $\begin{array}{l}0.9905(0.01) \\
0.9491(0.09) \\
0.8908(0.06)\end{array}$ & \\
\hline (c) & $\begin{array}{l}\text { Year } \\
\text { Side } \\
\text { Site (Year) } \\
\text { Year x Side } \\
\text { Site (Year) x Side } \\
\text { Residuals } \\
\text { Total }\end{array}$ & $\begin{array}{c}1 \\
1 \\
4 \\
1 \\
4 \\
140 \\
151\end{array}$ & $\begin{array}{l}\mathbf{0 . 0 0 0 1}(\mathbf{3 7 . 6 6 )} \\
\mathbf{0 . 0 0 0 1}(\mathbf{2 3 7 . 2 7}) \\
0.2498(1.37) \\
\mathbf{0 . 0 0 0 1}(\mathbf{1 6 . 5 9 )} \\
0.1245(1.82)\end{array}$ & $\begin{array}{l}\mathbf{0 . 0 0 0 1}(\mathbf{1 0 . 5 3 )} \\
\mathbf{0 . 0 0 0 1}(\mathbf{3 4 . 2 2}) \\
\mathbf{0 . 0 4 4 7}(\mathbf{1 . 6 7 )} \\
\mathbf{0 . 0 0 0 1}(\mathbf{7 . 8 7}) \\
0.2021(1.26)\end{array}$ & $\begin{array}{l}0.6910(0.18) \\
\mathbf{0 . 0 0 0 1}(\mathbf{2 9 . 8 4 )} \\
0.2306(1.40) \\
0.6938(0.18) \\
0.2310(1.40)\end{array}$ & $\begin{array}{l}\mathbf{0 . 0 1 6 2}(\mathbf{4 . 7 5}) \\
\mathbf{0 . 0 0 0 9}(\mathbf{8 . 4 1}) \\
0.0843(1.99) \\
\mathbf{0 . 0 1 7 4}(\mathbf{4 . 7 5 )} \\
0.0906(1.99)\end{array}$ & $\begin{array}{l}\mathbf{0 . 0 0 0 3}(\mathbf{6 . 5 3 )} \\
0.3138(1.11) \\
\mathbf{0 . 0 0 3 2}(\mathbf{4 . 0 1 )} \\
0.3090(1.11) \\
\mathbf{0 . 0 3 4 1}(\mathbf{2 . 3 3 )}\end{array}$ & \\
\hline
\end{tabular}



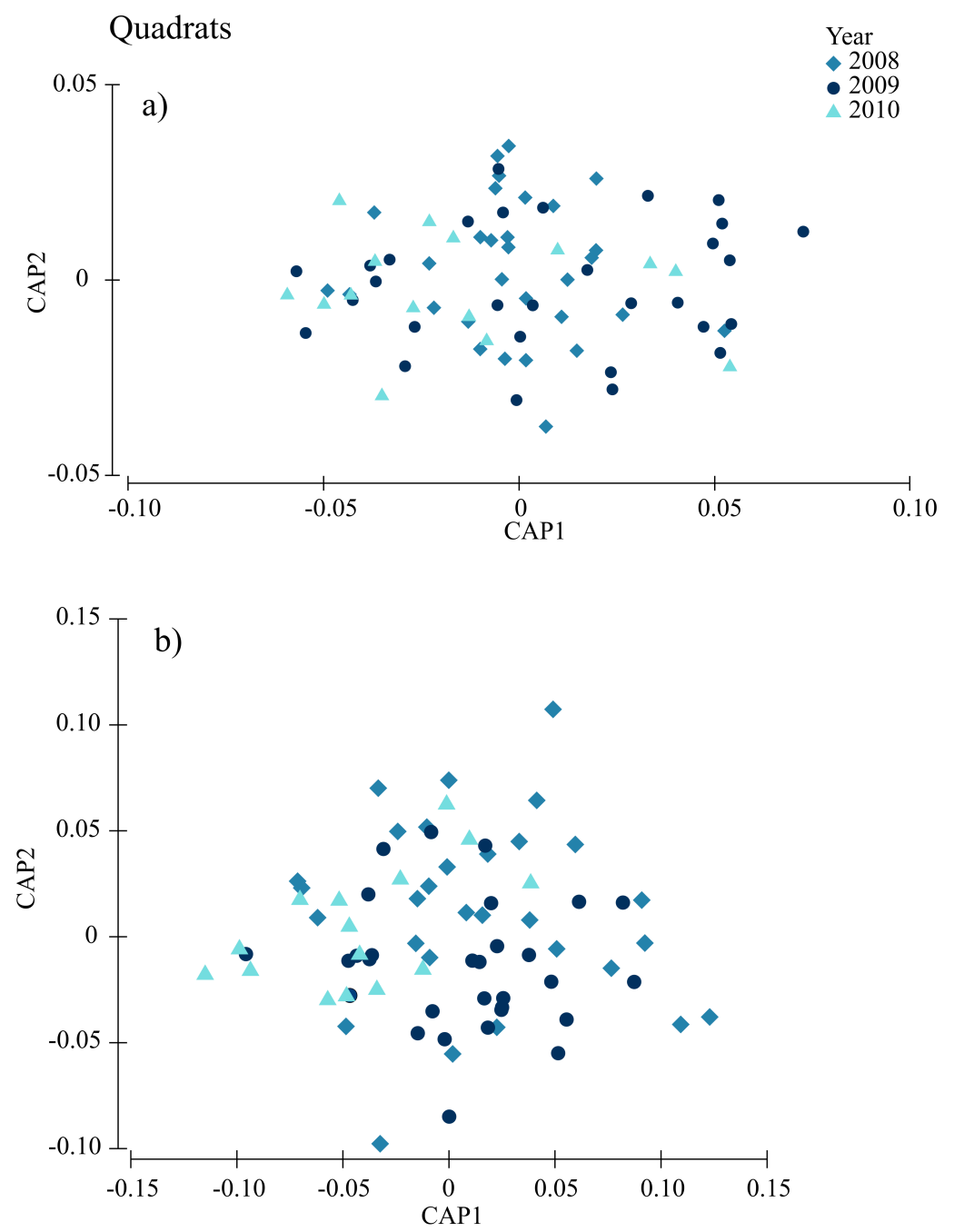

Panels

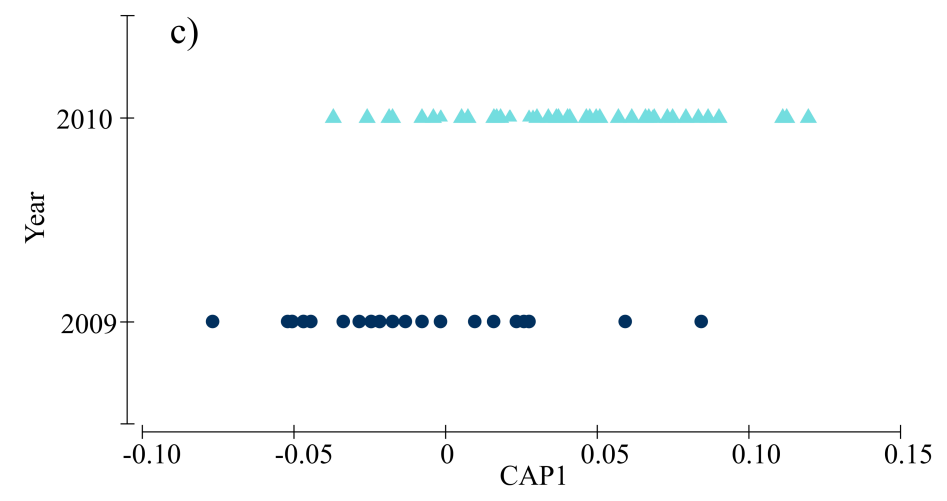

Figure 3.2 Canonical analysis of principal components (CAP) ordination visualising sponge assemblage differences over years showing non-significant differences in the semi-permanent quadrat a) densities and b) cover, respectively and significant differences $(p<0.001)$ in $c)$ sponge densities on recruitment panels based upon a zeroadjusted Bray-Curtis similarity matrix with a dispersion weighting pre-treatment. 
The abundance data of three important species (univariate data) as identified in Chapter 2 were also $\log (\mathrm{X}+1)$ transformed and analysed using the same PERMANOVA designs as described above. These species were Haliclona caerulea (also known as Haliclona (Gellius) caerulea, Haliclona (Soestella) caerulea or Sigmadocia caerulea) and Gelliodes fibrosa, which are two confirmed non-indigenous species introduced to Palmyra (see Appendix I) and Hawai'i (DeFelice et al. 2001) from the Caribbean and the Philippines, respectively, and Iotrochota protea (de Laubenfels 1950), which is the dominant species in the lagoons at Palmyra and native to Hawai'i. It is unknown, however, whether this latter species was found on Palmyra prior to the WWII modifications.

Changes in species diversity (an index based on richness and evenness) were examined in the semi-permanent quadrats using the same PERMANOVA designs as described above, using the Hills N1 index (exponential of the Shannon Wiener function), which is sensitive to changes in rare species and therefore appropriate to examine introductions or losses of new species to the quadrats over time. All analyses were conducted using PRIMER v6 (Clarke \& Gorley 2006) and the PERMANOVA+ add-on package (Anderson et al. 2008).

\subsection{Results}

\subsubsection{Sponge recruitment variability}

In total, 11 species were identified on the settlement panels (Table 3.1) in addition to the 'other' group. All but one (Poecilosclerida sp.) of the identified species on the panels were also found in the quadrats (Table 3.1). Total sponge abundance, per panel, on average increased from $2( \pm 5)$ individuals to $6( \pm 8)$ between 2009 and 2010 and per site in total increased by $137 \%$ from $59( \pm 35)$ individuals in 2009 to $140( \pm 25)$ in 2010. Interspecific recruitment was highly variable (Fig 3.3a) with sponge assemblages becoming more dissimilar from each other over time (Fig 3.2). Sponge settlement was also predominantly to the underside of the panels with an average of 0.3 $( \pm 0.9)$ individuals on the top and $7.6( \pm 7.8)$ on the underside (Fig 3.3). 

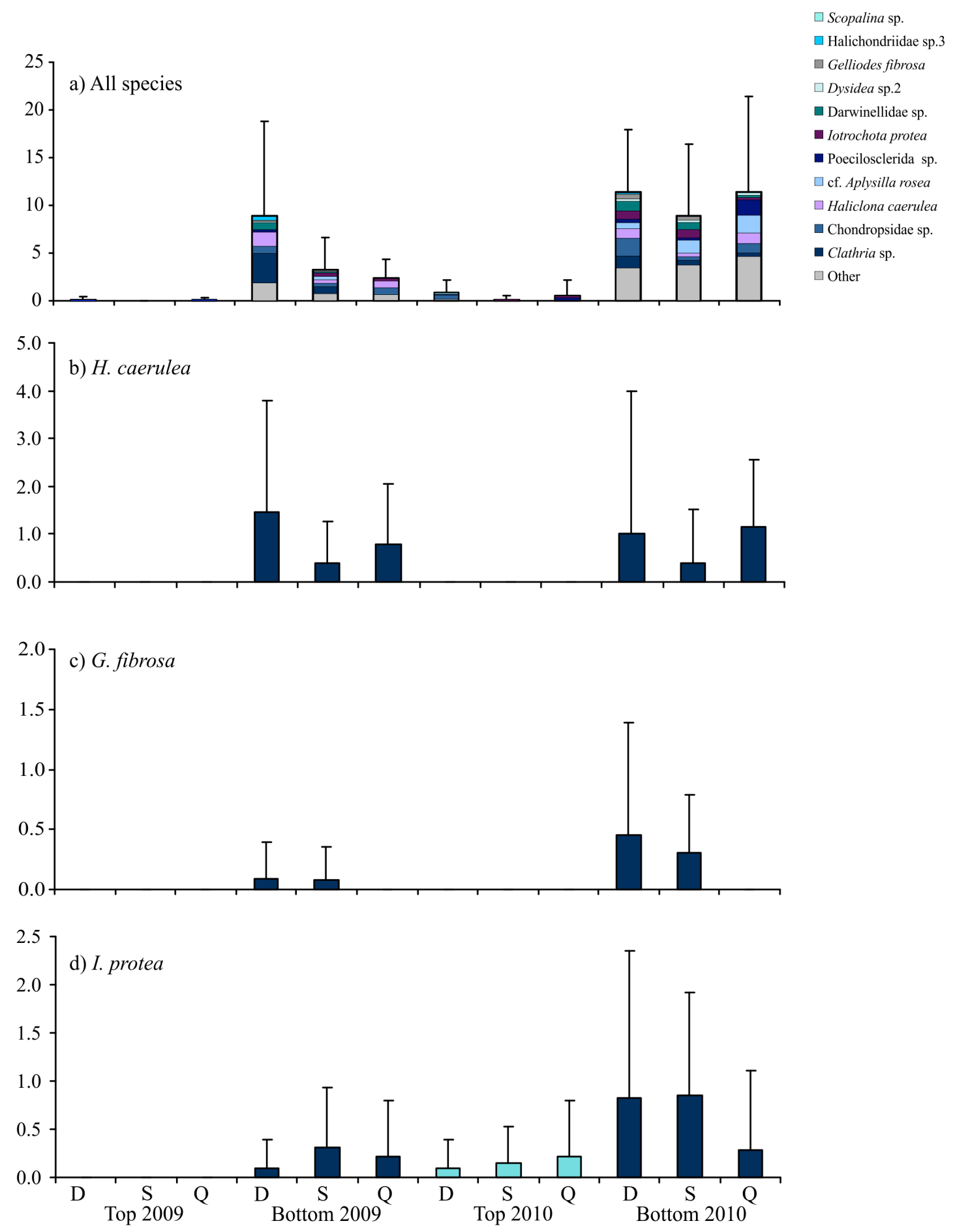

Figure 3.3 Mean ( \pm SD) sponge abundance (no. of individuals) across sites, panel side and year for all species (a), non-indigenous species (b and c), and the dominant species (d) in the lagoons at Palmyra. 
Total sponge abundance (number of individual recruits) did not differ between sites, but differed between years and panel side (Fig 3.3), with a significant interaction between these two factors (Table 3.2) as sponge density increased significantly between years predominantly on the underside of the tiles. Significant differences in sponge assemblages were found between all factors (site, year and side) with a significant $(\mathrm{p}<0.05)$ interaction between side and year. Further pairwise analysis revealed that Quail (East Lagoon) had significantly different assemblages to The Dolphins (West Lagoon) $(\mathrm{t}=1.52, \mathrm{p}=0.035)$.

Recruitment levels differed between species (Fig 3.3), with Iotrochota protea recruits only establishing to the underside of the panels in 2009 and increasing over time, while recruitment to the top of the panels only occurred in 2010. Recruitment events were obvious on the panels as individual patches were often not close to each other, which would be the case if they formed from fragmentation. Overall, I. protea had significantly higher $(\mathrm{p}<0.05)$ abundance in 2010 versus 2009 and overall significantly $(\mathrm{p}<0.05)$ higher densities at Strawn versus The Dolphins $(\mathrm{t}=2.27, \mathrm{p}=$ 0.017); however there was also a significant $(\mathrm{p}<0.05)$ interaction between site and side (Table 3.2). An interaction between sites and sides here is indicative of sponge recruitment levels differing between panel sides at the different sites. Haliclona caerulea and Gelliodes fibrosa densities were significantly $(\mathrm{p}<0.05)$ higher on the underside of the panel versus the top, with G. fibrosa only recruiting to panels at two sites (The Dolphins and Strawn Island) (Fig 3.3). Haliclona caerulea and G. fibrosa did not recruit to the top of the panels but had mean densities of $0.8( \pm 1.7)$ and $0.1( \pm 0.5)$, respectively, on the underside of each panel. Gelliodes fibrosa densities also increased significantly between 2009 and 2010, but significantly $(\mathrm{p}<0.05)$ interacted with site.

\subsubsection{Temporal variability in sponge assemblages}

In total, 23 species were identified in the quadrats at the 3 stations over the 3 years (Table 3.1). Mean total sponge cover was $19.1 \%( \pm 9.7)$ while densities were $99.0( \pm 41.9)$. Sponge assemblages did not differ significantly between years or seasons (Fig 3.2 and Table 3.2), but species diversity (Fig 3.4 and Table 3.2) was significantly lower in 2010 (3.7) compared with $2008(4.6)(\mathrm{t}=2.56, \mathrm{p}=0.013)$ and $2009(4.8)(\mathrm{t}=$ $2.45, p=0.016)$. In addition, no significant differences were found between the cover and densities of the non-indigenous and dominant species (important notable species) 
over time, despite an apparent decline in cover in Haliclona caerulea and Gelliodes fibrosa between July 2009 and July 2010.

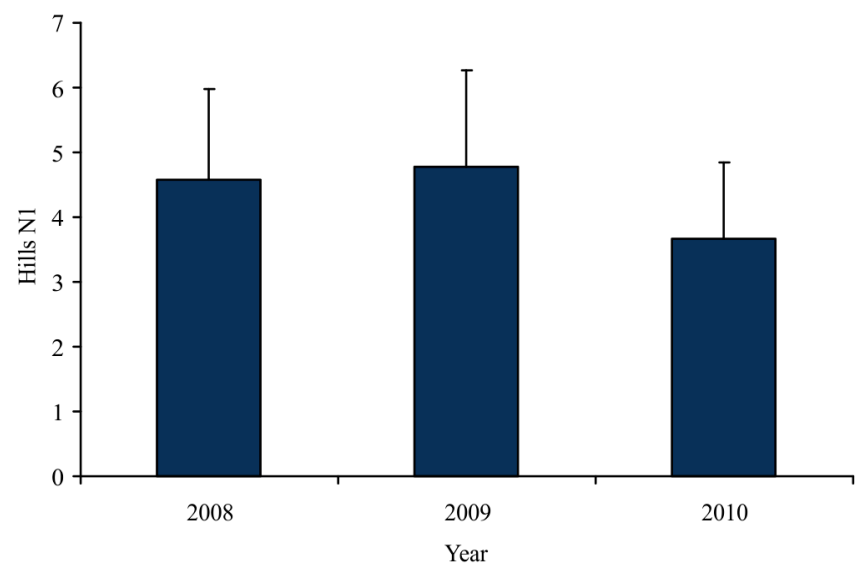

Figure 3.4 Mean ( \pm SD) sponge species diversity in the quadrats over 3 years; based on the Hills N1 index (exponential of the Shannon Wiener function).

\subsection{Discussion}

Remote and uninhabited atolls and islands support some of the last remaining near-pristine reefs in the world (Knowlton \& Jackson 2008) but a number of the Pacific islands that support some of these ecosystems were altered by the US military during WWII (Maragos 1993). Palmyra Atoll is an example of a military modified nearpristine system where currently in the lagoons sponges, not corals, dominate the hard substrate (see Chapter 2 and Appendix I). One of the concerns regarding the sponges in the lagoons is their potential to extend to the adjacent near-pristine reef. I found that the sponges were capable of recruiting to newly available substrate but there were no significant differences in sponge cover or densities (number of individual sponges) on boulders over time, indicating that mortality and recruitment of sponges are in equilibrium. Therefore the sponges have the potential to extend onto the reef via larval dispersal. The sponge assemblages and important notable species, excluding Iotrochota protea, were also significantly more abundant on the underside of the panels indicating that the majority of sponge species recruit to cryptic locations and then growth allows them to colonise the tops of boulders as they establish. 


\subsubsection{Sponge recruitment}

Sponge abundance on the panels increased and assemblages changed significantly over time and between locations, which is consistent with earlier studies (Uriz et al. 1998, Fairfull \& Harriott 1999, Vermeij 2006). This indicates that the sponges are reproducing and/or fragmenting and recruiting in the lagoons and are therefore capable of extending onto the reef. When examining the important species, $I$. protea and Gelliodes fibrosa, their abundance increased significantly over time whilst Haliclona caerulea did not. Haliclona caerulea in the Caribbean releases larvae between July and September (peaking in August-September) (Maldonado \& Young 1996). Therefore when the tiles were examined for the $2^{\text {nd }}$ time in July 2010, at the beginning of the reproductive season ( $1^{\text {st }}$ time in October 2009), it is unlikely that even if the larvae settled on the panels they would have grown large enough to be visible. Unfortunately nothing is known of the larval release times for I. protea and G. fibrosa; however, it is possible that they spawn at different times (Bergquist \& Sinclair 1973, Zea 1993) to $H$. caerulea resulting in the different growth patterns observed over the time of the study. They obviously release larvae in the summer as they were observed in the $1^{\text {st }}$ collection (October 2009) but may have a different peak spawning time to $H$. caerulea, perhaps in the winter months between the sampling periods, or they may spawn all year round, although further recruitment studies are required to establish this fact. This temporal interspecific variability in recruitment patterns is noted across all the species identified on the panels (Fig 3.4a), so it appears likely that there may be seasonal differences in larval release times for all sponges (Bergquist \& Sinclair 1973, Zea 1993, Mariani et al. 2005) including those found in the lagoon at Palmyra.

Spatial variability was also observed for I. protea, which had significantly lower densities at The Dolphins compared to Strawn Island. Chapter 2 indicated that across the lagoons I. protea covered approximately $20 \%$ of the available hard substrate at Strawn Island and only $5 \%$ at The Dolphins. Therefore the lower number of conspecifics at The Dolphins most likely led to the reduced recruitment to the panels here because the recruitment stock for larvae is smaller compared to Strawn Island (Uriz et al. 1998). A significant interaction between site and side may belie this result; however it appears that the levels of successful recruitment of I. protea at Quail Island were similar on both sides of the panels over time (Fig 3.3d) but not at Strawn Island or The Dolphins. This suggests that under different conditions I. protea may or may not settle more in cryptic locations. 
Recruitment to the underside of the panels was also significantly greater than to the tops, with the exception of I. protea. In 2010 there was however, an increase in recruits the top surface of the tiles, due perhaps to the build up of a biofilm here, which is preferentially settled on by sponge larvae when compared to smooth surfaces (Kjerfve 1986, Whalan et al. 2008). Settlement to the underside of surfaces is however more common in sessile invertebrates because the larvae are predominantly negatively phototactic (Hurlbut 1992, Maldonado 2006). Cryptic surfaces also provide protection from predators (Pawlik 1998), reduced sedimentation (Maida et al. 1994), UV radiation (Jokiel 1980) and algal biomass (Vermeij 2006). I propose that the majority of those species recorded on both the underside of the panels and in the quadrats (species found on top of boulders) initially settle in these cryptic locations and then grow or fragment to the top of the boulders (Pawlik 1998).

\subsubsection{Temporal variation in sponge assemblages}

This study found no inter- or intra-annual variation in assemblages or total cover over three years, supporting some earlier studies (Fowler \& Laffoley 1993, Garrabou \& Zabala 2001). However, species diversity did change over time and sponges successfully recruited to panels, suggesting that mortality and recruitment of sponges in the lagoons are in equilibrium. This equilibrium of sponge assemblages suggests that the sponge populations are self-sustaining and maintained in the lagoons.

Variability in sponge assemblages over time have been attributed to both environmental and biological parameters (Bell et al. 2006, Carballo et al. 2008, Berman 2012). Therefore, the non-significant temporal changes in the sponge assemblages may be due to the lack of environmental and seasonal variation in the lagoons (see Gardner et al. 2011). It is unknown why there would be a drop in sponge diversity in 2010 compared to the other years and it may be due to natural biological variation. Alternatively, the reduction in sponge diversity may be in response to an El NiñoSouthern Oscillation (ENSO) event which reached Palmyra in late 2009 and averagely raised water temperatures by $2{ }^{\circ} \mathrm{C}$ resulting in a mild coral bleaching event across the atoll (Williams et al. 2010). This rise in water temperature may therefore have subsequently affected the sponge diversity in the lagoon; however, little is known of the thermal tolerance or ecological effects of ENSO events on sponges but they may be important in shaping their assemblages (Carballo 2006). Annual seasonal temperature changes can result in a reduction in sponge body size and the formation of silica and 
spongin skeletons (Simpson 1978, Francis 1984, Bavestrello et al. 1993) with warmer temperatures reducing silica uptake and spiculogenesis (Hartman 1958, Stone 1970, Hooper 1991). Therefore, the different thermal tolerances of sponges may have resulted in different diversities in 2010 compared to the other years. The temperature change however, was not sufficiently high enough to alter the sponge assemblages, which suggests a possible reduction in the number of species and/or abundance of the species rather than a shift in assemblages over time.

\subsubsection{Evidence of a phase-shift in the lagoon}

The overall equilibrium between sponge recruitment and mortality over time suggests that a) the sponges are capable of recruiting to boulders on the reef and b) they are self-sustaining in the lagoon, possibly indicating that the lagoon has experienced a phase-shift away from the original coral reef community, as purported in pre-military modification reports (Woodbury et al. 1946, Anon. 1947). A phase shift occurs when there has been a sustained change in the environment due to pulse perturbations, which were transient but large in impact and scale. These perturbations result in the removal of the original species, which largely maintained the system, and are replaced with new individuals, which are self-sustaining and maintained in the newly altered ecosystem (Petraitis \& Dudgeon 2004).

Establishing that the lagoons at Palmyra have undergone a phase shift may require further experimental research to confirm this hypothesis, such as coral transplantations from the reef to the lagoon. A phase-shift assumes a new single state (e.g. environmental change or predator loss) different from that of the original, which is unlikely to change compared to an 'alternate stable state', which implies that the at least two assemblages are changeable and both can occur in the same environmental conditions but just not at the same time (Done 1992, Edmunds \& Carpenter 2001, Petraitis \& Dudgeon 2004). However, from the evidence so far it appears likely that the lagoons at Palmyra did experience a phase shift from a coral to sponge dominated system based on the history of modifications and the current evidence of the sponge assemblages and the limited presence of coral species in the lagoons (Williams et al. 2008). The alterations to the lagoons at Palmyra were made over an 18-24 month period nearly 70 years ago (Dawson 1959) and the changes altered the lagoon sufficiently that it has not returned to an ecosystem represented by corals and is still 
currently characterised by low water flow, high sedimentation and boulders $\left(<0.5 \mathrm{~m}^{2}\right)$, and the sponges appear self-sustaining in this modified environment.

Unlike phase shifts from coral to algal dominated systems, which are often, but not always, controlled by top-down dynamics (e.g. overfishing) (Hughes et al. 2007), shifts to sponge dominance appear to be associated primarily with bottom-up effects (e.g. mass coral bleaching, disease and water quality) (Holmes 2000, Ward-Paige et al. 2005); they are also attributable to top-down controls (spongivory) (Hill 1998).

This is the first study to observe a coral to sponge phase shift in response to substantial human influence in the form of a top-down impact, which removed the reef forming corals from the lagoon. However, bottom-up effects may be preventing the return of the corals to the lagoon because of the altered environmental conditions resulting from the military modification (Dawson 1959, Maragos 1993). Although it is difficult to establish what the conditions were like before the naval base was built the water flow was altered dramatically (Collen et al. 2009) which may have altered the water clarity, nutrient levels and sedimentation, possibly making it unsuitable for coral larval settlement and growth and more suitable for sponges (Rose \& Risk 1985, WardPaige et al. 2005). The sponges may also be directly impeding the return of corals through competition for space (de Voogd et al. 2004) and recruit overgrowth (Vermeij 2006); however if the environmental conditions are not suitable for coral growth, the direct affect of sponges may be negligible. Also, as sponges have the potential to remove vast quantities of particulate matter and nutrients from the water (Reiswig 1974, Ribes et al. 1999) they may in fact be having a positive impact on the water quality (Peterson et al. 2006) in the lagoon.

Currently, without further testing, the evidence for a phase shift in the lagoons at Palmyra is compiled from the history of the modifications and the results from this study indicating that the sponges appear to be self-sustaining, supporting the notion that the lagoons have shifted from a coral to sponge dominated fauna on the hard substrate. It also appears likely that the corals will not return to the lagoon in the near future because in the last 70 years they have not yet successfully reseeded the lagoon despite the adjacent near-pristine reef acting as a source of viable coral larvae. However, it also seems unlikely that the sponges will extend on to the adjacent reefs and will remain in this altered ecosystem. 


\section{Chapter 4}

Filtering capability of sponges in an altered atoll lagoon and their potential impact on an adjacent near pristine reef.

\subsection{Abstract}

Sponges process large volumes of water to extract nutrients and food. Therefore, when their densities are high they can have a considerable influence on food nutrient availability for other organisms. At Palmyra Atoll, the reefs are near-pristine, but the lagoons were heavily modified during WWII and now sponges are the dominant fauna on the remaining hard substrate. Tidal-driven water from the lagoon, which has been filtered by the sponges, flows out over the adjacent reef. The aim was to assess the turnover rate of the lagoon water by the sponge assemblages, and determine their influence on oxygen and dissolved organic carbon (DOC) in the water. In 2010, the pumping rates (volume flux per unit area) of six representative species inhabiting the lagoon were measured. The six species were then broadly placed into one of two morphological groups: encrusting and massive. This information was combined with data from the literature on sponge nutrient consumption rates to estimate the effects that sponges might be having on the water column. Excurrent flow speed from the sponges was measured in situ using fluorescein dye, an underwater camera system and image analysis software. No significant difference was found in volume flux per unit volume of sponge between massive and encrusting morphotypes at $0.06 \pm 0.01 \mathrm{~cm}^{3} \mathrm{~s}^{-1} \mathrm{~cm}^{3}$. Across the lagoons the sponges filter approximately $5.2 \mathrm{~m}^{3} \mathrm{H}_{2} \mathrm{O} \mathrm{sec}{ }^{-1}$ or $389,892 \mathrm{~m}^{3}$ $\mathrm{H}_{2} \mathrm{O}$ day ${ }^{-1}$, and have the potential to filter all of the moving water every 3 to 6 days. Extrapolations based on the filtering rates of water revealed that sponges in the lagoons consume up to $19 \%$ of the DOC and $8 \%$ of the oxygen in the lagoon and therefore appear to be a sink for DOC, but do not remove considerable amounts of oxygen likely to cause concern for other species. I conclude that in altered atoll lagoons like Palmyra, where sponges are in high densities, they may have a considerable impact on the water column but the effects on reef organisms is likely to be small. 


\subsection{Introduction}

Coral reefs are one of the most economically important and ecologically diverse but threatened ecosystems in the world (Moberg \& Folke 1999, Knowlton 2001, Bellwood et al. 2004, Hoegh-Guldberg et al. 2007) and remote and uninhabited Pacific atolls and islands are amongst the last remaining quasi-pristine reef systems. However, despite their current lack of human habitation remote reefs are still at risk from external perturbations such as coral bleaching events, disease outbreaks, fishing, poaching and ship wrecks (see Maragos et al. 1996, Work et al. 2008, Williams et al. 2010, Williams et al. 2011a, Kelly et al. 2012). A number of these atolls and islands were also modified during WWII by the US military (Stoddart 1968, Maragos 1993), removing native species and habitat, and introducing non-indigenous species particularly to the islets and lagoons (Flint 1992, Eldredge 1994; Appendix I). Due to the connection that atoll lagoons often have with their adjacent reefs it is important to understand the impacts that any introduced species might have on the reef, either directly through competition with the corals by extending out of the lagoon or indirectly by influencing the water column, which subsequently flows out onto the reef.

Water quality is important to coral reef health (Fabricius 2005, De'ath \& Fabricius 2010). Poor water quality increases mortality rates of corals through smothering and erosion, alters the chemical composition of the seawater, results in hypoxia (oxygen depletion) and encourages microbial and algal growth (Rogers 1990, Fabricius et al. 2005, Kline et al. 2006, Dinsdale et al. 2008). Nutrients such as nitrate, phosphate and ammonia are routinely measured as components of water quality; however, these may not directly result in substantial coral mortality, though hypoxia and high levels of dissolved organic carbon (DOC) can be fatal to corals (Simpson et al. 1993, Kuntz et al. 2005, Kline et al. 2006). DOC is the largest reservoir of carbon in the oceans and makes up the greater portion of total organic carbon (TOC), with the remaining fraction made up of particulate organic carbon (POC) (Martin \& Fitzwater 1992, Benner 2002). Microbes are large consumers of DOC; therefore, high concentrations of this carbon source can increase bacterioplankton production resulting in localised hypoxia and coral death (Kuntz et al. 2005, Kline et al. 2006, Smith et al. 2006). High DOC can also disrupt the balance between the coral host and its associated microbiota (archaea, bacteria and viruses) in the coral mucus layer (Kline et al. 2006) resulting in increased susceptibility to coral disease or mortality (Segel \& Ducklow 
1982, Knowlton \& Rohwer 2003). DOC is derived from primary producers, such as algae and mangroves, and is a major food source for suspension feeders (Khailov \& Burlakova 1969, Roditi et al. 2000, Yahel et al. 2003, Dittmar et al. 2006, de Goeij et al. 2008).

Benthic suspension feeders, including sponges, are important and successful components of coral reef systems, primarily because of their ability to process large quantities of water and remove organic and inorganic matter and nutrients from the water column (Gili \& Coma 1998). The high filtration rate of benthic suspension feeders means that when densities of individuals are high, substantial impacts on an ecosystem and its inhabitants can occur. This is particularly evident in partially enclosed bodies of water such as bays and lagoons, where benthic suspension feeders can dramatically reduce nuisance phytoplankton blooms and eutrophication through water filtration (Cloern 1982, Officer et al. 1982, Hily 1991, Gili \& Coma 1998). The suspension feeders can also have this dramatic impact on these semi-enclosed locations because the time the water is in the lagoon or bay (residence time) is longer than the time taken by the suspension feeders to filter all of the water (clearance time), therefore giving them the opportunity to remove nutrients and particles before the water exits (Grall \& Chauvaud 2002).

Research into the regulation of water quality by benthic fauna has primarily focused on molluscs, which have the potential to directly regulate primary production and indirectly secondary production because of their ability to filter and assimilate organic particles in the water column (Cloern 1982, Officer et al. 1982, Kimmerer et al. 1994). Sponges, however, also have strong interactions with the water column (Bell 2008a), filtering large volumes of water of up to $24,0001 \mathrm{~kg}^{-1}$ of sponge day ${ }^{-1}$ (Vogel 1977), and removing nutrients (e.g. oxygen) and food particles. Sponges primarily feed on DOC $(<0.45 \mu \mathrm{m})$ (de Goeij et al. 2008), ultraplankton $(<20 \mu \mathrm{m})$ and picoplankton $(<2 \mu \mathrm{m})$ (Reiswig 1971a, 1974, Pile et al. 1996, Ribes et al. 1999), as well as bacteria $(1-10 \mu \mathrm{m})($ Reiswig 1975, Frost 1978) and possibly viruses $(0.03-0.1 \mu \mathrm{m})$ (Hadas et al. 2006). Retention rates of food particles by sponges are high, ranging from 58 to $99 \%$ (Pile et al. 1997, Lesser 2006, de Goeij et al. 2008), making them very important in linking primary and secondary production (Gili \& Coma 1998).

In high densities, sponges can interact with the water column by depleting oxygen levels (Richter et al. 2001), playing key roles in nitrogen, phosphorus (Ribes et al. 2005, Jiménez \& Ribes 2007) and silicon cycling (Maldonado et al. 2005), and 
consuming large quantities of carbon with $90 \%$ of TOC removed in the form of DOC (Yahel et al. 2003, Lesser 2006, de Goeij et al. 2008). However, despite the large impact that sponges can have on ecosystems, studies into the water-clearing role of sponge assemblages on a system are limited, with the majority focussing on individual species (e.g. Savarese et al. 1997, Milanese et al. 2003, Longo et al. 2010). Peterson (2006) did, however, find that the decline in sponge assemblages in Florida Bay was most likely the cause of the subsequent phytoplankton and cyanobacteria blooms. Also Perea- Blázquez et al. (2012) found that sponge assemblages in New Zealand play an important role in water column interactions due to their high rates of particulate organic carbon (POC) removal. Therefore, overall sponge-assemblage removal rates of DOC in semi-enclosed systems could be considerable if the density of individuals is high.

Palmyra Atoll, located in the north Central Pacific, is a tropical system with near-pristine reefs surrounding partially enclosed and modified lagoons (Dawson 1959). Interestingly, while the outer-reefs are mostly devoid of large macroinvertebrates (Williams et al. in review), sponges are the dominant fauna in the lagoons covering 27\% $( \pm 6 \%)$ of the available hard substrate (see Chapter 2). Given their abundance, sponges have the potential to exert a considerable effect on the water column in the lagoons through removal of DOC and oxygen. Therefore, given the altered condition of the lagoon, one potential concern at Palmyra is the potential influence of the lagoon outflow onto the adjacent near-pristine reef. Sponges could be reducing oxygen levels but helping to reduce the DOC in the water that flows over the reef, which could potentially cause coral disease and mortality.

In this chapter, I estimate total sponge densities and the filtration rates for all morphologies to determine the turnover rate of the lagoon water by the entire sponge assemblage. Then based on my calculations and data from the literature, I estimate the potential influence that the sponges are having on the DOC and oxygen levels in the lagoon water, which subsequently flows over the adjacent reef.

\subsection{Methods}

\subsubsection{Sponge percentage cover surveys}

Sponge cover surveys were completed in 2008 on SCUBA at ten sites across 3 of the lagoons (Fig 4.1) at depths between 5-8 m. See Chapter 2 for further explanation of the sponge survey methods. 


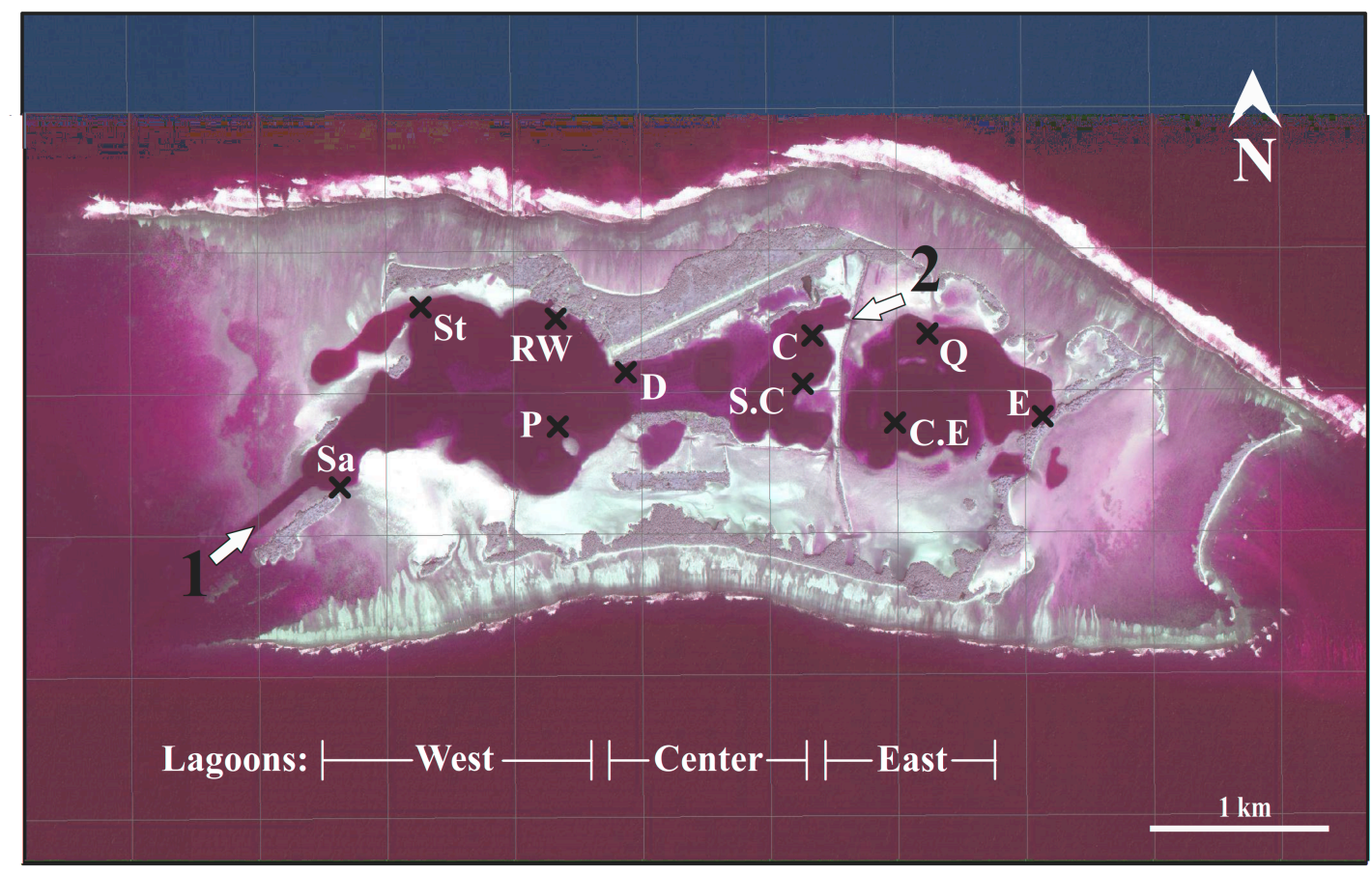

Figure 4.1 Location of the 10 survey sites within the 3 lagoons: Sand Island (Sa); Strawn Island (St); Ripple Wharf (RW); Paradise Island (P); The Dolphins (D); The Cut (C); South of the Cut (S.C); Quail Island (Q); Eastern Island (E) and Central East (C.E). The black arrows indicate locations of military modifications; $1=$ excavated entrance channel, 2 = the north-south causeway, specifically the cut allowing boat access between the Center and East Lagoons.

\subsubsection{Sponge species and morphologies}

All measurements of sponge filtration rates were taken at sites in West and East lagoon $\left(05^{\circ} 53.089 \mathrm{~N} 162^{\circ} 05.074 \mathrm{~W}\right.$ and $\left.05^{\circ} 53.037 \mathrm{~N} 162^{\circ} 04.079 \mathrm{~W}\right)$ at 5 to $8 \mathrm{~m}$ depth. The rates were measured for six species representing the four sponge morphologies in the lagoon (Fig 4.2): Clathria sp. (Schmidt, 1862) (thinly encrusting, < $2 \mathrm{~mm}$ ); Spirastrella sp. (Schmidt, 1868) and Chondropsidae sp. (Carter 1886) (thickly encrusting, < $5 \mathrm{~mm}$ ); Dysidea sp. 2 (Johnston, 1842) and Haliclona (Sigmadocia) caerulea (Hechtel, 1965) (massive); and Halichondria sp.1 sp. (Fleming, 1828) (digitate). Three to four individuals were sampled per species with three to four oscula recorded per individual, giving a total of 74 oscula measured across all sponges. The six sampled species represented all morphologies in the lagoon and therefore all species, making it possible to extrapolate to the total volume flux by all sponges across the lagoons. 


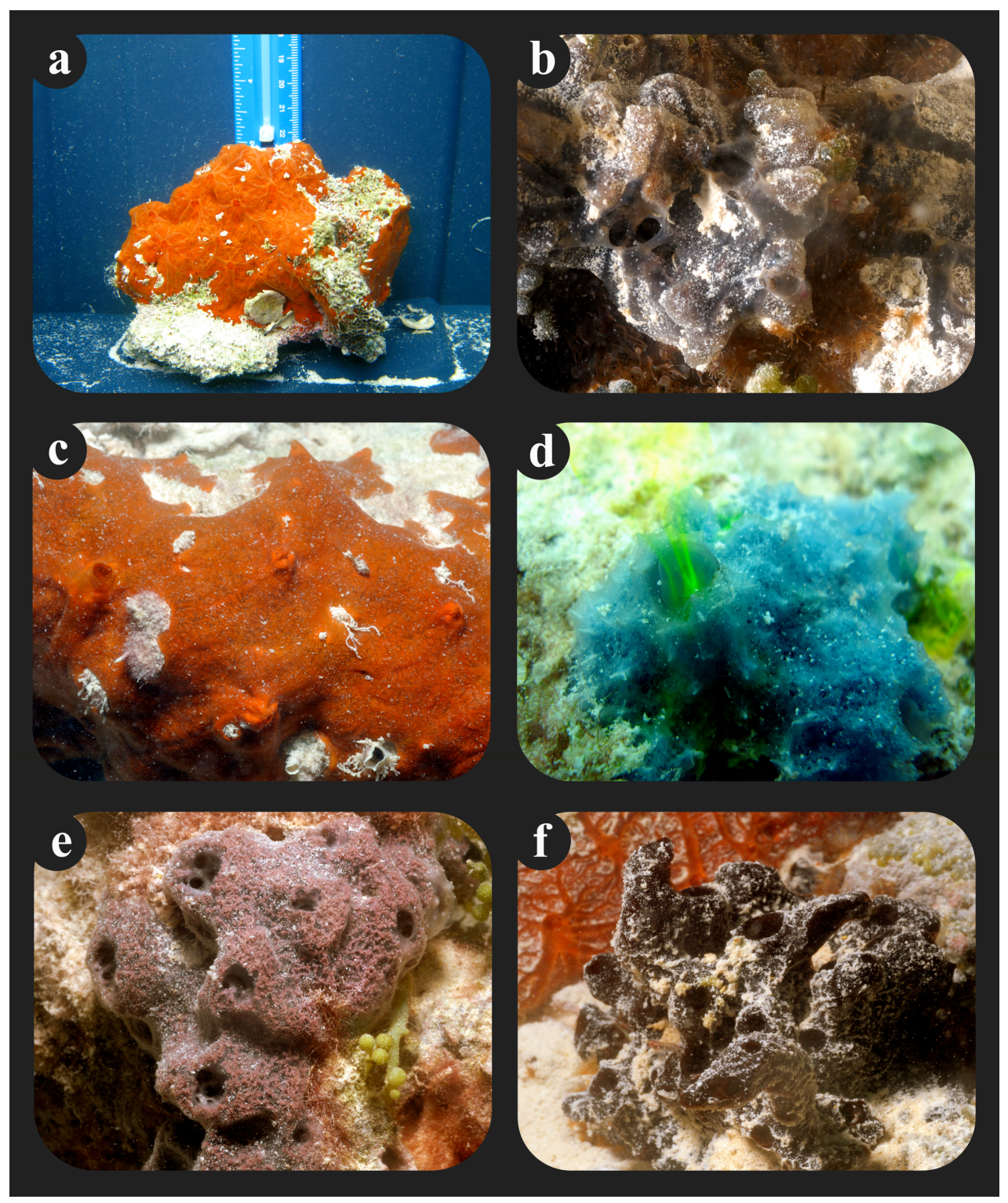

Figure 4.2 Photos of the 6 species filtration rates were calculated for in situ in the West and East lagoons. a) Clathria sp. (thinly encrusting); b) Chondropsidae sp. and c) Spirastrella sp. (thickly encrusting); d) Dysidea sp. (with dye stream) and e) Haliclona (Sigmadocia) caerulea (massive) and f) Halichondria sp.1 sp. (digitate).

Permutational multivariate analyses of variance (PERMANOVA) (Anderson 2001, Clarke \& Gorley 2006) was used to examine differences between the volume flux per unit area of sponge cover $\left(\mathrm{cm}^{3} \mathrm{sec}^{-1} \mathrm{~m}^{-2}\right)$ of the four morphological groups to determine whether any morphologies could be combined. Analyses (both the global test and subsequent pairwise comparisons) were based on 9999 random permutations of the raw data and zero-adjusted Bray-Curtis similarity matrices, and completed using PRIMER v6 (Clarke \& Gorley 2006) and the PERMANOVA+ add-on (Anderson et al. 2008). No pre-weighting was applied to the raw data because the values were based on 
sum values over multiple species. On the basis of this analysis, the four morphological groups were reduced down to two as the PERMANOVA analysis revealed significant differences between the encrusting species and the massive/digitate species but not within the two groups (Table 4.1). The thin and thick encrusting species are termed hereafter as 'encrusting' and the massive and digitate species as 'massive'. The two morphological groupings were used for all subsequent calculations.

Table 4.1 Pairwise post-hoc test results indicating significant differences between encrusting and massive/digitate species. a) Clathria sp. (thin encrusting); b) Spirastrella sp. and c) Chondropsidae sp. (thick encrusting); d) Dysidea sp. and e) Haliclona caerulea (massive) and f) Halichondria sp.1 sp. (digitate).

\begin{tabular}{rccccc}
\hline & Thin (a) & Thick (b) & Thick (c) & Massive (d) Massive (e) \\
\hline Thin (a) & & & & & \\
Thick (b) & 0.2199 & & & & \\
Thick (c) & 0.6128 & 0.5327 & & & \\
Massive (d) & $\mathbf{0 . 0 0 0 1}$ & $\mathbf{0 . 0 0 0 3}$ & $\mathbf{0 . 0 0 0 3}$ & & \\
Massive (e) & $\mathbf{0 . 0 0 5 2}$ & $\mathbf{0 . 0 3 3 6}$ & $\mathbf{0 . 0 3 3 9}$ & 0.0945 & \\
Digitate (f) & $\mathbf{0 . 0 0 0 1}$ & $\mathbf{0 . 0 0 0 1}$ & $\mathbf{0 . 0 0 0 1}$ & 0.7643 & 0.0652 \\
\hline
\end{tabular}

\subsubsection{Filtration measurements}

Sponge pumping rates were recorded in situ on SCUBA using a solution of fluorescein dye and seawater $(2.5 \mathrm{mg}: 100 \mathrm{ml})$ to visualise the excurrent flow velocity (Fig 4.2d). Fluorescein dye is a nontoxic fluorescent dye and is commonly used as a tracer to indicate water movement patterns. The dye was released next to the sponge using a $50 \mathrm{ml}$ syringe and filmed leaving the osculum. To improve visibility of the fluorescein dye and minimise the surrounding water flow, each sponge was carefully placed on a shelf in a dark box (with the front and top removed) (Fig 4.2a). Next to the sponge, attached to the back of the box, was a scale bar, which was used to record the height of the exhalent flow of dye during video analyses. All selected sponges were between 3 and $25 \mathrm{~cm}$ in length and on small moveable boulders, which could be transported to the box without touching the samples. It was important to avoid direct contact and other disturbances before and during filming because jarring/touching sponges can momentarily stop them from pumping for 20-50 seconds (Lawn et al. 1981) to several minutes (Leys et al. 1999). I noted in particular that Spirastrella sp. was prone to closing its oscula for an indeterminate amount of time (longer than a 
single dive) if disturbed too much. Therefore, all oscula were counted, and measured and the length and width of the sponge were recorded after filming.

All sponges, before filming, were first tested for active pumping by releasing dye near the sponge. If a sponge was not filtering it was replaced and if this occurred for more than three individuals then surveying was postponed, as it was assumed that the sponges were no longer actively filtering water. All dives were conducted in the morning to early afternoon to reduce the potential variability in sponge pumping rates with time of the day. Reiswig (1971a) noted species-specific patterns in filtering cessation times from diurnal to periodic to continuous pumping. I noted a midday reduction of sponge pumping across all species examined as described by Annandale (1907), who presumed that this was because of the increase in temperature associated with this time of day. The cessation of pumping due to an increase in temperature was also found by Leys et al. (1999). To examine temperature change at the experimental site, a pendant $\mathrm{HOBO}^{\circledR}$ (accuracy $\pm 0.54^{\circ} \mathrm{C}$ ) (www.onsetcomp.com) was located on a stainless steel pole at $5 \mathrm{~m}$ and set to record once every 2 minutes for 15 days (the duration of the research trip). It was observed that the sponges would stop pumping around 14:00 when the water temperature was $29.6^{\circ} \mathrm{C}( \pm 0.4)$ and would not drop to below this temperature until around 16:00. Therefore, the calculations were based on the sponges pumping for 21 hours a day.

\subsubsection{Filtration calculations}

Pumping velocity was calculated by measuring the time it took the dye plume to travel $2 \mathrm{~cm}$ once it left the target osculum. All measurements of sponge area cover and osculum diameter were made using ImageJ. Tracker ${ }^{\odot}$ v4.05 (Brown 2004) video analysis software was used to determine the number of frames taken for the dye to travel $2 \mathrm{~cm}$ to then calculate the flow speed $\left(\mathrm{cm} \mathrm{sec}^{-1}\right)$ (Table 4.2). For both morphological groups (encrusting and massive), the volume flux per unit area of sponge $(F)\left(\mathrm{m}^{3} \mathrm{sec}^{-1} \mathrm{~m}^{-2}\right)$ was calculated as

$$
F=d l s
$$

where $d$ is the number of oscula per unit area, $l$ is the oscula area $\left(\mathrm{m}^{2}\right)$ and $s$ is the flow speed $(\mathrm{m} / \mathrm{sec})$. The sponge pumping rates used in the extrapolation calculations were based on the volume flux per unit area of sponge cover $\left(\mathrm{cm}^{3} \mathrm{sec}^{-1} \mathrm{~m}^{-2}\right)$ rather than volume flux per unit volume of sponge $\left(\mathrm{cm}^{3} \mathrm{sec}^{-1} \mathrm{~m}^{-3}\right)$. This is because all the surveys estimated sponge area cover (top-down view) not volume. However, to make volume 
flux calculations comparable with the literature, I converted volume flux per unit area to per unit volume (Table 4.2). To calculate the sponge volumes the sponges were assumed to be cylindrical in shape with an estimated average thickness for each species; volume flux was then calculated per $\mathrm{cm}^{3}$ of sponge.

Table 4.2 Species mean and standard deviation values used to calculate the volume flux per unit area and per unit volume of sponge $\left(\mathrm{cm}^{3}\right)$. Where $\mathrm{n}=$ number of individuals, $\mathrm{VF}=$ volume flux.

\begin{tabular}{|c|c|c|c|c|c|c|c|c|c|}
\hline Species name & $\mathrm{n}$ & Morphology & $\begin{array}{l}\text { Number } \\
\text { of oscula }\end{array}$ & $\begin{array}{c}\text { Oscular area } \\
\left(\mathrm{cm}^{2}\right)\end{array}$ & $\begin{array}{c}\text { Sponge surface } \\
\text { area }\left(\mathrm{cm}^{2}\right)\end{array}$ & $\begin{array}{c}\text { Flow speed } \\
\left(\mathrm{cm} \mathrm{s}^{-1}\right)\end{array}$ & $\begin{array}{c}V F \\
\left(\mathrm{~cm}^{3} \mathrm{~s}^{-1}\right) \\
\end{array}$ & $\begin{array}{c}\mathrm{VF} / \text { unit area } \\
\text { of sponge } \\
\left(\mathrm{cm}^{3} \mathrm{~s}^{-1} \mathrm{~cm}^{2}\right)\end{array}$ & $\begin{array}{c}\mathrm{V} / \text { unit volume } \\
\text { of sponge } \\
\left(\mathrm{cm}^{3} \mathrm{~s}^{-1} \mathrm{~cm}^{3}\right) \\
\end{array}$ \\
\hline Clathria sp. & 4 & Thin enc. & $19( \pm 7)$ & $0.08( \pm 0.04)$ & $147.90( \pm 47.3)$ & $4.58( \pm 1.07)$ & $0.34( \pm 0.16)$ & $0.04( \pm 0.02)$ & $0.09( \pm 0.03)$ \\
\hline Spirastrella sp. & 4 & Thick enc. & $7( \pm 3)$ & $0.09( \pm 0.04$ & $130.90( \pm 102.7)$ & $5.58( \pm 1.54)$ & $0.52( \pm 0.28)$ & $0.05( \pm 0.08)$ & $0.05( \pm 0.01)$ \\
\hline Chondropsidae sp. & 3 & Thick enc. & $7( \pm 2)$ & $0.14( \pm 0.12)$ & $114.20( \pm 49.3)$ & $5.06( \pm 1.46)$ & $0.81( \pm 0.94)$ & $0.05( \pm 0.04)$ & $0.05( \pm 0.03)$ \\
\hline Dysidea sp. & 4 & Massive & $24( \pm 11)$ & $0.1( \pm 0.08)$ & $59.20( \pm 40.4)$ & $5.66( \pm 1.56)$ & $0.53( \pm 0.42)$ & $0.21( \pm 0.11)$ & $0.07( \pm 0.02)$ \\
\hline Haliclona caerulea & 4 & Massive & $17( \pm 8)$ & $0.14( \pm 0.13)$ & $124.20( \pm 147.3)$ & $5.33( \pm 1.71)$ & $0.84( \pm 0.93)$ & $0.24( \pm 0.27)$ & $0.06( \pm 0.05)$ \\
\hline Halichondria sp. & 4 & Digitate & $14( \pm 8)$ & $0.08( \pm 0.06)$ & $19.10( \pm 13.8)$ & $4.87( \pm 1.60)$ & $0.37( \pm 0.33)$ & $0.27( \pm 0.24)$ & $0.05( \pm 0.04)$ \\
\hline
\end{tabular}

Due to the large uncertainty associated with many of the variables in calculating the total flux across the lagoons, propagation of errors was used to enumerate the overall error of the lagoon flux based on the individual errors associated with each measured or inferred variable (Lo 2005, Wu et al. 2006). Given the equation for $F$, the equation for the standard deviation of volume flux is given as the sum of partial derivatives ( $\partial$ ) of $F$ with respect to its constituent components (Table 4.3):

$$
{\sigma_{F}}^{2}=\left(\frac{\partial F}{\partial d}\right)^{2} \sigma_{d}^{2}+\left(\frac{\partial F}{\partial s}\right)^{2} \sigma_{s}^{2}+\left(\frac{\partial F}{\partial l}\right)^{2} \sigma_{l}^{2}
$$

Therefore the error on the volume flux was calculated according to:

$$
{\sigma_{F}}^{2}=(l s)^{2} \sigma_{d}{ }^{2}+(d l)^{2} \sigma_{s}{ }^{2}+(d s)^{2} \sigma_{l}{ }^{2}
$$

Where a standard deviation could not be calculated, but appropriate, e.g. sponge area an error of $20 \%$ of the mean was assumed. 
Table 4.3 Pairwise post-hoc test results indicating site differences in a) percentage encrusting species cover b) percentage massive species cover and c) percentage available hard substrate. Those sites with no significant differences for all variables were grouped together for subsequent analyses. Sites names: Sand Island (Sa); Strawn Island (St); Ripple Wharf (RW); Paradise Island (P); The Dolphins (D); The Cut (C); South of the Cut (S.C); Quail Island (Q); Eastern Island (E) and Central East (C.E).

$\begin{array}{llccccccccc}\text { Encrusting } & & \text { Sa } & \text { St } & \text { Rw } & \text { P } & \text { D } & \text { C } & \text { S.C } & \text { Q } & \text { E.I } \\ & \text { St } & 0.896 & & & & & & & & \\ \text { Rw } & \mathbf{0 . 0 1 9} & \mathbf{0 . 0 0 1} & & & & & & & \\ \text { P } & 0.629 & 0.466 & \mathbf{0 . 0 0 2} & & & & & & \\ \text { D } & 0.061 & \mathbf{0 . 0 1 4} & 0.606 & \mathbf{0 . 0 4 2} & & & & & \\ \text { C } & 0.743 & 0.905 & \mathbf{0 . 0 0 1} & 0.315 & \mathbf{0 . 0 0 6} & & & & \\ \text { S.C } & 0.599 & 0.399 & \mathbf{0 . 0 1 2} & 0.895 & 0.089 & 0.258 & & & \\ \text { Q } & 0.759 & 0.907 & \mathbf{0 . 0 0 1} & 0.305 & \mathbf{0 . 0 0 8} & 0.979 & 0.246 & & \\ \text { E.I } & 0.628 & 0.821 & \mathbf{0 . 0 0 0} & 0.271 & \mathbf{0 . 0 0 2} & 0.955 & 0.210 & 0.858 & \\ \text { C.E } & 0.550 & 0.745 & \mathbf{0 . 0 0 0} & 0.274 & \mathbf{0 . 0 0 4} & 0.856 & 0.212 & 0.727 & 0.977\end{array}$

$\begin{array}{lllllllllll}\text { Massive } & & & & & & & & & \\ & \text { Sa } & \text { St } & \text { Rw } & \text { P } & \text { D } & \text { C } & \text { S.C } & \text { Q } & \text { E.I } \\ \text { St } & 0.951 & & & & & & & & \\ \text { Rw } & 0.144 & 0.093 & & & & & & & \\ \text { P } & 0.232 & 0.299 & \mathbf{0 . 0 0 2} & & & & & & \\ \text { D } & 0.216 & 0.128 & 0.470 & \mathbf{0 . 0 0 6} & & & & & \\ \text { C } & 0.137 & 0.165 & \mathbf{0 . 0 0 0} & 0.604 & \mathbf{0 . 0 0 1} & & & & \\ \text { S.C } & \mathbf{0 . 0 1 0} & \mathbf{0 . 0 1 1} & \mathbf{0 . 0 0 0} & 0.184 & \mathbf{0 . 0 0 1} & 0.084 & & & \\ \text { Q } & 0.942 & 0.943 & 0.061 & 0.401 & 0.108 & 0.271 & \mathbf{0 . 0 1 5} & & \\ \text { E.I } & \mathbf{0 . 0 2 5} & \mathbf{0 . 0 2 7} & \mathbf{0 . 0 0 0} & 0.390 & \mathbf{0 . 0 0 1} & 0.252 & 0.911 & \mathbf{0 . 0 4 6} & \\ \text { C.E } & 0.443 & 0.471 & 0.303 & \mathbf{0 . 0 2 8} & 0.215 & \mathbf{0 . 0 0 7} & \mathbf{0 . 0 0 0} & 0.303 & \mathbf{0 . 0 0 1} \\ & & & & & & & & & \\ \text { Hard substrate } & & & & & & & & & & \\ & & & & & & & & & \\ & & \text { Sa } & \text { St } & \text { RW } & \text { P } & \text { D } & \text { C } & \text { S.C } & \text { Q } & \text { E.I } \\ \text { RW } & \mathbf{0 . 0 2 8} & \mathbf{0 . 0 0 0} & & & & & & & \\ \text { P } & \mathbf{0 . 0 0 3} & 0.060 & \mathbf{0 . 0 0 0} & & & & & & \\ \text { D } & 0.655 & \mathbf{0 . 0 0 0} & \mathbf{0 . 0 0 3} & \mathbf{0 . 0 0 7} & & & & & \\ \text { C } & 0.112 & \mathbf{0 . 0 0 1} & \mathbf{0 . 0 0 0} & \mathbf{0 . 0 4 5} & 0.195 & & & & \\ \text { S.C } & 0.555 & \mathbf{0 . 0 1 3} & \mathbf{0 . 0 0 9} & 0.098 & 0.788 & 0.583 & & & \\ \text { Q } & 0.130 & 0.079 & \mathbf{0 . 0 0 2} & 0.444 & 0.212 & 0.701 & 0.457 & & \\ \text { E.I } & \mathbf{0 . 0 4 2} & 0.579 & \mathbf{0 . 0 0 1} & 0.738 & 0.065 & 0.215 & 0.154 & 0.435 & \\ \text { C.E } & 0.067 & 0.311 & \mathbf{0 . 0 0 1} & 0.964 & 0.101 & 0.361 & 0.244 & 0.627 & 0.755\end{array}$

\subsubsection{Estimating lagoon area and volume}

The number of site groups (Fig 4.3), based on the original sponge survey sites (Fig 4.1), was reduced to make the estimation of sponge and boulder cover across the lagoon simpler and more accurate. PERMANOVA analyses determined that the 10 survey sites could be reduced down to 6 (Fig 4.3, Table 4.3) based on non-significant differences in all of the 3 factors: percentage cover of encrusting sponges, percentage cover of massive sponges and percentage available hard substrate. The area occupied by sponges $\left(\mathrm{m}^{2}\right)$ for each group (1-6) (Fig 4.3) was determined by the vicinity of the 
group to the original sponge survey sites (Sa, St, Rw etc) (Fig 4.1) with estimates extended across the lagoons to areas of similar characteristics (Fig 4.3). Average available hard substrate was calculated from habitat surveys conducted in 2010 (see

Chapter 2). The encrusting and massive sponge covers for each site were calculated as covering a proportion of the available hard substrate; for example, site 1 (Fig 4.3) had a total area of $100,741 \mathrm{~m}^{2}$ and $23 \%\left(23170 \mathrm{~m}^{2}\right)$ of it was hard substrate and $26 \%$ of this hard substrate was covered by encrusting sponges $\left(6023 \mathrm{~m}^{2}\right)$ and $4 \%\left(926 \mathrm{~m}^{2}\right)$ by massive species.

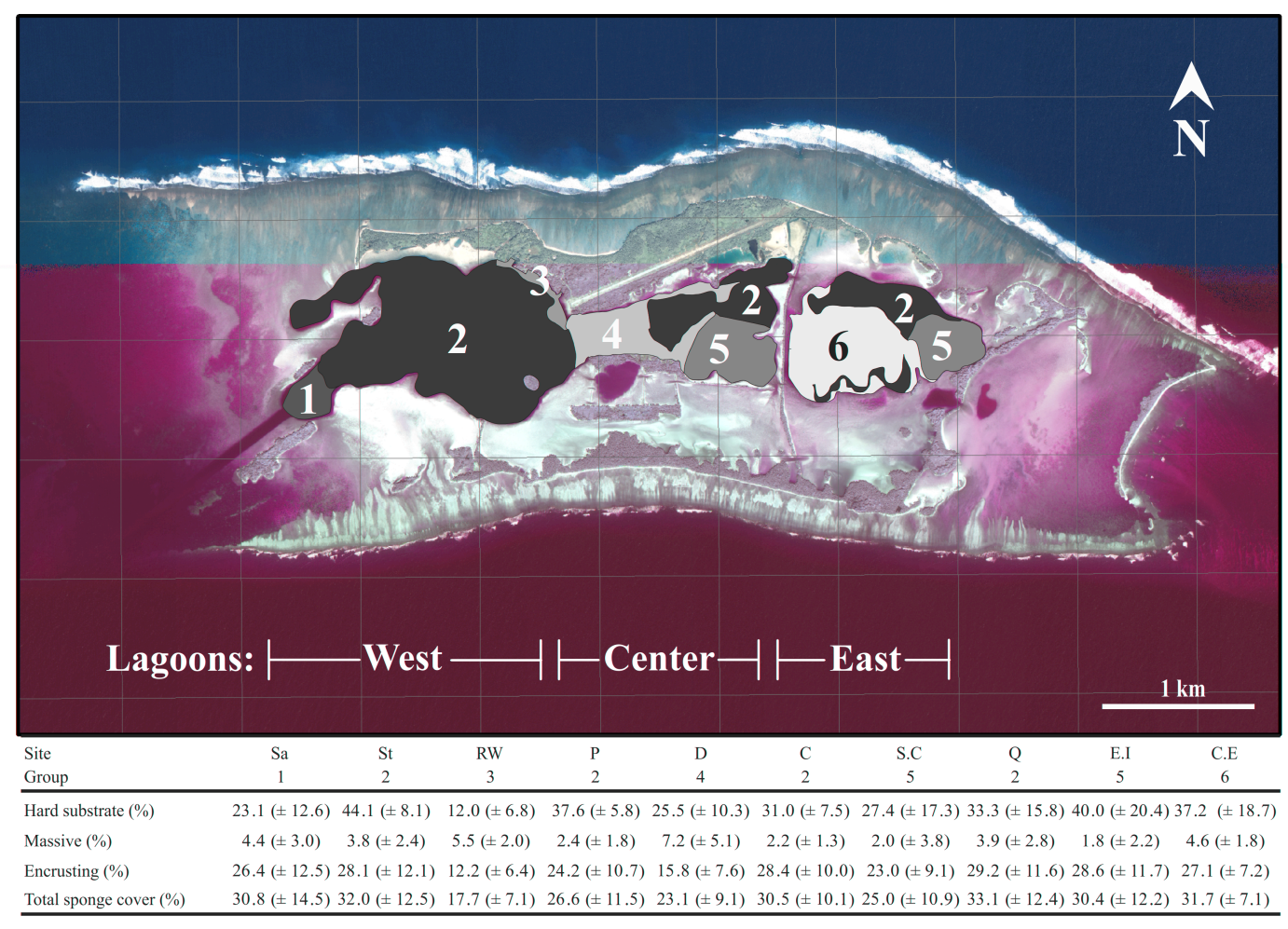

Figure 4.3 The site values and groupings based on the PERMANOVA analyses from Table 5.3 (similarity in percentage cover of encrusting and massive species and available hard substrate). Sites names: Sand Island (Sa); Strawn Island (St); Ripple Wharf (RW); Paradise Island (P); The Dolphins (D); The Cut (C); South of the Cut (S.C); Quail Island (Q); Eastern Island (E) and Central East (C.E).

The maximum depth of the lagoons was $52 \mathrm{~m}$ but sponge cover estimates were made from 2 to $20 \mathrm{~m}$ because sponges were rarely seen shallower than $2 \mathrm{~m}$ (and most sites had drop-offs from the lagoon flats), and boulder and sponge densities were sparse beyond 20-25 m (author's pers. obs.). Sponges can inhabit locations below thermoclines and in low oxygen conditions, but at reduced abundances (Bell \& Barnes 2000c, a), so it was assumed that most of the sponge assemblage was in these 
shallower depths since oxygen levels are low in the deeper parts of the lagoon (Gardner et al. 2011). Based on the measurements of the proportion of available habitat and percent cover of encrusting and massive species at each of these sites the overall volume flux, $F^{T}$ is given by

$$
F^{T}=F^{E}\left(\sum_{s=1}^{s=6} A^{s} H^{s} E^{s}\right)+F^{M}\left(\sum_{s=1}^{s=6} A^{s} H^{s} M^{s}\right)
$$

where $F^{E}$ and $F^{M}$ are the volume flux for encrusting and massive species respectively, $A$ is the area of each site, $H$ is the $\%$ available habitat, $E$ and $M$ are the $\%$ cover of encrusting and massive species respectively and superscript $s$ denotes the site label.

The depth ranges used in the water volume calculation were $0 \mathrm{~m}$ to: $20 \mathrm{~m}, 30 \mathrm{~m}$ and $\approx 50 \mathrm{~m}$. Water volume down to $20 \mathrm{~m}$ was examined because it is the depth limit known to be colonised by sponges and $52 \mathrm{~m}$ was the maximum depth in the lagoons. Thirty meters was included as a middle depth because across the lagoons at Palmyra, vertical water mixing below $30 \mathrm{~m}$ is reduced, with low to zero dissolved oxygen, increased turbidity and relatively stable temperature, salinity and density below this depth (Gardner et al. 2011). Therefore, it is possible that the sponges have access to this water, but below $30 \mathrm{~m}$ water movement is reduced. The lagoon has a maximum tidal range of $1.18 \mathrm{~m}$ therefore the volume was calculated as the median of this $(0.64 \mathrm{~m})$ with an error of $10 \%$ included. All area cover and volume estimates were calculated using ArcGIS (Fig 4.4). Given the lagoon volume, the clearance time $(t)$ due to sponge pumping was

$$
t=\frac{V}{F^{T}}
$$

where $V$ is the volume of the lagoon $\left(\mathrm{m}^{3}\right), F$ is the flux per unit area of sponge $\left(\mathrm{cm}^{3} / \mathrm{sec} / \mathrm{m}^{2}\right)$ and $T$ is the area of lagoon habitable by sponges $\left(\mathrm{m}^{2}\right)$. 


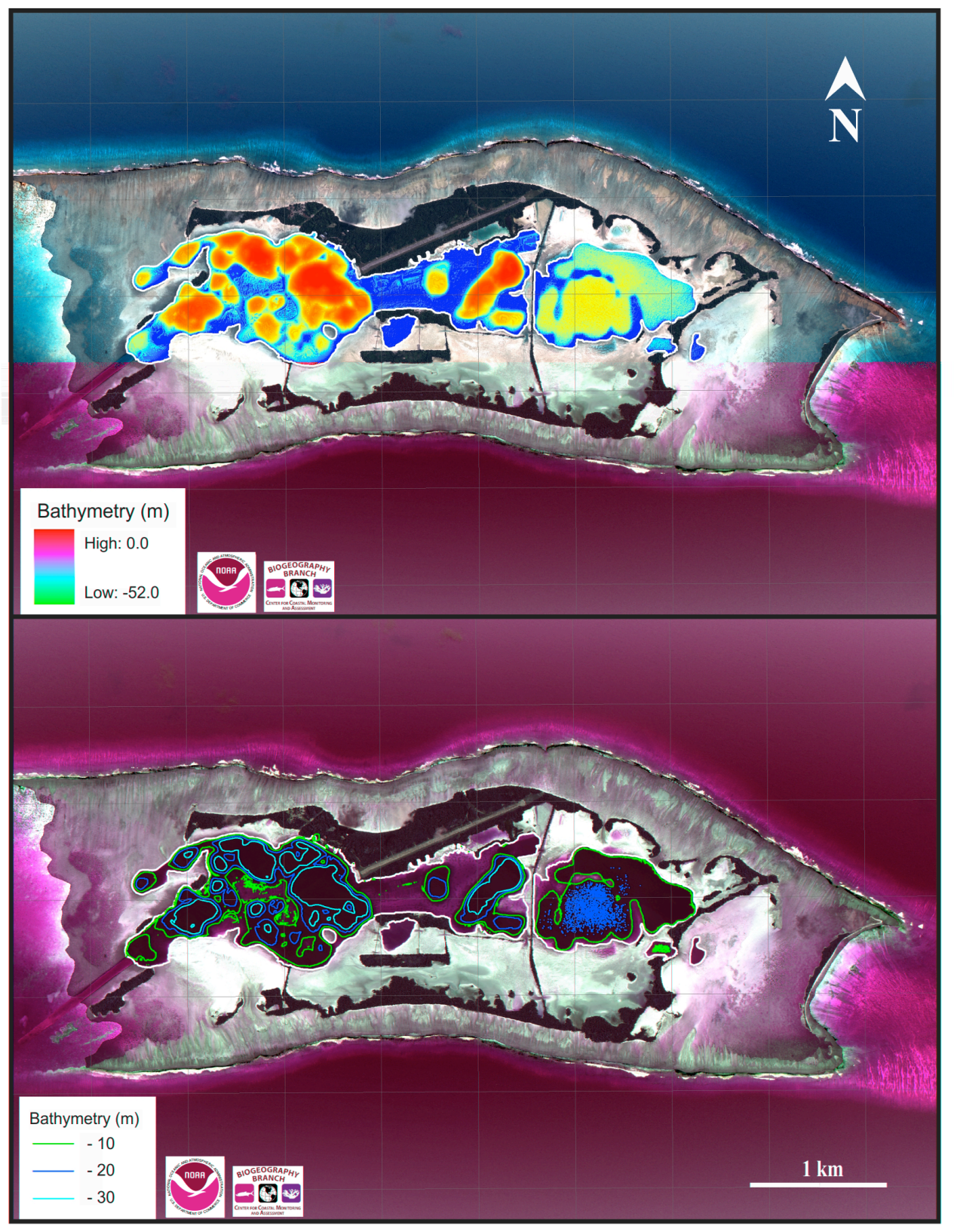

Figure 4.4 Bathymetric maps indicating a) the depth gradient and b) the depth contours for the lagoons at Palmyra, Central Pacific. Area and volume estimates for GIS analysis were based on the outlines (of the 3 largest lagoons) as indicated in this figure.

Several assumptions were made when calculating overall turnover rate of the lagoon water: 1) for an individual sponge all oscula are the same size and have the same density as those measured for flow speed; 2) other species with similar morphologies filter water at the same rate; 3) hydrodynamic conditions in the lagoon restrict water movement to the top $30 \mathrm{~m}$; 4) all sponges filter for 21 hours a day, due to the high temperatures around midday; 5) available hard substrate and sponge cover can be extrapolated out to the entire lagoon down to $20 \mathrm{~m}$. 


\subsubsection{Oxygen and dissolved organic carbon estimates}

While sponges can be heterotrophic or phototrophic, and can derive up to $50 \%$ of their nutrition from phototrophic associations (Wilkinson 1983), it was assumed that the sponges in the lagoons where heterotrophic feeders because of the low light conditions. Sponges found on reefs, where phototrophic species typically inhabit, generally experience high light and low organic nutrient levels (Wilkinson 1983) unlike the conditions in the lagoons at Palmyra (McCauley et al. 2012; Chapter 2).

Total available dissolved oxygen in the lagoon was taken from Gardner et al. (2011) and estimated for water down to $30 \mathrm{~m}$; below this depth water mixing is much reduced. Oxygen saturation was averaged at 70\% ( $\pm 15 \%)$ because levels went from $\sim 100 \%$ down to $50-60 \%$ at $30 \mathrm{~m}$. Sponge oxygen consumption rates were taken from de Goeij et al. (2008) at $6.7( \pm 1.9) \mathrm{mmol} \mathrm{m}^{-2} \mathrm{~h}^{-1}$. Based on these consumption rates the overall oxygen removal by sponges ( $\delta^{O_{2}}$ ) across Palmyra's whole lagoon is:

$$
\delta^{O_{2}}=R^{O_{2}}\left(\sum_{s=1}^{s=6} A^{s} H^{s}\left(E^{s}+M^{s}\right)\right)
$$

where $R^{O_{2}}$ is the oxygen consumption rate. Unfortunately, because I was examining area cover of sponges and not volume, the values found in other studies were not comparable because of problems with converting the units. Percentage removal of oxygen by the sponges was estimated for a 21 hour day and calculated based on the volume of water down to $30 \mathrm{~m}$ and the sponge cover down to $20 \mathrm{~m}$.

It was not possible to measure dissolved organic carbon (DOC) directly for logistical reasons, so estimates were based on the literature with the same lagoon criteria and calculations as the oxygen levels. Ambient DOC levels were taken from Pagès et al. (1997) and based on the most similar atoll (Haraiki Atoll, Tuamotu archipelago) to Palmyra in size and morphometric characteristics, such as permeability to the surrounding waters (Pagès et al. 1997, Torréton et al. 2002). Also, mean chlorophyll- $a$ levels at Haraiki Atoll are similar at $0.33 \mu \mathrm{g} \mathrm{l}^{-1} \pm 0.05$ (Torréton et al. 2002) compared to Palmyra: $0.36 \mu \mathrm{g} \mathrm{l^{-1 }} \pm 0.21$ (see Chapter 2) and chlorophyll- $a$ levels are positively associated to DOC levels (Naumann et al.). The average DOC levels for the lagoon were estimated as $0.83( \pm 0.07) \mathrm{mg} \mathrm{C}^{-1}$ (Pagès et al. 1997), which is similar to the average for the other atolls at $0.96( \pm 0.20) \mathrm{mg} \mathrm{C}^{-1}$ (Pagès et al. 1997, Torréton et al. 2002). DOC removal rates by sponges range between 80 and $1800 \mathrm{mg} \mathrm{C}$ $\mathrm{m}^{-2}$ sponge $\mathrm{d}^{-1}$ (Pile 1996, Pile et al. 1997, Gili \& Coma 1998). Due to the range in DOC removal rates, I calculated an upper and lower bound for the DOC removed 
across the whole lagoon based around DOC removal rates of 80 and $1800 \mathrm{mg} \mathrm{C} \mathrm{m}$ sponge $\mathrm{d}^{-1}$ according to

$$
\delta^{D O C}=R^{D O C}\left(\sum_{s=1}^{s=6} A^{s} H^{s}\left(E^{s}+M^{s}\right)\right)
$$

where $R^{D O C}$ is the DOC removal rate per unit area of sponge.

\subsubsection{Lagoon residence time}

Delesalle and Sournia (1992) found a linear relationship between lagoon residence time and phytoplankton biomass (based on chlorophyll-a levels). Residence time here is defined as "the average time during which a molecule or unit volume of water stays in a lagoon before being flushed out". Average chlorophyll- $a$ levels were taken from Chapter 2 and residence time was calculated using the regression equation in Delesalle and Sournia (1992).

\subsection{Results}

\subsubsection{Lagoon characteristics}

The lagoons at mid-tide hold approximately $0.029 \mathrm{~km}^{3}$ of water down to $20 \mathrm{~m}$, $0.043 \mathrm{~km}^{3}$ down to $30 \mathrm{~m}$ and $0.066 \mathrm{~km}^{3}$ in total. Total substrate area (sand and boulders) of the lagoons between 2-20 m was $2.42 \mathrm{~km}^{2}$ and $3.55 \mathrm{~km}^{2}$ in total (Table 4.4). The mean number of days $( \pm \mathrm{SD})$ taken for all the sponges in the lagoon (between 2 and $20 \mathrm{~m}$ ) to filter the water down to $20 \mathrm{~m}$ was $2.8 \pm 1.1$ and down to $30 \mathrm{~m} 4.1 \pm 1.6$, and it would take $6.4 \pm 2.4$ days for them to filter all the water in the lagoon.

Table 4.4 Approximate lagoon area cover (sand and boulders) $\left(\mathrm{km}^{2}\right)$ and volume $\left(\mathrm{km}^{3}\right)$. Measurements made using ArcGIS. *Actual maximum depth across all lagoons is $52 \mathrm{~m}$. In bold are overall total values for the lagoons.

\begin{tabular}{lccccccc}
\hline & \multicolumn{3}{c}{ Area $\left(\mathrm{km}^{2}\right)$} & & \multicolumn{3}{c}{ Volume $\left(\mathrm{km}^{3}\right)$} \\
\cline { 2 - 7 } Lagoon & $2-20 \mathrm{~m}$ & $2-30 \mathrm{~m}$ & $2-50 \mathrm{~m} *$ & $0-20 \mathrm{~m}$ & $0-30 \mathrm{~m}$ & $0-50 \mathrm{~m} *$ \\
\hline West & 1.001 & 1.412 & 1.904 & 0.011 & 0.022 & 0.041 \\
Center & 0.446 & 0.554 & 0.664 & 0.004 & 0.006 & 0.011 \\
East & 0.975 & 0.985 & 0.985 & 0.014 & 0.015 & 0.015 \\
Total & 2.423 & 2.951 & $\mathbf{3 . 5 5 2}$ & 0.029 & 0.043 & $\mathbf{0 . 0 6 6}$ \\
\hline
\end{tabular}




\subsubsection{Sponge surveys}

The six species sampled were reduced to two groups (encrusting and massive) due to significant differences in volume flux per unit area of sponge cover $\left(\mathrm{cm}^{3} \mathrm{sec}^{-1} \mathrm{~m}^{-}\right.$ ${ }^{2}$ ) for different groups of sponges (Pseudo- $F_{5}, 73=7.6628, \mathrm{p}<0.001$ ) (Table 4.1). Of the 29 species recorded in the survey quadrats, $79 \%$ were encrusting species and the remainder were massive/digitate species. Encrusting morphologies dominate the lagoons with an average cover of hard substrate of $21.2 \%( \pm 7.0)$ compared to massive species with an average cover of $4.1 \%( \pm 1.9)$ (Fig 4.3).

Significant differences were found between sites for encrusting species cover (Pseudo$F_{9,99}=3.1367, \mathrm{p}<0.05$ ), massive species cover (Pseudo- $F_{9,}, 99=3.7091, \mathrm{p}<0.05$ ) and hard substrate availability (Pseudo- $F_{99}, 99=5.0289, \mathrm{p}<0.001$ ). Based on the similarities in these three variables, the 10 sites were reduced down to 6 site groups (Table 4.3).

\subsubsection{Filtration rates}

There was no significant difference in the volume flux per $\mathrm{cm}^{3}$ (unit volume) of sponge between encrusting and massive sponges (Pseudo- $F_{1}, 73=4.9913, \mathrm{p}=0.9834$ ), with an average rate of $0.06 \pm 0.01 \mathrm{~cm}^{3} \mathrm{~s}^{-1} \mathrm{~cm}^{3}$ for both morphotypes. For individual species values see Table 4.2. However, the volume flux per unit area occupied of encrusting and massive sponge was $4.9 \pm 1.2 \times 10^{-4} \mathrm{~cm}^{3} \mathrm{sec}^{-1} \mathrm{~m}^{-2}$ and $22.9 \pm 4.5 \times 10^{-4}$ $\mathrm{cm}^{3} \mathrm{sec}^{-1} \mathrm{~m}^{-2}$, respectively. The total volume flux of all the sponges between $2-20 \mathrm{~m}$ in the lagoon was $137 \pm 50 \mathrm{~cm}^{3} \mathrm{sec}^{-1}$, which equates to $5.2 \mathrm{~m}^{3}$ of water being pumped by all of the sponges in the lagoon every second or $389,892 \mathrm{~m}^{3} \mathrm{H}_{2} \mathrm{O}$ day $^{-1}$ (21 hours pumping).

\subsubsection{Residence time, nutrients and DOC}

The mean water residence time in the lagoons at Palmyra was estimated as 22 days $( \pm 13)$. The percentage of oxygen removed by all the sponges in the lagoons per day was estimated at $0.36 \%( \pm 0.1)$ of the total available oxygen down to $30 \mathrm{~m}$ assuming $70 \%$ saturation. Assuming that the water stays on average 22 days in the lagoon, the sponges could remove $8 \%( \pm 5)$ of the oxygen from the water over that time before leaving the lagoon. The average oxygen concentration across the lagoons down to $30 \mathrm{~m}$ (based on $70 \% \pm 15 \%$ saturation) was $5.60( \pm 1.2) \mathrm{mg} \mathrm{O}_{2} \mathrm{l}^{-1}$. After 1 day (21 h), assuming no water movement, the sponges would reduce the oxygen concentration to $5.58 \mathrm{mg} \mathrm{O}_{2} \mathrm{l}^{-1}$ and after 22 days to $5.2( \pm 0.8) \mathrm{mg} \mathrm{O}_{2} \mathrm{l}^{-1}$. 
Removal estimates revealed that the sponges might filter $13,365-300,713 \mathrm{~g} \mathrm{C} \mathrm{d}^{-}$ ${ }^{1}$ equal to $0.04-0.8 \%$ of the total DOC every day, and assuming the residence time of the water is 22 days, the sponges may remove $0.8-18.7 \%$ of the DOC in the water column in the lagoons during this time.

\subsection{Discussion}

Sponges perform essential functional roles in marine ecosystems, and in high densities can have a considerable influence on the water column due to their highly efficient filtering capabilities (Peterson et al. 2006). This study aimed to calculate the turnover time of the lagoon water at Palmyra Atoll in the Central Pacific by all of the resident sponges and to use these values to estimate the potential influence that they have on the DOC and oxygen levels in the lagoons. Appreciating the influence that the sponges have on the water column in the lagoon is important because in semi-enclosed areas suspension feeders can exert a considerable influence on the water column, and have even been shown to mitigate nuisance phytoplankton blooms and eutrophication events (Officer et al. 1982, Hily 1991, Peterson et al. 2006). At Palmyra, understanding the influence of the lagoon sponge assemblage on the water quality in the lagoons is particularly important because it flows out and over a quasi-pristine reef the likes of which are in decline globally (Knowlton \& Jackson 2008). It was found that the sponges filter all of the water in the lagoons every 3-6 days, have a negligible impact on the oxygen levels but are a potential sink for DOC.

\subsubsection{Filtration rates}

The average filtration rate per unit volume of sponge for the six species was $0.06( \pm 0.01) \mathrm{cm}^{3} \mathrm{~s}^{-1} \mathrm{~cm}^{-3}$, which is comparable to other freshwater and marine species that are reported to filter between 0.006 and $0.583 \mathrm{~cm}^{3} \mathrm{~s}^{-1} \mathrm{~cm}^{-3}$ (Reiswig 1974, Frost 1980, Savarese et al. 1997, Osinga et al. 2001, Peterson et al. 2006). This study however, found far less variability between species as reported in other studies (e.g. Reiswig 1974, Peterson et al. 2006), which may be because all observations were carried out in situ, which reduces the stress on the sponge, a response which varies among species (Reiswig 1971a). Variability between species may also be low because morphological variation in the lagoon is low (no species grows higher than $25 \mathrm{~cm}$ ) with no large morphologies like chimneys or vases. However, it is difficult to make direct 
comparisons between filtration rates for different species because of the variation in method used (Bell 2008a).

The sponge assemblages in the lagoons $\left(\right.$ per $\mathrm{m}^{2}$ ) at Palmyra filtered $8-13 \mathrm{~cm}^{3}$ (or $\mathrm{ml}$ ) $\mathrm{H}_{2} \mathrm{O} \mathrm{sec}$. Across the 3 lagoons the sponges down to $20 \mathrm{~m}$ filtered approximately $5.2 \mathrm{~m}^{3} \mathrm{H}_{2} \mathrm{O} \mathrm{sec}{ }^{-1}$ and had the potential to filter all of the moving water ( $<30 \mathrm{~m}$ depth) every 3-6 days. Of the six species recorded in this study, we found significant differences in the volume flux per unit area of sponge $\left(\mathrm{cm}^{2}\right)$ between massive and encrusting species but no difference in the volume flux per unit volume of sponge $\left(\mathrm{cm}^{3}\right)$. Most studies estimate filtration rates to examine and compare the physiological attributes of different species using units of total dry weight, organic dry weight and caloric content (e.g. Reiswig 1981, Ribes et al. 1999, Yahel et al. 2003, Peterson et al. 2006). This study based calculated extrapolations on area-based estimates $\left(\mathrm{cm}^{2}\right)$ of sponge filtration rates. Filtration rates based on area cover of sponges are more practical for ecological purposes because scaling up of values to estimate the impact of sponge assemblages is simpler. Also, because most of the sponges at Palmyra are encrusting species, estimating volumes accurately is difficult. Therefore, where massive species are in higher densities than encrusting ones; the amount of water filtered will be larger because they occupy the same area but the volume of the sponge is greater.

\subsubsection{Carbon removal}

The influence of sponge assemblages on ecosystems and their inhabitants has been relatively understudied compared to other sessile suspension feeders, such as molluscs. However, sponges have been shown to ameliorate phytoplankton blooms in the Florida Keys (Peterson et al. 2006) and remove considerable amounts of particulate organic carbon (POC) (the other portion making up TOC) in temperate waters (PereaBlázquez et al. 2012). Also, in reef framework cavities sponge assemblages can influence phytoplankton, picoplankton and nutrient levels (Richter et al. 2001). Sponges in crevices and caves are considered sinks for DOC (de Goeij et al. 2008) but their role at larger scales has not been examined. DOC removal on a daily basis in the lagoons at Palmyra appears to be negligible, however assuming an average residency time of the lagoons of 22 days, the sponges could be removing up to $19 \%$ of the DOC in the water column, thus making the lagoonal sponges an important sink for DOC. 
Although sponge recruitment and mortality were in equilibrium over the three year time period at Palmyra (see Chapter 3), it is unknown how stable the assemblages are over greater time periods. Theoretically, if sponge area cover increased to 50, 75 or even $100 \%$ on the available hard substrate (currently $27 \%$ ), the sponges could remove up to 32,47 and $63 \%$, respectively, of the available DOC, assuming a residency time of 22 days. Therefore, the sponges have great potential for removing considerable amounts of DOC, which is of particular interest to Palmyra because between four of the reefs in the Northern Line Islands (two of which are inhabited), the highest DOC levels were found on the reefs at Palmyra (Dinsdale et al. 2008). The source is unknown but could be due to upwelling, terrestrial run-off or the high proportion of autotrophic bacteria in the water column (Dinsdale et al. 2008). Blooms of plankton, as a source of DOC, have also been observed annually in Palmyra's lagoons around the end of June each year (authors pers. obs. from 2008 to 2010) until after October, with a subsequent drop in horizontal water visibility from 5-8 $\mathrm{m}$ to 1-3 $\mathrm{m}$. Therefore, the lagoon seems a plausible source of the high DOC values on Palmyra's reefs and if the sponges were ever removed, phytoplankton, DOC and bacterioplankton values could increase on the reefs. Knowing more about the trophic interactions and carbon flow across the atoll could therefore be important for its future management because the lagoon could be playing a key functional role in the carbon cycle of the atoll.

\subsubsection{Oxygen removal}

Whilst local oxygen depletion has been reported in conjunction with high sponge cover in consumption by sponges is low with only $3.3-10 \%$ of the oxygen pumped through the body being utilized (Jorgensen et al. 1986, Koopmans et al. 2010). I estimated that the sponges remove $0.36 \%( \pm 0.1) \mathrm{O}_{2}$ day $^{-1}$ and it would take 308 days $( \pm 66)$ to filter all of the oxygen out of the lagoon assuming no influx of oxygenated water, a relatively small fraction considering the hypoxia limits of organisms. Lethal and sublethal limits of hypoxia depend on the organism in question but are on average 4.6 and $5.0 \mathrm{mg} \mathrm{O}_{2} \mathrm{l}^{-1}$ for all marine organisms, respectively; however sublethal limits for cnidarians are far lower at $1.4 \mathrm{mg} \mathrm{O}_{2} \mathrm{l}^{-1}$ (Vaquer-Sunyer \& Duarte 2008). Tolerance levels between motile and sessile organisms are also significantly different; sessile fauna are more tolerant than motile ones, indicating an adaptation to lower oxygen conditions because of their lack of motility, so a coral's tolerance to hypoxia is generally much higher compared to fish (Vaquer-Sunyer \& Duarte 2008). 
The sponges in Palmyra's lagoons have the potential to remove $0.02 \mathrm{mg} \mathrm{O}_{2} \mathrm{l}^{-1} \mathrm{~d}^{-}$ ${ }^{1}$ and $0.44 \mathrm{mg} \mathrm{O}_{2} \mathrm{l}^{-1}$ over 22 days. Oxygen concentrations across the lagoons above 30 $\mathrm{m}$ are variable (see Gardner et al. 2011), but on average even after 22 days, assuming no water movement, all the sponges do not remove enough oxygen to reach sublethal limits for the majority of organisms. Therefore, I conclude that the likelihood of the sponges reducing oxygen levels in the water column to sublethal levels for corals is unlikely.

\subsubsection{Conclusions}

The lagoons at Palmyra were heavily modified by the US military during WWII resulting in reduced water flow. However, despite this, over the last 60 years sponges (including introduced species) now occupy almost a third of the hard substrate in the lagoons. At Palmyra the sponges filter the equivalent of all of the water in the lagoons $(<30 \mathrm{~m})$ every 3-6 days at a rate of $0.06( \pm 0.01) \mathrm{cm}^{3} \mathrm{~s}^{-1} \mathrm{~cm}^{-3}$ regardless of morphology, consuming up to $19 \%$ of the DOC and $8 \%$ of the oxygen in the lagoon water. Therefore, overall the sponges in the lagoons appear to be a sink for DOC, but do not remove considerable amounts oxygen suggesting that they may be playing a positive interactive role on the water column in the lagoons and currently do not appear to pose a threat to the adjacent reef via water column interactions. 


\section{Chapter 5}

\section{Origins of an invasive sponge to Palmyra Atoll (Haliclona caerulea), (order: Haplosclerida) are obscured by cryptic speciation}

\subsection{Abstract}

Globally, few coral reef atolls remain near-pristine, including and a number in the Central Pacific, which have altered lagoons making them vulnerable to species introductions. Introduced species can have major ecological impacts on recipient biota and ecosystems, so it is important to determine their introduction pathway to implement management strategies. Many species, however, have cryptic species making identification difficult. Cryptic speciation in particular is widespread across the phylum Porifera, a problem which is not easily resolved with morphological characteristics. This is particularly apparent in the widespread Haplosclerida order due to their limited and plastic micromorphological features. Therefore the best approach to confirm the introduction of Haplosclerida species across oceans is to use molecular markers. This study attempted to examine the reported introduction of Haliclona caerulea from the Caribbean to Palmyra Atoll via Hawai'i, but cryptic speciation complicated the findings. Based on morphologically identified samples, $H$. caerulea was collected from seven sites. One nuclear (18s rDNA) and three mitochondrial (CO1, the barcoding CO1 extension (ext) and $r n l$ rDNA) regions were sequenced and analysed using neighbour joining, maximum likelihood, and Bayesian inference. To determine between and within species level differences among subclades, sequence divergence values were ascertained based on the number of variable nucleotides in a sequence. Traditionally, spicules are used to identify species, so I also examined, at the site level, spicules lengths from Hawaiian and Palmyra samples. The micromorphological measurements failed to differentiate between groups; however, both mtDNA and nDNA phylogenetic trees supported similar topologies resolving two main clades from different orders: Halichondrida and Haplosclerida. Within the Haplosclerida clade, all individual gene regions (except the $\mathrm{CO} 1$ ext) showed no nucleotide differences between samples from all geographical regions. However, the concatenated mtDNA tree resolved twelve subclades corresponding to geographic locations, with the CO1 ext yielding most of the variability between the samples. Low sequence divergence values $(0.68 \%)$ between two of the Haplosclerida subclades indicated that the same species is found at Palmyra, 
Hawai' $i$ and the Caribbean, which supports the hypothesis that $H$. caerulea was introduced to Palmyra from the Caribbean. However, the pattern of fine-scale cryptic speciation complicates the introduction hypothesis, as it is not clear how many cryptic species there might be within those specimens considered to be $H$. caerulea. This study illustrates how understanding the scale of within species as opposed to between species level genetic variation is critical for determining the origins of introduced organisms.

\subsection{Introduction}

Cryptic species, which are morphologically indistinguishable from each other, have long been an problem for taxonomists and biologists across all biomes making estimates of biodiversity, and native and introduced species ranges difficult to measure (Bickford et al. 2007). The identification of a species is a basic, yet fundamental part of conservation and management (Ladner \& Palumbi 2012) but is complicated by the lack of distinct morphological traits in some groups. This problem is particularly apparent in members of the phylum Porifera, which are notoriously difficult to identify in the field due to their limited yet plastic morphologies in response to environmental variability (Wulff 2001). Poriferans are also ecologically important (Bell 2008a), and invasive species can pose significant threats to ecosystems (Coles 2007) as they are efficient spatial competitors (Bell \& Barnes 2003b, Wulff 2006) and can directly impact water column characteristics (Fu et al. 2006, Peterson et al. 2006; Chapter 6, Fu et al. 2007) through the removal of organic and inorganic particles, and nutrients (Gili \& Coma 1998). Therefore, it is important to identify introduced sponge species before any management plans can be implemented.

In marine, brackish and freshwaters worldwide there are 7,500 confirmed sponge species with an estimated 15,000 in total (Hooper \& van Soest 2002, van Soest et al. 2012). Some species long believed to be cosmopolitan, widely spread or introduced across several oceans have been revealed by molecular markers to be complexes of cryptic species (e.g. Klautau et al. 1999, Xavier et al. 2010). The issue of cryptic species identification is not only a taxonomic conundrum, because determining whether a species is introduced will affect management actions (Concepcion et al. 2010). This is particularly troublesome when it comes to sponges which are phenotypically plastic and difficult to identify in the field (Wulff 2001).

Morphological characteristics such as spicules and spongin architecture have classically been the primary focus in sponge taxonomy to identify species (Hooper \& 
van Soest 2002). However, morphological plasticity and the low number of phenotypic characteristics in sponges make consistent and accurate identification problematic (Wulff 2001). Therefore, genetic markers have become useful tools to identify divergent cryptic species and have revealed that the distribution ranges of many socalled "cosmopolitan species" have often been overestimated because they are not simply a single species (Boury-Esnault et al. 1992, Klautau et al. 1999, Hoshino et al. 2008). Confirming the identity of an introduced species is therefore the first step to studying its phylogeographic distribution and introduction pathway.

The class Demospongiae encompasses $85 \%$ of the known sponge species making it the largest, most diverse group in the phylum Porifera. The order Haplosclerida (Topsent 1928) is considered the most diverse group in this class and includes all freshwater species and a large number of shallow water marine sponges (van Soest \& Hooper 2002), although the monophyly of this class is still contentious (Redmond et al. 2011). The range of spicule types in the Haplosclerida is very limited (megascleres are either oxeas or strongyloxeas and the microscleres, if present, are sigmas, microxeas, microstrongyles or toxas) making classification difficult compared to some other sponge groups e.g. Tetractinellida and Calcispongia (Chombard et al. 1998, Manuel et al. 2003), which have more distinct morphological features. More recently, genetic analyses using a range of markers have been employed to examine interspecific phylogenies to resolve the order Haplosclerida, which is currently divided into 2 to 4 suborders, but there are still major discrepancies between the molecular markers as to how many suborders there are within the order (McCormack et al. 2002, Itskovich et al. 2007, Redmond et al. 2011). At the species level there have been a number of examples of taxonomic confusion, for example in the genus Haliclona, where multiple samples of the same species, H. oculata and H. cinerea, both had individuals (presumed to be the same species) which were subsequently found to be genetically distinct and distantly related according to $\mathrm{CO} 1$ and $18 \mathrm{~s}$ rDNA markers (Raleigh et al. 2007, Redmond \& McCormack 2008). Therefore, it is clear that there are taxonomic problems and a lack of resolution at all levels of the order Haplosclerida, which complicates phylogeographic studies because even species identification is difficult.

The initial aim of this study was to investigate the potential introduction of Haliclona caerulea (order Haplosclerida) to the Central Pacific from the Caribbean (DeFelice et al. 2001, Coles et al. 2006; Appendix I). It is thought that H. caerulea was 
introduced to Hawai' $\mathrm{i}$ and then onto Palmyra Atoll, a near-pristine atoll in the Central Pacific, via fouling on ships and yachts (Godwin 2003b; Appendix I) or other structures (e.g. barges) as this was the primary pathway of introduction to Hawai'i (Molnar et al. 2008), as Hawai'i has long been the predominant shipping connection to Palmyra (Dawson 1959; Appendix I). The limited larval dispersal capabilities of H. caerulea (to several meters) (Maldonado \& Young 1999) also suggests that the chances of this species naturally increasing its range from the Caribbean to the Central Pacific is unlikely. However, considering the limited micromorphologies of Haplosclerida species (Redmond et al. 2011), it is likely that there is undetected biodiversity (cryptic speciation) in this order, and it is at least possible that the sponge species in the lagoons at Palmyra are endemic as some suspected invasive species are actually not introduced. For example Concepcion et al. (2010) found that the invasive snowflake coral (Carijoa riisei), which overgrows black coral (Antipathes spp.) in Hawai'i was believed to be introduced from the Caribbean turned out to be an endemic species. Therefore confirming that the same species is found in the Caribbean, Hawai' $i$ and Palmyra will be important in developing future management plans for Palmyra. Therefore this study aimed to use molecular tools to identify whether the Caribbean species H. caerulea was introduced to Palmyra Atoll via Hawai'i or whether the regional populations represent cryptic species. Classical spicule (oxea) length measurements of $H$. caerulea from Palmyra and Hawai' $i$ were also examined to confirm whether morphological variability could be used to distinguish between the samples and test the utility of spicules to identify species or population differences. In order to examine the introduction hypothesis of $H$. caerulea to Palmyra from the Caribbean, four genes, both nuclear and mitochondrial, were examined: 18s rRNA, mtDNA rnl (large subunit rDNA) and the standard barcoding fragment, cytochrome oxidase subunit 1 (CO1) (Wörheide et al. 2007), along with the suggested extension, which is more variable and thought to provide greater resolution for intraspecific differences (Rot et al. 2006).

\subsection{Methods}

\subsubsection{Study species}

Haliclona caerulea (Hechtel 1965) (family Chalinidae), commonly known as the 'Blue Caribbean sponge', is found on rocks, dock pilings and mangrove roots in shallow water embayements, harbours and disturbed habitats, all with restricted water flow (Hechtel 1965, Cubit \& Williams 1983, Wulff 1997, De Weerdt 2000, DeFelice et 
al. 2001). This species is also known as Sigmadocia caerulea, Haliclona (Gellius) caerulea, and Haliclona (Soestella) caerulea, but here I use Haliclona caerulea. Haliclona caerulea is characteristically blue, but the morphology can alter when it forms a mutualistic relationship with the red branching coralline alga Jania adherens, which is visible in individuals from the Pacific Coast of Panama (Wulff 1997), Mexico (Carballo \& Avila 2004) and Palmyra Atoll (Appendix I). The megasclere spicules are bent oxeas, and the microscleres are C-shaped sigmas, which are less common throughout the purple mutualistic forms (Hechtel 1965).

\subsubsection{Sampling design}

In total 313 specimens were sampled from 7 locations in the Line Islands, Hawai' $i$ and the Caribbean. Samples were collected on SCUBA from Palmyra Atoll in the Line Islands and on snorkel in Hawai'i: Kāne‘ohe Bay, Ke'ehi Bay, Ala Moana and the Caribbean: St Thomas Island and St James Island in the US Virgin Islands and Puerto Rico (Fig 5.1 and Table 5.1), which at the furthest point are 10,572 km apart. All collected samples were of the blue colour morph with the exception of those from Palmyra, which were all purple with fragments taken from the base of the sponge where there is more blue sponge tissue compared to the associated $J$. adherens algae. On average 30-60 samples were collected from each location with the exception of Palmyra Atoll where 100 samples were collected and Ke'ehi Bay where only 10 specimens were collected (representing all those individuals found). To avoid sampling clones, individuals were collected at least $2 \mathrm{~m}$ apart from each other and stored in individual $2 \mathrm{ml}$ Eppendorf tubes. Immediately after collection, to reduce specimen atrophy, the seawater was replaced with dimethyl sulfoxide (DMSO), a saturated salt buffer for storage and a highly efficient storage solution for invertebrates, particularly in remote field locations (Dawson et al. 1998). 


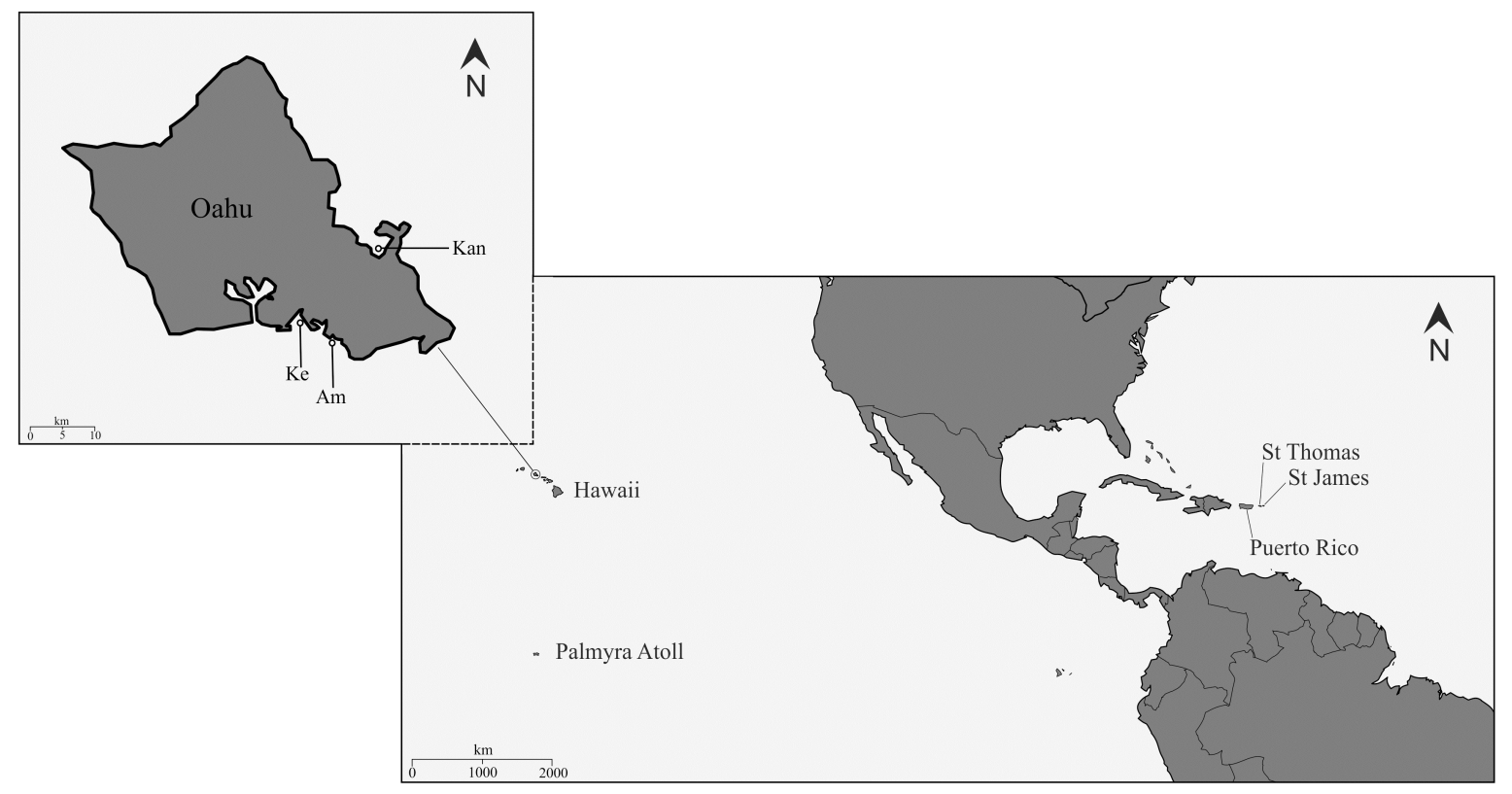

Figure 5.1 Map of the sampling locations for Haliclona caerulea in the Caribbean and Pacific along with the individual collection sites on O'ahu, Hawai'i: Ke'ehi Bay (Ke), Ala Moana (Am) and Kāne‘ohe Bay (Kan).

Table 5.1 Location, code IDs and numbers of sequences included in the final analyses of Haliclona caerulea samples.

\begin{tabular}{llllc}
\hline Sites & Code & Region & Latitude \& Longitude & $\mathrm{n}$ \\
\hline Ala Moana & $(\mathrm{Am})$ & Hawaii & $21^{\circ} 17^{\prime} \mathrm{N}, 157^{\circ} 50^{\prime} \mathrm{W}$ & 7 \\
Ke'ehi Bay & $(\mathrm{Ke})$ & Hawaii & $21^{\circ} 19^{\prime} \mathrm{N}, 157^{\circ} 53^{\prime} \mathrm{W}$ & 6 \\
Kāne'ohe Bay & (Kan) & Hawaii & $21^{\circ} 25^{\prime} \mathrm{N}, 157^{\circ} 47^{\prime} \mathrm{W}$ & 13 \\
St John Island & $(\mathrm{StJ})$ & Caribbean & $1^{\circ} 19^{\prime} \mathrm{N}, 64^{\circ} 44^{\prime} \mathrm{W}$ & 7 \\
St Thomas Island & $(\mathrm{StT})$ & Caribbean & $18^{\circ} 18^{\prime} \mathrm{N}, 64^{\circ} 54^{\prime} \mathrm{W}$ & 3 \\
Puerto Rico & $(\mathrm{PR})$ & Caribbean & $18^{\circ} 17^{\prime} \mathrm{N}, 67^{\circ} 12^{\prime} \mathrm{W}$ & 5 \\
Palmyra Atoll & $(\mathrm{PA})$ & Line Islands & $0^{\circ} 53^{\circ} \mathrm{N}, 162^{\circ} 5^{\prime} \mathrm{W}$ & 15 \\
Total & & & & $\mathbf{5 6}$ \\
\hline
\end{tabular}

\subsubsection{DNA extraction and PCR amplification}

The sponge samples were extracted using a Qiagen DNeasy Tissue Kit following the manufacturers protocol. After initial screening with twenty one primer sets from Jarman et al. (2002) and Redmond et al. (2007), four regions were successfully sequenced and all samples were screened with these primers. The primer regions included three mitochondrial regions: $\mathrm{CO} 1$ and $\mathrm{CO} 1$ extension (ext) (mtDNA) and $r n l$ (rDNA) and the nuclear region 18s (rDNA) (see Table 5.2). CO1 is one of the three protein coding subunits in the cytochrome c oxidase complex involved in aerobic metabolism and $r n l$ is a large ribosomal subunit (one of the two) in the metazoan mitochondrial DNA (the other is the small subunit $r n s$ ) (Boore 1999). 18s is found in the small subunit 40 s of eukaryotic ribosomal RNA. 
Table 5.2 Primers used in the PCR and sequencing of Haliclona caerulea samples.

\begin{tabular}{llll}
\hline Primer name & Region & Primer sequence $\left(5^{\prime}-\right.$ 3') $^{\prime}$ & Reference \\
\hline dgLCO1490 & CO1 & GGT CAA CAA ATC ATA AAG AYA TYG G & Meyer et al., (2005) \\
dgHCO2198 & & TAA ACT TCA GGG TGA CCA AAR AAY CA & \\
COX1-R1 & CO1 ext & TGT TGR GGG AAA AAR GTT AAA TT & Rot et al., (2006) \\
COX1-D2 & & AAT ACT GCT TTT TTT GAT CCT GCC GG & \\
diplo-rnl-f1 & rnl & TCG ACT GTT TAC CAA AAA CAT AGC & Lavrov et al., (2008) \\
diplo-rnl-r1 & & AAT TCA ACA TCG AGG TSG GAA AC & \\
18s_1-600_F2 & \multirow{2}{*}{$18 \mathrm{~s}$} & GCC AGT AGT CAT ATG CTT GTC TCA & This paper* \\
18s_1-600_R1 & & GAC TTG CCC TCC AAT TGT TC & \\
\hline *modified from Redmond et al., (2007) &
\end{tabular}

Due to difficulties in sequencing, instead of using the standard barcoding CO1 region from Folmer et al. (1994) I employed the degenerate primers developed by Meyer et al. (2005). Also, due to the lack of variability in the standard CO1 region in sponges (Duran \& Rützler 2006, Wörheide 2006), I sequenced the suggested downstream extension region described by Rot et al. (2006), which includes an intron and has higher substitution rates (Erpenbeck et al. 2006). After alignment and trimming, the final sequence lengths were 554 and 318 base pairs (bp) for $\mathrm{CO} 1$ and CO1 ext, respectively. The Porifera-optimized primers diplo-rnl-f1 and diplo-rnl-r1 described by Lavrov et al. (2008) were used to amplify the mitochondrial $r n l$ ribosomal RNA region $(\approx 700 \mathrm{bp}$ ), of which $311 \mathrm{bp}$ were examined in this study. The $18 \mathrm{~s}$ rRNA region is approximately 1,800 nucleotides long in Haplosclerida sponges (Redmond \& McCormack 2008) and this study examined the first 407 bp after multiple sequence alignment and trimming.

PCR amplifications were performed in $15 \mu 1$ reactions consisting of: $8.5 \mu 1$ nanopure $\mathrm{H}_{2} \mathrm{O}, 1.5 \mu 1$ 10x NH $\mathrm{N}_{4}$ buffer, $0.45 \mu \mathrm{MgCl}_{2}, 0.30 \mu \mathrm{dNTP}$ 's (10 mM), $2.0 \mu 1$ 40x bovine serum albumin (BSA), $0.1 \mu \mathrm{l} \mathrm{Taq}$ polymerase (Biolase, Bioline), $0.075 \mu 1$ of each primer and $2 \mu 1$ of DNA template with the following temperature profile: $95{ }^{\circ} \mathrm{C}$ for $3 \mathrm{~min}$, followed by 35 cycles at $94{ }^{\circ} \mathrm{C}$ for $30 \mathrm{~s}, 58^{\circ} \mathrm{C}(\mathrm{rnl}$ and $\mathrm{CO} 1)$ or $50^{\circ} \mathrm{C}(18 \mathrm{~s})$ for $45 \mathrm{~s}, 72{ }^{\circ} \mathrm{C}$ for $45 \mathrm{~s}$ and a final extension step at $72{ }^{\circ} \mathrm{C}$ for $10 \mathrm{~min}$. The PCR products were then purified using ExoSAP-IT (USB Corporation) and sequenced using BigDye Terminators (PerkinElmer) at the EPSCoR core genetics facility at the Hawai' $i$ Institute of Marine Biology on a ABI-3130XL automated sequencer. 


\subsubsection{Data analysis}

All sequences were evaluated and aligned using Geneious Pro (v.5.3.6) (Drummond et al. 2011). The poriferan origin of the sequences was confirmed using the BLAST search engine in GenBank. For all data-sets, the outgroup taxon was Amphimedon queenslandica, also from the order Haplosclerida (van Soest \& Hooper 2002). Those samples that did not produce comparable sequences across all regions, despite several attempts at sequencing, were removed. Simple Neighbour joining (NJ) trees (in Mega5 (Tamura et al. 2011) with a p-distance model, pairwise deletion of gap positions and 1,000 bootstrap replicates) were then produced to provide an initial overview of the data for each region. The number of samples where then reduced to improve the visualization of results and reduce analysis time while still representing the genetic diversity between samples, with up to 5 identical individuals selected per tree grouping per region resulting in 56 samples across all locations (see Table 5.1).

The mitochondrial regions (CO1, CO1 ext and $r n l)$ for all 56 samples were then examined separately to determine if there were major differences in topologies between regions. The results indicated that there were no major conflicts in topology (Fig 5.2); therefore the mitochondrial regions were additionally concatenated to form a total evidence tree for the mtDNA to increase the resolution of information. To determine within and between species level differences between the subclades, the pairwise percent sequence divergence $(\mathrm{P})$ (see Table 5.3) was calculated for all gene regions in MEGA5 as the proportion of variable nucleotide sites in each alignment. 


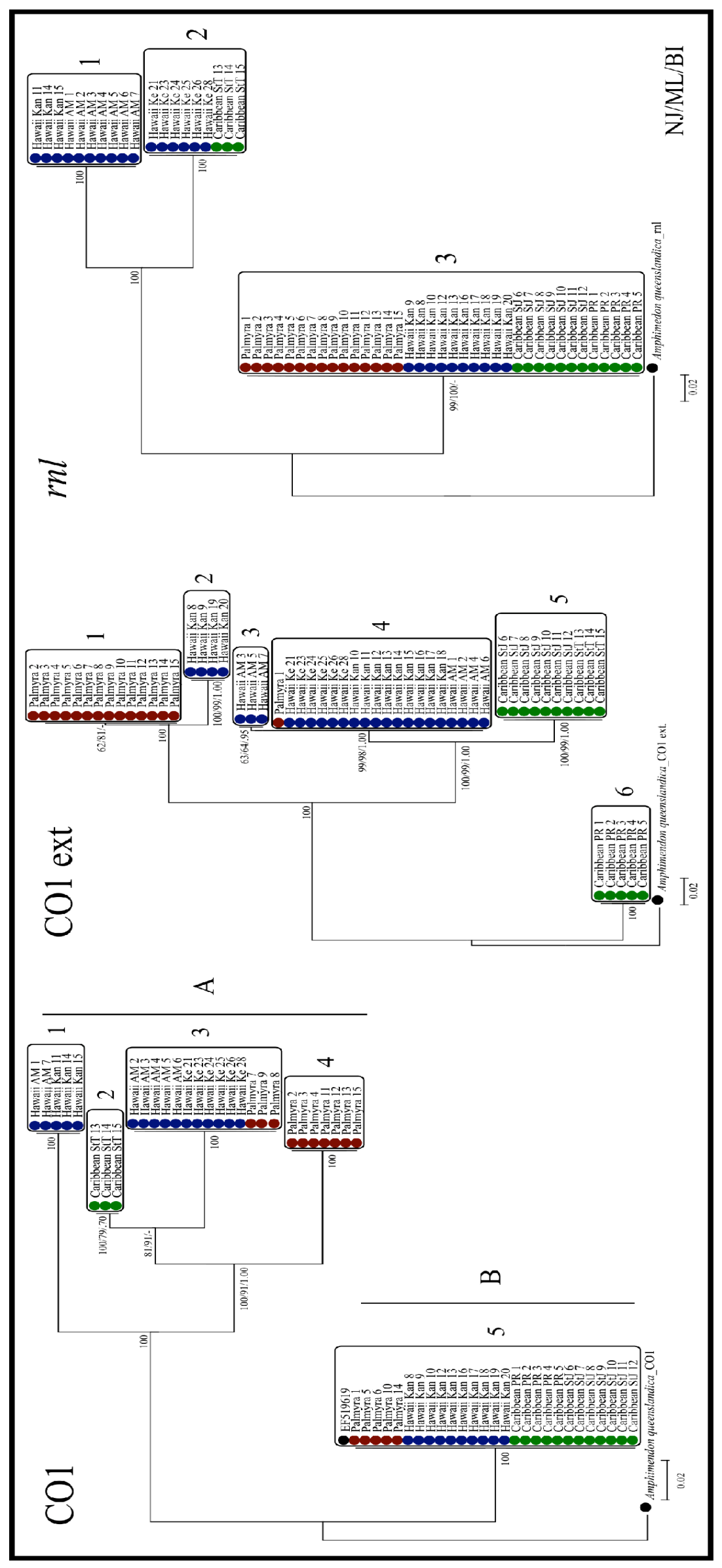

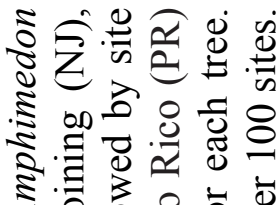

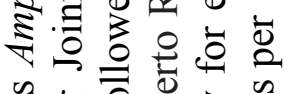
- $\frac{0}{0} \overline{0} \stackrel{0}{0} \approx$ की

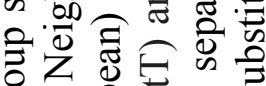

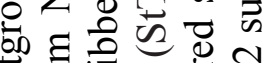

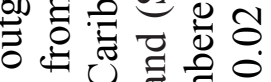

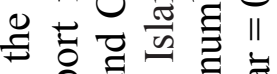
들 चै चै

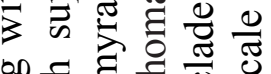
o.

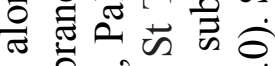
凹

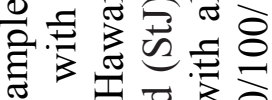

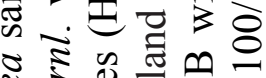
ฐ)

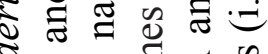

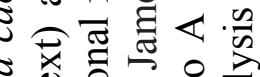

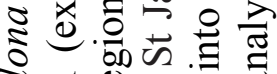
ธี

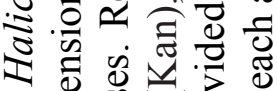

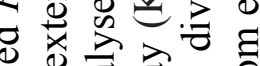

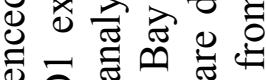

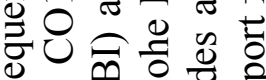
舟 ஸेष

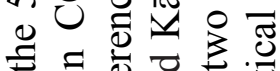
‡ิ फั0.0

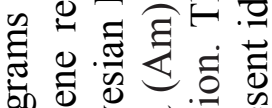

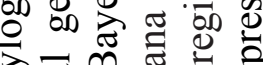

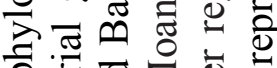

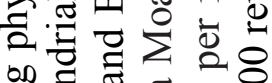

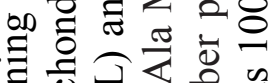

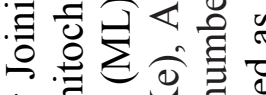
$\exists$ 记声 官

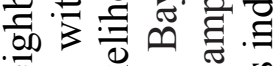
एक 0 : $=$

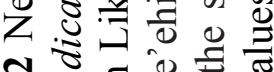
กำ

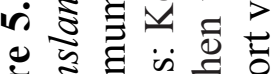

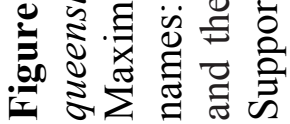


Table 5.3 Total number of base pairs (bp), samples (n), haplotypes (H) and pairwise per site, per alignment percentage sequence differences $(\mathrm{P})$ for each sampling location and across all samples. ext $=$ extension region.

\begin{tabular}{llcccc}
\hline Sites & Gene & Total length $(\mathrm{bp})$ & $\mathrm{n}$ & $\mathrm{H}$ & $\mathrm{P}(\%)$ \\
\hline Palmyra Atoll & CO1 & 554 & 15 & 3 & 27 \\
& CO1 ext & 318 & 15 & 2 & 11 \\
& rnl & 366 & 15 & 1 & 0 \\
& mtDNA & 1182 & 15 & 4 & 16 \\
& nDNA & 407 & 15 & 3 & 11 \\
Hawaii & CO1 & 554 & 26 & 3 & 31 \\
& CO1 ext & 318 & 26 & 3 & 15 \\
& rnl & 366 & 26 & 3 & 27 \\
& mtDNA & 1182 & 26 & 6 & 27 \\
Caribbean & nDNA & 407 & 26 & 3 & 13 \\
& CO1 & 554 & 15 & 2 & 20 \\
& CO1 ext & 318 & 15 & 2 & 19 \\
& rnl & 366 & 15 & 2 & 22 \\
& mtDNA & 1182 & 15 & 3 & 21 \\
All sequences & nDNA & 407 & 15 & 3 & 10 \\
& CO1 & 554 & 56 & 5 & 32 \\
& CO1 ext & 318 & 56 & 6 & 27 \\
& rnl & 366 & 56 & 3 & 27 \\
& mtDNA & 1182 & 56 & 12 & 31 \\
& nDNA & 407 & 56 & 6 & 14 \\
\hline
\end{tabular}

Phylograms were created separately for each region (CO1, CO1 ext, rnl and $18 \mathrm{~s}$ ) as well as the concatenated mitochondrial region with NJ, Maximum Likelihood (MP) and Bayesian inference (BI) values supporting branch topologies. Maximum likelihood trees were generated by MEGA5 using the Nearest-Neighbour Interchange (NNI) heuristic method with gaps included at all sites and 1,000 bootstrap replicates. Neighbour Joining trees were also estimated by MEGA5 with the same conditions as described above. Bayesian analyses were conducted by MrBayes v3.1.2 (Ronquist \& Huelsenbeck 2003) using the Markov Chain Monte Carlo (MCMC) analyses (Geyer 1991) for 300,000 generations, sampling 4 chains every 300 generations with the first 250 trees $(75,000$ generations $)$ discarded at the burn-in period. All trees were based on the NJ topology and drawn by MEGA5.

To determine the best-fit nucleotide substitution model for each data set, corrected Akaike information criterion (AICc) model selections were performed by jModelTest v2.0 (Posada \& Crandall 1998). The jModelTest results identified Hasegawa, Kishino and Yano HKY +G (Gamma) models for both CO1 regions and HKY for the $r n l$ region as the best fitting prior models of evolution. Tranversion (TVM $+\mathrm{G}$ ) and transitional models (TIM2ef $+\mathrm{G}$ ) were selected for the concatenated mitochondrial and nuclear data sets, respectively. However, for the Bayesian and 
Maximum likelihood analyses, TVM and TIM models were not available in MrBayes and MEGA5, therefore a General Time Reversible (GTR) model with Gamma rates (G) was used as it is the closest to the suggested models from jModelTest (Posada \& Crandall 2001, Zakharov et al. 2009).

One voucher specimen sequence of the CO1 region (no extension) for $H$. caerulea from the Caribbean (ID\# EF519619) (Erpenbeck et al. 2007) was found in GenBank and included in the analyses in order to confirm the identification of $H$. caerulea based on the sponge barcoding basic region.

\subsubsection{Spicule analyses}

To identify any local site level morphological differences between specimens ,the oxea lengths from the Hawaiian and Palmyra atoll samples (Fig 5.1) were measured using ImageJ (Abràmoff et al. 2004) based on photographs taken under a light microscope. To prepare the samples, a $2 \mathrm{~mm}^{3}$ fragment was taken from each specimen and placed in a $1 \mathrm{ml}$ Eppendorf tube filled with sodium hypochlorite to remove the tissue and leave only the silicate spicules. After 24 hours, the samples were rinsed with distilled water three times. The samples were then vortexed and a drop of water and spicules was pipetted onto a slide, with a cover slip and a drop of oil. Thirty to forty spicules were photographed under the microscope with the thirty clearest photos measured. A non-metric Multidimensional Scaling (nMDS) ordination (Anderson 2001) was executed on the Bray-Curtis similarity matrix to visualise the spicule length size groups, which was performed in PRIMER v6 (Clarke \& Gorley 2006) with the PERMANOVA+ add-on (Anderson et al. 2008).

\subsection{Results}

\subsubsection{Individual regions}

When examining the $\mathrm{CO} 1, r n l$ and 18 s regions (excluding the $\mathrm{CO} 1$ extension) two clades were evident (Fig 5.2). The CO1 region identified five subclades with the voucher sample from Erpenbeck et al. (2007) nesting within clade B, which includes samples from all the sites, excluding St. Thomas. When examining the subclades in clade A with the barcoding region in the BLAST search engine, I found that the samples were most similar to Halichondria spp. (order: Halichondrida), while clade B was most similar to Haplosclerida species. Further resolution of clade B was not possible with the $\mathrm{CO} 1$ marker or the $r n l$ region as all sequences were identical. The 
CO1 extension resolved clade B more than any other marker (except the concatenated mtDNA region) resulting in 6 subclades in total with the subdivisions more consistent with geography than the other gene region.

The nuclear 18s marker was most congruent with the $\mathrm{CO} 1$ region indicating 6 groups in total; however, although the St James subclade (group 6) splits off it is not significantly supported by the NJ or ML analyses and when looking between samples there is only $1 \mathrm{bp}(0.3 \%$ sequence divergence) difference between groups 5 and 6 . Therefore the $18 \mathrm{~s}$ nDNA region is more similar to the $\mathrm{CO} 1$ and $r n l$ regions, indicating one Caribbean group, which is in sharp contrast to the $\mathrm{CO} 1$ ext, which splits off the Puerto Rican samples, which had a 60 bp difference (19\% sequence divergence).

\subsubsection{Concatenated mtDNA versus $n D N A$}

There were no major discrepancies between the mtDNA and nDNA regions, (Fig 5.3) supporting two major clades (Halichondrida and Haplosclerida spp.) subdivided into a number of different terminal groups, all supported by congruent significant values from the NJ, ML and BI analyses. Therefore, the different analyses are in agreement, indicating that the trees provide a relatively robust visualisation of the data. The concatenated mtDNA tree was the most resolved, with the $\mathrm{CO} 1$ ext providing most of the polymorphism, yet not distinguishing all subclades. Overall the concatenated tree (mtDNA tree) revealed that there is fine-scale cryptic speciation that correlates to geographic differences. The mtDNA tree revealed a similar topography to the nDNA indicating two main clades, but with better-resolved subclades. The percentage sequence divergence between sites (see Table 5.3), however, was the lowest with nDNA (14\%) compared to the mtDNA (31\%) for all locations revealing slower rates of sequence evolution in the nDNA marker. Sequence divergence values also revealed both within and between species level differences among the Haplosclerida subclades. The only subclade in the mtDNA tree with samples from more than one geographic region was group 10 in clade $\mathrm{B}$, which contained both Palmyra and Hawaiian samples. The next closest subclade (11) grouped Caribbean samples from St James Island, which had only $0.68 \%$ sequence divergence ( $8 \mathrm{bp}$ different, all from the CO1 ext region) compared to subclade 10 (containing Palmyra and Hawai'i samples) also suggesting that are effectively the same species. The remaining subclades in clade $\mathrm{B}, 8,9$ and 12 had sequence divergence values of 4.0, 3.0 and $4.9 \%$ respectively, which may correspond to congeneric species-level differences, or populations that are highly 
isolated. Overall, between all subclades in clade B the sequence divergence was $7.5 \%$ but $22.8 \%$ between all samples in clade A, suggesting that samples within clade B were more closely related and less divergent. The clades or individual subclades could not be identified further as the Genbank database is currently not comprehensive enough to provide such information. 


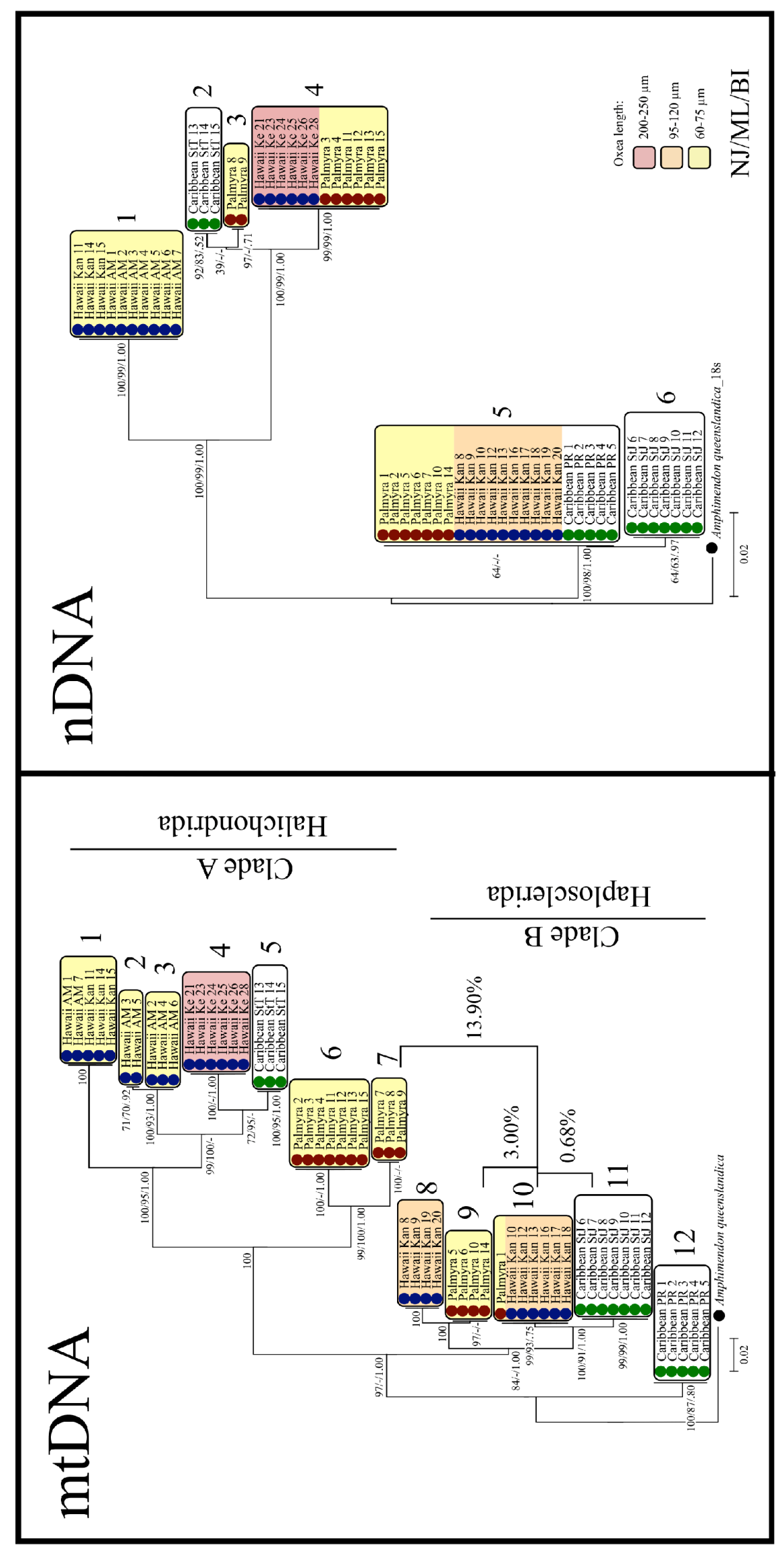

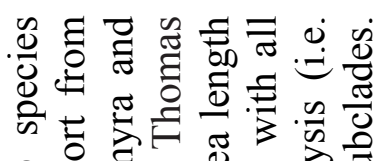

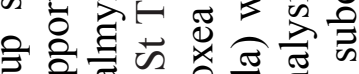

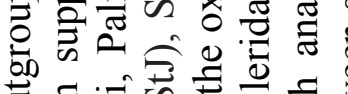

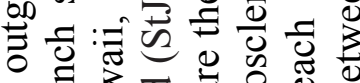

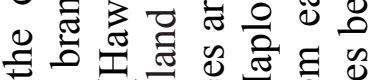

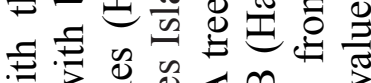

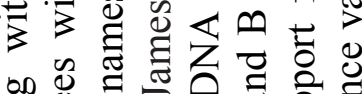

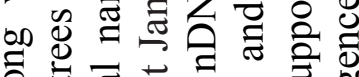
훙

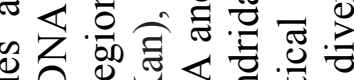

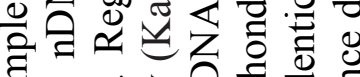

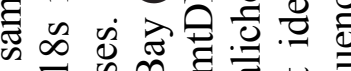

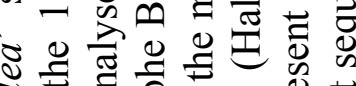

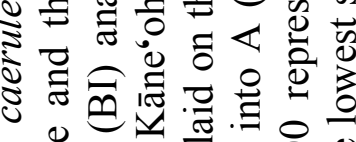

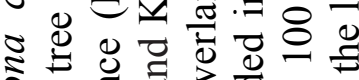
४ 记

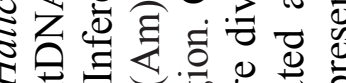

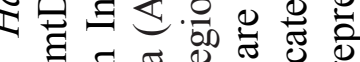
o . ज :

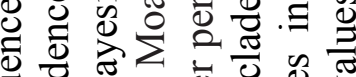

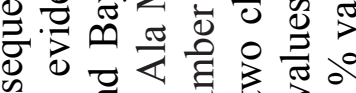
क

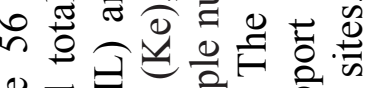

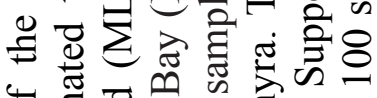
पे 뭉 की की

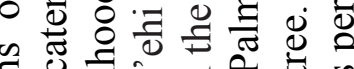

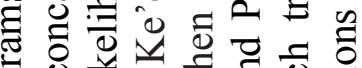
50.40 웡

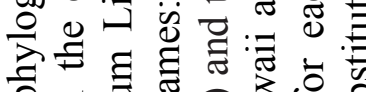

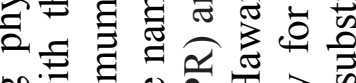
on

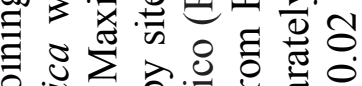

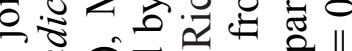

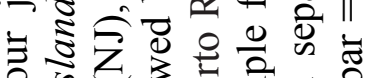

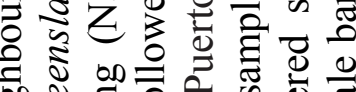
क0

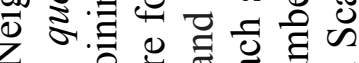

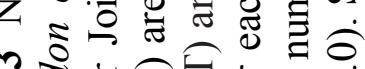

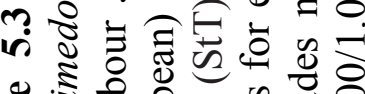

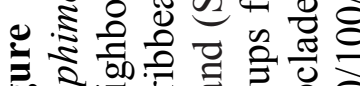

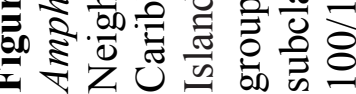




\subsubsection{Morphological characteristics}

The spicule length data formed three size classes: $60-75 \mu \mathrm{m}, 95-120 \mu \mathrm{m}$ and 200-250 $\mu \mathrm{m}$, as indicated in the nMDS plot (Fig 5.4). The size classes when overlaid on the topographical trees revealed polyphyletic groups that were not consistent with the molecular data, including within subclades, with the exception of group 4 in the mtDNA tree, which confirmed that the Ke'ehi Bay individuals were significantly different from all other locations.

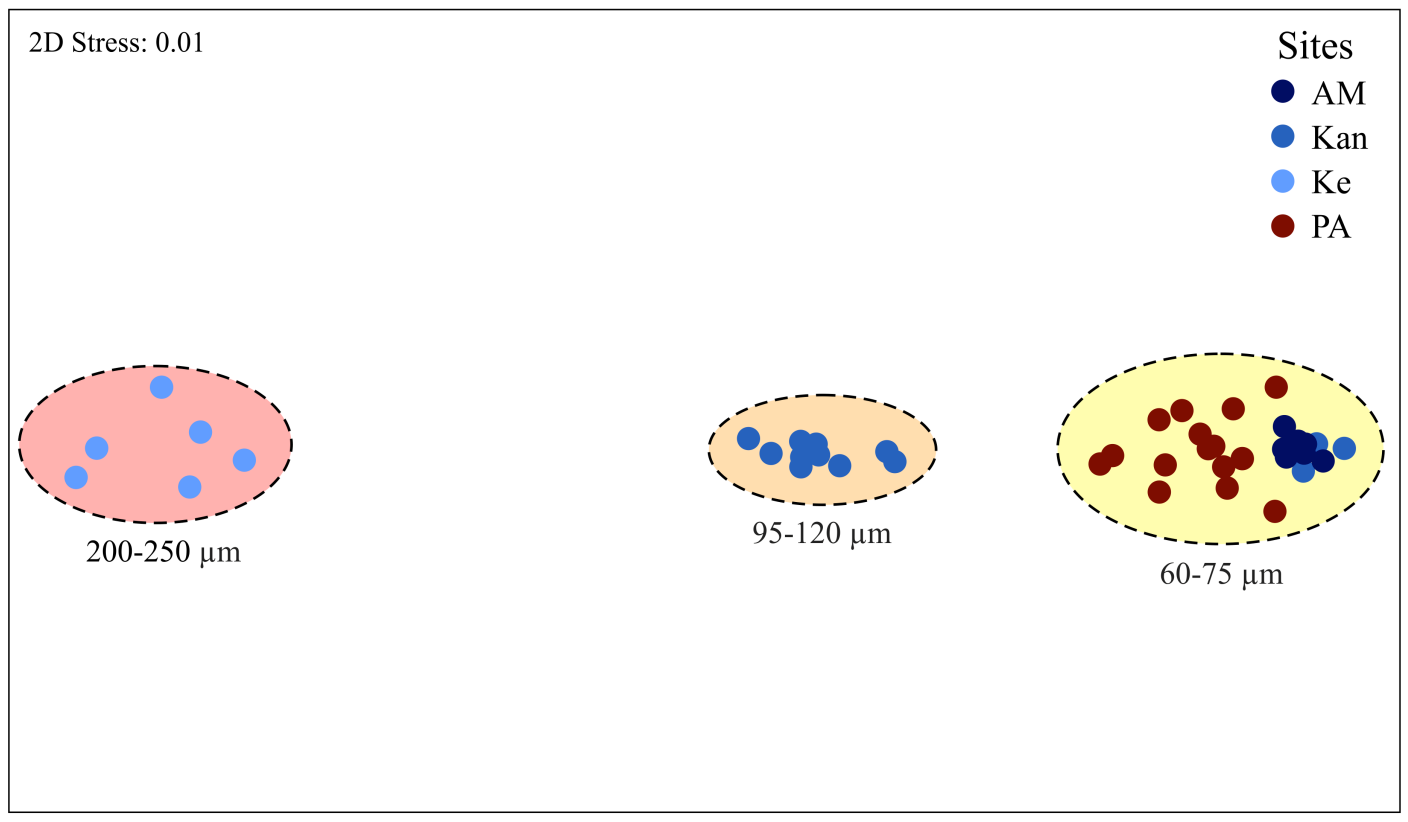

Figure 5.4 Non-metric multidimensional scaling (nMDS) ordination visualising grouped sponge oxea lengths $(\mu \mathrm{m})$ over sites Ke'ehi Bay $(\mathrm{Ke})$, Ala Moana (Am) and Kāne'ohe Bay (Kan) from Hawai'i and from Palmyra Atoll (PA) based upon a zeroadjusted Bray-Curtis similarity matrix.

\subsection{Discussion}

Cryptic speciation is a major problem when trying to understand the introduction of a species (Bickford et al. 2007) and can be particularly difficult when working with sponges, which are often difficult to identify in the field (Wulff 2001). Haplosclerida sponges are considered a taxonomically difficult order because of the low variability in morphological characteristics, but high levels of macromorphological plasticity; recent phylogenetic investigations suggests that this order needs revision at all taxonomic levels (Redmond et al. 2011). In particular, examining species level differences in this order is fraught with difficulties, including cryptic speciation and problems defining within or between species level differences (Raleigh et al. 2007, 
Redmond \& McCormack 2008). Establishing the level of within and between species differences between locations will determine whether a species is introduced (one species spread across several locations) or endemic (multiple species in their own locations). Therefore confirming the identity of a species is important when considering the management of potential introductions to non-endemic locations such as Haliclona caerulea to the isolated and near-pristine Palmyra Atoll (Appendix I).

This study found molecular evidence to indicate that $H$. caerulea is found at Palmyra Atoll, Hawai' $i$ and the Caribbean; however, cryptic speciation complicates phylogeographical relationships between sampling regions. Overall, three of the four gene regions ( $\mathrm{CO} 1, r n l$ and $18 \mathrm{~s}$ ) provided low resolution between the samples and broadly grouped individuals into two order level clades (Halichondrida and Haplosclerida) (Fig 5.2 and 5.3) with almost no sequence divergence within the Haplosclerida clade B. Inclusion of the micromorphological characteristics did not improve the data resolution. Only the CO1 ext and the mtDNA trees increased the resolution within the Haplosclerida samples and revealed further evidence for cryptic speciation with up to twelve subclades that corresponded to geographic locations. Despite the high levels of cryptic speciation in the Haplosclerida clade (B), sequence divergence values revealed evidence of within species differences between the Caribbean, Hawai'i and Palmyra Atoll, which supports the hypothesis of introduction of $H$. caerulea to Palmyra via human transportation.

\subsubsection{Gene regions}

This study found considerable genetic variability within three mitochondrial and one nuclear DNA markers when examining samples of apparently morphologically similar H. caerulea and found that the two mtDNA markers, CO1 and rnl, provided the lowest resolution. Mitochondrial genes have long been used to study population genetics along with the identification of species because they have high mutation rates, shorter coalescence times and recombination is rare (an issue with nDNA) (Avise 2000a, Lavrov 2007). The sponge barcoding project uses the CO1 region as its basic identification region (Wörheide et al. 2007) and has been used successfully to resolve some sponges down to species level (e.g. Pöppe et al. 2010). However, often in sponges (and other non-bilaterians e.g. Cnidarians) the mutation rate in the mitochondrial genes is too slow to determine population structure or even species differences (Shearer et al. 2002, Duran et al. 2004b, Wörheide 2006). The issues regarding the use of 
mitochondrial regions are evident in the low resolution of the $r n l$ and $\mathrm{CO} 1$ trees. Therefore, the sponge barcoding project suggests the inclusion of a extension region to aid in the differentiation between species (Rot et al. 2006). In this study the CO1 extension provided the most resolved tree out of the 4 individual regions examined therefore supporting the use of this "add-on" in conjunction with the established barcoding region for identification of sponges down to species level. However, overall the best resolution was provided by the concatenated mtDNA tree, which had high support values for each subclade despite the disparity between individual regions, which if examined alone (Fig 5.2) may have resulted in different conclusions about the species identification between samples.

Classically, 18s rDNA is also slowly evolving and therefore used to resolve higher taxonomic levels (Peterson \& Addis 2000, Borchiellini et al. 2001), generally making it unsuitable for resolving finer population structure (Wörheide et al. 2002a, Wörheide et al. 2002b). When looking at the number of variable sites in H. caerulea the sequence divergence in the mtDNA was approximately 2 times higher compared to the 18s nDNA, an observation also noted by Lavrov et al. (2005), who found sequence divergence to be 4.3 times greater in mtDNA compared to nDNA in the sponges Geodia neptuni and Tethya actinia. The low sequence diversity in this $18 \mathrm{~s}$ region concurs with my findings and is most likely due to higher divergence in mtDNA compared to $18 \mathrm{~s}$ nDNA in sponges. The low level of polymorphisms in most mtDNA regions is consistent with other studies (Hudson et al. 1987, Shearer et al. 2002, Duran et al. 2004b); however, the relatively high levels of polymorphism in the CO1 ext offer a stark contrast.

The variable power of resolution between markers in this study is most likely due to different evolutionary pressures on each region resulting in varying levels of polymorphism and phylogenetic resolution between markers. For example, there is a disparity between the Palmyra samples, which group predominantly into one clade with the $\mathrm{CO} 1$ ext and $r n l$ or two with the $\mathrm{CO} 1$ and $18 \mathrm{~s}$ regions suggesting different mutational pressures or evolutionary histories acting on the different genetic markers. Genetic recombination is a possible explanation for these results; however it is rare in mitochondrial DNA and therefore unlikely to explain this pattern (Solé-Cava \& Wörheide 2007). Mitochondrial pseudogenes, which result in non-functional copies of the mtDNA in the nDNA being sequenced, could also result in the sequencing of mtDNA of an ancestral origin (Bensasson et al. 2001) and a division of the Palmyra 
samples into multiple subclades as seen in the CO1 tree. However, this is also an unlikely explanation of non-monophyly of the Palmyra samples with the CO1 marker, as the nDNA topology was broadly similar (Fukami et al. 2008). Natural selection may also result in different evolutionary pressures on particular regions, unfortunately most tests for selection or neutrality compare synonymous to nonsynonymous nucleotide substitutions, which is not applicable to the CO1 extension, since it is a an intron and not a protein coding gene. Concatenating the mtDNA data resulted in a topology with high support values, which concurs with the nDNA but with higher resolution. This suggests that the data partitions are generally congruent and minor topological differences are primarily due to comparing highly conserved genes that lack phylogenetic resolution with an intron under relaxed selection pressures.

\subsubsection{Cryptic speciation within H. caerulea}

The genetic data indicate several hierarchical levels of cryptic speciation, which limits any interpretation of any phylogeographical findings because of the taxonomic difficulties. Initially, the CO1 data suggest at least two groups from the orders Halichondrida (clade A) and Haplosclerida (clade B), which have large geographic distributions and subpopulations, as individuals from all regions were found in both clades. However, the concatenated mitochondrial tree revealed that there may be up to 12 different isolated species (corresponding with the 12 geographic subclades). It is more likely that there are greater rather than fewer species due to the high support values for each of the subclades and number of substitutions.

Focusing on the target Haplosclerida order, the concatenated mitochondrial tree indicates that the same species is found at Palmyra Atoll and Hawai' $i$, with samples from both grouping in subclade 10 with $100 \%$ similarity over the $1,182 \mathrm{bp}$ sampled. The Caribbean and Palmyra samples are very closely related with only $0.68 \%$ (8bp) divergence between groups 10 and 11. Huang et al. (2008) found that the intraspecific differences for sponges (taken from all CO1 sequences in GenBank in September 2006) were $0.60 \%( \pm 0.10)$ and $3.76 \%( \pm 0.57)$ for the closest congeneric interspecific distances. The percentage of divergence between groups 10 and 11 may therefore suggest that these subclades are from the same species. Looking at the next closest subclades to the Palmyra-Hawaiian group, 8, 9 and 12 had divergence values of 4.0, 3.0 and $4.9 \%$ respectively, indicating that samples in subclades 8 and 9 are consistent with cryptic congeneric species-level differences. However, Huang et al. (2008) focused on 
sequences from the $\mathrm{CO} 1$ region in the analyses, most likely excluding the extension region identified by Rot et al. (2006) as the sequence data were collected before the publication of this study. In this study, with the $\mathrm{CO} 1$ marker there was $0 \%$ difference between the clade B samples, which included samples from all locations. However, but it was the $\mathrm{CO} 1$ extension which provided the greatest resolution of the data, which may have resulted in the higher values found between sequences in the concatenated tree. Therefore, it is unclear what the true species boundaries are between the sublclades in clade B. When looking at the sequence divergence between the subclades 10 (clade B) and 6 (clade A) there is $13.9 \%$ difference between these groups, which supports the premise that these cryptic taxa represent higher level, distantly related taxonomic divisions (perhaps at the order level) that are presently morphologically indistinguishable from H. caerulea.

Although the possibility that $H$. caerulea is endemic but previously unrecognised in Palmyra cannot be entirely ruled out, it is exceedingly unlikely to observe such shallow geographic diversification across approximately $10,000 \mathrm{~km}$, since H. caerulea larvae cannot travel far (Maldonado \& Young 1999) without human transportation (DeFelice et al. 2001). Therefore it seems likely that H. caerulea has been transported to Palmyra Atoll from the Caribbean via Hawai'i. Unfortunately due to the high level of genetic variation among samples the data are not sufficient to draw any conclusions on connectivity patterns between the sampling regions. It therefore remains unknown whether $H$. caerulea was introduced just once or on multiple occasions. The overall large number of subclades may be partially explained by rapid diversification due to selection on the $\mathrm{CO} 1$ ext intron, however since rates of mtDNA evolution are low in sponges (Shearer et al. 2002, Duran et al. 2004b, Wörheide 2006), it is more likely that there were multiple introductions of diverse populations or closely related species from as of yet unsampled geographic locations in the Caribbean, which can be resolved in the future with additional geographic sampling.

\subsubsection{Using morphological characteristics to identify H. caerulea}

The spicule lengths grouped by the nMDS ordination (Fig 5.4) were not congruent to the tree topologies and did not help explain the variability between groups with the exception of the Ke'ehi Bay samples, which were distinctly longer (200-250 $\mu \mathrm{m})$ than for all other locations. DeFelice et al. (2001) noted that H. caerulea's oxeas in Hawai'i were 170-230 $\mu \mathrm{m}$ long and Cruz-Barraza and Carballo (2008) identified 
lengths of $82-210 \mu \mathrm{m}$ in Mexico, while the original description by Hechtel (1965) found that the oxea lengths in Jamaica varied between 117-200 $\mu \mathrm{m}$ depending on a location's water flow rates. Therefore we can assume that the micromorphology of Haplosclerida species is not a suitable tool for identification because it is either highly dependent on environmental conditions, has homoplastic non-distinct morphological features or both. Unfortunately, the Haplosclerida micromorphological traits may not even be useful on the order level as some Halichondrida species have similar oxeas to those seen in Haplosclerida (Erpenbeck \& Soest 2002), which explains the lack of morphological resolution found in this study.

\subsubsection{Conclusions}

Understanding the scale of differentiation between samples (within and between species) is important to ascertain with regard to the management of introduced species particularly those which exhibit cryptic speciation and morphological plasticity. This study found surprising levels of genetic subdivision corresponding to geography; however, it is possible to suggest that there has been a movement of species across the Pacific with the same species found at Palmyra Atoll, Hawai'i and possibly even the Caribbean. This study forms a foundation for further exploring newly discovered cryptic speciation and it provides an example of why it is important to do so. 


\section{Chapter 6}

\section{General Discussion}

The overall aims of this thesis were to examine the sponges in the WWII modified lagoons at Palmyra Atoll, and to establish their diversity (specifically NIS), impacts on the water-column and potential to extend onto the adjacent near-pristine reef. In summary, sponge diversity at Palmyra is similar to other atoll systems in the Pacific and includes non-indigenous species presumably introduced by ships. Based on the results of my thesis, I propose that the sponges in the lagoon are unlikely to extend onto the reef because: a) the environmental conditions in the lagoons are preferred; b) the assemblages appear temporally stable with sponge mortality and recruitment in equilibrium and c) their current distribution suggests that they can disperse effectively against the predominant water flow direction, but still have not extended onto the reefs. Also the impacts of the sponges on the water column appear negligible, if not beneficial, and the risk of their future influence on the water column seems low because recruitment and mortality are in equilibrium, so their overall abundance is probably stable. Here I discuss how my research contributes to the current body of knowledge of sponge ecology and invasion biology, as well examine the future of the sponges and the lagoons at Palmyra Atoll, and the implications of my results for other atolls or semienclosed systems such as harbours and bays.

\subsection{Sponges: Wealth of benefits, paucity of knowledge}

\subsubsection{Diversity and distribution}

Sponges are economically and ecologically valuable (see Duckworth et al. 2007, Becerro 2008, Bell 2008a), moreover, they are a highly diverse phylum with roughly 8,500 known sponge species, but an estimated 15,000 in total (Hooper \& van Soest 2002, van Soest et al. 2012) compared to 5,600-8,000 for bryozoans (Ryland 2005) and 700 for corals (Cesar et al. 2003); however, sponges still remain relatively understudied. In general, the majority of tropical sponge research has focused on the Caribbean, with studies in the Pacific and Indo-Pacific mainly conducted around Australia, Mexico and Indonesia with very little information available on the Central Pacific. Compared to other tropical locations, the Central Pacific appears to have low 
sponge diversity with 1 to 61 species per island or atoll in this region (Fig 6.1) (de Laubenfels 1949, 1950, 1951, 1954, 1955, Bergquist 1965, Chiriboga et al. 2011, van Soest et al. 2011). However, through this work 51 new species can now be added to the Line Islands ecoregion, which currently has only 10 recorded for this archipelago (Fig 6.1) (van Soest et al. 2012).

Despite these additions and the continued work in documenting the distribution of sponges, the global ecoregion diversity, although up to date, may not represent the true global diversity as the hotspots appear to relate to the location of institutes and the disproportionate research efforts in these locations (Hendriks \& Duarte 2008). Therefore species diversity across the Central Pacific is likely to be higher as the number of publications for this area is low compared to other regions as it is difficult to access (Fisher et al. 2011). At Palmyra, the diversity is also most certainly higher than reported in this work (Chapter 2) as it was not possible to record all of the bioeroding sponges and those species found underneath the boulders reef crevices and deep waters in this thesis. The total number of sponge species is also likely to be higher at Palmyra and all other locations due to the potential high levels of cryptic speciation within sponges (Klautau et al. 1999, Blanquer \& Uriz 2007, Hoshino et al. 2008, Xavier et al. 2010). In Chapter 5, I showed that at Palmyra Haliclona caerulea was potentially introduced to Palmyra from the Caribbean via Hawaii but cryptic speciation complicates this finding.

The identification of cryptic speciation across many phyla has been increasing over the years, particularly with the advent of molecular techniques (Bickford et al. 2007). Therefore, it seems highly like that the total number of sponge species is nearer 15,000 (Hooper \& van Soest 2002) compared to the current confirmed number (roughly 8,500) (van Soest et al. 2012). Cryptic species by definition are similar in phenotypic form and are often found in similar habitats in parallel evolution, resulting in cryptic speciation across different locations as described in Chapter 5 where H. caerulea had cryptic species in the Caribbean, Hawai' $i$ and Palmyra. Although it is unusual, two cryptic species can coexist at the same location and exploit the same resources (Zhang et al. 2004, De Meester et al. 2011). Coexisting cryptic species, although morphologically similar, can have disparate ecological interactions with e.g. predators (De Meester et al. 1995), food (McManus et al. 2010), intra and interspecifics (Zhang et al. 2004), parasites (Westram et al. 2011) and symbionts (Jaenike \& Brekke 2011), and because they exploit alternate resources may influence food web dynamics differently 
(Kaartinen et al. 2010). In the case of cryptic sponges they may appear similar because their functional morphology is constrained (Manuel et al. 2003, Botting et al. 2012) but they can in fact differ in other traits, for example chemical defences (Haber et al. 2011) and food source niche partitioning (Perea-Blázquez 2011), which allows them to coexist in the same habitat and increase the biodiversity.

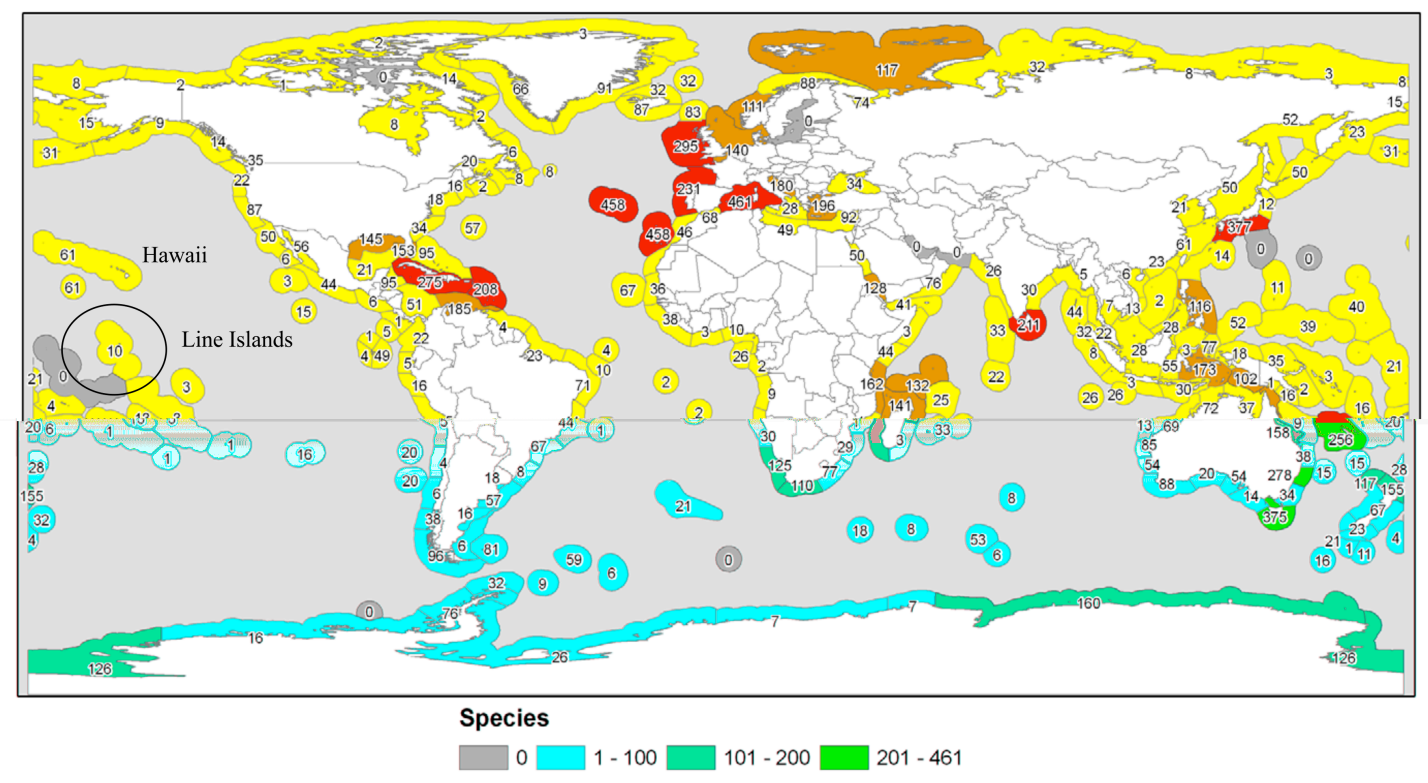

Figure 6.1 Map indicating the global diversity of sponges in each of the 232 marine ecoregions of the world highlighting the Line Islands where Palmyra is located and Hawai'i, in the Central Pacific. Modified from van Soest et al. (2012).

\subsubsection{Filtration rates}

To feed and respire, sponges filter vast quantities of water and can be particularly influential on semi-enclosed bodies of water (Peterson et al. 2006; Chapter 4). Gross morphology influences the amount of water filtered by a sponge over time by affecting the surface area to volume ratio and water flow over the surface of the sponge (Reiswig 1974, Frost 1980, Savarese et al. 1997, Osinga et al. 2001, Peterson et al. 2006). However, the majority of pumping rates recorded in the literature only report one or two species at a single location, with the majority being non-encrusting species (but see Peterson et al. 2006). Comparisons between morphologies are also difficult to make across studies as the site location may affect the pumping rates (even for sponges with the same morphology), as food availability and other environmental conditions (e.g. temperature and water flow) vary (Riisgard et al. 1993, Coma \& Ribes 2003). 
Therefore, the work in this thesis (Chapter 4) provides directly comparable information on filtration rates of sponges for a range of species and morphologies. Overall, I found that the average filtration rate per unit volume of lagoon sponge is comparable to other freshwater and marine species (Reiswig 1974, Frost 1980, Savarese et al. 1997, Osinga et al. 2001, Peterson et al. 2006), but with lower variability between species (e.g. Reiswig 1974, Peterson et al. 2006). This low variability in sponge filtration rates across morphologies at Palmyra suggests a link to low variability in environmental conditions in the lagoons (Chapter 2). This low variability in environmental conditions therefore made it possible to compare filtration rates between species and morphologies accurately. I found that morphology was more important than species level differences in affecting the filtration rates, as multiple species could be grouped by morphology (Table 4.1).

This research was only the third example (the other two were: (Peterson et al. 2006, Perea-Blázquez et al. 2012) examining the impact that the filtering capabilities of an entire sponge assemblage can have on the water column in a habitat, but was the first to examine the impacts of sponges on the removal of DOC and dissolved oxygen. This work was also the first to highlight the importance of incorporating the propagation of errors when scaling up recorded measurements and values e.g. from sponge filtration rates to area and volume of the lagoons. This is also one of the first studies to use propagation of errors in a marine case study to answer an ecological question, as typically this work has focused on terrestrial systems (Deutschman et al. 1999, Ruckelshaus et al. 2003, Chave et al. 2004). Propagation of errors allows us to incorporate the variability in calculations which have more than one measured variable and gives the maximum possible error around the mean, so providing greater confidence in the results. Knowing the maximum and minimum filtration capabilities of sponge assemblages illustrates that even assuming the lowest filtration rates that the sponges still turnover all the water in the lagoons every six days, which means they still roughly filter all of the available water in the lagoons at least three times before it leaves. Therefore, it seems likely that sponge assemblages, particularly in a semienclosed body of water, play an important role in water column filtration. Understanding the impacts that entire assemblages can have on a system can be complex and not initially apparent. Palmyra Atoll provides an excellent model site to not only understand the current biological impacts that species can have on habitats but 
also how historical anthropogenic perturbations can affect a system long after it has happened.

\subsubsection{Phase shifts}

Chapter 3 indicates that there is strong evidence that a coral to sponge dominated phase shift has occurred in the lagoons at Palmyra. Phase shifts as a result of anthropogenic disturbances have often been noted in marine systems, which can lead to a loss of coral cover and species diversity (McManus \& Polsenberg 2004, Mumby 2009). The majority of case studies observe dominance shifts from coral to algae; however this is not the only trajectory that reefs may follow after anthropogenic pressures alter habitats (Norström et al. 2009). A number of studies have observed phase shifts from coral to corallimorphs (Work et al. 2008), soft corals (Stobart et al. 2005), anemones (Chen \& Dai 2004), ascidians (Bak et al. 1996) and sponges (Aronson et al. 2002, Rützler 2002, Ward-Paige et al. 2005). Despite the number of coral to sponge phase shifts already documented, this is the first research to demonstrate this outside of the Caribbean. Describing this phase shift is particularly interesting because Roff and Mumby (2012) predict that the Caribbean is predisposed to phase shifts in comparison to Pacific reefs, which are more resilient to these events. Palmyra Atoll is considered a near-pristine reef (Sandin et al. 2008) and therefore more resilient to perturbations like bleaching and coral disease (Bellwood et al. 2004, Côté \& Darling 2010, Williams et al. 2010, Williams et al. 2011b); however, the lagoons are heavily degraded making them more susceptible to introduced species (Appendix I) and phase shifts (Chapter 3). Therefore the resilience of an ecosystem is not just regionally dependent but also strongly influenced by local levels of degradation. It is also commonly accepted that one mechanism of phase shifts is the loss of consumer predators (Bellwood et al. 2004). However, at Palmyra there is a high abundance of apex predators (DeMartini et al. 2008, Sandin et al. 2008); therefore it is unlikely that this is a mechanism which perpetuates the phase shift within the lagoon. Instead the primary mechanism was the dredging of the lagoons in WWII, but the intact food web at Palmyra should assist with the eventual recovery of this degraded habitat.

Overall the work at Palmyra Atoll adds to the body of knowledge that not all current assumptions on sponge ecology need necessarily apply to all locations, particularly those found in different oceans (e.g. Motta 1989, Becerro et al. 2003). The 
work at Palmyra Atoll has increased our knowledge on the diversity of sponges in an area where there is very limited information on sponges. It revealed that the number of species is comparable to other locations (Chapter 2); however, the diversity is likely to be higher not only at Palmyra Atoll or the Central Pacific but globally as well. In particular, sponge diversity is greatly underestimated due to the potential for high levels of cryptic speciation (Chapter 5) and through species introductions (Appendix I). Although introduced species may increase diversity they can also threaten native species diversity. However, as the results of this thesis indicate (Chapter 3 and 4) it may be unimportant at Palmyra that the sponges are introduced if they are not having a negative impact on the atoll system.

\subsection{Are all marine "invasions" bad?}

There is considerable evidence to support the negative impacts of invasive species on recipient ecosystems and biota (Briggs 2012, Simberloff et al. 2012). Invasive species are purported to cost the United States US \$120 billion a year in damage (e.g. through predation, extinctions, spread of pathogens) and control measures implemented to remove them (Pimentel et al. 2005), which because of logistical reasons are particularly costly in remote locations like Palmyra Atoll (Wegmann et al. 2011). However, controversially it has been suggested that not all alien species have negative impacts. Gurevitch and Padilla (2004) suggested that only $6 \%$ of threatened taxa will face extinction due to invasive species and $<2 \%$ of extinctions are a result of alien species. There are also a number of reports indicating that species diversity has even increased with the introduction of non-native species (McKinney 2002, Tecco et al. 2006).

Unfortunately, introduced species are often found in association with habitat disturbance or loss, making it unclear whether any negative impacts on native species are due to invasive species or simply correlate with the effects of habitat disturbances (Didham et al. 2005, MacDougall \& Turkington 2005). Within the lagoons at Palmyra, the sponges are the dominant fauna on the hard substrate with few coral species (Williams et al. 2008; see Chapter 2); however, pre-WWII corals were purportedly prominent in the lagoons before the military modifications (see Chapter 3) (Anon. 1947). Artificial substrates, like those in the lagoons at Palmyra, often harbour introduced fouling communities including sponges (Sutherland \& Karlson 1977, Tyrrell $\&$ Byers 2007). The structures and the inevitable disturbance to the environment during 
the military construction most likely shaped the subsequent communities at these sites by creating ecosystems better suited to fouling communities and reducing the capability of the native fauna to compete (Vitousek et al. 1997, Mooney \& Cleland 2001, Tyrrell \& Byers 2007), even potentially resulting in a complete phase-shift (see Chapter 3). Palmyra Atoll is therefore an extreme case of a habitat subjected to a rapid pulse disturbance, but it still raises the question as to whether the "newly" dominant sponges are having or will potentially have a negative/positive impact on the atoll ecosystem directly and/or indirectly.

Direct competition of the sponges at Palmyra with endemic species was not studied in this thesis although I did observe (Chapter 4) a potentially positive impact on the water column by the sponges through the removal of DOC. High concentrations of DOC can cause coral disease and death, and is worryingly the highest on the reefs at Palmyra compared to the rest of the Line Islands (Dinsdale et al. 2008). Other than removing DOC sponges can also reduce harmful bacteria (Fu et al. 2006, Stabili et al. 2006) and phytoplankton levels (Peterson et al. 2006) in semi-enclosed bodies of water as well as accumulate heavy metals including iron, copper, nickel, lead, zinc and cadmium making them useful biological filters and biomonitors of water quality (Patel et al. 1985, Hansen et al. 1995, Cebrian et al. 2007, Padovan et al. 2012). At Palmyra the sponge assemblage filters the lagoon water every 3-6 days and can remove up to $19 \%$ of DOC which suggests that sponges also have the ability to reduce the risk of phytoplankton blooms as suggested by Peterson et al. (2006), which in extreme cases causes eutrophication and hypoxia (Cloern 2001). Gordon et al. (1971) noted that in coral reef lagoons it is the residence time of the water that will influence whether phytoplankton blooms will occur because it will determine the level of nutrients. Delesalle and Sournia (1992), however, found no link with nutrients and residence time, but did find a linear relationship with chlorophyll- $a$ levels. Therefore based on the chlorophyll- $a$ levels in the lagoon it was estimated that the mean residence time in the lagoons at Palmyra was 22 days $( \pm 13)$. Considering that the residence time is longer than the time taken for the sponges to filter all of the flowing water in lagoons (3-6 days) and the high retention rates of sponges, it seems likely that the sponges have the potential to regulate the lagoon ecosystem by preventing eutrophication events (Grall \& Chauvaud 2002).

The US construction of a military base at Palmyra in WWII potentially all but removed the native species from the lagoons and changed the environment (e.g. by 
removing the hard substrate and reducing water flow) (Dawson 1959, Collen et al. 2009) so it was no longer suitable for the re-establishment of endemic species such as corals and clams. The proliferation of the sponges in the lagoons, a number of which are non-indigenous, however may not be a negative side-effect. If the sponges are vigorously filtering the water while not competing with native species and not currently extending onto the adjacent near-pristine reef, then they should not be viewed in a negative light. However, on an ecological timescale the time since the modifications is fairly short and it is unknown what will happen to the sponge assemblages in the future. There is still a chance that they could extend onto the reef if environmental conditions change to become more similar to that of the lagoons (see Chapter 2). However, the sponges may also play a key role in the natural succession and recovery of the lagoons. Assuming that the dredging removed the majority of reef-forming species and left relatively clear boulders, the sponges have already increased the complexity of the benthos since the WWII modifications. The added structure of the sponges also creates turbulence (e.g. small eddies) and reduces water flow over the substrate, therefore increasing residency time of particles in their locality and allowing more time for particle consumption by all suspension feeders (Gili \& Coma 1998). With the addition of more energy to a system through increased water flow (i.e. with the break through of the north-south causeway at Palmyra (Chapter 1)) species complexity can again increase due to a greater availability of food particles and therefore available niches (Margalef 1997). Generally, fouling communities will be the first to settle on a cleared substrate, which are generally encrusting species (like the majority (79\%) of the sponges in the lagoon), but over time there might be an increase in digitate and massive species (currently $21 \%$ of sponge species) (Richmond \& Seed 1991). Although it should be considered that not all introductions have negative impacts, fouling communities often consist of potentially harmful introduced species, a threat which increases with the prospect of global climate change (Sorte et al. 2010). Therefore, establishing which species are introduced and the path of introduction may be important to the future management of Palmyra Atoll as well as other locations that undergo high levels of disturbance such as bays and harbours.

Molecular tools are often useful in understanding the unintentional introduction of species, including confirming the species identification and indicating the path of introduction (Lee 2002, Molnar et al. 2008, Wilson et al. 2009), which can then be managed (e.g. via hull cleaning) to reduce the influx of further non-endemic species 
(Godwin 2003a). Establishing the path of introduction can yield surprising and informative results important to the future management of remote sites. For example Concepcion et al. (2010) found that the snowflake coral (Carijoa riisei) in Hawai'i, once believed to be an introduced species from the Caribbean was in fact an endemic species and most likely introduced to the Caribbean from Hawai' $i$, which resulted in the cessation of attempts to remove it from the commercially important Antipathidae black coral.

Globally it is also becoming clear that despite the lack of conventional barriers to gene flow in marine systems (Bierne et al. 2003), a number of species are more structured and isolated than previously thought (López-Duarte et al. 2012, Schulze et al. 2012) and the once considered cosmopolitan marine species (with high intra-species plasticity) are often complexes of cryptic species (e.g. Klautau et al. 1999, Blanquer \& Uriz 2007). Molecular analyses have aided in the clarification of cryptic speciation (Boury-Esnault et al. 1992, Muricy et al. 1996, Blanquer \& Uriz 2007), which is required for the identification and management of invasive species (Bickford et al. 2007). Species identification using genetics is particularly useful with sponges due to their high morphological plasticity and low number of informative characteristics (Erwin \& Thacker 2007), which hinders taxonomic clarity (Hooper \& van Soest 2002). Chapter 5 supports the notion that $H$. caerulea was likely brought to Palmyra from the Caribbean, but the interpretation was complicated by the number of cryptic species. Therefore the number of total species is likely to be higher than originally identified in Chapter 2. Also, more importantly it demonstrates the ability for species to be introduced to the lagoons at Palmyra, a number of which may have been introduced by the more recent (post-WWII) visits by yachts to the atoll (see Appendix I). Therefore, the potential for further introductions to the lagoons at Palmyra is likely and should be closely observed and managed, as even though the sponges are currently not a threat other introductions might be.

\subsection{The future for Palmyra's lagoons and sponges}

\subsubsection{Planned removal of the north-south causeway}

In 2008 the USFWS outlined a proposal to encourage the restoration of Palmyra's lagoons by removing a section of the causeway to restore water flow across the Atoll (Chapter 1). It is predicted that removing the causeway will increase the east to west water flow in the lagoons and relieve the sediment stress on the eastern backreefs, but 
will also potentially have further ecological consequences for the lagoon and western reef (Williams et al. 2011c). If turbidity increases substantially in the lagoons there is also a possibility that not only coral species will be affected, but the sponges as well. Sediment loading on sponges could affect them in the short and long term via reducing sponge metabolism (Bannister et al. 2011) and pumping rates (Gerrodette \& Flechsig 1979, Tompkins-MacDonald \& Leys 2008) as well as reproductive output (Roberts et al. 2006, Whalan et al. 2007) and larval survival (Maldonado et al. 2008, Wahab et al. 2011). Despite the unknown origin of all of the sponge species in the lagoon, their highly efficient water filtering capabilities might be having a positive influence in returning the lagoons to their pre-war state. For example, Peterson (2006) found that sponges have the potential to control nuisance phytoplankton blooms in the Florida Keys. Increased flow between the lagoons, when the north-south causeway was breached in 1979 (Collen et al. 2009) appears to have started the natural restoration of the lagoons. Dawson (1959) noted that soon after the military modifications, the lagoons were essentially dead with no living coral worth mentioning, and the East Lagoon was filled with sediment, was stagnant and often smelt of hydrogen sulphide. However, currently more than 7 genera of coral (Williams et al. 2008) inhabit the lagoons, already indicating an improvement in the water conditions. The increase in sediment due to the removal of the causeway would not only smother the corals already in the lagoon but further impact larval settlement and survival (Hodgson 1990, Connell et al. 1997). Coral larvae in particular cannot settle in shifting sediments (Rogers 1990). This would suggest that with the limited hard substrate and high sediment in the lagoons, the time it would take for corals to re-establish might increase by preventing coral and sponge larval settlement and survival (Hodgson 1990, Connell et al. 1997, Maldonado et al. 2008). Therefore I suggest, along with Williams (2011c), that any removal of the causeway be taken in small incremental steps with monitoring of the reef and lagoon species, because if the sponges are removed the conditions of the lagoons could worsen (see Chapter 4) as well as inhibit the current natural restoration of coral species already taking place.

\subsubsection{Shipwrecks and military debris}

The ability of the sponges to accumulate heavy metals may also form an important functional role at Palmyra because the military construction activities (Dawson 1959) and the shipwrecks (Work et al. 2008) may have led to higher levels of 
heavy metals such as iron into the surrounding environment (Youssef \& El-Said 2011). The long-line shipwreck at Palmyra on the western terrace, which grounded on the reef in 1991, is of particular concern as it is strongly associated with a phase-shift from a coral to corallimorph (Rhodactis howesii) dominated reef (Work et al. 2008). It is speculated that as the steel ship corrodes it leaches iron, which is normally a limited resource for many marine organisms (Butler 1998). This leaching may therefore be resulting in the evident dominance of $R$. howesii around the wreck as well as sites with the steel chains marking mooring buoys (Work et al. 2008). Also at Palmyra, considering that there are a number of iron and steel structures across the lagoons, levels of heavy metals including iron are likely to be higher than if no modifications occurred to the atoll. Therefore the sponges may be playing an important role in removing these heavy metals from the water (Perez et al. 2005, Padovan et al. 2012). The sponges could also even be used to assess the levels of other heavy metals across the lagoons (Fichez et al. 2005, Perez et al. 2005, de Mestre et al. 2011) left over from the military modifications. Although there is currently no evidence of heavy metal contamination when examining bivalve shells at Palmyra (Collen et al. 2011), the sponges may provide a different result because all marine invertebrates accumulate trace metals in different concentrations in different tissues/cells (see Rainbow 2002). The sponges may also reveal the metabolically available metal compared to the stored detoxified metals in bivalve shells (see Rainbow 2002, Rainbow 2007). Also because only trace levels of iron may be required for $R$. howesii to proliferate, they may be too low to be considered as contamination, but are still influencing the corallimorphs. Therefore the sponges may be helping to reduce these trace elements from the water column including those from the atoll alterations.

\subsubsection{Future identification of sponge extension on to the reefs}

Although it currently seems unlikely that the sponges will extend onto the reefs, some invasive species can have lag times before they become more aggressive (Crooks 2005) and therefore the sponges should still be considered a potential risk. Also the time since the military modifications is not long on an evolutionary time scale. Fortunately, detecting the movement of the sponges may be as simple as identifying an indicator species (Zacharias \& Roff 2001). Throughout this thesis I have identified Iotrochota protea as a potential indicator species because identification is fairly easy compared to other sponges as it stains the skin purple, it is the most dominant species in 
the lagoons and therefore can clearly establish on newly available substrates, and it also recruits to the top surface of boulders so it is visible without the need to turn over rocks or look in the reef matrices. Due to the dominance of I. protea over any other species in the lagoon it is also the greatest species of concern, particularly as it is likely that it is an introduced species from Hawai' $i$ where it is endemic (see Chapter 2). Although this currently cannot be confirmed because there are no sponge species lists for the Line Islands and I. protea has only been recorded in the Hawaiian archipelago (van Soest 2002) and has not been noted at other islands or atolls in the Line Islands including Kingman, which is only $67 \mathrm{~km}$ away (pers obs G. Williams). Iotrochta protea also generally inhabits sandy or rubble substrates in sheltered bays (Hoover 2006) and has very poor dispersal ability (a few minutes to a few days; (Maldonado 2006)). Natural colonisation between the islands therefore seems unlikely.

\subsection{Concluding remarks}

Sponges have been studied for well over 100 years with considerable advances made in this field; however, relatively little of this research has been conducted in the Central Pacific. This thesis reveals that the species diversity in the Central Pacific can be considerable even in remote locations and highlights the important filtering role that sponges can have on an ecosystem even if the assemblage includes introduced species. Molecular examination into the introduced species, $H$. caerulea, suggests that it was introduced to Palmyra from the Caribbean via Hawai'i, most likely via boating activity. The genetic analyses also revealed high levels of cryptic speciation, which indicates that the identification of sponge species introductions using in situ identification can be difficult. Ecologically, my work at Palmyra demonstrated that environmental conditions alone can maintain sponge assemblages in one location. It was also found that locations other than the Caribbean have undergone a rapid coral to sponge phase shift; however it is important to note that not all introductions are negative as they may eventually result in the natural succession of a system back to its climax community with time. 


\section{References}

Abràmoff MD, Magalhães PJ, Ram SJ (2004) Image processing with ImageJ. Biophon Internat 11:36-42

Akaike H (1973) Information theory as an extension of the maximum likelihood principal. In: Petrov BN, Caski F (eds). Proc 2nd international symposium on information theory

Anakina RP, Drozdov AL (2001) Gamete structure and fertilization in the Barents Sea sponge Leucosolenia complicata. Russ J Mar Biol 27:143-150

Anderson MJ (2001) A new method for non-parametric multivariate analysis of variance. Austral Ecol 26:32-46

Anderson MJ (2004) CAP: a FORTRAN computer program for canonical analysis of principal coordinates. Department of Statistics, University of Auckland, New Zealand.

Anderson MJ, Gorley RN, Clarke KR (2008) PERMANOVA+ for PRIMER: guide to software and statistical methods. PRIMER-E Plymouth, UK.

Anderson MJ, Willis TJ (2003) Canonical analysis of principal coordinates: a useful method of constrained ordination for ecology. Ecology 84:511-524

Annandale N (1907) Notes on freshwater sponges. VI. The midday siesta of Spongilla in the tropics. Rec Ind Mus 1:387

Anon. (1947) Building the Navy's bases in World War II; history of the bureau of yards and docks and the civil engineer corps 1940-1946, Vol 2. U.S. Government Printing Office, Washington

Aronson RB, Precht WF, Toscano MA, Koltes KH (2002) The 1998 bleaching event and its aftermath on a coral reef in Belize. Mar Biol 141:435-447-447

Avise JC (2000a) Phylogeography: the history and formation of species, Vol 1. Harvard Univ Press

Avise JC (2000b) Stability, equilibrium and molecular aspects of conservation in marine species. Hydrobiologia 420:XI-XII

Ayling AL (1980) Patterns of sexuality, asexual reproduction and recruitment in some subtidal marine Demospongiae. Biol Bull 158:271-282

Bak RPM, Lambrechts DYM, Joenje M, Nieuwland G, Van Veghel MLJ (1996) Long-term changes on coral reefs in booming populations of a competitive colonial ascidian. Mar Ecol Prog Ser 133:303-306

Bannister RJ, Battershill CN, de Nys R (2011) Suspended sediment grain size and mineralogy across the continental shelf of the Great Barrier Reef: Impacts on the physiology of a coral reef sponge. Cont Shelf Res

Barbier EB, Hacker SD, Kennedy C, Koch EW, Stier AC, Silliman BR (2011) The value of estuarine and coastal ecosystem services. Ecol Monogr 81:169-193

Barott KL, Caselle JE, Dinsdale EA, Friedlander AM, Maragos JE, Obura D, Rohwer FL, Sandin SA, Smith JE, Zgliczynski B (2010) The lagoon at Caroline/Millennium Atoll, Republic of Kiribati: natural history of a nearly pristine ecosystem. PLoS ONE 5:e10950

Barthel D, Tendal OS (1993) The sponge association of the abyssal Norwegian Greenland Sea: species composition, substrate relationships and distribution. Sarsia 78:83-96

Bavestrello G, Bonito M, Sarà M (1993) Silica content and spicular size variation during an annual cycle in Chondrilla nucula Schmidt (Porifera, Demospongiae) in the Ligurian Sea. Scientia Marina 57:421-425 
Bax N, Carlton JT, Mathews-Amos A, Haedrich RL, Howarth FG, Purcell JE, Rieser A, Gray A (2001) The control of biological invasions in the world's oceans. Conserv Biol 15:1234-1246

Bax N, Williamson A, Aguero M, Gonzalez E, Geeves W (2003) Marine invasive alien species: a threat to global biodiversity. In. Proc Global Conference on Oceans and Coasts

Becerro M, Thacker RW, Turon X, Uriz MJ, Paul VJ (2003) Biogeography of sponge chemical ecology: comparisons of tropical and temperate defenses. Oecologia 135:91-101

Becerro MA (2008) Quantitative trends in sponge ecology research. Mar Ecol 29:167177

Behrens Yamada S, Gillespie GE (2008) Will the European green crab (Carcinus maenas) persist in the Pacific Northwest? ICES Journal of Marine Science: Journal du Conseil 65:725-729

Bell JJ (2004) Evidence for morphology-induced sediment settlement prevention on the tubular sponge Haliclona urceolus. Mar Biol 146:29-38

Bell JJ (2007) The ecology of sponges in Lough Hyne Marine Nature Reserve (southwest Ireland): Past, present and future perspectives. J Mar Biol Assoc UK $87: 1655-1668$

Bell JJ (2008a) The functional roles of marine sponges. Estuar Coast Shelf Sci 79:341-353

Bell JJ (2008b) Sponges as agents of biological disturbance. Mar Ecol Prog Ser 368:127-135

Bell JJ, Barnes DKA (2000a) The distribution and prevalence of sponges in relation to environmental gradients within a temperate sea lough: inclined cliff surfaces. Divers Distrib 6:305-323

Bell JJ, Barnes DKA (2000b) The influences of bathymetry and flow regime upon the morphology of sublittoral sponge communities. J Mar Biol Assoc UK 80:707718

Bell JJ, Barnes DKA (2000c) A sponge diversity centre within a marine 'island'. Hydrobiologia 440:55-64

Bell JJ, Barnes DKA (2003a) Effect of disturbance on assemblages: an example using porifera. Biol Bull 205:144-159

Bell JJ, Barnes DKA (2003b) The importance of competitor identity, morphology and ranking methodology to outcomes in interference competition between sponges. Mar Biol 143:415-426

Bell JJ, Barnes DKA, Turner JR (2002) The importance of micro and macro morphological variation in the adaptation of a sublittoral demosponge to current extremes. Mar Biol 140:75-81

Bell JJ, Burton M, Bullimore B, Newman PB, Lock K (2006) Morphological monitoring of subtidal sponge assemblages. Mar Ecol Prog Ser 311:79-91

Bell JJ, Carballo JL (2008) Patterns of sponge biodiversity and abundance across different biogeographic regions. Mar Biol 155:563-570

Bell JJ, Smith D (2004) Ecology of sponge assemblages (Porifera) in the Wakatobi region, south-east Sulawesi, Indonesia: Richness and abundance. J Mar Biol Assoc UK 84:581-591

Bell JJ, Turner JR (2000) Factors influencing the density and morphometrics of the cup coral Caryophyllia smithii in Lough Hyne. J Mar Biol Assoc UK 80:437441

Bellwood DR, Hughes TP, Folke C, Nystrom M (2004) Confronting the coral reef crisis. Nature 429:827-833 
Benner R (2002) Chemical composition and reactivity. In: Hansell DA, Carlson CA (eds) Biogeochemistry of marine dissolved organic matter. Academic Press, pp. 59-90.

Bensasson D, Zhang D-X, Hartl DL, Hewitt GM (2001) Mitochondrial pseudogenes: evolution's misplaced witnesses. Trends Ecol Evol 16:314-321

Bergquist PR (1965) The sponges of Micronesia, Part I: The Palau Archipelago. Pac Sci 19:123-204

Bergquist PR (1978) Sponges, Vol. Hutchinson \& Co, London

Bergquist PR, Sinclair ME (1973) Seasonal variation in settlement and spiculation of sponge larvae. Mar Biol 20:35-44

Bergquist PR, Sinclair ME, Hogg JJ (1970) Adaptation to intertidal existence: reproductive cycles and larval behaviour in Demospongiae. Symp Zool Soc Lond 25:247-271

Berman J (2012) Patterns of temporal and spatial variability of sponge assemblages. $\mathrm{PhD}$, Victoria University of Wellington, New Zealand

Bickford D, Lohman DJ, Sodhi NS, Ng PKL, Meier R, Winker K, Ingram KK, Das I (2007) Cryptic species as a window on diversity and conservation.

Bierne N, Bonhomme F, David P (2003) Habitat preference and the marine-speciation paradox. Philos T Roy Soc B 270:1399-1406

Blanquer A, Uriz M-J (2007) Cryptic speciation in marine sponges evidenced by mitochondrial and nuclear genes: a phylogenetic approach. Mol Phylogen Evol 45:392-397

Bloesch J (1994) A review of methods used to measure sediment resuspension. Hydrobiologia 284:13-18

Bond C (1992) Continuous cell movements rearrange anatomical structures in intact sponges. J Exp Zool 263:284-302

Boore JL (1999) Animal mitochondrial genomes. Nucleic Acids Res 27:1767-1780

Borchiellini C, Manuel M, Alivon E, Boury-Esnault N, Vacelet J, Le Parco Y (2001) Sponge paraphyly and the origin of Metazoa. J Evol Biol 14:171-179

Botting JP, Muir LA, Li XF, Lin J (2012) An enigmatic, possibly chemosymbiotic, hexactinellid sponge from the early Cambrian of South China. Acta Palaeontol Pol doi: http://dx.doi.org/10.4202/app.2011.0140

Boury-Esnault N, Solé-Cava AM, Thorpe JP (1992) Genetic and cytological divergence between colour morphs of the Mediterranean sponge Oscarella lobularis Schmidt (Porifera, Demospongiae, Oscarellidae). J Nat Hist 26:271284

Briggs JC (2012) Marine species invasions in estuaries and harbors. Mar Ecol Prog Ser 449:297-302

Brown D (2004) Tracker video analysis and modeling tool. (v4.05). http://www.cabrillo.edu/ dbrown/tracker/

Brusca RC, Brusca GJ (1990) Invertebrates, Vol. Sinauer, Sunderland, Massachusetts

Budd GE (2008) The earliest fossil record of the animals and its significance. Philos T Roy Soc B 363:1425-1434

Burnham KP, Anderson DR (2002) Model Selection and Multimodel Inference: A Practical Information-Theoretic Approach. 2nd ed. Springer-Verlag

Buscema M, de Sutter D, van de Vyver G (1980) Ultrastructural study of differentiation processes during aggregation of purified sponge archaeocytes. Wilhelm Roux's Archives of Developmental Biology 188:45-53

Butler A (1998) Acquisition and utilization of transition metal ions by marine organisms. Science 281:207-209 
Butman CA (1987) Larval settlement of soft-sediment invertebrates: the spatial scales of pattern explained by active habitat selection and the emerging role of hydrodynamical processes. Oceano Mar Biol Annu Rev 25:113-165

Byers JE (2002) Impact of non-indigenous species on natives enhanced by anthropogenic alteration of selection regimes. Oikos 97:449-458

Callaway RM, Ridenour WM (2004) Novel weapons: invasive success and the evolution of increased competitive ability. Front Ecol Environ 2:436-443

Carballo JL (2006) Effect of natural sedimentation on the structure of tropical rocky sponge assemblages. Ecoscience 13:119-130

Carballo JL, Avila E (2004) Population dynamics of a mutualistic interaction between the sponge Haliclona caerulea and the red alga Jania adherens. Mar Ecol Prog Ser 279:93-104

Carballo JL, Vega C, Cruz-Barraza JA, Yanez B, Nava H, Avila E, Wilson M (2008) Short- and long-term patterns of sponge diversity on a rocky tropical coast: evidence of large-scale structuring factors. Mar Ecol 29:216-236

Carlton JT, Geller JB (1993) Ecological roulette: the global transport of nonindigenous marine organisms. Science 261:78-82

Cebrian E, Uriz MJ, Turon X (2007) Sponges as biomonitors of heavy metals in spatial and temporal surveys in northwestern Mediterranean: Multispecies comparison. Environ Toxicol Chem 26:2430-2439

Cesar H, Burke L, Pet-Soede L (2003) The economics of worldwide coral reef degradation.

Charpy-Roubaud CJ, Charpy L, Cremoux JL (1990) Nutrient budget of the lagoonal waters in an open central South Pacific atoll (Tikehau, Tuamotu, French Polynesia). Mar Biol 107:67-73

Chave J, Condit R, Aguilar S, Hernandez A, Lao S, Perez R (2004) Error propagation and scaling for tropical forest biomass estimates. Philos T Roy Soc B 359:409420

Chen CA, Dai CF (2004) Local phase shift from Acropora-dominant to Condylactisdominant community in the Tiao-Shi Reef, Kenting National Park, southern Taiwan. Coral Reefs 23:508-508

Cheshire AC, Wilkinson CR (1991) Modelling the photosynthetic production by sponges on Davies Reef, Great Barrier Reef. Mar Biol 109:13-18

Chiriboga A, Ruiz D, Banks S (2011) CDF Checklist of Galapagos Sponges - FCD Lista de especies de Esponjas de Galápagos. In: Bungartz F, Herrera, H., Jaramillo, P., Tirado, N., Jímenez-Uzcategui, G., Ruiz, D., Guézou, A. \& Ziemmeck, F. (ed) Charles Darwin Foundation Galapagos Species Checklist Lista de Especies de Galápagos de la Fundación Charles Darwin Charles Darwin Foundation / Fundación Charles Darwin, Puerto Ayora, Galapagos: http://wwwdarwinfoundationorg/datazone/checklists/marineinvertebrates/porif era.

Chombard C, Boury-Esnault N, Tillier S (1998) Reassesment of homology of morphological characters in tetractinellid sponges based on molecular data. Syst Biol 47:351-366

Clarke KR, Chapman MG, Somerfield PJ, Needham HR (2006a) Dispersion-based weighting of species counts in assemblage analyses. Mar Ecol Prog Ser 320:11-27

Clarke KR, Gorley RN (2006) Primer v6: User manual/tutorial. PRIMER-E Ltd: Plymouth, United Kingdom.

Clarke KR, Somerfield PJ, Chapman MG (2006b) On resemblance measures for ecological studies, including taxonomic dissimilarities and a zero-adjusted 
Bray-Curtis coefficient for denuded assemblages. J Exp Mar Biol Ecol 330:5580

Cloern JE (1982) Does the benthos control phytoplankton biomass in south San Francisco Bay? Mar Ecol Prog Ser 9:191-202

Cloern JE (2001) Our evolving conceptual model of the coastal eutrophication problem. Mar Ecol Prog Ser 210:223-253

Cohen AN, Carlton JT, Fountain MC (1995) Introduction, dispersal and potential impacts of the green crab Carcinus maenas in San Francisco Bay, California. Mar Biol 122:225-237

Cole JJ, Findlay S, Pace ML (1988) Bacterial production in fresh and saltwater ecosystems: a cross-system overview. Mar Ecol Prog Ser 43:1-10

Coles SL, Bolick H (2007) Invasive introduced sponge Mycale grandis overgrows reef corals in Kane'ohe Bay, O'ahu, Hawai'i. Coral Reefs 26:911-911

Coles SL, DeFelice RC, Eldredge LG, Carlton JT (1997) Biodiversity of marine communities in Pearl Harbor, Oahu, Hawaii with observations on introduced marine species. Bishop Museum of Technology Reports 10

Coles SL, DeFelice RC, Eldredge LG, Carlton JT (1999) Historical and recent introductions of non-indigenous marine species into Pearl Harbor, Oahu, Hawaiian Islands. Mar Biol 135:147-158

Coles SL, DeFelice RC, Minton D (2001) Marine Species Survey of Johnston Atoll, Central Pacific Ocean, June 2000 Bishop Museum Technical Report No 19, Honolulu

Coles SL, Kandel FLM, Reath PA, Longenecker K, Eldredge LG (2006) Rapid assessment of non-indigenous marine species on coral reefs in the main Hawaiian Islands. Pac Sci 60:483-507

Coles SL, Marchetti, J. Bolick, H. and Montgomery A. (2007) Assessment of Invasiveness of the Orange Keyhole Sponge Mycale armata in Kāne'ohe Bay, O'ahu, Hawaii. Bishop Museum and Hawaii State Department of Land and Natural Resources Division of Aquatic Resources Honolulu, Hawaii.

Collen JD, Baker JA, Dunbar RB, Rieser U, Gardner JP, Garton DW, Christiansen KJ (2011) The atmospheric lead record preserved in lagoon sediments at a remote equatorial Pacific location: Palmyra Atoll, northern Line Islands. Mar Pollut Bull 62:251-257

Collen JD, Garton DW, Gardner JPA (2009) Shoreline Changes and Sediment Redistribution at Palmyra Atoll (Equatorial Pacific Ocean): 1874-Present. J Coast Res 25:711-722

Coma R, Ribes M (2003) Seasonal energetic constraints in Mediterranean benthic suspension feeders: effects at different levels of ecological organization. Oikos 101:205-215

Concepcion GT, Kahng SE, Crepeau MW, Franklin EC, Coles SL, Toonen RJ (2010) Resolving natural ranges and marine invasions in a globally distributed octocoral (genus Carijoa). Mar Ecol Prog Ser 401:113-127

Connell JH, Hugues TP, Wallace CC (1997) 30-Year study of coral abundance, recruitment, and disturbance at several scales in space and time. Ecol Monogr 67:461-488

Corriero G, Sara M, Vaccaro P (1996) Sexual and asexual reproduction in two species of Tethya (Porifera, Demospongiae) from a Mediterranean coastal lagoon. Mar Biol 126:175-181

Côté IM, Darling ES (2010) Rethinking ecosystem resilience in the face of climate change. PLoS Biol 8:e1000438 
Coutts ADM, Moore KM, Hewitt CL (2003) Ships' sea-chests: an overlooked transfer mechanism for non-indigenous marine species? Mar Pollut Bull 46:1510-1513

Craft CB, Seneca ED, Broome SW (1991) Loss on ignition and kjeldahl digestion for estimating organic-carbon and total nitrogen in estuarine marsh soils calibration with dry combustion. Estuaries 14:175-179

Cranfield HJ, Rowden AA, Smith DJ, Gordon DP, Michael KP (2004) Macrofaunal assemblages of benthic habitat of different complexity and the proposition of a model of biogenic reef habitat regeneration in Foveaux Strait, New Zealand. J Sea Res 52:109-125

Crooks JA (2005) Lag times and exotic species: The ecology and management of biological invasions in slow-motion. Ecoscience 12:316-329

Crossland CJ, Hatcher BG, Smith SV (1991) Role of coral reefs in global ocean production. Coral Reefs 10:55-64

Cruz-Barraza JA, Carballo JL (2008) Taxonomy of sponges (Porifera) associated with corals from the Mexican Pacific Ocean. Zool Stud 47:741-758

Cubit J, Williams S (1983) The invertebrates of Galeta Reef (Caribbean Panama): a species list and bibliography. Atoll Res Bull 269

Dawson EY (1959) Changes in Palmyra Atoll and its vegetation through the activities of man, 1913-1958. Pac Nat 1:1-52

Dawson MN, Raskoff KA, Jacobs DK (1998) Field preservation of marine invertebrate tissue for DNA analyses. Mol Mar Biol Biotechnol 7:145-152

De'ath G, Fabricius K (2010) Water quality as a regional driver of coral biodiversity and macroalgae on the Great Barrier Reef. Ecol Appl 20:840-850

de Goeij JM, van den Berg H, van Oostveen MM, Epping EHG, van Duyl FC (2008) Major bulk dissolved organic carbon (DOC) removal by encrusting coral reef cavity sponges. Mar Ecol Prog Ser 357:139-151

de Laubenfels MW (1936) A discussion of the sponge fauna of the Dry Tortugas in particular and the West Indies in general, with material for a revision of the families and orders of the Porifera. Publications of the Carnegie Institution of Washington, Papers from Tortugas Laboratory 30:1-225

de Laubenfels MW (1947) Ecology of the sponges of a brackish water environment, at Beaufort, N.C. Ecol Monogr 17:31-46

de Laubenfels MW (1949) New sponges from the Yap archipelago. Pac Sci 3:124-126

de Laubenfels MW (1950) The sponges of Kaneohe Bay, Oahu. Pac Sci 4:3-36

de Laubenfels MW (1951) The sponges of the island of Hawaii. Pac Sci 5:256-271

de Laubenfels MW (1954) The sponges of the west central Pacific. Oregon State Monographs Studies in Zoology 7:320

de Laubenfels MW (1955) Sponges of Onotoa. Pac Sci 9:137-143

De Meester L, Weider LJ, Tollrian R (1995) Alternative antipredator defenses and genetic-polymorphism in a pelagic predator-prey system. Nature 378:483-485

De Meester N, Derycke S, Bonte D, Moens T (2011) Salinity effects on the coexistence of cryptic species: a case study on marine nematodes. Mar Biol 158:2717-2726

de Mestre C, Maher W, Roberts D, Broad A, Krikowa F, Davis AR (2011) Sponges as sentinels: patterns of spatial and intra-individual variation in trace metal concentration. Mar Pollut Bull 64:80-89

de Voogd NJ, Becking LE, Hoeksema BW, Noor A, van Soest RWM (2004) Sponge interactions with spatial competitors in the Spermonde Archipelago. Bollettino dei Musei e degli Istituti Biologici della Universita di Genova 68:253-261

de Voogd NJ, Cleary DFR (2007) Relating species traits to environmental variables in Indonesian coral reef sponge assemblages. Mar Fresh Res 58:240-249 
De Weerdt WH (2000) A monograph of the shallow-water Chalinidae (Porifera, Haplosclerida) of the Caribbean. Beaufortia Bull Zoo Mus, University of Amsterdam 50:1-67

DeFelice RC, Eldredge LG, Carlton JT (2001) Non-indigenous marine invertebrates. In: A guidebook to introduced marine species in Hawai'i Eldredge LG, Smith CM (eds), Bishops Museum Technical Report 21

Delesalle B, Sournia A (1992) Residence time of water and phytoplankton biomass in coral reef lagoons. Cont Shelf Res 12:939-949

DeMartini EE, Friedlander AM, Sandin SA, Sala E (2008) Differences in fishassemblage structure between fished and unfished atolls in the northern Line Islands, central Pacific. Mar Ecol Prog Ser 365:199-215

Deutschman DH, Levin SA, Pacala SW (1999) Error propagation in a forest succession model: the role of fine-scale heterogeneity in light. Ecology 80:1927-1943

Diaz MC, Ward BB (1997) Sponge-mediated nitrification in tropical benthic communities. Mar Ecol Prog Ser 156:97-107

Didham RK, Tylianakis JM, Hutchison MA, Ewers RM, Gemmell NJ (2005) Are invasive species the drivers of ecological change? Trends Ecol Evol 20:470474

Dinsdale EA, Pantos O, Smriga S, Edwards RA, Angly F, Wegley L, Hatay M, Hall D, Brown E, Haynes M, Krause L, Sala E, Sandin SA, Thurber RV, Willis BL, Azam F, Knowlton N, Rohwer F (2008) Microbial ecology of four coral atolls in the northern Line Islands. PLoS ONE 3:e1584

Dittmar T, Hertkorn N, Kattner G, Lara RJ (2006) Mangroves, a major source of dissolved organic carbon to the oceans. Global Biogeochem Cycles 20:1-7

Dlugosch KM, Parker IM (2008) Founding events in species invasions: genetic variation, adaptive evolution, and the role of multiple introductions. Mol Ecol $17: 431-449$

Done TJ (1992) Phase shifts in coral reef communities and their ecological significance. Hydrobiologia 247:121-132

Drummond AJ, Ashton B, Buxton S, Cheung M, Cooper A, Duran C, Field M, Heled J, Kearse M, Markowitz S, Moir R, Stones-Havas S, Sturrock S, Thierer T, Wilson A (2011) Geneious v5.4, Available from http://www.geneious.com/

Duckworth AR, Wolff C, Cobb R, Webster N (2007) Ecological role and potential value of sponges to Torres Strait. Annual Report: Marine and Tropical Sciences Research Facility, Cairns

Duffy JE (1992) Host use patterns and demography in a guild of tropical spongedwelling shrimps. Hydrobiologia 90:127-138

Dufour P, Berland B (1999) Nutrient control of phytoplanktonic biomass in atoll lagoons and Pacific ocean waters: Studies with factorial enrichment bioassays. J Exp Mar Biol Ecol 234:147-166

Dufrêne M, Legendre P (1997) Species Assemblages and Indicator Species: The Need for a Flexible asymmetrical approach. Ecol Monogr 67:345-366

Duggan IC, van Overdijk CDA, Bailey SA, Jenkins PT, Limen H, MacIsaac HJ (2005) Invertebrates associated with residual ballast water and sediments of cargo-carrying ships entering the Great Lakes. Can J Fish Aquat Sci 62:24632474

Dunlap M, Pawlik JR (1996) Video-monitored predation by Caribbean reef fishes on an array of mangrove and reef sponges. Mar Biol 126:117-123

Duran S, Giribet G, Turon X (2004a) Phylogeographical history of the sponge Crambe crambe (Porifera, Poecilosclerida): range expansion and recent 
invasion of the Macaronesian islands from the Mediterranean Sea. Mol Ecol 13:109-122

Duran S, Pascual M, Turon X (2004b) Low levels of genetic variation in mtDNA sequences over the western Mediterranean and Atlantic range of the sponge Crambe crambe (Poecilosclerida). Mar Biol 144:31-35

Duran S, Rützler K (2006) Ecological speciation in a Caribbean marine sponge. Mol Phylogen Evol 40:292-297

Edmunds PJ, Carpenter RC (2001) Recovery of Diadema antillarum reduces macroalgal cover and increases abundance of juvenile corals on a Caribbean reef. Proc Nat Acad Sci USA 98:5067

Eldredge LG (1994) Perspective in aquatic exotic species management in the Pacific Islands. Volume 1: Introductions of commercially significant aquatic organisms to the Pacific Islands, South Pacific Commission, South Pacific Regional Environment Programme, New Caledonia

Elton CS (1958) The ecology of invasions by animals and plants. The ecology of invasions by animals and plants:181p. Illus. Maps.

Erpenbeck D, Breeuwer JAJ, Parra-Velandia FJ, van Soest RWM (2006) Speculation with spiculation? - Three independent gene fragments and biochemical characters versus morphology in demosponge higher classification. Mol Phylogen Evol 38:293-305

Erpenbeck D, Duran S, Rutzler K, Paul V, Hooper JNA, Worheide G (2007) Towards a DNA taxonomy of Caribbean demosponges: a gene tree reconstructed from partial mitochondrial CO1 gene sequences supports previous rDNA phylogenies and provides a new perspective on the systematics of Demospongiae. J Mar Biol Assoc UK 87:1563-1570

Erpenbeck D, Soest RWMv (2002) Family Halichondriidae Gray, 1867. In: Hooper JNA, Soest RWMv (eds) Systema Porifera: a guide to the classification of sponges, Book 1. Kluwer Academic/Plenum Publishers, New York, pp. 787815.

Erwin PM, Thacker RW (2007) Phylogenetic analyses of marine sponges within the order Verongida: a comparison of morphological and molecular data. Invertebr Biol 126:220-234

Fabricius K, De'ath G, McCook L, Turak E, Williams DM (2005) Changes in algal, coral and fish assemblages along water quality gradients on the inshore Great Barrier Reef. Mar Pollut Bull 51:384-398

Fabricius KE (2005) Effects of terrestrial runoff on the ecology of corals and coral reefs: review and synthesis. Mar Pollut Bull 50:125-146

Fairfull SJL, Harriott VJ (1999) Succession, space and coral recruitment in a subtropical fouling community. Mar Freshwat Res 50:235-242

Fell PE (1974) Diapause in the gemmules of the marine sponge, Haliclona loosanoffi, with a note on the gemmules of Haliclona oculata. Biol Bull 147:333-351

Fichez R, Adjeroud M, Bozec YM, Breau L, Chancerelle Y, Chevillon C, Douillet P, Fernandez JM, Frouin P, Kulbicki M (2005) A review of selected indicators of particle, nutrient and metal inputs in coral reef lagoon systems. Aquat Living Resour 18:125-147

Fisher R, Radford BT, Knowlton N, Brainard RE, Michaelis FB, Caley MJ (2011) Global mismatch between research effort and conservation needs of tropical coral reefs. Conserv Lett 4:64-72

Flint E (1992) Survey of the terrestrial biota of Palmyra Atoll: 18 February to 9 March 1992. U.S. Fish and Wildlife Service. Unpublished trip report 
Folk RL (1974) Petrology of sedimentary rocks, Vol. Hemphill Publishing Company, Austin, Texas, USA

Folmer O, Black M, Hoeh W, Lutz R, Vrijenhoek R (1994) DNA primers for amplification of mitochondrial cytochrome $\mathrm{C}$ oxidase subunit I from diverse metazoan invertebrates. Mol Mar Biol Biotechnol 3:294-299

Fowler S, Laffoley D (1993) Stability in Mediterranean-Atlantic sessile epifaunal communities at the northern limits of their range. J Exp Mar Biol Ecol 172:109

Francis JC (1984) Reduction body formation and subsequent regeneration of Ephydatia fluviatilis (Porifera: Spongillidae) in laboratory culture. T Am Microsc soc 103:347-352

Fromont J, Bergquist PR (1994) Reproductive biology of three sponge species of the genus Xestospongia (Porifera: Petrosida) from the Great Barrier Reef. Coral Reefs 13:119-126

Frost IM (1978) In situ measurements of clearance rates for the freshwater sponge Spongilla lacustris. 23:1034-1039

Frost TM (1980) Clearance rate determinations for the freshwater sponge Spongilla lacustris: effects of temperature, particle type and concentration and sponge size. Arch Hydrobiol 90:330-356

$\mathrm{Fu} \mathrm{W,} \mathrm{Sun} \mathrm{L,} \mathrm{Zhang} \mathrm{X,} \mathrm{Zhang} \mathrm{W} \mathrm{(2006)} \mathrm{Potential} \mathrm{of} \mathrm{the} \mathrm{marine} \mathrm{sponge}$ Hymeniacidon perleve as a bioremediator of pathogenic bacteria in integrated aquaculture ecosystems. Biotechnol Bioeng 93:1112-1122

Fu W, Wu Y, Sun L, Zhang W (2007) Efficient bioremediation of total organic carbon (TOC) in integrated aquaculture system by marine sponge Hymeniacidon perleve. Biotechnol Bioeng 97:1387-1397

Fukami H, Chen CA, Budd AF, Collins A, Wallace C, Chuang Y-Y, Chen C, Dai CF, Iwao K, Sheppard C, Knowlton N (2008) Mitochondrial and nuclear genes suggest that stony corals are monophyletic but most families of stony corals are not (Order Scleractinia, Class Anthozoa, Phylum Cnidaria). PLoS ONE 3:e3222

Galtsoff PS (1923) The amoeboid movement of dissociated sponge cells. Biol Bull 45:153-161

Galtsoff PS (1925) Regeneration after dissociation (An experimental study on sponges) II Histogenesis of Microciona prolifera, Verf. J Exp Zool 42:223255

Gardner JPA, Garton DW, Collen JD (2011) Near-surface mixing and pronounced deep-water stratification in a compartmentalised, human-disturbed atoll lagoon system. Coral Reefs 30:271-282

Garrabou J, Zabala M (2001) Growth dynamics in four Mediterranean demosponges. Estuar Coast Shelf Sci 52:293-303

Gerrodette T, Flechsig AO (1979) Sediment-induced reduction in the pumping rate of the tropical sponge Verongia lacunosa. Mar Biol 55:103-110

Geyer CJ (1991) Markov chain Monte Carlo maximum likelihood. In: Keramidas EM (ed). Proc Computing science and statistics: 23rd Symposium on the Interface

Gili JMM, Coma R (1998) Benthic suspension feeders in marine food webs. Trends Ecol Evol 13:297-337

Godwin LS (2003a) Development of an initial framework for the management of hull fouling as a marine invasive species transport mechanism. In: Hull fouling as a mechanism for marine invasive species introductions, Honolulu, Hawaii, p. 47. 
Godwin LS (2003b) Hull fouling of maritime vessels as a pathway for marine species invasions to the Hawaiian Islands. Biofouling 19:123-131

Gordon DC, Fournier RO, Krasnick GJ (1971) Note on the planktonic primary production in Fanning Island lagoon. Pac Sci 25:228-233

Goreau TF, Hartman WD (1966) Sponge: effect on the form of reef corals. Science (US) 151:343-344

Graham KR, Sebens KP (1996) The distribution of marine invertebrate larvae near vertical surfaces in the rocky subtidal zone. Ecology 77:933-949

Grall J, Chauvaud L (2002) Marine eutrophication and benthos: the need for new approaches and concepts. Global Change Biol 8:813-830

Grigg RW (1984) Resource management of precious corals: a review and application to shallow water reef building corals. Mar Ecol 5:57-74

Grosholz ED, Ruiz GM (1996) Predicting the impact of introduced marine species: Lessons from the multiple invasions of the European green crab Carcinus maenas. Biol Conserv 78:59-66

Gurevitch J, Padilla DK (2004) Are invasive species a major cause of extinctions? Trends in Ecology \&amp; Evolution 19:470-474

Haber M, Carbone M, Mollo E, Gavagnin M, Ilan M (2011) Chemical defense against predators and bacterial fouling in the Mediterranean sponges Axinella polypoides and $A$. verrucosa. Mar Ecol Prog Ser 422:113-122

Hadas E, Marie D, Shpigel M, Ilan M (2006) Virus predation by sponges is a new nutrient-flow pathway in coral reef food webs. Limnol Oceanogr 51:15481550

Hansen IV, Weeks JM, Depledge MH (1995) Accumulation of copper, zinc, cadmium, and chromium by the marine sponge Halichondria panicea Pallas and the implications for biomonitoring. Mar Pollut Bull 31:133-138

Hare MP (2001) Prospects for nuclear gene phylogeography. Trends Ecol Evol 16:700-706

Hartman WD (1958) Natural history of the marine sponges of southern New England. Bulletin of the Peabody Museum of Natural History, Yale University 12:1-155

Hechtel GH (1965) A systematic study of the Demospongiae of Port Royal, Jamaica. Bull Peabody Mus Nat Hist 20:1-103

Hendriks IE, Duarte CM (2008) Allocation of effort and imbalances in biodiversity research. J Exp Mar Biol Ecol 360:15-20

Hill MS (1998) Spongivory on Caribbean reefs releases corals from competition with sponges. Oecologia 117:143-150

Hily C (1991) Is the activity of benthic suspension feeders a factor controlling water quality in the Bay of Brest? Mar Ecol Prog Ser 69:179-188

Hiscock K, Stone SMK, George JD (1983) The marine fauna of Lundy. Porifera (sponges): a preliminary study. Report of the Lundy Field Society 34:16-31

Hodgson G (1990) Sediment and the settlement of larvae of the reef coral Pocillopora damicornis. Coral Reefs 9:41-43-43

Hoegh-Guldberg O (2011) Coral reef ecosystems and anthropogenic climate change. Reg Env Ch 11:215-227

Hoegh-Guldberg O, Mumby PJ, Hooten AJ, Steneck RS, Greenfield P, Gomez E, Harvell CD, Sale PF, Edwards AJ, Caldeira K, Knowlton N, Eakin CM, Iglesias-Prieto R, Muthiga N, Bradbury RH, Dubi A, Hatziolos ME (2007) Coral reefs under rapid climate change and ocean acidification. Science 318:1737-1742 
Holmes KE (2000) Effects of eutrophication on bioeroding sponge communities with the description of new West Indian sponges, Cliona spp. (Porifera : Hadromerida : Clionidae). Invertebr Biol 119:125-138

Hooper JNA (1991) Revision of the family Raspailiidae (Porifera: Demospongiae), with descriptions of Australian species. Invertebr Taxon 5:1179-1418

Hooper JNA, van Soest RWM (2002) Systema Porifera: a guide to the classification of sponges, Vol. Kluwer Academic/Plenum Publishers, New York, NY (USA)

Hoover JP (2006) Hawaii's sea creatures, a guide to Hawaii's marine invertebrates. Revised Edition, Vol. Mutual publishing, Honolulu, Hawaii

Hoppe WF, Reichert MJM (1987) Predictable annual mass release of gametes by the coral reefs sponge Neofibularia nolitangere (Porifera: Demospongiae). Mar Biol 94:277-285

Hoshino S, Saito DS, Fujita T (2008) Contrasting genetic structure of two Pacific Hymeniacidon species. Hydrobiologia 603:313-326

Huang D, Meier R, Todd PA, Chou LM (2008) Slow mitochondrial COI sequence evolution at the base of the metazoan tree and its implications for DNA barcoding. J Mol Evol 66:167-174

Hudson RR, Kreitman M, Aguadé M (1987) A test of neutral molecular evolution based on nucleotide data. Genetics 116:153-159

Hughes TP (1996) Demographic approaches to community dynamics: a coral reef example. Ecology 77:2256-2260

Hughes TP, Baird AH, Bellwood DR, Card M, Connolly SR, Folke C, Grosberg R, Hoegh-Guldberg O, Jackson JBC, Kleypas J, Lough JM, Marshall P, Nystrom M, Palumbi SR, Pandolfi JM, Rosen B, Roughgarden J (2003) Climate change, human impacts, and the resilience of coral reefs. Science 301:929-933

Hughes TP, Rodrigues MJ, Bellwood DR, Ceccarelli D, Hoegh-Guldberg O, McCook L, Moltschaniwskyj N, Pratchett MS, Steneck RS, Willis B (2007) Phase shifts, herbivory, and the resilience of coral reefs to climate change. Curr Biol 17:360-365

Hurlbut CJ (1992) Larval release and supply predict temporal variation in settlement of a colonial ascidian. Mar Ecol Prog Ser 80:215-219

Ilan M (1995) Reproductive biology, taxonomy and aspects of chemical ecology of Latrunculiidae (Porifera). Biol Bull 188:306-312

Ilan M, Abelson A (1995) The life of a sponge in a sandy lagoon. Biol Bull 189:363369

Itskovich VB, Belikov S, Efremova S, Masuda Y, Perez T, Alivon E, Borchiellini C, Boury-Esnault N (2007) Phylogenetic relationships between freshwater and marine Haplosclerida (Porifera, Demospongiae) based on the full length $18 \mathrm{~S}$ rRNA and partial COXI gene sequences. Porifera research: biodiversity, innovation and sustainability Museu Nacional, Rio de Janeiro 28

Jackson JBC (1997) Reefs since Colombus. Coral Reefs 16:S23-S32

Jackson JBC, Buss L (1975) Allelopathy and spatial competition among coral reef invertebrates. P Natl Acad Sci USA 72:5160-5163

Jaenike J, Brekke TD (2011) Defensive endosymbionts: a cryptic trophic level in community ecology. Ecol Lett 14:150-155

Jansen VAA, Vitalis R (2007) The evolution of dispersal in a Levins' type metapopulation model. Evolution 61:2386-2397

Jarman SN, Ward RD, Elliott NG (2002) Oligonucleotide primers for PCR amplification of coelomate introns. Mar Biotechnol 4:347-355

Jiménez E, Ribes M (2007) Sponges as a source of dissolved inorganic nitrogen: nitrification mediated by temperate sponges. Limnol Oceanogr 52:948-958 
Jokiel PL (1980) Solar ultraviolet radiation and coral reef epifauna. Science 207:1069-1071

Jorgensen CB, Mohlenberg F, Sten-Knudsen O (1986) Nature of relation between ventilation and oxygen consumption in filter feeders. Mar Ecol Prog Ser 29:73-88

Kaartinen R, Stone GN, Hearn J, Lohse K, Roslin T (2010) Revealing secret liaisons: DNA barcoding changes our understanding of food webs. Ecol Entomol 35:623-638

Kelly LW, Barott KL, Dinsdale E, Friedlander AM, Nosrat B, Obura D, Sala E, Sandin SA, Smith JE, Vermeij MJA, Williams GJ, Willner D, Rohwer F (2012) Black reefs: iron-induced phase shifts on coral reefs. ISME J 6:638-649

Kench PS (1998) Physical processes in an Indian Ocean atoll. Coral Reefs 17:155-168

Khailov KM, Burlakova ZP (1969) Release of dissolved organic matter by marine seaweeds and distribution of their total organic production to inshore communities. Limnol Oceanogr 14:521-527

Kimmerer WJ, Gartside E, Orsi JJ (1994) Predation by an introduced clam as the likely cause of substantial declines in zooplankton of San Francisco Bay Mar Ecol Prog Ser 113:81-93

Kjerfve B (1986) Comparative oceanography of coastal lagoons. Estuar var:63-81

Klautau M, Russo C, Lazoski C, Boury-Esnault N, Thorpe JP, Solé-Cava AM (1999) Does cosmopolitanism in morphologically simple species result from overconservative systematics? A case study using the marine sponge Chondrilla nucula. Evolution 53:1414-1422

Kline DI, Kuntz NM, Breitbart M, Knowlton N, Rohwer F (2006) Role of elevated organic carbon levels and microbial activity in coral mortality. Mar Ecol Prog Ser 314:119-125

Knott NA, Underwood AJ, Chapman MG, Glasby TM (2004) Epibiota on vertical and on horizontal surfaces on natural reefs and on artificial structures. J Mar Biol Assoc UK 84:1117-1130

Knowlton N (2001) The future of coral reefs. P Natl Acad Sci USA 98:5419-5425

Knowlton N, Jackson JBC (2008) Shifting baselines, local impacts, and global change on coral reefs. PLoS Biol 6:e54

Knowlton N, Rohwer F (2003) Multispecies Microbial Mutualisms on Coral Reefs: The Host as a Habitat. The American Naturalist 162:551-562

Kohler KE, Gill SM (2006) Coral Point Count with Excel extensions (CPCe): A Visual Basic program for the determination of coral and substrate coverage using random point count methodology. Comput Geosci 32:1259-1269

Kolar CS, Lodge DM (2001) Progress in invasion biology: predicting invaders. Trends Ecol Evol 16:199-204

Koopmans M, Martens D, Wijffels R (2010) Growth Efficiency and Carbon Balance for the Sponge Haliclona oculata. Mar Biotechnol 12:340-349

Kuntz NM, Kline DI, Sandin SA, Rohwer F (2005) Pathologies and mortality rates caused by organic carbon and nutrient stressors in three Caribbean coral species. Mar Ecol Prog Ser 294:173-180

Ladner JT, Palumbi SR (2012) Extensive sympatry, cryptic diversity and introgression throughout the geographic distribution of two coral species complexes. Mol Ecol 21:2224-2238

Lafferty KD, Kuris AM (1996) Biological control of marine pests. Ecology 77:19892000

Lavrov DV (2007) Key transitions in animal evolution: a mitochondrial DNA perspective. Integr Comp Biol 47:734-743 
Lavrov DV, Forget L, Kelly M, Lang F (2005) Mitochondrial genomes of two Demosponges provide insights into an early stage of animal evolution. Mol Biol Evol 22:1231-1239

Lavrov DV, Wang XJ, Kelly M (2008) Reconstructing ordinal relationships in the Demospongiae using mitochondrial genomic data. Mol Phylogen Evol 49:111124

Lawn ID, Mackie GO, Silver G (1981) Conduction system in a sponge. Science (US) 211:1169-1171

Le Roux J, Wieczorek AM (2009) Molecular systematics and population genetics of biological invasions: towards a better understanding of invasive species management. Ann Appl Biol 154:1-17

Lee CE (2002) Evolutionary genetics of invasive species. Trends Ecol Evol 17:386391

Leibold MA, Holyoak M, Mouquet N, Amarasekare P, Chase JM, Hoopes MF, Holt RD, Shurin JB, Law R, Tilman D, Loreau M, Gonzalez A (2004) The metacommunity concept: a framework for multi-scale community ecology. Ecol Lett 7:601-613

Lesser MP (2006) Benthic-pelagic coupling on coral reefs: feeding and growth of Caribbean sponges. J Exp Mar Biol Ecol 328:277-288

Levine JM, D'Antonio CM (2003) Forecasting biological invasions with increasing international trade. Conserv Biol 17:322-326

Leys SP, Mackie GO, Meech RW (1999) Impulse conduction in a sponge. J Exp Biol 202:1139-1150

Li CW, Chen JY, Hua TE (1998) Precambrian sponges with cellular structures. Science (US) 279:879-882

Lo E (2005) Gaussian error propagation applied to ecological data: post-ice-stormdowned woody biomass. Ecol Monogr 75:451-466

Lockwood JL, Cassey P, Blackburn T (2005) The role of propagule pressure in explaining species invasions. Trends Ecol Evol 20:223-228

Lodge DM (1993) Biological invasions: lessons for ecology. Trends Ecol Evol 8:133137

Longo C, Corriero G, Licciano M, Stabili L (2010) Bacterial accumulation by the Demospongiae Hymeniacidon perlevis: a tool for the bioremediation of polluted seawater. Mar Pollut Bull 60:1182-1187

López-Duarte PC, Carson HS, Cook GS, Fodrie FJ, Becker BJ, DiBacco C, Levin LA (2012) What controls connectivity? An empirical, multi-species approach. Integr Comp Biol 52:511-524

MacDougall AS, Turkington R (2005) Are invasive species the drivers or passengers of change in degraded ecosystems? Ecology 86:42-55

Mack RN, Simberloff D, Lonsdale WM, Evans H, Clout M, Bazzaz FA (2000) Biotic invasions: Causes, epidemiology, global consequences, and control. Ecol Appl 10:689-710

Maida M, Coll JC, Sammarco PW (1994) Shedding new light on scleractinian coral recruitment. J Exp Mar Biol Ecol 180:189-202

Maldonado M (2006) The ecology of the sponge larva. Can J Zool 84:175-194

Maldonado M, Carmona MC, Velásquez Z, Puig A, Cruzado A, López A, Young CM (2005) Siliceous Sponges as a Silicon Sink: An Overlooked Aspect of Benthopelagic Coupling in the Marine Silicon Cycle. Limnol Oceanogr 50:799-809

Maldonado M, Giraud K, Carmona C (2008) Effects of sediment on the survival of asexually produced sponge recruits. Mar Biol 154:631-641 
Maldonado M, Young C (1999) Effects of the duration of larval life on postlarval stages of the demosponge Sigmadocia coerulea. J Exp Mar Biol Ecol 232:9-21

Maldonado M, Young CM (1996) Effects of physical factors on larval behavior, settlement and recruitment of four tropical demosponges. Mar Ecol Prog Ser 138:169-180

Manuel M, Borchiellini C, Alivon E, Le Parco Y, Vacelet J, Boury-Esnault N (2003) Phylogeny and evolution of calcareous sponges: monophyly of Calcinea and Calcaronea, high Level of morphological homoplasy, and the primitive nature of axial symmetry. Syst Biol 52:311-333

Maragos J, Friedlander AM, Godwin S, Musburger C, Tsuda R, Flint E, Pantos O, Ayotte P, Sala E, Sandin S, McTee S, Siciliano D, Obura D (2008) US coral reefs in the Line and Phoenix Islands, central Pacific Ocean: Status, threats and significance. In: Riegl B, Dodge RE (eds) Coral Reefs of the USA. Springer, Amsterdam, pp. 643-654.

Maragos JE (1993) Impact of coastal construction on coral reefs in the United-Statesaffiliated Pacific Islands. Coast Manage 21:235-269

Maragos JE, Crosby MP, McManus JW (1996) Coral Reefs and Biodiversity: A Critical and Threatened Relationship. Oceanography 9:83-99

Maragos JE, Williams GJ (2011a) Pacific Coral Reefs: an introduction. In: Hopley E (ed) Encyclopedia of Modern Coral Reefs. Springer-Verlag, p. 1236.

Maragos JE, Williams GJ (2011b) Pacific coral reefs: an introduction. In: Hopley D (ed) Encyclopedia of modern coral reefs. Springer-Verlag.

Margalef R (1997) Our Biosphere, Vol 10. Ecology Institute Oldendorf/Luhe, Germany

Mariani S, Uriz MJ, Turon X (2005) The dynamics of sponge larvae assemblages from northwestern Mediterranean nearshore bottoms. J Plankton Res 27:249262

Martin JH, Fitzwater SE (1992) Dissolved organic carbon in the Atlantic, Southern and Pacific oceans. Nature 356:699-700

McArdle BH, Anderson MJ (2001) Fitting multivariate models to community data: a comment on distance-based redundancy analysis. Ecol Soc 82:290-297

McCauley DJ, DeSalles PA, Young HS, Dunbar RB, Dirzo R, Mills MM, Micheli F (2012) From wing to wing: the persistence of long ecological interaction chains in less-disturbed ecosystems. Sci Rep 2

McClintock JB, Amsler CD, Baker BJ, van Soest RWM (2005) Ecology of antarctic marine sponges: An overview. Integr Comp Biol 45:359-368

McCormack GP, Erpenbeck D, Van Soest RWM (2002) Major discrepancy between phylogenetic hypotheses based on molecular and morphological criteria within the Order Haplosclerida (Phylum Porifera: Class Demospongiae). J Zool Syst Evol Res 40:237-240

McKinney ML (2002) Do human activities raise species richness? Contrasting patterns in United States plants and fishes. Global Ecol Biogeogr 11:343-348

McManus GB, Xu D, Costas BA, Katz LA (2010) Genetic identities of cryptic species in the Strombidium stylifer/apolatum/oculatum cluster, including a description of Strombidium rassoulzadegani n. sp. J Eukaryot Microbiol 57:369-378

McManus JW, Polsenberg JF (2004) Coral-algal phase shifts on coral reefs: ecological and environmental aspects. Prog Oceanogr 60:263-279

Meyer CP, Geller JB, Paulay G (2005) Fine scale endemism on coral reefs: archipelagic differentiation in turbinid gastropods. Evolution 59:113-125 
Milanese M, Chelossi E, Manconi R, Sarà A, Sidri M, Pronzato R (2003) The marine sponge Chondrilla nucula Schmidt, 1862 as an elective candidate for bioremediation in integrated aquaculture. Biomol Eng 20:363-368

Moberg F, Folke C (1999) Ecological goods and services of coral reef ecosystems. Ecol Econ 29:215-233

Molnar JL, Gamboa RL, Revenga C, Spalding MD (2008) Assessing the global threat of invasive species to marine biodiversity. Front Ecol Environ 6:485-492

Mooney HA, Cleland EE (2001) The evolutionary impact of invasive species. P Natl Acad Sci USA 98:5446-5451

Motta PJ (1989) Dentition patterns among Pacific and Western Atlantic butterflyfishes (Perciformes, Chaetodontidae): relationship to feeding ecology and evolutionary history. Environ Biol Fishes 25:159-170

Müller WEG (1995) Molecular phylogeny of Metazoa (Animals): monophyletic origin. Naturwissenschaften 82:321-329

Muller WEG, Brummer F, Batel R, Muller IM, Schroder HC (2003) Molecular biodiversity. Case study: Porifera (sponges). Naturwissenschaften 90:103-120

Mumby PJ (2009) Phase shifts and the stability of macroalgal communities on Caribbean coral reefs. Coral Reefs 28:761-773

Muricy G, Solé-Cava AM, Thorpe JP, Boury-Esnault N (1996) Genetic evidence for extensive cryptic speciation in the subtidal sponge Plakina trilopha (Porifera: Demospongiae: Homoscleromorpha). Mar Ecol Prog Ser 138:181-187

Naumann M, Haas A, Jantzen C, Iglesias-Prieto R, Wild C (2012) Benthic-pelagic coupling in a Caribbean reef lagoon affected by hurricane" Dolly". In. Proc 12th International Coral Reef Symposium

Nei M, Maruyama T, Chakraborty R (1975) Bottleneck effect and genetic-variability in populations. Evolution 29:1-10

Norström AV, Nyström M, Lokrantz J, Folke C (2009) Alternative states on coral reefs: beyond coral-macroalgal phase shifts. Mar Ecol Prog Ser 376:295-306

Officer CB, Smayda TJ, R. M (1982) Benthic filter feeding: a natural eutrophication control. Mar Ecol Prog Ser 9:203-210

Osinga R, Kleijn R, Groenendijk E, Niesink P, Tramper J, Wijffels RH (2001) Development of in vivo sponge cultures: Particle feeding by the tropical sponge Pseudosuberites aff. andrewsi. Mar Biotechnol 3:544-554

Padovan A, Munksgaard N, Alvarez B, McGuinness K, Parry D, Gibb K (2012) Trace metal concentrations in the tropical sponge Spheciospongia vagabunda at a sewage outfall: synchrotron X-ray imaging reveals the micron-scale distribution of accumulated metals. Hydrobiologia:1-14

Pagès J, Torréton J-P, Sempéré R (1997) Dissolved organic carbon in coral-reef lagoons, by high temperature catalytic oxidation and UV spectrometry. CR Acad Sci II A 324:915-922

Palumbi SR (1984) Tactics of acclimation-morphological-changes of sponges in an unpredictable environment. Science 225:1478-1480

Palumbi SR (1986) How body plans limit acclimation- responses of a Demosponge to wave force. Ecology 67:208-214

Palumbi SR (2004) Marine reserves and ocean neighborhoods: The spatial scale of marine populations and their management. Annual Review of Environment and Resources 29:31-68

Pandolfi JM, Bradbury RH, Sala E, Hughes TP, Bjorndal KA, Cooke RG, McArdle D, McClenachan L, Newman MJH, Paredes G, Warner RR, Jackson JBC (2003) Global trajectories of the long-term decline of coral reef ecosystems. Science 301:955-958 
Pastorok RA, Bilyard GR (1985) Effects of sewage pollution on coral-reef communities. Mar Ecol Prog Ser 21:175-189

Patel B, Balani MC, Patel S (1985) Sponge 'sentinel' of heavy metals. Sci Total Environ 41:143-152

Paulay G, Kirkendale L, Lambert G, Meyer C (2002) Anthropogenic biotic interchange in a coral reef ecosystem: A case study from Guam. Pac Sci 56:403-422

Pawlik JR (1998) Coral reef sponges: Do predatory fishes affect their distribution? Limnol Oceanogr 43:1396-1399

Penney JT, Racek AA (1968) Comprehensive revision of a worldwide collection of freshwater sponges (Porifera: Spongillidae). United States National Museum Bulletin 272:1-184

Perea-Blázquez A (2011) Interactions between sponges and the water column: nutrient utilisation and feeding by New Zealand subtidal sponges. http://hdl.handle.net/10063/1866

Perea-Blázquez A, Davy SK, Bell JJ (2012) Estimates of particulate organic carbon flowing from the pelagic environment to the benthos through sponge assemblages. PLoS ONE 7:e29569

Perez T, Longet D, Schembri T, Rebouillon P, Vacelet J (2005) Effects of 12 years' operation of a sewage treatment plant on trace metal occurrence within a Mediterranean commercial sponge (Spongia officinalis, Demospongiae). Mar Pollut Bull 50:301-309

Peterson BJ, Chester CM, Jochem FJ, Fourqurean JW (2006) Potential role of sponge communities in controlling phytoplankton blooms in Florida Bay. Mar Ecol Prog Ser 328:93-103

Peterson KJ, Addis JS (2000) Clypeatula cooperensis gen. n., sp. n., a new freshwater sponge (Porifera, Spongillidae) from the Rocky Mountains of Montana, USA. Zool Scr 29:265-274

Petraitis PS, Dudgeon SR (2004) Detection of alternative stable states in marine communities. J Exp Mar Biol Ecol 300:343-371

Pile AJ (1996) Finding Reiswig's missing carbon: quantification of sponge feeding using dual-beam flow cytometry. In: Lessios HA (ed) 8th international coral reef symposium, June 24-29, 1996, Panama, abstract. ICRS, Panama, p. 158.

Pile AJ, Patterson MR, Savarese M, Chernykh VI, Fialkov VA (1997) Trophic effects of sponge feeding within Lake Baikal's littoral zone. 2. Sponge abundance, diet, feeding efficiency, and carbon flux. Limnol Oceanogr 42:178-184

Pile AJ, Patterson MR, Witman JD (1996) In situ grazing on plankton $<10 \mu \mathrm{m}$ by the boreal sponge Mycale lingua. Mar Ecol Prog Ser 141:95-102

Pimentel D, McNair S, Janecka J, Wightman J, Simmonds C, O'Connell C, Wong E, Russel L, Zern J, Aquino T, Tsomondo T (2001) Economic and environmental threats of alien plant, animal, and microbe invasions. Agric Ecosyst Environ $84: 1-20$

Pimentel D, Zuniga R, Morrison D (2005) Update on the environmental and economic costs associated with alien-invasive species in the United States. Ecol Econ 52:273-288

Pöppe J, Sutcliffe P, Hooper JNA, Wörheide G, Erpenbeck D (2010) CO I barcoding reveals new clades and radiation patterns of Indo-Pacific sponges of the family Irciniidae (Demospongiae: Dictyoceratida). PLoS ONE 5:e9950

Posada D, Crandall KA (1998) Modeltest: testing the model of DNA substitution. Bioinformatics 14:817-818 
Posada D, Crandall KA (2001) Selecting models of nucleotide substitution: an application to Human Immunodeficiency Virus 1 (HIV-1). Mol Biol Evol 18:897-906

Powell AL, Hepburn LJ, Smith DJ, Bell JJ (2010) Patterns of Sponge Abundance Across a Gradient of Habitat Quality in the Wakatobi Marine National Park, Indonesia. Op Mar Biol J 4:31-38

Puth LM, Post DM (2005) Studying invasion: have we missed the boat? Ecol Lett 8:715-721

Rainbow PS (2002) Trace metal concentrations in aquatic invertebrates: why and so what? Environ Pollut 120:497-507

Rainbow PS (2007) Trace metal bioaccumulation: models, metabolic availability and toxicity. Environ Int 33:576-582

Raleigh J, Redmond NE, Delahan E, Torpey S, Van Soest RWM, Kelly M, McCormack GP (2007) Mitochondrial cytochrome oxidase 1 phylogeny supports alternative taxonomic scheme for the marine Haplosclerida. J Mar Biol Assoc UK 87:1577-1584

Rapport DJ, Whitford WG (1999) How Ecosystems Respond to Stress. Am Inst Biol Sci 49:193-203

Redmond NE, McCormack GP (2008) Large expansion segments in 18S rDNA support a new sponge clade (Class Demospongiae, Order Haplosclerida). Mol Phylogen Evol 47:1090-1099

Redmond NE, Raleigh J, van Soest RWM, Kelly M, Travers SAA, Bradshaw B, Vartia S, Stephens KM, McCormack GP (2011) Phylogenetic relationships of the marine Haplosclerida (Phylum Porifera) employing ribosomal (28S rRNA) and mitochondrial (coxl, nad1) Gene Sequence Data. PLoS ONE 6:e24344

Redmond NE, van Soest RW, Kelly M, Raleigh J, Travers SA, McCormack GP (2007) Reassessment of the classification of the Order Haplosclerida (Class Demospongiae, Phylum Porifera) using 18S rRNA gene sequence data. Mol Phylogenet Evol 43:344-352

Reiswig HM (1971a) In situ pumping activities of tropical Demospongiae. Mar Biol 9:38-50

Reiswig HM (1971b) Particle feeding in natural populations of three marine demosponges. Biol Bull 141:568-591

Reiswig HM (1974) Water transport, respiration and energetics of three tropical marine sponges. J Exp Mar Biol Ecol 14:231-249

Reiswig HM (1975) Bacteria as food for temperate water marine sponges. Can J Zool 53:582-589

Reiswig HM (1981) Partial carbon and energy budgets of the bacteriosponge Verongia fistularis (Porifera: Demospongiae) in Barbados. PSZNI Mar Ecol 2:273-293

Ribes M, Coma R, Atkinson MJ, Kinzie Iii RA (2003) Particle removal by coral reef communities: Picoplankton is a major source of nitrogen. Mar Ecol Prog Ser 257:13-23

Ribes M, Coma R, Atkinson MJ, Kinzie Iii RA (2005) Sponges and ascidians control removal of particulate organic nitrogen from coral reef water. Limnol Oceanogr 50:1480-1489

Ribes M, Coma R, Gili JM (1999) Natural diet and grazing rate of the temperate sponge Dysidea avara (Demospongiae, Dendroceratida) throughout an annual cycle. Mar Ecol Prog Ser 176:179-190

Richmond MD, Seed R (1991) A review of marine macrofouling communities with special reference to animal fouling. Biofouling 3:151-168 
Richter C, Wunsch M, Rasheed M, Kotter I, Badran MI (2001) Endoscopic exploration of Red Sea coral reefs reveals dense populations of cavitydwelling sponges. Nature 413:726-730

Riisgard HU, Thomassen S, Jakobsen H, Weeks JM, Larsen PS (1993) Suspension feeding in marine sponges Halichondria panicea and Haliclona urceolus: effects of temperature on filtration rate and energy cost of pumping. Mar Ecol Prog Ser 96:177-188

Roberts DE, Davis AR (1996) Patterns in Sponge (Porifera) assemblages on temperate coastal reefs off Sydney, Australia. Mar Fresh Res 47:897-906

Roberts DE, Davis AR, Cummings SP (2006) Experimental manipulation of shade, silt, nutrients and salinity on the temperate reef sponge Cymbastela concentrica. Mar Ecol Prog Ser 307:143-154

Roditi HA, Fisher NS, Sanudo-Wilhelmy SA (2000) Uptake of dissolved organic carbon and trace elements by zebra mussels. Nature 407:78-80

Roff G, Mumby PJ (2012) Global disparity in the resilience of coral reefs. Trends Ecol Evol 27:404-413

Rogers CS (1990) Responses of coral reefs and reef organisms to sedimentation. Mar Ecol Prog Ser 62:185-202

Rogers SI, Clarke KR, Reynolds JD (1999) The taxonomic distinctness of coastal bottom-dwelling fish communities of the North-east Atlantic. J Anim Ecol 68:769-782

Ronquist F, Huelsenbeck JP (2003) MrBayes 3: Bayesian phylogenetic inference under mixed models. Bioinformatics 19:1572-1574

Rooney JJ, Wessel P, Hoeke R, Weiss J, Baker J, Parrish F, Fletcher CH, Chojnacki J, Garcia M, Brainard R, Vroom P (2008) Geology and geomorphology of coral reefs in the Northwestern Hawaiian Islands. In: Riegl BM, Dodge RE (eds) Coral Reefs of the USA, Book 1. Springer Netherlands, Amsterdam, pp. 519571.

Rose CS, Risk MJ (1985) Increase in Cliona delitrix infestation of Montastrea cavernosa heads on an organically polluted portion of the Grand Cayman fringing reef. PSZNI Mar Ecol 6:345-362

Rot C, Goldfarb I, Ilan M, Huchon D (2006) Putative cross-kingdom horizontal gene transfer in sponge (Porifera) mitochondria. BMC Evol Biol 6:71

Ruckelshaus M, Hartway C, Kareiva P (2003) Assessing the data requirements of spatially explicit dispersal models. Conserv Biol 11:1298-1306

Rützler K (1975) The role of burrowing sponges in bioerosion. Oecologia 19:203-216

Rützler K (2002) Impact of crustose Clionid sponges on Caribbean reef corals. Acta Geol Hisp 37:61-72

Ruiz GM, Carlton JT (2003) Invasive species: vectors and management strategies. Afr J Aquat Sci 29:287

Ruiz GM, Carlton JT, Grosholz ED, Hines AH (1997) Global invasions of marine and estuarine habitats by non-indigenous species: Mechanisms, extent, and consequences. Am Zool 37:621-632

Ryland JS (2005) Bryozoa: an introductory overview. Denisia 16:9-20

Sandin SA, Smith JE, DeMartini EE, Dinsdale EA, Donner SD, Friedlander AM, Konotchick T, Malay M, Maragos JE, Obura D, Pantos O, Paulay G, Richie M, Rohwer F, Schroeder RE, Walsh S, Jackson JBC, Knowlton N, Sala E (2008) Baselines and degradation of coral reefs in the northern Line Islands. PLoS ONE 3:e1548 
Savarese M, Patterson MR, Chernykh VI, Fialkov VA (1997) Trophic effects of sponge feeding within Lake Baikal's littoral zone. 1. In situ pumping rates. Limnol Oceanogr 42:171-178

Schulze A, Maiorova A, Timm LE, Rice ME (2012) Sipunculan larvae and “cosmopolitan" species. Integr Comp Biol doi: 10.1093/icb/ics082

Schutze J, Krasko A, Custodio MR, Efremova SM, Muller IM, Muller WEG (1999) Evolutionary relationships of Metazoa within the eukaryotes based on molecular data from Porifera. Proc R Soc Lond B Biol Sci 266:63-73

Segel LA, Ducklow HW (1982) A theoretical investigation into the influence of sublethal stresses on coral-bacterial ecosystem dynamics. Bull Mar Sci 32:919-935

Shearer TL, Van Oppen MJH, Romano SL, Wörheide G (2002) Slow mitochondrial DNA sequence evolution in the Anthozoa (Cnidaria). Mol Ecol 11:2475-2487

Simberloff D, Martin JL, Genovesi P, Maris V, Wardle DA, Aronson J, Courchamp F, Galil B, García-Berthou E, Pascal M (2012) Impacts of biological invasions: what's what and the way forward. Trends Ecol Evol 10.1016/j.tree.2012.07.013

Simpson CJ, Cary JL, Masini RJ (1993) Destruction of corals and other reef animals by coral spawn slicks on Ningaloo Reef, Western Australia. Coral Reefs 12:185-191

Simpson TL (1978) The biology of the marine sponge Microciona prolifera (Ellis and Solander). III. Spicule secretion and the effect of temperature on spicule size. J Exp Mar Biol Ecol 35:31-42

Simpson TL (1984) The cell biology of sponges, Vol. Springer Verlag, New York

Smith JE, Shaw M, Edwards RA, Obura D, Pantos O, Sala E, Sandin SA, Smriga S, Hatay M, Rohwer FL (2006) Indirect effects of algae on coral: algae-mediated, microbe-induced coral mortality. Ecol Lett 9:835-845

Solé-Cava AM, Thorpe JP (1986) Genetic differentiation between morphotypes of the marine sponge Suberites ficus (Demospongiae: Hadromerida). Mar Biol 93:247-253

Solé-Cava AM, Wörheide G (2007) The perils and merits (or The Good, the Bad and the Ugly) of DNA barcoding of sponges a controversial discussion. In: Custódio MR, Lôbo-Hajdu G, Hajdu E, Muricy G (eds) Porifera research biodiversity, innovation and sustainability, Book 28. Editora do Museu Nacional do Rio de Janeiro, Rio de Janeiro, pp. 603-612.

Sorte CJB, Williams SL, Zerebecki RA (2010) Ocean warming increases threat of invasive species in a marine fouling community. Ecology 91:2198-2204

Stabili L, Licciano M, Giangrande A, Longo C, Mercurio M, Marzano CN, Corriero G (2006) Filtering activity of Spongia officinalis var. adriatica (Schmidt) (Porifera, Demospongiae) on bacterioplankton: implications for bioremediation of polluted seawater. Water Res 40:3083-3090

Stobart B, Teleki K, Buckley R, Downing N, Callow M (2005) Coral recovery at Aldabra Atoll, Seychelles: five years after the 1998 bleaching event. Phil Trans R Soc A 363:251-255

Stockman AK, Bond JE (2007) Delimiting cohesion species: extreme population structuring and the role of ecological interchangeability. Mol Ecol 16:33743392

Stockwell CA, Ashley MV (2004) Diversity - Rapid adaptation and conservation. Conserv Biol 18:272-273

Stockwell CA, Hendry AP, Kinnison MT (2003) Contemporary evolution meets conservation biology. Trends Ecol Evol 18:94-101 
Stoddart DR (1968) Catastrophic Human Interference with Coral Atoll Ecosystems. Geography 53:25-40

Stone AR (1970) Seasonal variations of spicule size in Hymeniacidon perleve. J Mar Biol Assoc UK 50:343-348

Sultan SAR, Ahmad F (1990) Flushing of a coastal lagoon in the Red sea. Estuar Coast Shelf Sci 31:345-349

Sutherland JP, Karlson RH (1977) Development and stability of the fouling community at Beaufort, North Carolina. Ecol Monogr 47:425-446

Suzuki A, Kawahata H (2003) Carbon budget of coral reef systems: an overview of observations in fringing reefs, barrier reefs and atolls in the Indo-Pacific regions. Tellus 55:428-444

Tamura K, Peterson D, Peterson N, Stecher G, Nei M, Kumar S (2011) MEGA5: molecular evolutionary genetics analysis using maximum likelihood, evolutionary distance, and maximum parsimony methods. Mol Biol Evol 28:2731-2739

Tarjuelo I, Posada D, Crandall KA, Pascual M, Turon X (2001) Cryptic species of Clavelina (Ascidiacea) in two different habitats: harbours and rocky littoral zones in the northwestern Mediterranean. Mar Biol 139:455-462

Tecco PA, Gurvich DE, Diaz S, Pérez-Harguindeguy N, Cabido M (2006) Positive interaction between invasive plants: the influence of Pyracantha angustifolia on the recruitment of native and exotic woody species. Austral Ecol 31:293300

Thrush SF, Dayton PK (2002) Disturbance to marine benthic habitats by trawling and dredging: implications for marine biodiversity. Annu Rev Ecol Syst 33:449473

Tompkins-MacDonald GJ, Leys SP (2008) Glass sponges arrest pumping in response to sediment: implications for the physiology of the hexactinellid conduction system. Mar Biol 154:973-984

Topsent E (1928) Spongiaires del'Atlantique et dela Méditerranée, provenant des croisières du prince Albert Ier deMonaco. Résultats des Campagnes Scientifiques du Prince Albert Ier deMonaco 74:1-376

Torréton J, Pagès J, Dufour P, Cauwet G (1997) Bacterioplankton carbon growth yield and DOC turnover in some coral reef lagoons. In: Lessios HA, Macintyre IG (eds). Proc 8th international coral reef symposium. Smithsonian Tropical Research Institute

Torréton JP, Pagès J, Talbot V (2002) Relationships between bacterioplankton and phytoplankton biomass, production and turnover rate in Tuamotu atoll lagoons. Aquat Microb Ecol 28:267-277

Townsin RL (2003) The ship hull fouling penalty. Biofouling 19:9-15

Tsutsui ND, Suarez AV, Holway DA, Case TJ (2000) Reduced genetic variation and the success of an invasive species. P Natl Acad Sci USA 97:5948-5953

Tyrrell MC, Byers JE (2007) Do artificial substrates favor nonindigenous fouling species over native species? J Exp Mar Biol Ecol 342:54-60

Uriz MJ, Carballo JL (2001) Phylogenetic relationships of sponges with placochelae or related spicules (Poecilosclerida, Guitarridae) with a systematic revision. Zool J Linn Soc 132:411-428

Uriz MJ, Maldonado M, Turon X, Marti R (1998) How do reproductive output, larval behaviour, and recruitment contribute to adult spatial patterns in Mediterranean encrusting sponges? Mar Ecol Prog Ser 167:137-148 
Uriz MJ, Turon X, Becerro MK, Agell G (2003) Siliceous spicules and skeleton frameworks in sponges: origin, diversity, ultrastructural patterns, and biological functions. Microsc Res Tech 62:279-299

van Soest RWM, Boury-Esnault N, Vacelet J, Dohrmann M, Erpenbeck D, De Voogd NJ, Santodomingo N, Vanhoorne B, Kelly M, Hooper JNA (2012) Global diversity of sponges (Porifera). PLoS ONE 7:e35105

van Soest RWM, Hooper JNA (2002) Order Haplosclerida Topsent, 1928. In: Hooper JNA, Soest RWMv (eds) Systema Porifera: a guide to the classification of sponges, Book 1. Kluwer Academic/Plenum Publishers, New York, pp. 831834.

van Soest RWM, Kaiser KL, Van Syoc R (2011) Sponges from Clipperton Island, East Pacific. Zootaxa 2839:1-46

van Soest RWMv (2002) Family Iotrochotidae Dendy, 1922. In: Hooper JNA, Soest RWMv (eds) Systema Porifera: A Guide to the Classification of Sponges, Book 1. Kluwer Academic/Plenum Publishers, New York, pp. 594-601.

Vaquer-Sunyer R, Duarte CM (2008) Thresholds of hypoxia for marine biodiversity. Proc Nat Acad Sci USA 105:15452-15457

Vermeij GJ (1991) When biotas meet-understanding biotic interchange. Science 253:1099-1104

Vermeij GJ (1996) An agenda for invasion biology. Biol Conserv 78:3-9

Vermeij MJA (2006) Early life-history dynamics of Caribbean coral species on artificial substratum: the importance of competition, growth and variation in life-history strategy. Coral Reefs 25:59-71

Vitousek PM (1997) Human domination of Earth's ecosystems. Science 277:494-499

Vitousek PM, Dantonio CM, Loope LL, Rejmanek M, Westbrooks R (1997) Introduced species: A significant component of human-caused global change. N Z J Ecol 21:1-16

Vogel S (1977) Current-induced flow through living sponges in nature. P Natl Acad Sci USA 74:2069-2071

Wahab MA, de Nys R, Whalan S (2011) Closing the lifecycle for the sustainable aquaculture of the bath sponge Coscinoderma matthewsi. Aquaculture 324325:281-289

Walton WC, MacKinnon C, Rodriguez LF, Proctor C, Ruiz GA (2002) Effect of an invasive crab upon a marine fishery: green crab, Carcinus maenas, predation upon a venerid clam, Katelysia scalarina, in Tasmania (Australia). J Exp Mar Biol Ecol 272:171-189

Ward-Paige CA, Risk MJ, Sherwood OA, Jaap WC (2005) Clionid sponge surveys on the Florida reef tract suggest land-based nutrient inputs. Mar Pollut Bull 51:570-579

Watkins RF, Beckenbach AT (1999) Partial sequence of a sponge mitochondrial genome reveals sequence similarity to Cnidaria in cytochrome oxidase subunit II and the large ribosomal RNA subunit. J Mol Evol 48:542-554

Webb CO, Ackerly DD, McPeek MA, Donoghue MJ (2002) Phylogenies and community ecology. Annu Rev Ecol Syst 33:475-505

Wegmann A, Buckelew S, Howald G, Helm J, Swinnerton K (2011) Rat eradication campaigns on tropical islands: novel challenges and possible solutions. Island invasives: eradication and management:239-243

Westram AM, Baumgartner C, Keller I, Jokela J (2011) Are cryptic host species also cryptic to parasites? Host specificity and geographical distribution of acanthocephalan parasites infecting freshwater Gammarus. Infection, Genetics and Evolution 11:1083-1090 
Whalan S, Battershill C, De Nys R (2007) Variability in reproductive output across a water quality gradient for a tropical marine sponge. Mar Biol 153:163-169

Whalan S, Ettinger-Epstein P, Battershill C, De Nys R (2008) Larval vertical migration and hierarchical selectivity of settlement in a brooding marine sponge. Mar Ecol Prog Ser 368:145-154

Whalan S, Johnson MS, Harvey E, Battershill C (2005) Mode of reproduction, recruitment, and genetic subdivision in the brooding sponge Haliclona sp. Mar Biol 146:425-433

Wilkinson CR (1983) Net primary productivity in coral reef sponges. Science (US) 219:410-412

Wilkinson CR, Cheshire AC (1989) Patterns in the distribution of sponge populations across the Central Great Barrier Reef. Coral Reefs 8:127-134

Wilkinson CR, Evans E (1989) Sponge distribution across Davies Reef, Great Barrier Reef, relative to location, depth, and water movement. Coral Reefs 8:1-7

Williams G, Knapp I, Work T, Conklin E (2011a) Outbreak of Acropora white syndrome following a mild bleaching event at Palmyra Atoll, Northern Line Islands, Central Pacific. Coral Reefs 30:621

Williams GJ, Knapp IS, Aeby GS, Davy SK (2011b) Spatial and temporal patterns of scleractinian coral, soft coral, and zoanthid disease on a remote, near-pristine coral reef (Palmyra Atoll, central Pacific). Dis Aquat Org 94:89-100

Williams GJ, Knapp IS, Maragos JE, Davy SK (2010) Modeling patterns of coral bleaching at a remote Central Pacific atoll. Mar Pollut Bull 60:1467-1476

Williams GJ, Knapp IS, Maragos JE, Davy SK (2011c) Proximate environmental drivers of coral communities at Palmyra Atoll: establishing baselines prior to removing a WWII military causeway. Mar Pollut Bull 62:1842-1851

Williams GJ, Maragos JE, Davy SK (2008) Characterization of the coral communities at Palmyra Atoll in the remote Central Pacific Ocean. Atoll Res Bull 557:1-30

Williams GJ, Smith JE, Conklin EJ, Gove J, Sala E, Sandin SA (in review) Structure of benthic communities on functionally intact coral reefs. Coral Reefs

Wilson HV (1925) Silicious and horny sponges collected by the fisheries steamer "Albatross" during the Philippine expedition, 1907-10. Bull U S Natl Mus 2:273-532

Wilson JRU, Dormontt EE, Prentis PJ, Lowe AJ, Richardson DM (2009) Something in the way you move: dispersal pathways affect invasion success. Trends Ecol Evol 24:136-144

Witte U (1996) Seasonal reproduction in deep-sea sponges - triggered by vertical particle flux? Mar Biol 124:571-581

Wonham MJ, Carlton JT, Ruiz GM, Smith LD (2000) Fish and ships: relating dispersal frequency to success in biological invasions. Mar Biol 136:11111121

Woodbury DO, Réthi L, Ruyl LH (1946) Builders for battle: how the pacific naval air bases were constructed, Vol. E.P. Dutton and Company inc., New York

Woodin SA (1986) Settlement of infauna: larval choice? Bull Mar Sci 39:401-407

Wörheide G (2006) Low variation in partial cytochrome oxidase subunit I (COI) mitochondrial sequences in the coralline demosponge Astrosclera willeyana across the Indo-Pacific. Mar Biol 148:907-912-912

Wörheide G, Degnan BM, Hooper JNA, Reitner J (2002a) Phylogeography and taxonomy of the Indo-Pacific reef cave dwelling coralline demosponge Astrosclera willeyana: new data from nuclear internal transcribed spacer sequences. In: Moosa K (ed). Proc 9th International Coral Reef Symposium, Bali, October 2000 
Wörheide G, Epp LS, Macis L (2008) Deep genetic divergences among Indo-Pacific populations of the coral reef sponge Leucetta chagosensis (Leucettidae): Founder effects, vicariance, or both? BMC Evol Biol 8

Wörheide G, Erpenbeck D, Menke C (2007) The sponge barcoding project: aiding in the identification and description of poriferan taxa. In: Custódio MR, LôboHajdu G, Hajdu E, Muricy G (eds). Proc Porifera research: biodiversity, innovation and sustainability

Wörheide G, Hooper JNA, Degnan BM (2002b) Phylogeography of western Pacific Leucetta 'chagosensis' (Porifera : Calcarea) from ribosomal DNA sequences: implications for population history and conservation of the Great Barrier Reef World Heritage Area (Australia). Mol Ecol 11:1753-1768

Wörheide G, Solé-Cava AM, Hooper JNA (2005) Biodiversity, molecular ecology and phylogeography of marine sponges: Patterns, implications and outlooks. Integr Comp Biol 45:377-385

Work TM, Aeby GS, Maragos JE (2008) Phase Shift from a Coral to a CorallimorphDominated Reef Associated with a Shipwreck on Palmyra Atoll. PLoS ONE 3

Wu J, Jones KB, Li H, Loucks OL (2006) Scaling and uncertainty analysis in ecology: methods and applications, Vol. Springer Verlag, Amsterdam

Wulff J (1997) Causes and consequences of differences in sponge diversity and abundance between the Caribbean and Eastern Pacific of Panama. In: Lessios HA, Macintyre IG (eds). Proc Proceedings of the 8th international Coral Reef Symposium

Wulff J (2011) Encyclopedia of modern coral reefs: structure, form and process. In: Hopley D (ed) Recherche. Springer, Amsterdam.

Wulff JL (1984) Sponge-mediated coral reef growth and rejuvenation. Coral Reefs $3: 157-163$

Wulff JL (1985) Dispersal and survival of fragmentsof coral reef sponges. Proceedings of the fifth International Coral Reef Congress, Tahiti 2:119-124

Wulff JL (1991) Asexual fragmentation, genotype success, and population dynamics of erect branching sponges. J Exp Mar Biol Ecol 149:227-247

Wulff JL (1994) Sponge feeding by Caribbean angelfishes, trunkfishes, and filefishes. In: Soest RWMv, van Kempen TG, Braekman JC (eds) Sponge in time and space; Biology, Chemistry, Paleontology. A.A. Balkema, Rotterdam, pp. 265271.

Wulff JL (2000) Sponge predators may determine differences in sponge fauna between two sets of mangrove cays, Belize Barrier Reef. Atoll Res Bull:251263

Wulff JL (2001) Assessing and monitoring coral reef sponges: why and how? Bull Mar Sci 69:831-846

Wulff JL (2006) Ecological interactions of marine sponges. Can J Zool 84:146-166

Wulff JL, Buss LW (1979) Do sponges help hold coral reefs together? Nature 281:474-475

Xavier JR, Rachello-Dolmen PG, Parra-Velandia F, Schönberg CHL, Breeuwer JAJ, Van Soest RWM (2010) Molecular evidence of cryptic speciation in the "cosmopolitan" excavating sponge Cliona celata (Porifera, Clionaidae). Mol Phylogen Evol 56:13-20

Yahel G, Anton FP, Fabricius K, Marie D, Vaulot D, Genin A (1998) Phytoplankton Distribution and Grazing Near Coral Reefs. Limnol Oceanogr 43:551-563

Yahel G, Sharp JH, Marie D, Häse C, Genin A (2003) In situ feeding and element removal in the symbiont-bearing sponge Theonella swinhoei: bulk DOC is the major source for carbon. Limnol Oceanogr 48:141-149 
Yiming L, Zhengjun W, Duncan RP (2006) Why islands are easier to invade: human influences on bullfrog invasion in the Zhoushan archipelago and neighboring mainland China. Oecologia (Berlin) 148:129-136

Youssef DH, El-Said GF (2011) Assessment of some heavy metals in surface sediments of the Aqaba Gulf, Egypt. Environ Monit Assess 180:229-242

Zacharias MA, Roff JC (2001) Use of focal species in marine conservation and management: a review and critique. Aquat Conserv: Mar Freshwat Ecosyst 11:59-76

Zakharov EV, Lobo NF, Nowak C, Hellmann JJ (2009) Introgression as a likely cause of mtDNA paraphyly in two allopatric skippers (Lepidoptera: Hesperiidae). Heredity 102:590-599

Zea S (1993) Recruitment of demosponges (Porifera, Demospongiae) in rocky and coral reef habitats of Santa Marta, Colombian Caribbean. Mar Ecol 14:1-21

Zea S (1994) Patterns of coral and sponge abundance in stressed coral reefs at Santa Marta, Colombian Caribbean. In: van Soest RWM, van Kempen TG, Braekman JC (eds) Sponge in time and space; Biology, Chemistry, Paleontology. A.A. Balkema, Rotterdam, pp. 257-264.

Zea S (2001) Patterns of sponge (Porifera, Demospongiae) distribution in remote, oceanic reef complexes of the Southwestern Caribbean. Rev Acad Col Cien Exac Físicas Nat 25:579-592

Zhang DY, Lin K, Hanski I (2004) Coexistence of cryptic species. Ecol Lett 7:165169 
Appendix I

Published manuscript: Records of non-indigenous marine species at Palmyra Atoll in the US Line Islands. 


\title{
Records of non-indigenous marine species at Palmyra Atoll in the US Line Islands
}

\author{
I.S. KNAPP ${ }^{1}$, L.S. GODWIN ${ }^{2}$, J.E. SMITH $^{3}$, G.J. WILLIAMS ${ }^{3}$ AND J.J. BELL ${ }^{1}$ \\ ${ }^{1}$ Centre for Marine Environmental and Economic Research, School of Biological Sciences, Victoria University of Wellington, PO Box \\ 600 Wellington, New Zealand, ${ }^{2}$ Papahānaumokuākea Marine National Monument, National Oceanic and Atmospheric \\ Administration, National Marine Sanctuaries, 6600 Kalaniana'ole Hwy Suite 300, Honolulu, HI 96825, ${ }^{3}$ Scripps Institution of \\ Oceanography, Center for Marine Biodiversity and Conservation, La Jolla, California, 92083, USA
}

\begin{abstract}
Globally, introductions of non-indigenous species have caused dramatic economic and ecological damage. Most research on marine invasions has occurred in locations easily accessible by researchers, but much less is known about introductions to remote islands. In the central Pacific, Palmyra Atoll represents one of the last remaining quasi-pristine reef systems left in the world. In the 1940 s the Atoll underwent extensive military modifications, potentially making it susceptible to invasive species. Here we describe the presence of five non-indigenous invertebrate and algal introductions at Palmyra, including two sponges, Haliclona (Sigmadocia) caerulea and Gelliodes fibrosa; one bryozoan; Zoobotryon verticillatum; one hydroid, Pennaria disticha and one macroalga, Acanthophora spicifera. The Hawaiian Archipelago is the most likely source of the introductions via shipping or yachting activity to the Atoll. Currently, the impacts of these introductions remain unknown although future monitoring will assess the influence of these non-indigenous species on this remote reef system.
\end{abstract}

Keywords: non-indigenous, introduction, sponge, algae, hydroid, bryozoan, lagoon, coral reef, Palmyra Atoll

Submitted 13 September 2010; accepted 21 December 2010

\section{INTRODUCTION}

The historic isolation of many Pacific island marine communities generally provides these with greater protection from direct anthropogenic impacts compared to coastal communities. However, many of these island ecosystems such as Johnston and Wake Atolls, and Howland and Baker Islands were drastically altered during World War II due to military construction work (Maragos et al., 2008a). Both the alteration of habitats and the inadvertent and intentiona transport of terrestrial and marine non-indigenous propagules began the transition of these habitats away from their pristine state.

Palmyra Atoll (Figure 1) in the US Line Islands is part of the Pacific Remote Island Areas (PRIAs) Marine Nationa Monument created in 2008 and is administered by the US Fish and Wildlife Service of the US Department of Interior. The reefs surrounding Palmyra are richly diverse with high coral biodiversity (Williams et al., 2008) and large numbers of apex predators, providing one of the last remaining baselines for a 'near pristine' reef system (Sandin et al., 2008b). This atoll is a suitable site for studying historical alteration as it was developed into a military installation in the early 1940 , with upwards of 6000 servicemen stationed there during World War II (Dawson, 1959). Prior to development by the military, Palmyra was an undisturbed atoll with numerous small islets forming a perimeter around three distinct

Corresponding author:

J.J. Bell

Email: james.bell@vuw.ac.nz lagoons (Dawson, 1959). The military drastically altered the atoll by using dredged material from the lagoon to build up the islets, and create airstrips and connecting causeways. The causeways formed a perimeter road around the lagoons bisecting the eastern and central sections, essentially creating a fourth lagoon at the west end of the atoll and drastically altering the circulation patterns within the interior of the atoll (Dawson, 1959; Maragos, 1993; Maragos et al., 2008a, b; Collen et al., 2009). In addition, a navigation channel was excavated in the south-western end of the atoll to allow ships to enter the lagoon (Dawson, 1959). Therefore, the recent history of Palmyra Atoll is one of severe habitat alteration and potential exposure to terrestrial and marine non-indigenous species through anthropogenic transport mechanisms.

Dredging characteristically reduces habitat complexity and availability (Auster, 1998; Auster \& Langton, 1998) heavily impacting the macrobenthos (Rosenberg, 1977; Wassenberg et al., 2002), changing species composition, diversity and richness (Jones, 1992; Wassenberg et al., 2002; Hiddink et al., 2006). The dredging across the lagoons may initially have left non-indigenous species unchallenged due to the removal of the native biota as well as inadvertently creating conditions more suitable for introduced species over the recipient biota (Vitousek et al., 1997).

The terrestrial non-indigenous species at Palmyra have been documented extensively (Dawson, 1959; Flint, 1992), but no non-indigenous marine species, which may threaten the reefs, have yet been described. Here we present details of the recently reported non-indigenous species at Palmyra Atoll. To date, one macroalgae species and four marine invertebrates have been documented as non-indigenous to this 
$2 \mid$ I.S. KNAPP ET AL.

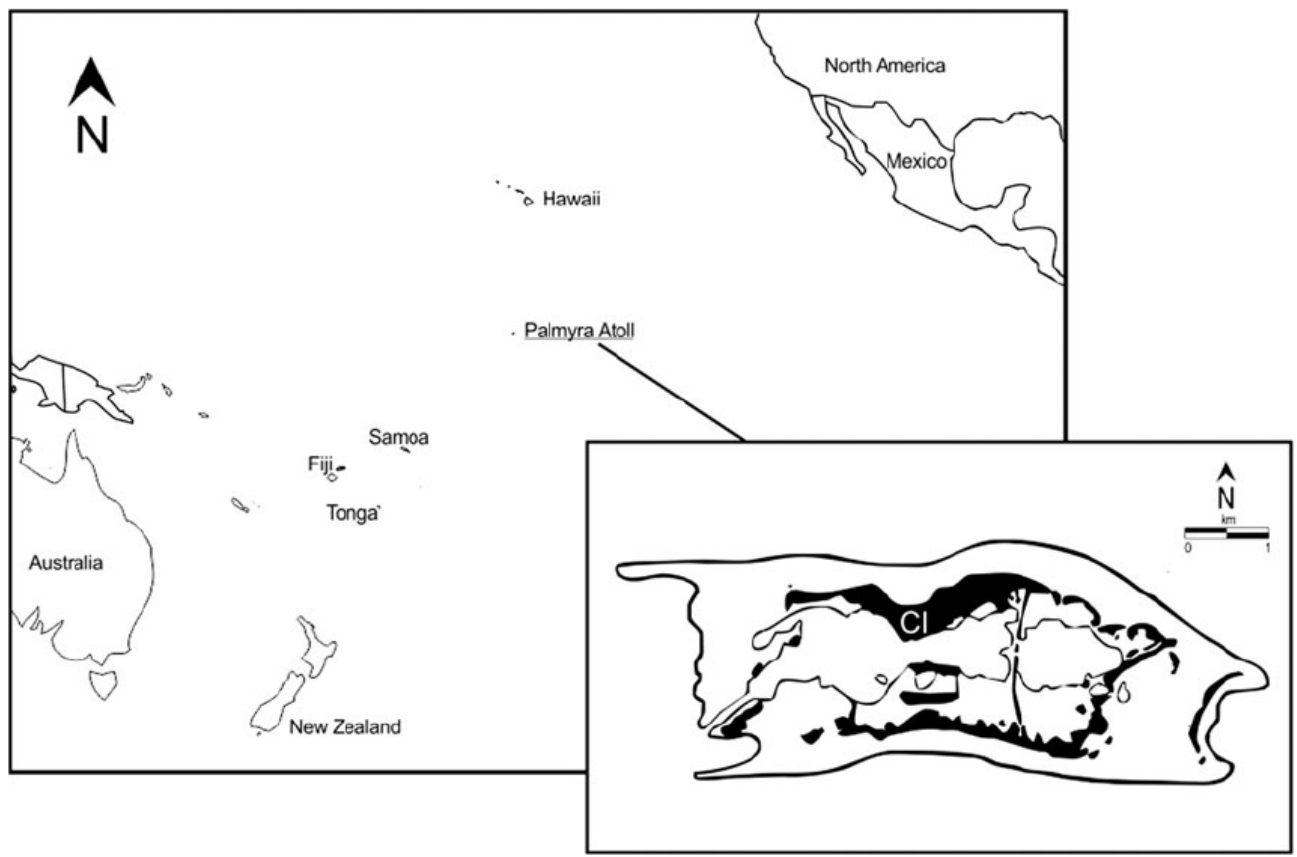

Fig. 1. Location of Palmyra Atoll within the Central Pacific Ocean. CI, Cooper Island.

remote atoll and include a red alga, two sponges, a hydroid and a bryozoan.

\section{MATERIALS AND METHODS}

Initial surveys for marine non-indigenous species began in 2002 through to 2009 under the auspices of inventory and monitoring activities conducted at Palmyra Atoll by the US Department of Commerce, National Oceanic and Atmospheric Administration (NOAA), Pacific Islands Fisheries Science Center and Coral Reef Ecosystem Division (CRED) (Godwin, 2002). These surveys examined both natural coral reef habitat and altered habitats in the lagoon including sea walls, docks and dredge spoil areas. Additional surveys began in 2008 by researchers from Victoria University of Wellington, New Zealand and the Scripps Institution of Oceanography associated with the Palmyra Atoll Research Consortium (PARC).

\section{Surveys}

The surveys for non-indigenous species at Palmyra Atoll were conducted by three institutes with independent objectives and therefore different, but appropriate, sampling methods were used for each.

\section{ALGAE}

An initial qualitative survey of Acanthophora spicifera (Børgesen, 1910) (see Figure 2) was conducted at a number of sites in 2002 and again in 2008 (as part of a lagoon restoration experiment). Regular annual quantitative monitoring takes place using $10 \times 1 \mathrm{~m}^{2}$ quadrats along each of $2 \times$
$25 \mathrm{~m}$ transect lines. Photographs of the benthos are taken and species abundance and composition are determined using image analysis software Photogrid ${ }^{\circ}$ v1.o (Bird, 2003). During 2008 a number of sites spanning from the western to eastern lagoons at 1-5 m depth were also surveyed.

NON-SPONGE INVERTEBRATES

The CRED surveys were conducted using two $25 \times 2 \mathrm{~m}$ belt transects at each site. Suspected non-indigenous species were sampled and preserved for later taxonomic analysis.

\section{SPONGES}

Surveys for the non-indigenous sponges were conducted in 2008 across all four lagoons at twelve sites using $10 \times 1 \mathrm{~m}^{2}$ quadrats subdivided into $20 \mathrm{~cm}^{2}$ squares at depths of 6$8 \mathrm{~m}$. Within each square, per species, we counted numbers of individuals, estimated the percentage area cover of both sponges and hard substratum and adjusted all data to the percentage of available substrate.

\section{RESULTS AND DISCUSSION}

\section{Acanthophora spicifera}

The red alga Acanthophora spicifera is currently the only known non-indigenous seaweed species present in the waters surrounding Palmyra Atoll. During surveys conducted in 2002, A. spicifera was not found around the atoll despite sampling a large number of sites including both lagoon and reef habitats (Godwin, 2002). However, in 2008 specimens of the alga were found conspicuously attached to several of the mooring buoys anchored in the western lagoon near 

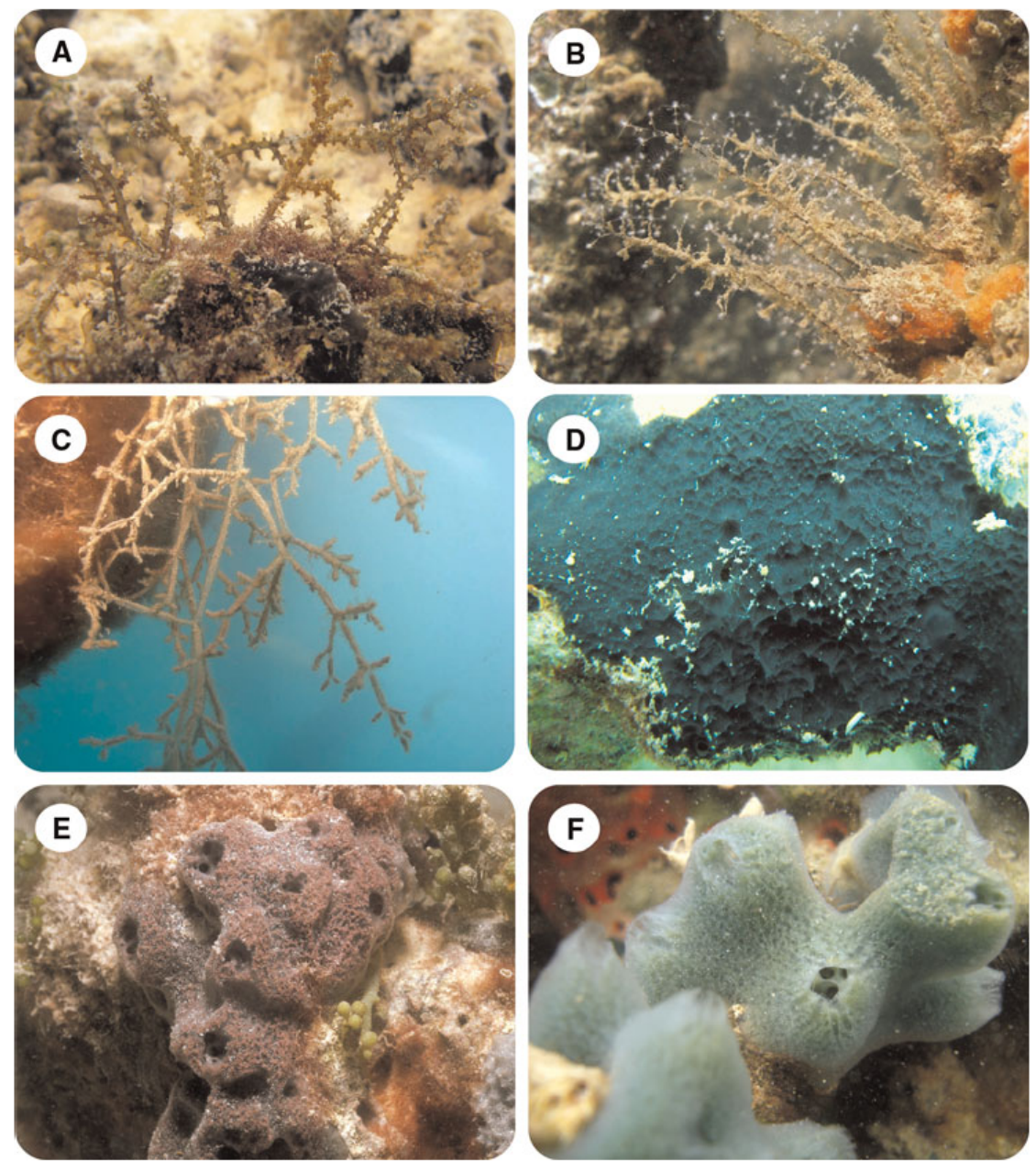

Fig. 2. Photographs of identified non-indigenous species at Palmyra Atoll. (A) Acanthophora spicifera; (B) Pennaria disticha; (C) Zoobotryon verticillatum; (D) Gelliodes fibrosa; (E) Haliclona (Sigmadocia) caerulea purple morph; (F) Haliclona (Sigmadocia) caerulea blue morph.

Cooper Island (see Figure 1), the current location of the field station. After this initial discovery, qualitative surveys were conducted around the lagoon and samples were found at the locations shown in Figure 3. Acanthophora spicifera is native to the western and south Pacific, the Indian Ocean and the Caribbean, but is a known invader in the Hawaiian Islands (Guiry \& Guiry, 2010).

Acanthophora spicifera was originally introduced to the Hawaiian Islands in the 1950 s via hull fouling on a barge that was brought from Guam to Oahu (Doty, 1961; Russell, 1992). This species has now spread throughout all of the main Hawaiian Islands and has most likely been transported via hull fouling of small vessels (Smith et al., 2002). Privately owned yachts are allowed entrance to Palmyra's lagoons for short periods of time with special permission and permitting through the USFWS. Therefore, it is likely that A. spicifera was transported on the hull of a yacht or small vessel from Hawaii to Palmyra sometime between 2002 and 2008. It likely first established on a mooring near Cooper Island and either through sexual reproduction or asexual fragmentation spread throughout much of the shallow water habitats $\left(>_{1} \mathrm{~m},<10 \mathrm{~m}\right)$ in the lagoon. While
A. spicifera is a red alga its coloration can be highly variable ranging from purple to brown and even yellow. The alga attaches to the substrate with a single holdfast and the upright portion of the thallus has an alternate branching pattern. All of the main branches are covered with short thick spines that radiate sporadically off of the algal thallus. On Palmyra this alga is primarily found on limestone flats or rubble zones spanning in depth from 1-5 $\mathrm{m}$. There are currently no data indicating the ecological impacts (if any) of this algal invader on the already highly degraded lagoon ecosystem of Palmyra, but observational evidence suggests that numerous green sea turtles found on the atoll are consuming it (E. Sterling, personal communications). Specimens of fertile female plants were collected in July 2010 suggesting that A. spicifera is now reproducing sexually, which may help facilitate its spread around the atoll. To date this alga has not been found on the outer reef habitats, but future survey efforts should pay special attention to this and other algal invaders as they have the potential to alter the coral and coralline algal dominated fore reef and reef terrace habitats (Sandin et al., 2008a). Documentation of the spread and ecology of A. spicifera around Palmyra Atoll could be very useful for 


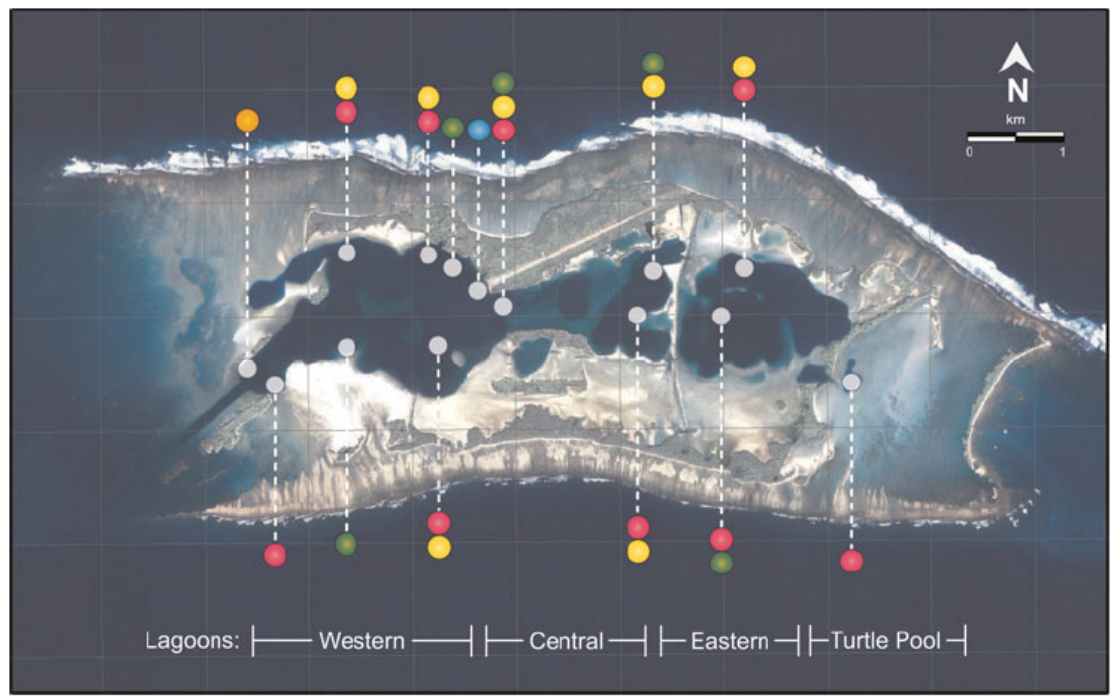

Fig. 3. Locations of non-indigenous species found across the lagoons at Palmyra Atoll. Acanthophora spicifera; $O$ Pennaria disticha; $\bigcirc$ Zoobotryon verticillatum; Haliclona (Sigmadocia) caerulea; and $\bigcirc$ Gelliodes fibrosa.

understanding the invasion ecology of this species in other locations. Finally, if any management or control strategy is going to be developed for A. spicifera on Palmyra a targeted monitoring programme should be established.

\section{Pennaria disticha (hydroid) and Zoobotryon verticillatum (bryozoan)}

The hydroid Pennaria disticha (Goldfuss, 1820) and the bryozoan Zoobotryon verticillatum (Della Chiaje, 1822) (see Figure 2) are the two recorded non-sponge invertebrate introductions to Palmyra Atoll.

Pennaria disticha, also known as the Christmas tree hydroid, is native to the western Atlantic and has now established within the western lagoon of Palmyra (see Figure 3). This species has become cosmopolitan in tropical and warm temperate seas and is a common sessile organism in harbours, natural lagoons and embayments. It has also been documented at remote coral reef habitats in the Hawaiian Archipelago (Godwin, 2006). Pennaria disticha has been observed to be an aggressive competitor for space in both man-made and natural habitats in the Hawaiian Archipelago (Godwin, personal observation). This behaviour has proved to be unpredictable with this species and could be associated with variations in environmental factors, which has been shown to be the case for hydroids in other locations (Boero, 1984).

Zoobotryon verticillatum is a stoloniferous bryozoan forming translucent colonies on hard substrates in bays and harbours. The colonies can form streaming masses and tangled mats that have been confused with macroalgae (Coleman, 1999). This species is found in many tropical and warm temperate waters around the world and has an uncertain home range (Carlton \& Eldredge, 2009). Zoobotryon verticillatum is considered high risk by management agencies in the United States based on documented economic and ecological impacts (Nagy, 2006; Williams, 2007). Its presence was first recorded at Palmyra Atoll in 2008, at which time it was forming large bushy aggregations at a long-term monitoring site established by CRED in 2002 within the main navigation channel (see Figure 3). These concentrated aggregations have the potential to overgrow coral communities if they spread to fore reef locations and create habitat changes in the shallow subtidal areas of the lagoon. Pederson \& Peterson (2002) showed that stoloniferous bryozoans create an ephemeral habitat in shallow subtidal zones that can cause shifts in species assemblages.

The distributions of $P$. disticha and $Z$. verticillatum can be attributed to their ability to foul boat hulls, which is welldocumented in remote tropical ecosystems, such as the Hawaiian Archipelago (Godwin, 2003; Godwin et al., 2004) and the Azores (Amat \& Tempera, 2009). Palmyra Atoll receives maritime vessel traffic in the form of commercial re-supply vessels from Hawaii and sporadic visits from sailing yachts that have frequented ports in the tropical Pacific. Therefore, identifying the source populations for $P$. disticha and $Z$. verticillatum found at Palmyra Atoll would be difficult.

\section{Haliclona (Sigmadocia) caerulea and Gelliodes fibrosa}

The two non-indigenous sponge species in the lagoons at Palmyra Atoll (see Figure 3), are the Demosponges Haliclona (Sigmadocia) caerulea (Hechtel, 1965), and Gelliodes fibrosa (Wilson, 1925) (see Figure 2) from the order Haplosclerida. Both species are found around the main Hawaiian Islands (De Felice et al., 2001; Coles et al., 2006) usually in shallow water embayments, harbours and disturbed habitats, all with restricted water flow (De Felice et al., 2001).

Haliclona caerulea (family Chalinidae), commonly known as the 'Blue Caribbean sponge' originates from the Caribbean Sea where it is found on rocks, dock pilings and mangrove 


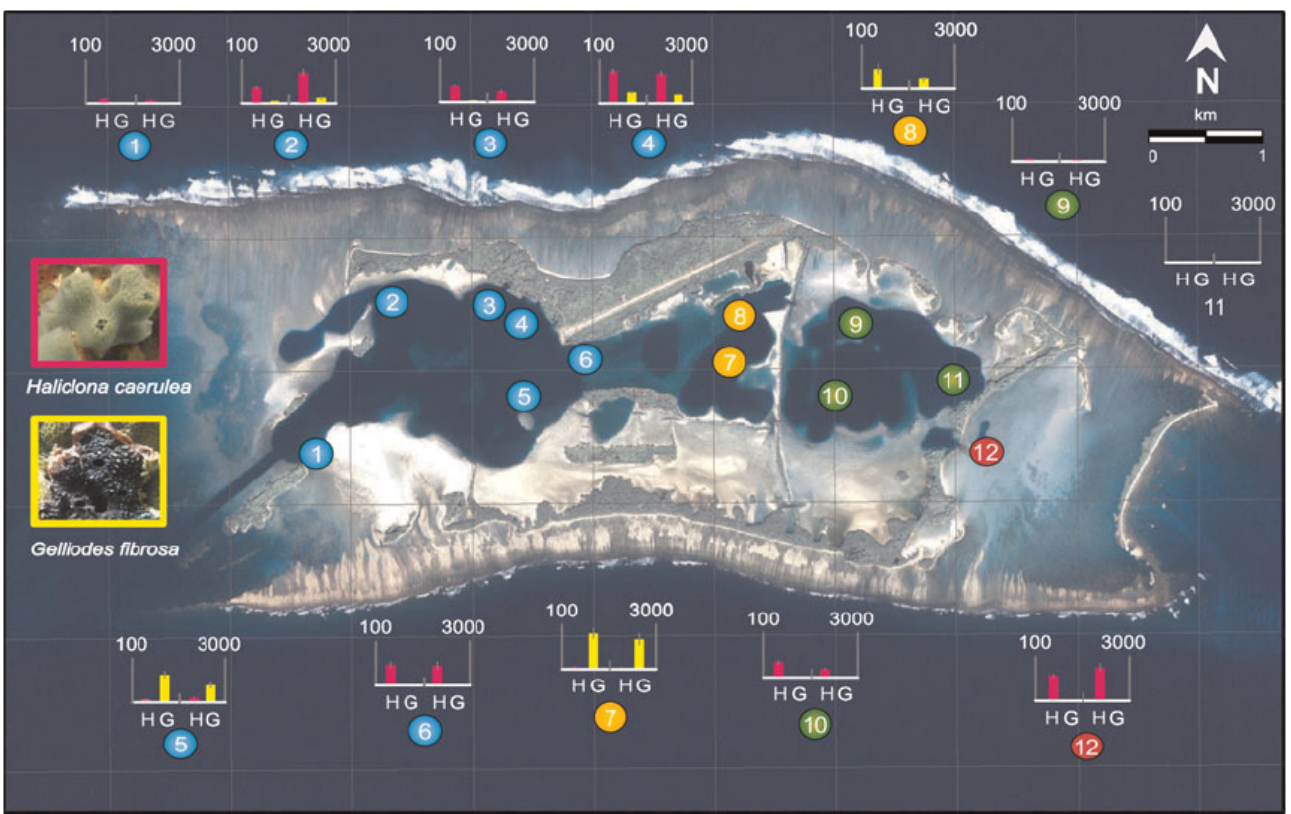

Fig. 4. Sponge densities (right hand side of graph), and area cover $\left(\mathrm{cm}^{2}\right)$ (left hand side of graph) of Haliclona (Sigmadocia) caerulea (H) $\square$ and Gelliodes fibrosa (G) $\square 10 \times 1 \mathrm{~m}^{2}$ quadrats at each of the 12 sites across the Western $\bigcirc(1-6)$, Central $\bigcirc(7-8)$, Eastern $\bigcirc$ (9-11) and Turtle Pool $\bigcirc$ (12) lagoons at Palmyra Atoll.

roots (Hechtel, 1965; Cubit \& Williams, 1983; Wulff, 1997; De Weerdt, 2000). Haliclona caerulea is pale blue with a beige interior and is soft and easy to tear. Interestingly, the majority of individuals at Palmyra are found in association with the red branching coralline alga Jania adherens. The alga rarely protrudes from the sponge tissue and provides skeletal structuring and rigidity (Carballo \& Avila, 2004). This mutualistic relationship also exists in individuals from the Pacific Coast of Panama (Wulff, 1997) and Mexico (Carballo \& Avila, 2004), and changes the colour of the sponge from its characteristic pale blue to purple, making the sponge brittle, but still easy to tear. The purple forms retain some blue tissue, normally at the base of the sponge aiding in the identification of this species. Haliclona caerulea develops into thickly encrusting or massive forms approximately $40 \mathrm{~cm}$ in diameter and 2$15 \mathrm{~cm}$ in height. The oscules $(0.5-1.5 \mathrm{~cm}$ diameter) are on top of thickly walled irregular volcano-like protrusions (1$5 \mathrm{~cm}$ in height). The megascleres are bent oxeas $(170-230$ $\mu \mathrm{m})$, and the microscleres are $\mathrm{C}$-shaped sigmas $(25 \mu \mathrm{m})$ (De Felice et al., 2001). The sigmas are common throughout the blue tissue, but less common in the purple forms (Hechtel, 1965).

Gelliodes fibrosa is characterized by its dark grey, blue/ black appearance, and tissue, which is fibrous, hard to tear, and if repeatedly squeezed turns beige. It forms thick encrusting mats or branches with a smooth to conulose surface and regular extruding fibres. The oscules, usually found on the flatter encrusting individuals, indent before forming the opening. The megascleres are curved oxeas $(160-180 \mu \mathrm{m})$ and the microscleres are sigmas $(15 \mu \mathrm{m})$. Gelliodes fibrosa was originally described from the Philippines and was introduced to Hawaii in the 1990s and has now also been documented in Guam (De Felice et al., 2001).
Spatial distribution patterns of $H$. caerulea indicate higher densities at sites across the northern edge of the western lagoon, the centre of the eastern lagoon and the eastern edge of Turtle Pool (see Figure 4). Gelliodes fibrosa was primarily located on the southern edge of the western lagoon, and the central lagoon. The abundance of both species was lower in the eastern lagoon, but interestingly $H$. caerulea also had high abundance in the far east of Turtle Pool. The reduction in sponge densities from the west to east lagoons may relate to the reproductive strategies of the sponges. Sponges can either fragment over short distances and/or produce larvae. The larvae are predominantly anchiplanic, remaining in the water column for only minutes to days, thus having limited dispersal capability (Maldonado, 2006). Increased densities of $H$. caerulea in the far eastern Turtle Pool suggests that sponge distribution patterns across Palmyra may not be limited by dispersal capabilities, but also influenced by environmental conditions across the lagoons.

It is most likely that H. caerulea and G. fibros $a$ were introduced to Palmyra from Hawaii, via fouling on ships and yachts (Godwin, 2003) or other structures (e.g. barges), as Hawaii has always been the predominant shipping connection to Palmyra (Dawson, 1959). Neither De Laubenfels (1950) or Bergquist (1967) recorded either species during their respective sponge surveys in Hawaii, therefore they are considered to be recent introductions.

The ecological impacts of H. caerulea and G. fibrosa at Palmyra are currently unknown; however, potential impacts include spatial competition with native fauna and a possible threat to corals (De Felice et al., 2001). Sponges are also highly efficient suspension feeders, pumping up to 24,000 1 of water a day $\left(\mathrm{kg}^{-1}\right.$ of sponge) (Vogel, 1977) and removing carbon resources, such as plankton, as well as oxygen and 
nitrogen from the water column (Reiswig, 1971, 1974). The vast quantity of water sponges pump each day means that in high densities they can significantly impact surrounding pelagic ecosystems (Bell, 2008), even potentially controlling phytoplankton levels (Peterson et al., 2006).

\section{CONCLUSIONS}

The modifications to the lagoons at Palmyra during World War II have likely created an environment with reduced water quality and lower circulation now better suited to fouling communities. The presence of these non-indigenous species at such a remote atoll is most likely attributable to man-made transport mechanisms in the form of vessels arriving from harbours and coastal areas such as Hawaii where all five species are also listed as non-indigenous. Future monitoring to assess the invasive potential of all the non-indigenous species established at Palmyra is important to ensure their impacts on the lagoon and adjacent reefs are limited and not progressive.

\section{ACKNOWLEDGEMENTS}

We are greatly indebted to the staff of The Nature Conservancy (TNC), the United States Fish and Wildlife service (USFWS) and the institutes involved in the Palmyra Atoll Research Consortium (PARC) for providing access to the refuge and logistical support, without which this work would not have been possible. Thanks need also to be given to National Oceanic and Atmospheric Administration (NOAA), Pacific Islands Fisheries Science Center-Coral Reef Ecosystem Division, NOAA RV 'Oscar Elton Sette' and NOAA RV 'Hiialakai'. We are also very grateful to Air New Zealand, the Centre for Marine Environmental and Economic Research (CMEER), the Centre for Biodiversity and Restoration Ecology (CBRE), Victoria University of Wellington and Scott and Karin Wilson for generously providing funding. This work was conducted under the USFWS special use permits: 12533-08004, 12521-02009, 12521-08005 and 12533-08015.

\section{REFERENCES}

Amat J.N. and Tempera F. (2009) Zoobotryon verticillatum Della Chiaje, 1822 (Bryozoa), a new occurrence in the archipelago of the Azores (North-Eastern Atlantic). Marine Pollution Bulletin 58, 761-764.

Auster P.J. (1998) A conceptual model of the impacts of fishing gear on the integrity of fish habitats. Conservation Biology 12, 1198-1203.

Auster P.J. and Langton R.W. (1998) The effects of fishing on fish habitat. Fish Habitat: Essential Fish Habitat and Rehabilitation 22, $150-187$

Bell J.J. (2008) The functional roles of marine sponges. Estuarine, Coastal and Shelf Science 79, 341-353.

Bergquist P.R. (1967) Additions to the sponge fauna of the Hawaiian Islands. Micronesica 3, 159-174

Bird C.E. (2003) Photogrid. Ecological analysis of digital photographs. http://www.photogrid.netfirms.com (accessed 10 October 2008).
Boero F. (1984) The ecology of marine hydroids and effects of environmental factors-a review. Marine Ecology-Pubblicazioni Della Stazione Zoologica Di Napoli I 5, 93-118.

Børgesen F. (1910) Some new or little known West Indian Florideae. II. Botanisk Tidsskrift 30, 177-207.

Carballo J.L. and Avila E. (2004) Population dynamics of a mutualistic interaction between the sponge Haliclona caerulea and the red alga Jania adherens. Marine Ecology Progress Series 279, 93-104.

Carlton J.T. and Eldredge L.G. (2009) Marine bioinvasions of Hawai'i: the introduced and cryptogenic marine and estuarine animals and plants of the Hawaiian archipelago. Bishop Museum Bulletins in Cultural and Environmental Studies 4, 202.

Coleman F.S. (1999) Note on Zoobotryon verticillatum (Bryozoa) in a solar saltfield. International Journal of Salt Lake Research 8, 71-74.

Coles S.L., Kandel F.L.M., Reath P.A., Longenecker K. and Eldredge L.G. (2006) Rapid assessment of non-indigenous marine species on coral reefs in the main Hawaiian Islands. Pacific Science 60, 483-507.

Collen J., Garton D.W. and Gardner J.P. (2009) Shoreline changes and sediment redistribution at Palmyra Atoll (Equatorial Pacific Ocean): 1874-present. Journal of Coastal Research 25, 711-722.

Cubit J. and Williams S. (1983) The invertebrates of Galeta Reef (Caribbean Panama): a species list and bibliography. Atoll Research Bulletin 269, 1-45.

Dawson E.Y. (1959) Changes in Palmyra Atoll and its vegetation through the activities of man, 1913-1958. Pacific Naturalist 1, 1-52.

De Felice R.C., Eldredge L.G. and Carlton J.T. (2001) Non-indigenous marine invertebrates. In Eldredge L.G. and Smith C.M. (eds) A guidebook to introduced marine species in Hawai'i, Bishop Museum Technical Report 21. Honolulu: Bishop Museum, pp. i-vi, 1-60.

De Laubenfels M.W.d. (1950) The sponges of Kaneohe bay, Oahu. Pacific Science $4,3-36$

De Weerdt W.H. (2000) A monograph of the shallow-water Chalinidae (Porifera, Haplosclerida) of the Caribbean. Beaufortia Bulletin Zoological Museum, University of Amsterdam 50, 1-67.

Doty M.S. (1961) Acanthophora, a possible invader of the marine flora of Hawaii. Pacific Science 15, 547-552.

Flint E. (1992) Survey of the terrestrial biota of Palmyra Atoll: 18 February to 9 March 1992. Unpublished trip report. US Fish and Wildlife Service, $19 \mathrm{pp}$.

Godwin L.S. (2002) Preliminary report on the non-coral invertebrates. Cruise Report TC-02-07, Northwestern Hawaiian Islands Division. NOAA - NMFS Coral Reef Ecosystem Division.

Godwin L.S. (2003) Hull fouling of maritime vessels as a pathway for marine species invasions to the Hawaiian Islands. Biofouling 19, $123-131$.

Godwin L.S. (2006) Reducing the potential impact of marine invasive species on the Northwestern Hawaiian Islands Marine National Monument. DOI, NOAA, National Ocean Service MOA 2005-008/ 6882, Amendment No.001, SOEST, UH Mãnoa. Available from the Hawaii Coral Reef Assessment and Monitoring Program (CRAMP) at http://cramp.wcc.hawaii.edu/ (accessed 22 April 2010).

Godwin L.S., Eldredge L.G. and Gaut K. (2004) The assessment of hull fouling as a mechanism for the introduction and dispersal of marine alien species in the main Hawaiian Islands. Bishop Museum Technical Report No. 28. Honolulu: Bishop Museum, 114 pp.

Goldfuss G.A. (1820) Handbuch der Zoologie. Zweite Abtheilung. Nürnburg: Johann Leonhard Schrag. 
Guiry M.D. and Guiry G.M. (2010) AlgaeBase. World-wide electronic publication. National University of Ireland, Galway. http://www.algaebase.org (accessed 16 January 2010).

Hechtel G.H. (1965) A systematic study of the Demospongiae of Port Royal, Jamaica. Bulletin of the Peabody Museum of Natural History 20, $1-103$.

Hiddink J.G., Jennings S., Kaiser M.J., Queiros A.M., Duplisea D.E. and Piet G.J. (2006) Cumulative impacts of seabed trawl disturbance on benthic biomass, production, and species richness in different habitats. Canadian Journal of Fisheries and Aquatic Sciences 63, 721-736.

Jones J.B. (1992) Environmental impact of trawling on the seabed: a review. New Zealand Journal of Marine and Freshwater Research 26, $59-67$.

Maldonado M. (2006) The ecology of the sponge larva. Canadian Journal of Zoology 84, 175-194

Maragos J.E. (1993) Impact of coastal construction on coral reefs in the United-States-affiliated Pacific Islands. Coastal Management 21, 235-269.

Maragos J., Friedlander A.M., Godwin S., Musburger C., Tsuda R., Flint E., Pantos O., Ayotte P., Sala E., Sandin S., McTee S., Siciliano D. and Obura D. (2008a) US coral reefs in the Line and Phoenix Islands, central Pacific Ocean: status, threats and significance. In Riegl B.M. and Dodge R.E. (eds) Coral reefs of the USA. Coral reefs of the world 1. New York: Springer, pp. 643-654.

Maragos J., Miller J., Gove J., DeMartini E., Friedlander A.M., Godwin S., Musburger C., Timmers M., Tsuda R., Vroom P., Flint E., Lundblad E., Weiss J., Ayotte P., Sala E., Sandin S., McTee S., Wass T., Siciliano D., Brainard R., Obura D., Ferguson S. and Mundy B. (2008b) US coral reefs in the Line and Phoenix Islands, central Pacific Ocean: history, geology, oceanography and biology. In Riegl B.M. and Dodge R.E. (eds) Coral reefs of the USA. Coral reefs of the world 1. New York: Springer, pp. 595-641.

Nagy L. (2006) Early detection and rapid response. Managers Tool Kit. http://www.invasivespeciesinfo.gov/toolkit/detelk.shtml (accessed 6 June 2010).

Pederson E.J. and Peterson M.S. (2002) Bryozoans as ephemeral estuarine habitat and a larval transport mechanism for mobile benthos and young fishes in the north-central Gulf of Mexico. Marine Biology 140, 935-947.

Peterson B.J., Chester C.M., Jochem F.J. and Fourqurean J.W. (2006) Potential role of sponge communities in controlling phytoplankton blooms in Florida Bay. Marine Ecology Progress Series 328, 93-103.

Reiswig H.M. (1971) In situ pumping activities of tropical Demospongiae. Marine Biology 9, 38-50.

Reiswig H.M. (1974) Water transport, respiration and energetics of three tropical marine sponges. Journal of Experimental Marine Biology and Ecology 14, 231-249.

Rosenberg R. (1977) Effects of dredging operations on estuarine benthic macrofauna. Marine Pollution Bulletin 8, 102-104.
Russell D.J. (1992) The ecological invasion of Hawaiian reefs by two marine red algae, Acanthophora spicifera and Hypnea musciformis, and their association with two native species, Laurencia nidifica and Hypnea cervicornis. ICES Marine Science Symposia 194, 110-125.

Sandin S.A., Smith J.E., DeMartini E.E., Dinsdale E.A., Donner S.D., Friedlander A.M., Konotchick T., Malay M., Maragos J.E., Obura D., Paulay G., Richie M., Rohwer F., Schroeder R.E., Walsh S.W., Jackson J.B.C., Knowlton N. and Sala E. (2008a), Baselines and degradation of coral reefs in the northern Line Islands. PLoS ONE 3 , e1548.

Sandin S.A., Smith J.E., DeMartini E.E., Dinsdale E.A., Donner S.D., Friedlander A.M., Konotchick T., Malay M., Maragos J.E., Obura D., Pantos O., Paulay G., Richie M., Rohwer F., Schroeder R.E., Walsh S., Jackson J.B.C., Knowlton N. and Sala E. (2008b) Baselines and degradation of coral reefs in the northern Line Islands. PLoS ONE 3, e1548. doi:1510.1371/journal.pone.0001548

Smith J.E., Hunter C.L. and Smith C.M. (2002) Distribution and reproductive characteristics of non-indigenous and invasive marine algae in the Hawaiian Islands. Pacific Science 3, 299-315.

Vitousek P.M., Dantonio C.M., Loope L.L., Rejmanek M. and Westbrooks R. (1997) Introduced species: a significant component of human-caused global change. New Zealand Journal of Ecology 21, $1-16$

Vogel S. (1977) Current-induced flow through living sponges in nature. Proceedings of the National Academy of Sciences of the United States of America 74, 2069-2071.

Wassenberg T.J., Dews G. and Cook S.D. (2002) The impact of fish trawls on megabenthos (sponges) on the north-west shelf of Australia. Fisheries Research 58, 141-151.

Williams G.J., Maragos J.E. and Davy S.K. (2008) Characterization of the coral communities at Palmyra Atoll in the remote Central Pacific Ocean. Atoll Research Bulletin 557, 1-30.

Williams S.L. (2007) Introduced species in seagrass ecosystems: Status and concerns. Journal of Experimental Marine Biology and Ecology $350,89-110$.

Wilson H.V. (1925) Silicious and horny sponges collected by the fisheries steamer 'Albatross' during the Philippine expedition, 1907-10. Bulletin of the United States National Museum 2, 273-532.

and

Wulff J. (1997) Causes and consequences of differences in sponge diversity and abundance between the Caribbean and Eastern Pacific of Panama. In 8th International Coral Reef Symposium Panama. Volume 2, pp. 1377-1382.

Correspondence should be addressed to: J.J. Bell

Centre for Marine Environmental and Economic Research School of Biological Sciences, Victoria University of Wellington PO Box 600 Wellington, New Zealand email: james.bell@vuw.ac.nz 


\section{Appendix II}

Published manuscript: Effect of depth on sponge assemblage structure at Palmyra Atoll, Central Pacific 


\title{
Effect of Depth on Sponge Assemblage Structure at Palmyra Atoll, Central Pacific
}

\author{
Ingrid S. S. Knapp ${ }^{*}$ and James J. Bell
}

Centre for Marine Environmental and Economic Research, School of Biological Sciences, Victoria University of Wellington, P.O. Box 600, Wellington, New Zealand

\begin{abstract}
We examined the influence of depth on sponge assemblages across three lagoons at Palmyra; a remote atoll situated in the Central Pacific. The atoll is unusual in that it was heavily altered during WWII resulting in an atypical lagoon system. We conducted surveys at both $6-8 \mathrm{~m}$ and $12-14 \mathrm{~m}$ at 3 sites at the atoll and recorded sponge densities, area cover and available substrate for the 29 species found at these sites. Multivariate analysis of sponge densities and area cover revealed significant variability in sponge assemblages between both site and depth. Univariate analysis also showed significant differences in area cover between depths, but not between sites. Diversity indices and the average number of species at each site showed an increase in diversity across lagoons from West to East. This study indicates that despite the small size of the atoll, depth is a factor that shapes sponge assemblages at Palmyra Atoll. The heavy alterations to the lagoon, particularly the area near the channel entrance may be influencing the sponge assemblage structure, however, other environmental variables still need to be investigated.
\end{abstract}

Keywords: Sponge, depth, Palmyra Atoll, sedimentation, Central Pacific, flow rate.

\section{INTRODUCTION}

To examine and identify the ecological processes that shape assemblages, species abundance and distribution patterns must first be described. Sponges are an important component of benthic fauna that are highly diverse as well as being an ecologically important invertebrate taxon. Despite their importance, sponges are vastly and notoriously understudied $[1,2]$ even though on some reefs, sponges can even exceed the species diversity and biomass of the scleractinian corals [3]. Understandably, due to the remoteness of some locations, such as Palmyra Atoll (located in the Central Pacific), accessibility for researchers can seriously limit our understanding of these assemblages. In the case of Palmyra Atoll, it is only through its recent co-ownership by The Nature Conservancy (TNC) and the U.S Fish and Wildlife Service (USFWS) in 2001, that this remote atoll can now be extensively studied. Palmyra is of particular interest to scientists because it remains one of the few 'near pristine' reef systems left in the world [4].

Palmyra consists of many islets with shallow lagoons surrounded by an extensive reef system. The lagoons were essentially an unaltered system until the Second World War when the U.S. Navy occupied the atoll making major alterations. The work included enlarging the islets, creating an entrance channel for boats, dredging the lagoons and building a central causeway to connect two islets, effectively interrupting the water flow between lagoons [5]; this would likely have had serious impacts on the marine fauna of the lagoons.

*Address correspondence to this author at the Centre for Marine Environmental and Economic Research, School of Biological Sciences, Victoria University of Wellington, P.O. Box 600, Wellington, New Zealand; Tel: 04-463-5109; E-mail: ingrid.knapp $@$ vuw.ac.nz
Sponges form an important part of subtidal benthic communities and inhabit most marine ecosystems $[6,7]$. The widespread distribution of this phylum is most likely due to a number of adaptive features including efficient suspension feeding capabilities $[8,9]$ and the ability to regenerate $[10$, 11]. Depth has long been recognised as a strong influencing factor on marine benthic community structure $[12,13]$ and therefore an important factor to consider when conducting surveys of new locations to understand assemblage structure.

The atoll system at Palmyra, like the rest of the Line Islands, is unusual in that large macro-invertebrates including sponges are uncommon on the outer reef systems ( $\mathrm{S}$. Godwin pers. Obs.) [4], usually an ecosystem abundant in such fauna e.g. in the Caribbean and the Indo-Pacific [3, 14, 15]. The reef system is considered 'near pristine', however, the lagoon is far from its original state. Lagoons, are generally low current systems and act like sediment 'sinks' and suffer from high levels of sedimentation [16]. Sponges, like many marine invertebrates are suspension feeders and as such obtain oxygen and food in the form of organic carbon from the water column [17]. High levels of sediment may clog the delicate filtering apparatus of sponges [18, 19]. However, they have been commonly documented inhabiting areas of high sedimentation $[14,16,20][21,22]$ and it is therefore of considerable interest to understand the distribution patterns of sponges within the lagoon system at Palmyra Atoll, particularly as it is an altered environment.

Understanding the diversity and abundance of sponges in the lagoons at Palmyra is also very important from management perspective because the diversity, distribution and abundance of sponge assemblages is presently unknown despite sponges appearing to be the dominant fauna of the lagoon environment. The lagoons at Palmyra are densely populated with sponges, however, little is known of their potential impact on the surrounding ecosystem or whether 
they are even native to Palmyra or were introduced during military occupation. Furthermore, another important reason to survey and study the sponges at Palmyra is that the lagoons are very shallow in places; areas of low water flow and the high sponge biomass could potentially remove large quantities of nutrients and oxygen from the water column $[23,24]$. Therefore, changes in sponge assemblages have the potential to affect the environment and organisms in the lagoons and even the reef as the water flows out across the reef systems [25].

The aim of this study is to determine the effect of depth on sponge assemblages at three different sites in the lagoon system at Palmyra Atoll. We quantified the sponge species density, cover, diversity and evenness, relative to the available boulder substrate at these different sites and depths.

\section{METHODS AND MATERIALS}

\section{Study Site}

Palmyra Atoll is located at the North-western end of the Line Islands $\left(5^{\circ} 53^{\prime} \mathrm{N}, 162^{\circ} 05^{\prime} \mathrm{W}\right), 1930 \mathrm{~km}$ south of Hawaii (Fig. 1). The atoll was designated a National Wildlife refuge in 2001 is now jointly owned by The Nature Conservancy and U.S. National and Fish and Wildlife. Palmyra is listed as one of the U.S. Pacific Remote Island Areas (PRIAs) and in 2009 became part of the Pacific Remote Islands Marine National Monument (8336).

\section{Sampling Design}

Surveys were conducted using SCUBA within the lagoons at Palmyra Atoll (See Fig. 1) between June to July and October to November 2008. Sponge assemblages were sampled at three sites across the three main lagoons at shallow (6-8m) and deep (12-14m) water sites. Fig. (1) indicates the location of the sites within the three lagoons. Site 1 is located in the Western lagoon adjacent to Strawn
Island $\left(05^{\circ} 53^{\prime} .318^{\prime \prime N}, 162^{\circ} 05^{\prime} .860^{\prime \prime} \mathrm{W}\right)$. Site 2 is in the Central lagoon on the south west side of the North-South causeway $\left(05^{\circ} 53^{\prime} .246^{\prime \prime} \mathrm{N}, 162^{\circ} 03^{\prime} .880^{\prime \prime} \mathrm{W}\right)$ and site 3 is north east of the Eastern lagoon just south of Aviation Island (see [5] for all island names); from here on each site is referred to by the name of the lagoon in which it is found, although it is not necessarily considered to represent the lagoon as a whole. The sites are characterised as having sandy slopes $\left(40-50^{\circ}\right)$ with small boulders generally $<1 \mathrm{~m}$ with negligible current flow rates $\left(<0.05 \mathrm{~cm}^{2} \mathrm{sec}^{-1}\right)$ and low boulder disturbance levels.

At each of the three sites, $10 \times 1 \mathrm{~m}^{2}$ quadrats (divided into $20 \times 20 \mathrm{~cm}$ sub-sections) were haphazardly placed over clusters of boulders and surveyed by counting the number of individual sponge patches (sponge density) and estimating the percentage area covered and available substrata for each species per sub-section. Sponge density and cover values were then adjusted to the total amount of available substrate to provide sponge abundance data per $\mathrm{m}^{2}$ of available substrate. Each species was given a number ID based on preliminary laboratory analysis (although these species have been distinguished they have not currently been identified).

\section{Statistical Analyses}

To characterise sponge assemblages, and compare them between sites and depths a number of indices were calculated including: number of species (S); Hill's numbers N1 and N2 and the modified Hill's ratio (N21') [26]. The Hill's N1 and Hill's N2 assess species diversity by examining the influence of rare and dominant species on assemblage structure, respectively. The modified Hill's ratio examines species equitability (evenness).

Spatial patterns of sponge densities and area occupied across the factors 'sites' and 'depths' were examined using a 2 factor nested permutational multivariate analysis of variance (PERMANOVA) with 9999 permutations [27] based on a zero-adjusted Bray-Curtis similarity matrix. The

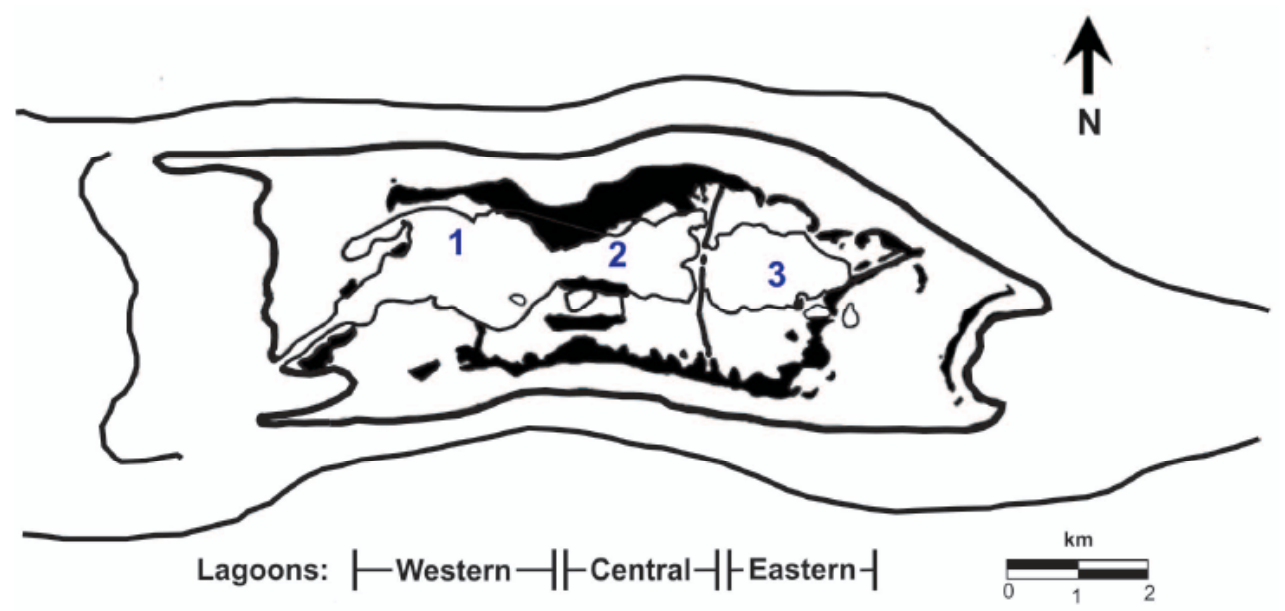

Fig. (1). Map of Palmyra with sites surveyed across the 3 lagoons at Palmyra Atoll. Site: $1=$ Strawn (Western lagoons), $2=$ South Cut (Central lagoon), $3=$ Aviation (Eastern lagoon). 
nature of the nested design used in the PERMANOVA test means any significant difference between depths is strictly relative to the sites within which they are nested. Site was a random factor (3 levels) with depth a fixed factor (2 levels) nested within sites. Pairwise post hoc tests were also carried out on significant factors from the main test. Univariate analyses of sponge densities and area covered at the different sites and depths were also conducted using PERMANOVA. All data was transformed using the dispersion weighting pretreatment, which negates the effect of spatial clustering [28], a characteristic of phyla (such as sponges) where species are known to reproduce asexually through budding, fragmentation and gemmule formation [29]. All analyses were conducted using the PRIMER v6 statistical package [26] in combination with the PERMANOVA+ add-on package [30].

\section{RESULTS}

A total of 29 distinct species were identified across all sites and depths; 15 species were found at both depths at the Western lagoon site, 19 species were found at Eastern lagoon site at both depths, while 15 species were found at the shallow site and 19 at the deep site at the Central lagoon site. Despite the similarity in the total number of species between sites and depths, assemblage composition differed considerably. The mean sponge densities $( \pm \mathrm{SE})$ are shown in Fig. (2) and range from $37( \pm 5.9)$ (Western-deep) to $72( \pm 13.7)$ (Eastern-shallow) sponges $\mathrm{m}^{-2}$, with a mean of $51( \pm 9.6)$ sponges $\mathrm{m}^{-2}$ across all three sites. The mean average sponge percentage cover across all sites was $15.2 \%( \pm 2.8)$ with a range of $10.6 \%( \pm 1.8)$ (Western-deep) to $20.8 \%( \pm 1.9)$ (Western-shallow). Analysing sponge densities with a PERMANOVA test showed no significant differences between sites or depths (pseudo- $F=2.19 ; \mathrm{p}=0.07$, pseudo$F=2.09 ; \mathrm{p}=0.06$ respectively). Sponge percentage cover also showed no significant difference between sites (pseudo$F=1.31, \mathrm{p}=0.26)$, but there was a significant difference between depths $(\mathrm{p}<0.05)$.

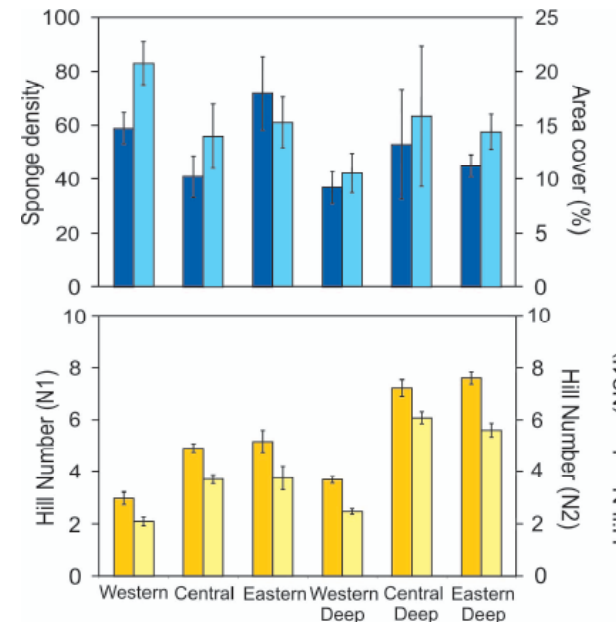

Fig. (2) shows that the Western lagoon site had the lowest mean number of species $(S=7-8)$, and the Eastern lagoon site had the highest number of species $(S=9-12)$, while the central lagoon had $S=8-10$. The Hill indices N1, $\mathrm{N} 2$ and the modified ratio N21' in Fig. (2) indicate similar diversity patterns amongst sites and depths. The Western lagoon site (shallow and deep water sampling locations) had the lowest diversity and the Eastern lagoon site (shallow and deep sampling locations) the highest.

Sponge assemblages were significantly different between the 2 factors, 'site' and 'depth' when analysing both sponge counts and area cover (PERMANOVA, $\mathrm{p}<0.001$ ). Furthermore, PERMANOVA pairwise comparisons also found significant $(p<0.001)$ differences between all sites and depths.

\section{DISCUSSION AND CONCLUSION}

The total number of species was similar at all sites, but sponge assemblages were significantly different between all sites and all depths (with depths nested within sites) across the lagoon system at Palmyra Atoll. We found no significant difference for univariate analyses of sponge densities, but we did find a significant difference between depth and area occupied. The average number of species along with the species diversity indices; N1, N2 and the modified ratio $\mathrm{N} 21$ ', indicate an increase in species numbers and diversity from the Western to Eastern lagoon sites.

Sponge assemblages vary considerably across environmental gradients [21,31-33], therefore it is unsurprising that this study has shown differences in assemblage structure and area occupied with changes in depth even on a local-scale across lagoons in an atoll $6 \mathrm{~km}$ long. Previous studies have shown that sponge species distribution and abundance often vary on small spatial scales $[6,29,31]$. The explanation for the variability in assemblage structure with depth in our study is, however, unlikely to be a simply result of depth, but

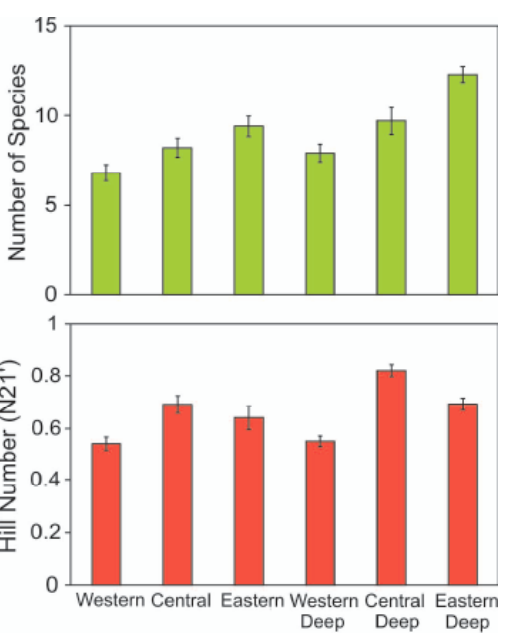

Fig. (2). Measures of sponge diversity (mean \pm SE) at the three sites and two depths in the lagoons at Palmyra Atoll. Shallow sites are between $6-8 \mathrm{~m}$ and deep sites are between $12-14 \mathrm{~m}$. N=10 for each site. Sponge densities and percentage area occupied are adjusted to available boulder substrate. 
the result of a combination of environmental factors which co-vary with depth [32]. Site-specific ecological processes that may account for the sponge assemblage structure identified in our study include; light attenuation [22], water flow regime [6], temperature [34] and oxygen concentrations [35].

Species diversity indices and species number averages indicate an increase in diversity (low to high) across the atoll from West to East. Historically, and more recently, the Western lagoon was the location of the highest levels of anthropogenic disturbance particularly during WWII [5]. The work included extensive dredging, increasing the land mass of the islets and excavating the channel through which large vessels could enter the lagoon and make safe passage to the nearby wharf (just $100 \mathrm{~m}$ from the Western lagoon site). Habitats subject to dredging are heavily altered, removing complexity and available substrate [36, 37]. Impacts on the macrobenthos is also well documented [38, 39]. Dredging causes changes in species composition, diversity, richness [39-41] and potential permanent faunal changes [40], sometimes even resulting in complete phase shifts [42]. We suggest that the relatively higher level of disturbance at the Western lagoon has potentially lead to a site, with reduced available substrate and created conditions which is habitable by fewer species, since it has the lowest diversity, density and average number of species. The Western lagoon site, however, has the highest sponge area cover (per $\mathrm{m}^{2}$ available substrate), which suggests that those species able to deal with the conditions in this environment have proliferated. Environmental factors, as mentioned above, may also provide a further insight into the diversity distribution of sponges across the lagoons and will be investigated in the future.

Diving restrictions at Palmyra (given it is a very remote site) limit deeper surveys, however, we have found that where there is available substrate in the lagoon at shallow depths there are abundant sponge assemblages. Therefore, we have no reason to believe this is not the case in deep waters, however, the deepest parts of the lagoons extend down to $50 \mathrm{~m}$ and are therefore unlikely to support sponges as the waters here become anoxic (pers. comm. John Collen \& Jonathan Gardner). This raises an interesting question as to the impact these abundant sponge assemblages may be having directly, as competitors, or indirectly through their efficient water filtration capabilities on other organisms. The ability of sponges to filter large quantities of water [9] has the potential to affect oxygen and nutrient levels in the lagoon, potentially influencing water quality as it leaves the lagoon and flows on to the surrounding reef. Future work will focus on broader-scale surveys of the sponge assemblages in the lagoons at Palmyra, the influence of environmental variables on distribution and the presence of sponges before the alterations.

\section{ACKNOWLEDGEMENTS}

This work could not have been possible without the help and support from Gareth Williams for diving support and data collection and Scott Godwin, Jonathan Gardner and John Collen for advisory help. We are also grateful to the staff from The Nature Conservancy (TNC), United States
Fish and Wildlife service (USFWS) and the institutes involved in the Palmyra Atoll Research Consortium (PARC) for providing access to the refuge and logistical support. We are grateful to Air New Zealand, the Centre for Marine Environmental and Economic Research (CMEER), the Centre for Biodiversity and Restoration Ecology (CBRE), and Victoria University of Wellington for providing funding. This work was conducted under the special use permit \#12533-08004 approved by USFWS.

\section{REFERENCES}

[1] Becerro MA. Quantitative trends in sponge ecology research. Mar Ecol 2008; 29(2): 167-77.

[2] Hooper JNA, van Soest RWM. Systema Porifera: a guide to the classification of sponges. London: Kulwer Academic/ Plenum Publishers 2002.

[3] Wulff JL. Assessing and monitoring coral reef sponges: why and how? Bull Mar Sci 2001; 69: 831-46.

[4] Sandin SA, Smith JE, DeMartini EE, et al. Baselines and degradation of coral reefs in the northern Line Islands. PLoS ONE 2008; 3(2): e1548

[5] Collen J, Garton DW, Gardner JP. Shoreline changes and sediment redistribution at Palmyra Atoll (Equatorial Pacific Ocean): 1874 Present. J Coast Res 2009; 25(3): 711-22.

[6] Bell JJ, Barnes DKA. A sponge diversity centre within a marine 'island'. Hydrobiologia 2000; 440:55-64.

[7] Witte U. Seasonal reproduction in deep-sea sponges - triggered by vertical particle flux? Mar Biol 1996; 124: 571-81.

vertical particle flux? Mar Biol 1996, 124: 57-81. Frost IM. In situ measurements of clearance rates for the freshwate sponge Spongilla lacustris. Limnol Oceanogr 1978; 23(5): 1034-9. Proc Natl Acad Sci USA 1977; 74: 2069-71.

[10] Ayling AL. Growth and regeneration rates in thinly encrusting Ayling AL. Growth and regeneration rates in thinly encrusting 52.

[11] Bell JJ. Regeneration rates of a temperate demosponge: the importance of water flow rate. J Mar Biol Assoc UK 2002; 82(1): $169-70$.

[12] Bergen M, Weisberg SB, Smith RW, et al. Relationship between depth, sediment, latitude, and the structure of benthic infaunal assemblages on the mainland shelf of southern California. Mar Biol 2001; 138(3): 637-47.

[13] Underwood AJ, Kingsford MJ, Andrew NL. Patterns in shallow subtidal marine assemblages along the coast of New South Wales. Austral Ecol 1991; 16(2): 231-49.

[14] Bell JJ, Smith D. Ecology of sponge assemblages (Porifera) in the abundance. J Mar Biol Assoc UK 2004; 84(3): 581-91.

[15] Jackson JBC, Buss L. Allelopathy and spatial competition among coral reef invertebrates. Proc Natl Acad Sci USA 1975; 72: 5160-3.

[16] Ilan M, Abelson A. The life of a sponge in a sandy lagoon. Biol Bull 1995; 189: 363-9.

[17] Hoffmann F, Larsen O, Rapp HT, Osinga R. Oxygen dynamics in choanosomal sponge explants. Mar Biol Res 2005; 1(2): 160-3.

[18] Gerrodette T, Flechsig AO. Sediment-induced reduction in the pumping rate of the tropical sponge Verongia-Lacunosa. Mar Biol 1979; 55(2): 103-10

[19] Tompkins-MacDonald GJ, Leys SP. Glass sponges arrest pumping in response to sediment: implications for the physiology of the hexactinellid conduction system. Mar Biol 2008; 154(6): 973-84.

[20] Bell JJ. Evidence for morphology-induced sediment settlement prevention on the tubular sponge Haliclona urceolus. Mar Biol 2004; 146(1): 29-38

[21] Bell JJ, Barnes DKA. The distribution and prevalence of sponges in relation to environmental gradients within a temperate sea lough: Vertical cliff surfaces. Divers Distrib 2000; 6(6): 283-303.

[22] Carballo JL. Effect of natural sedimentation on the structure of tropical rocky sponge assemblages. Ecoscience 2006; 13(1): 119 30.

[23] Reiswig HM. In-situ pumping activities of tropical Demospongiae. Mar Biol 1971; 9(1): 38-50.

[24] Reiswig HM. Water transport, respiration and energetics of three tropical marine sponges. J Exp Mar Biol Ecol 1974; 14: 231-49. 
[25] Sultan SAR, Ahmad F. Flushing of a coastal lagoon in the Red sea. Estuar Coast Shelf Sci 1990; 31(3): 345-9.

[26] Clarke KR, Gorley RN. Primer v6: User manual/tutorial. PRIMERE Ltd: Plymouth United Kingdom 2006.

[27] Anderson MJ. A new method for non-parametric multivariate analysis of variance. Austral Ecol 2001; 26: 32-46.

[28] Clarke KR, Chapman MG, Somerfield PJ, Needham HR. Dispersion-based weighting of species counts in assemblage Dispersion-based weighting of species co
analyses. Mar Ecol Prog Ser 2006; 320: 11-27.

[29] Ayling AL. Patterns of sexuality, asexual reproduction and recruitment in some subtidal marine Demospongiae. Biol Bul 1980; 158(3): 271-82.

[30] Anderson MJ, Gorley RN, Clarke KR. PERMANOVA+ for PRIMER: guide to software and statistical methods. PRIMER-E Plymouth: United Kingdom 2008.

[31] Roberts DE, Davis AR. Patterns in Sponge (Porifera) assemblages on temperate coastal reefs off Sydney, Australia. Mar Freshw Res 1996; 47(7): 897-906.

[32] de Voogd NJ, Cleary DFR. Relating species traits to environmental variables in Indonesian coral reef sponge assemblages. Mar Freshw Res 2007; 58(3): 240-9.

[33] Fraser SB, Sedberry GR. Reef morphology and invertebrate distribution at continental shelf edge reefs in the South Atlantic Bight. Southeast Nat 2008; 7(2): 191-206.
[34] Wilkinson CR, Cheshire AC. Patterns in the distribution of sponge populations across the Central Great Barrier Reef. Coral Reefs 1989; 8(3): 127-34

[35] Bell JJ, Barnes DKA. The distribution and prevalence of sponges in relation to environmental gradients within a temperate sea lough: Inclined cliff surfaces. Divers Distrib 2000; 6(6): 305-23.

[36] Auster PJ. A conceptual model of the impacts of fishing gear on the Auster PJ. A conceptual model of the impacts of fishing gear on
integrity of fish habitats. Conserv Biol 1998; 12(6): 1198-203.

[37] Auster PJ, Langton RW. The effects of fishing on fish habitat. Fish Habitat: Essent Fish Habit Rehabil 1998; 22: 150-87.

[38] Rosenberg R. Effects of dredging operations on estuarine benthic macrofauna. Mar Pollut Bull 1977; 8(5): 102-4.

[39] Wassenberg TJ, Dews G, Cook SD. The impact of fish trawls on megabenthos (sponges) on the north-west shelf of Australia. Fish Res 2002; 58(2): 141-51.

[40] Jones JB. Environmental impact of trawling on the seabed: a Jones JB. Environmental impact of trawling on

[41] Hiddink JG, Jennings S, Kaiser MJ, Queiros AM, Duplisea DE, Piet GJ. Cumulative impacts of seabed trawl disturbance on benthic biomass, production, and species richness in different habitats. Can J Fish Aquat Sci 2006; 63(4): 721-36.

[42] Done TJ, Potts DC. Influences of habitat and natural disturbances on contributions of massive Porites corals to reef communities. Mar Biol 1992; 114: 479-93.

(C) Knapp and Bell; Licensee Bentham Open.

This is an open access article licensed under the terms of the Creative Commons Attribution Non-Commercial License (http://creativecommons.org/licenses/by$\mathrm{nc} / 3.0 /$ ), which permits unrestricted, non-commercial use, distribution and reproduction in any medium, provided the work is properly cited. 
Appendix III

Photographs of collected and identified sponges from the lagoons and reefs at Palmyra Atoll.

\section{Methods to identify surveyed sponges:}

All samples were collected on SCUBA and each novel specimen was sampled at least 3 times. A minimum of one sample remained in New Zealand at Victoria University of Wellington, one was sent to the National Autonomous University of Mexico for identification by Dr José Luis Carballo and Dr José Antonio Cruz-Barraza and a third set was deposited in the Bishops Museum, Honolulu, Hawaii in 2012. If a sponge was suspected of being a novel species (even though similar in appearance to an already collected specimen) it was sampled separately. Fourteen specimens were later combined and identified as eight species. In the field each specimen was given a number ID in order to consistently identify the same specimens for data analysis before the identifications were confirmed. Labels refer to those used in the species list in chapter 2 (Table 2.2). 

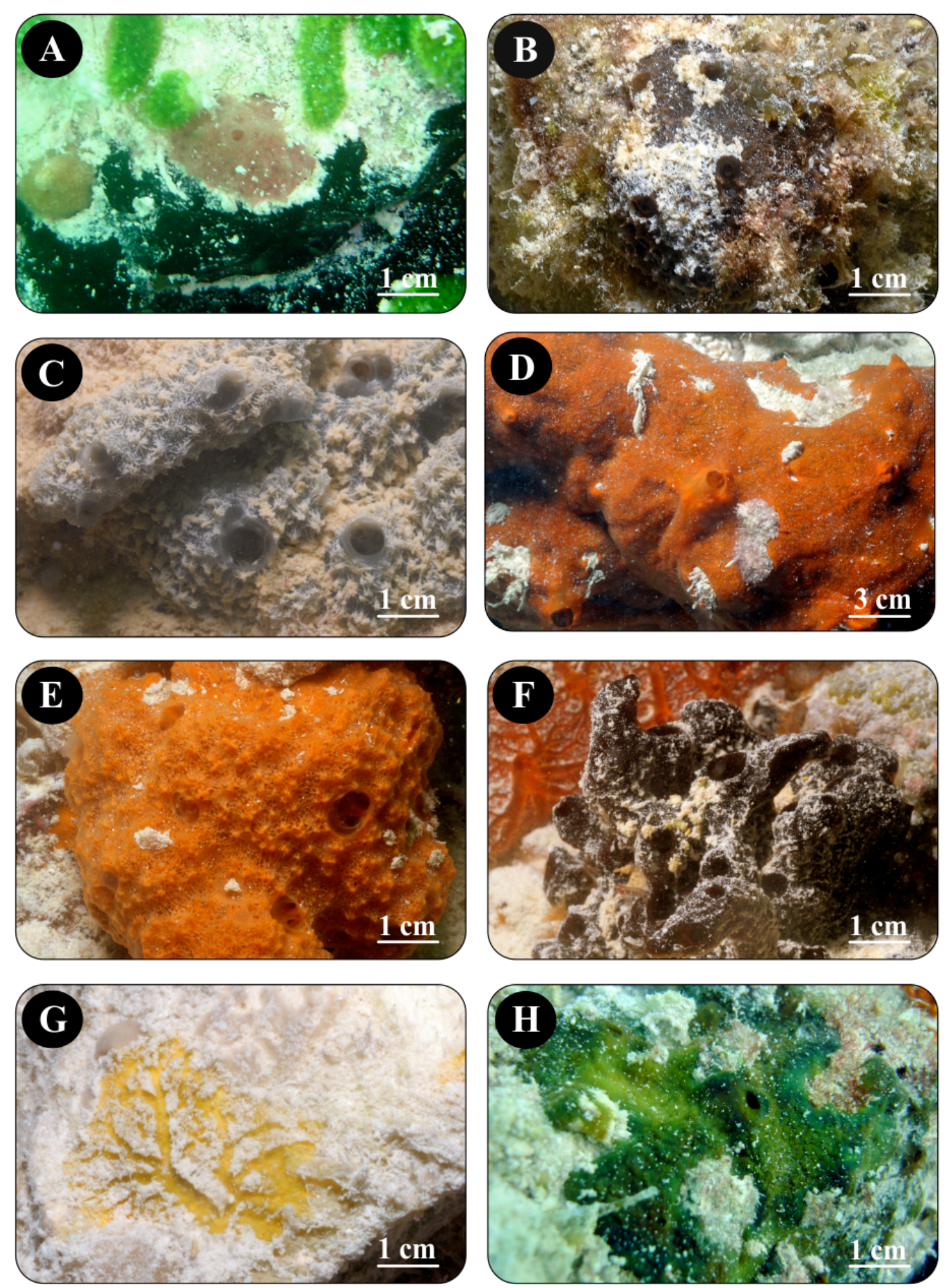

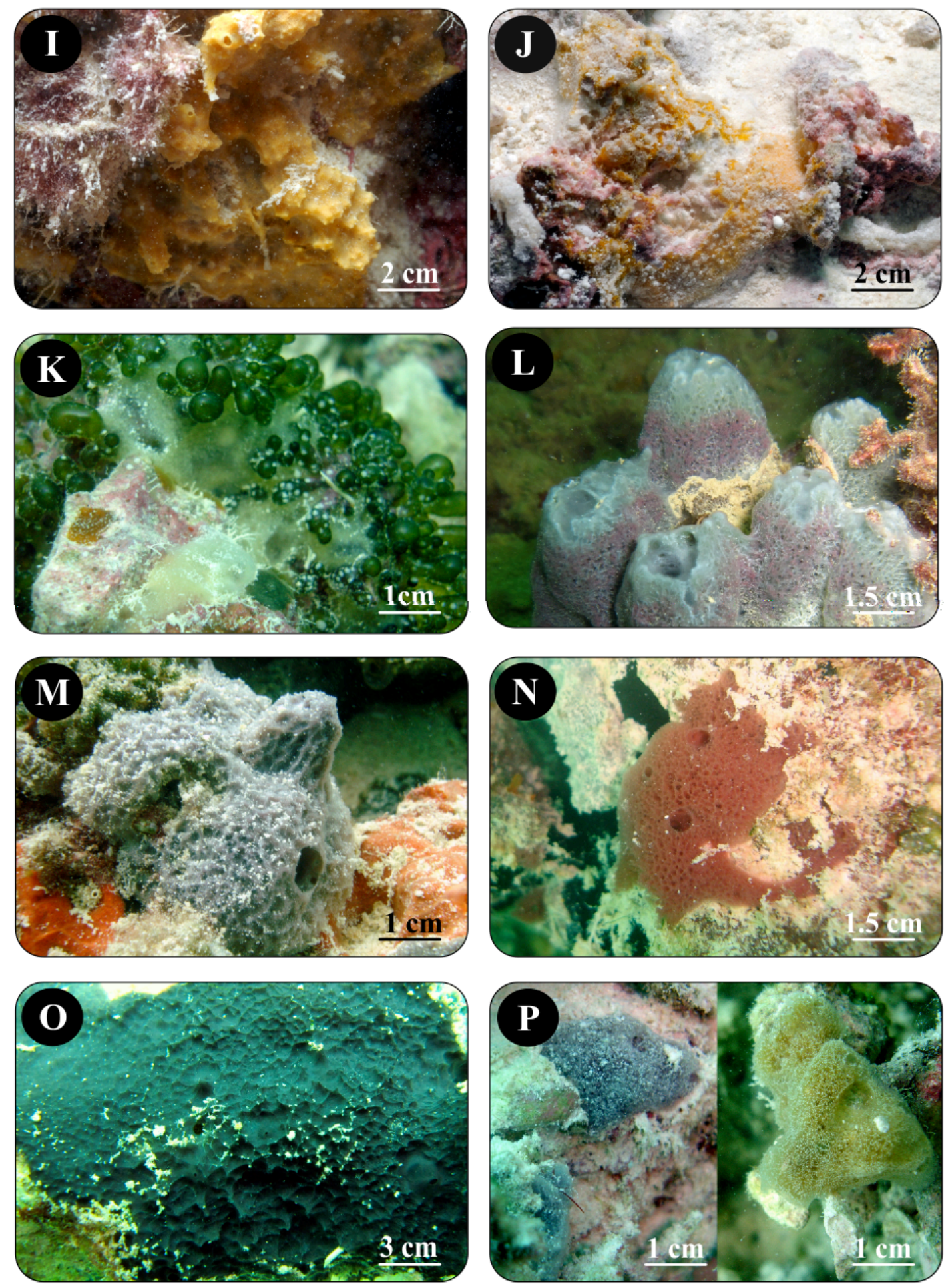

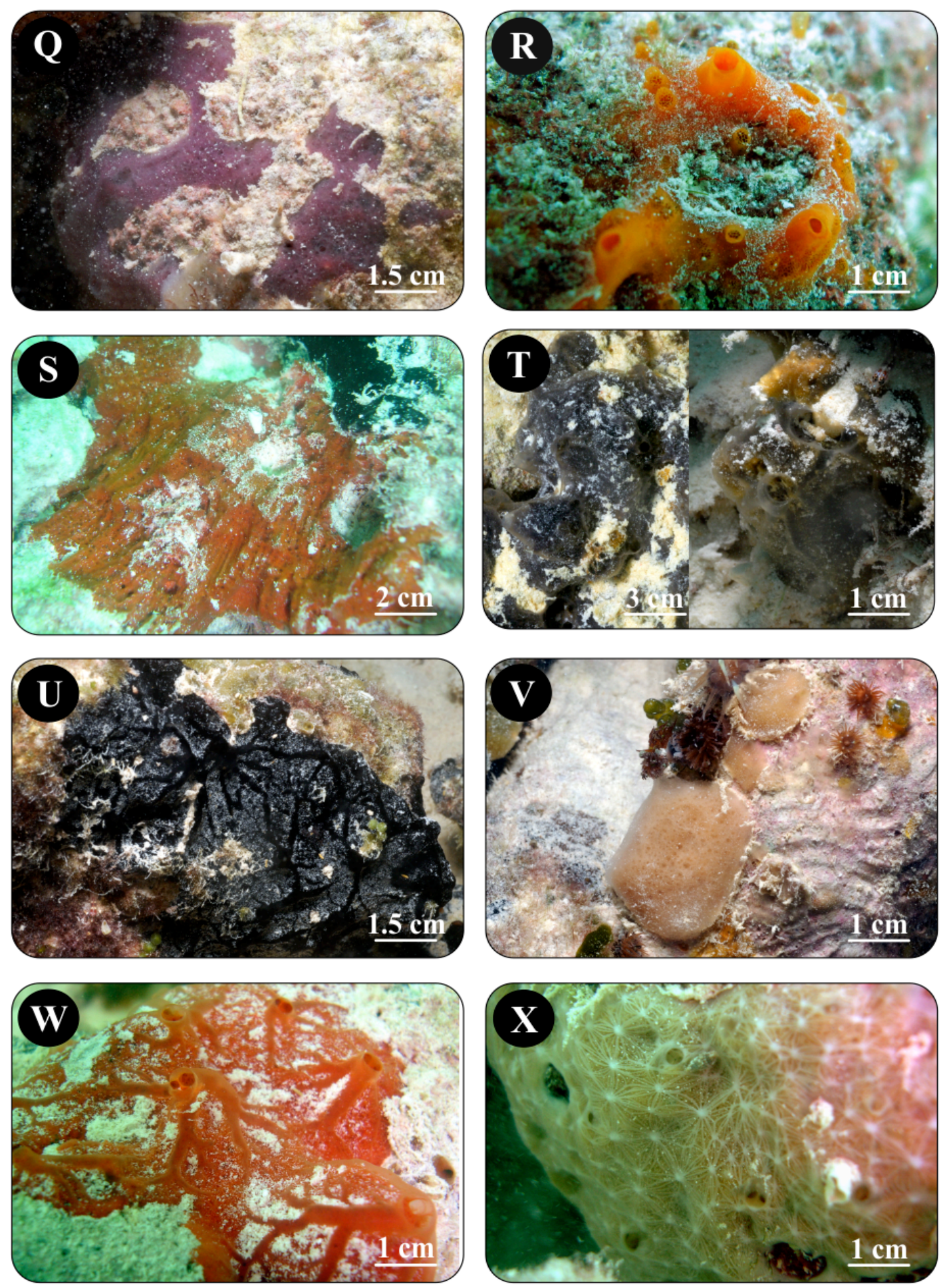

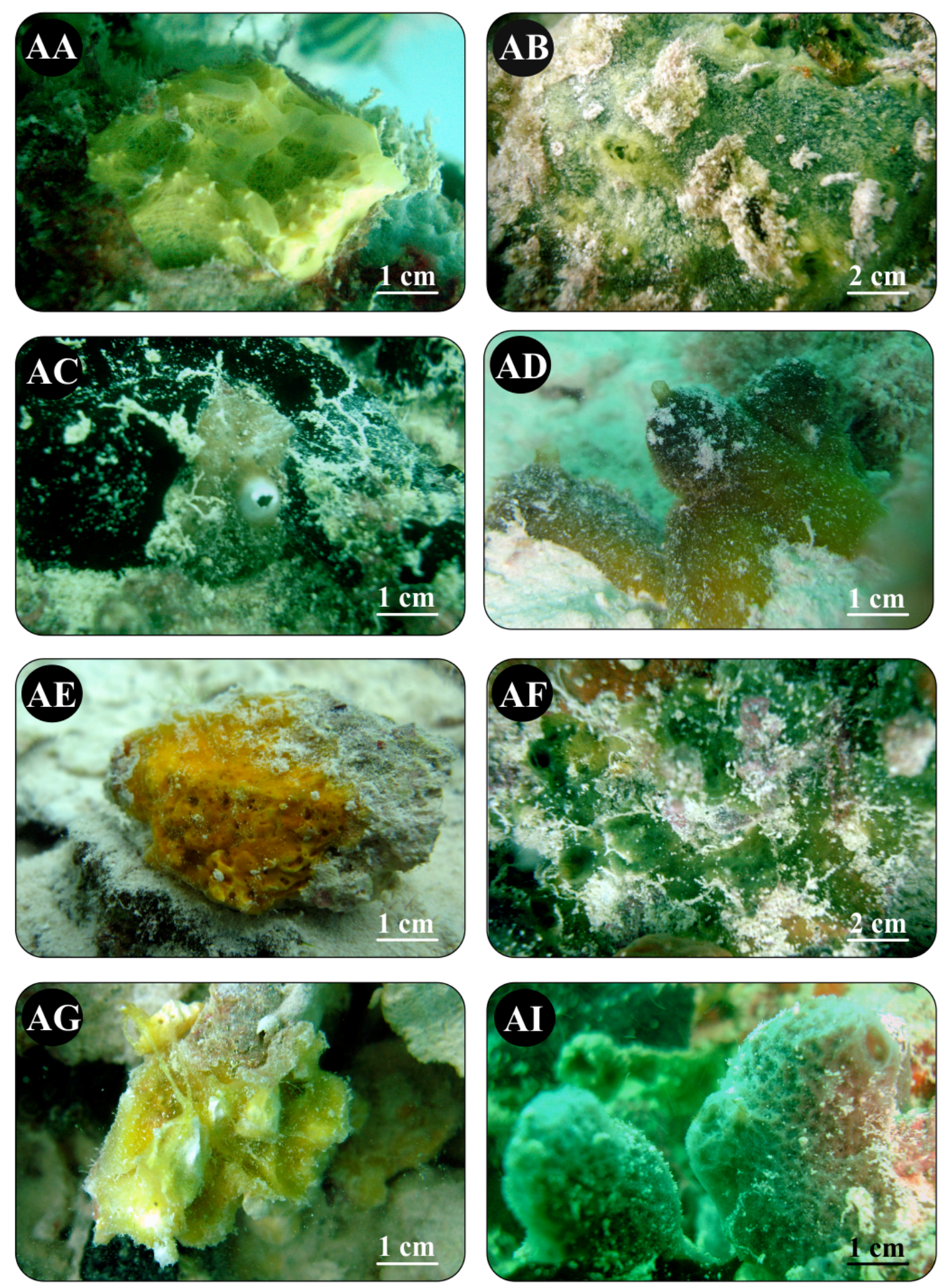

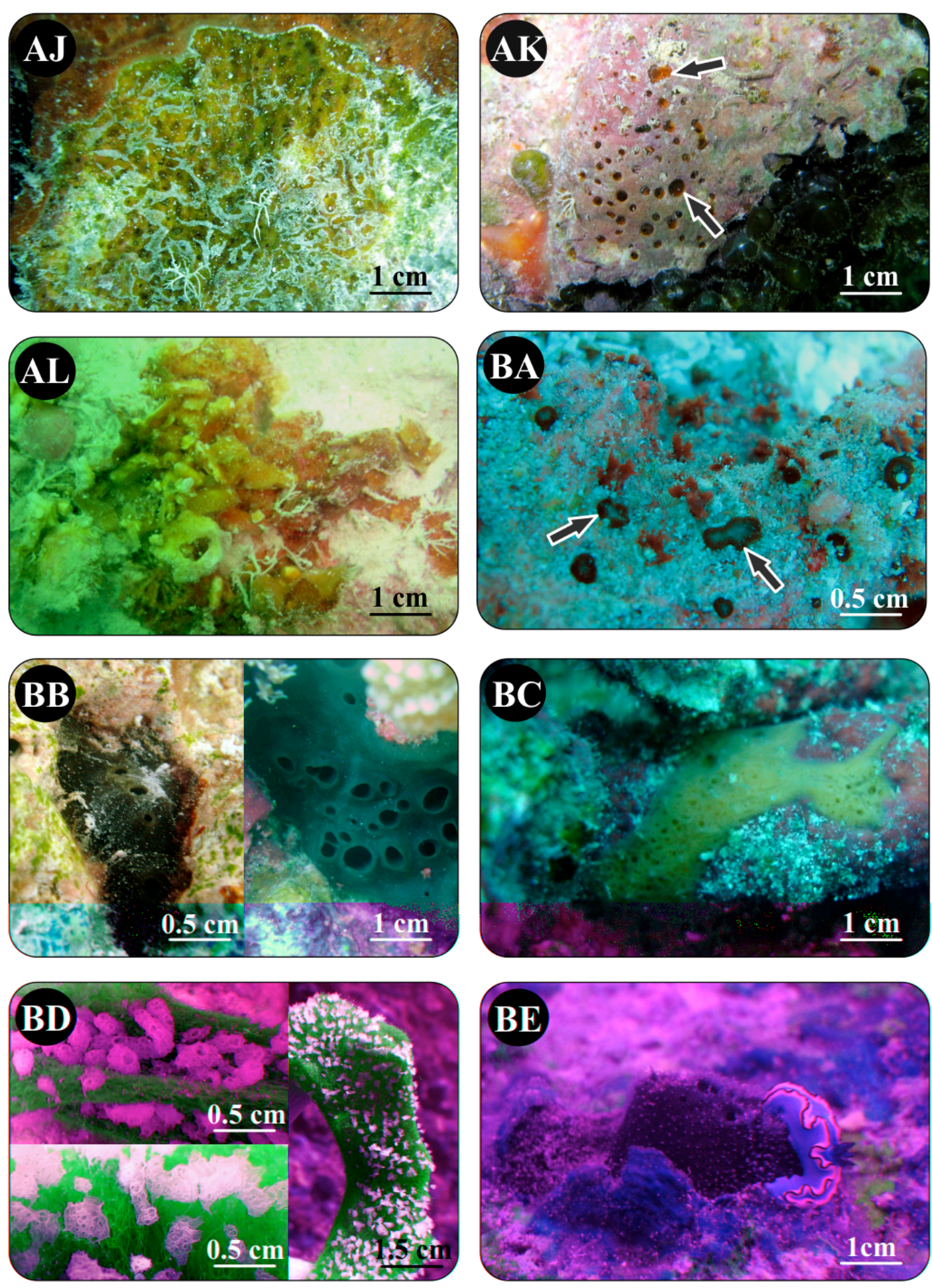

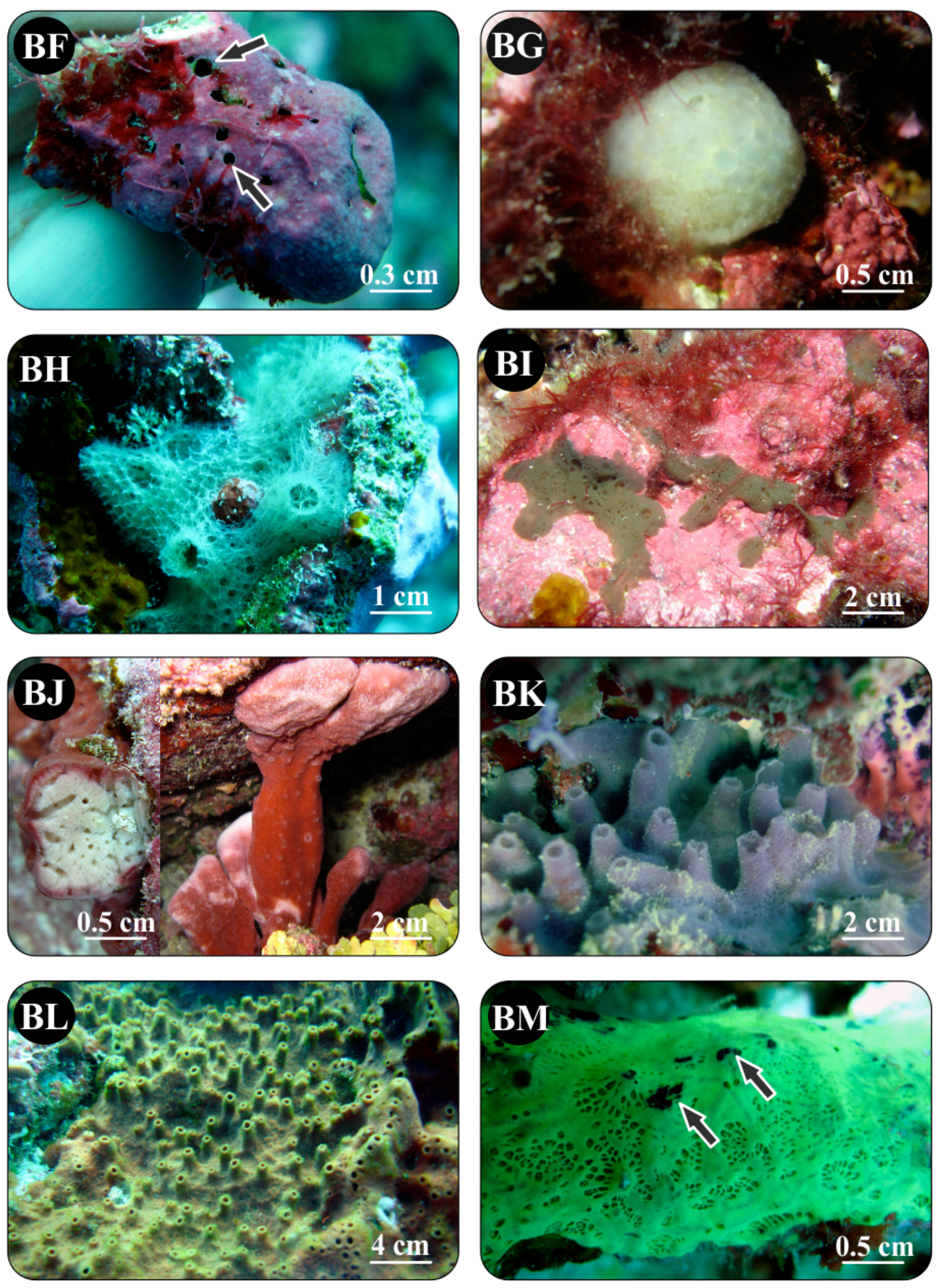

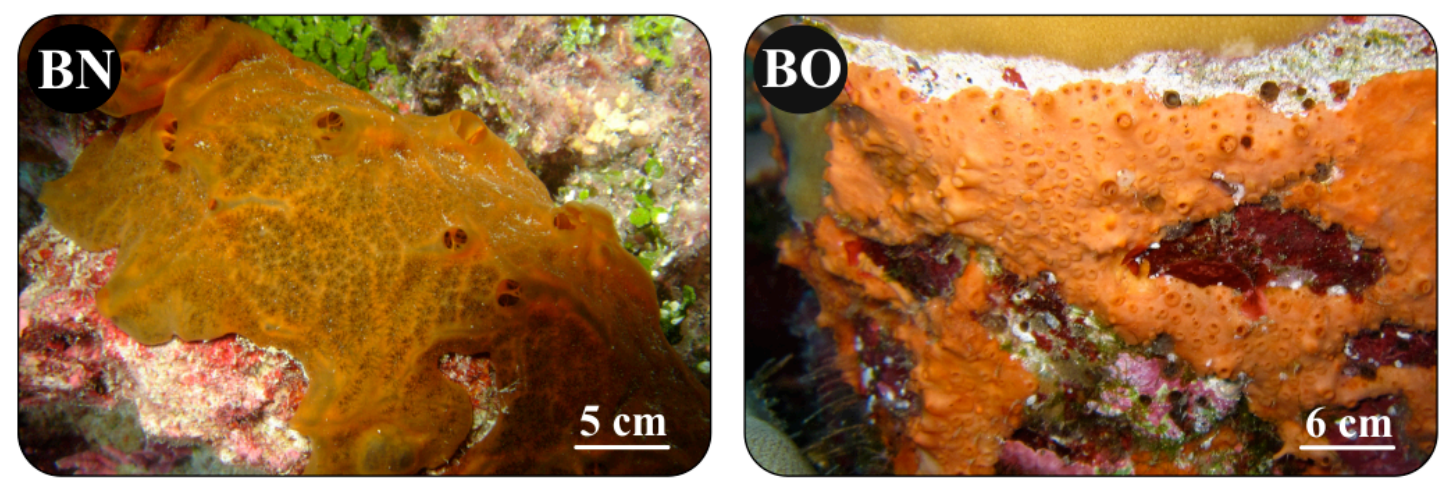


\section{Appendix IV}

Further ecological and morphological information for the Palmyra Atoll sponge species in Table 2.2 


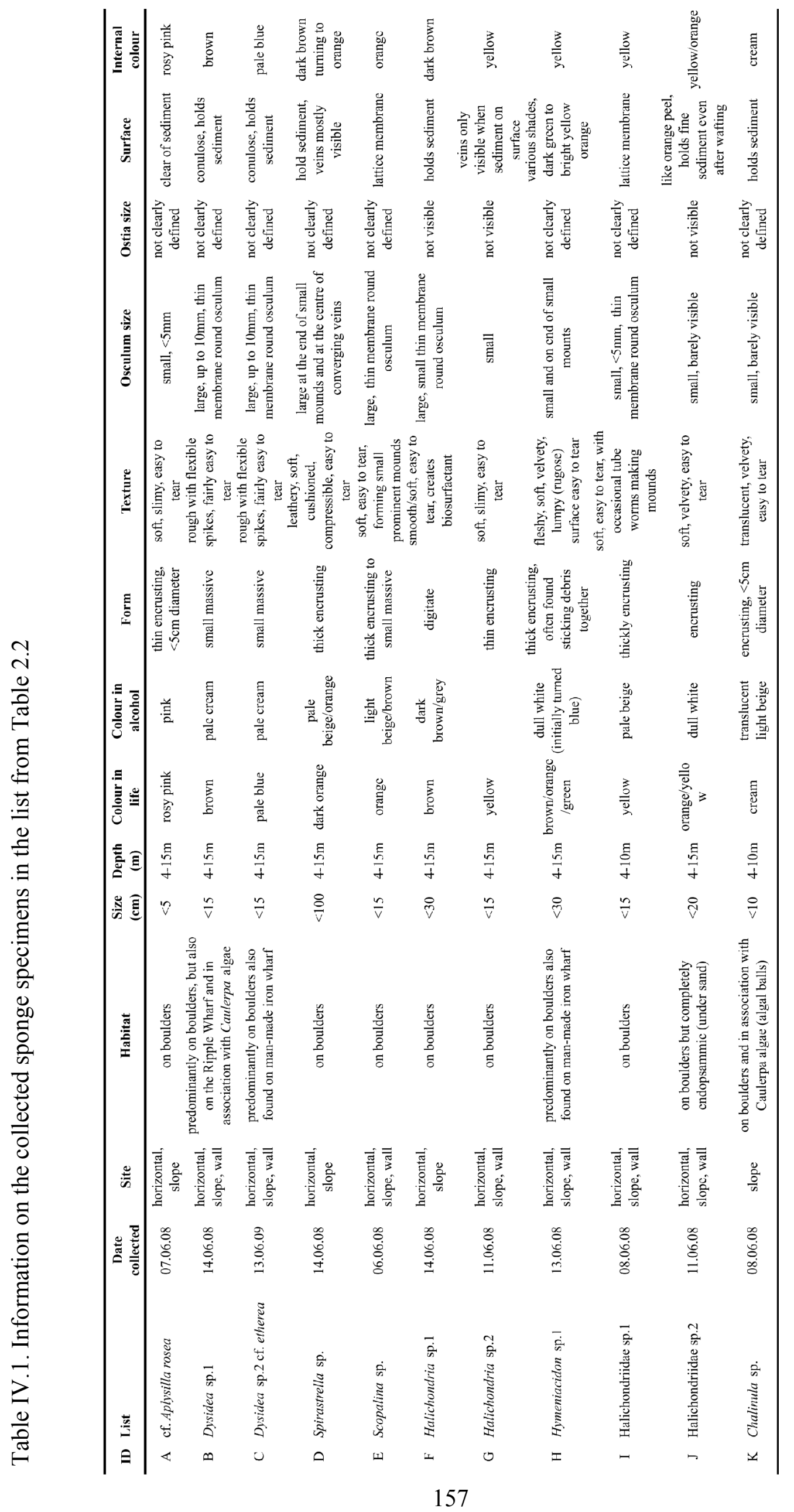




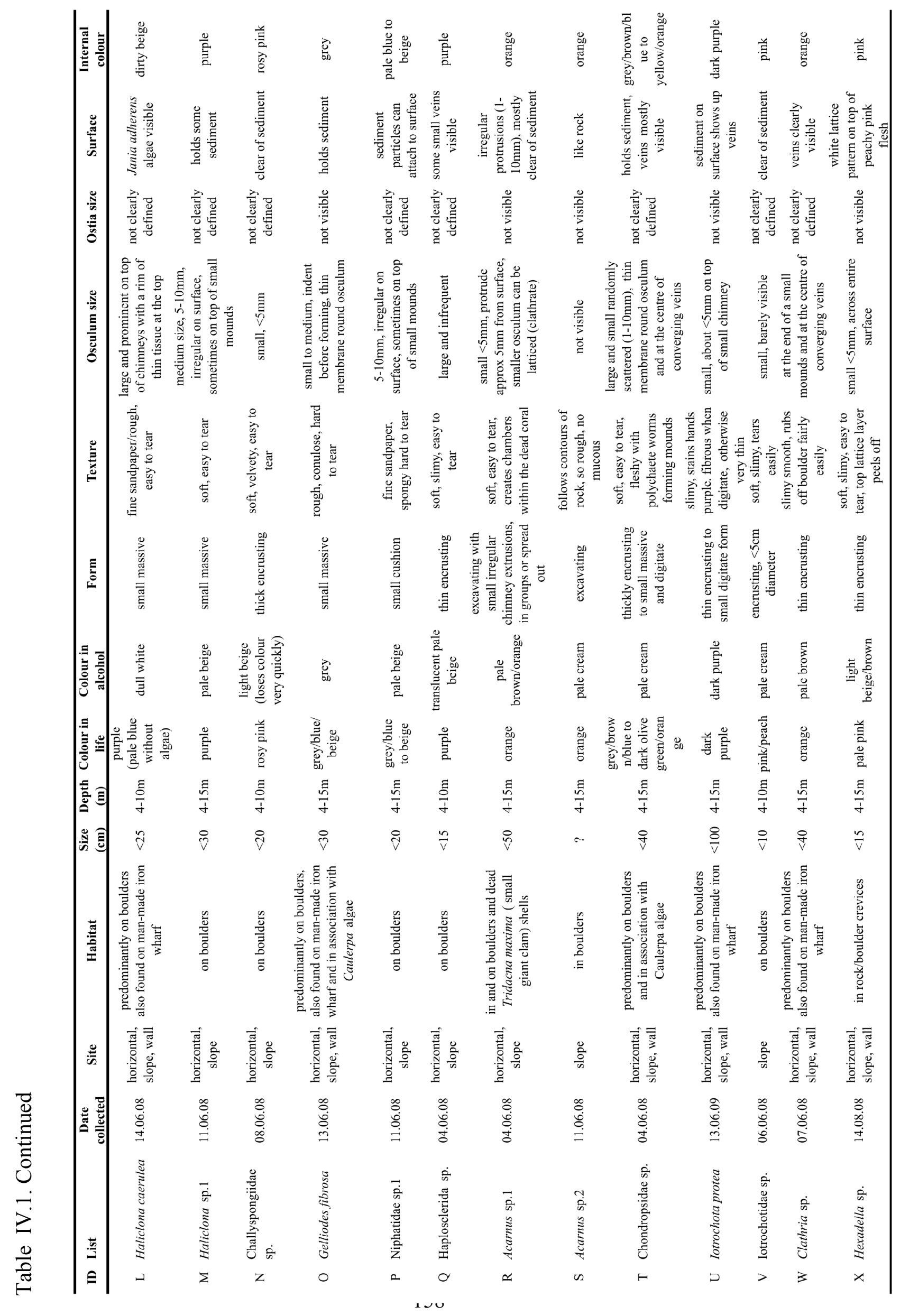




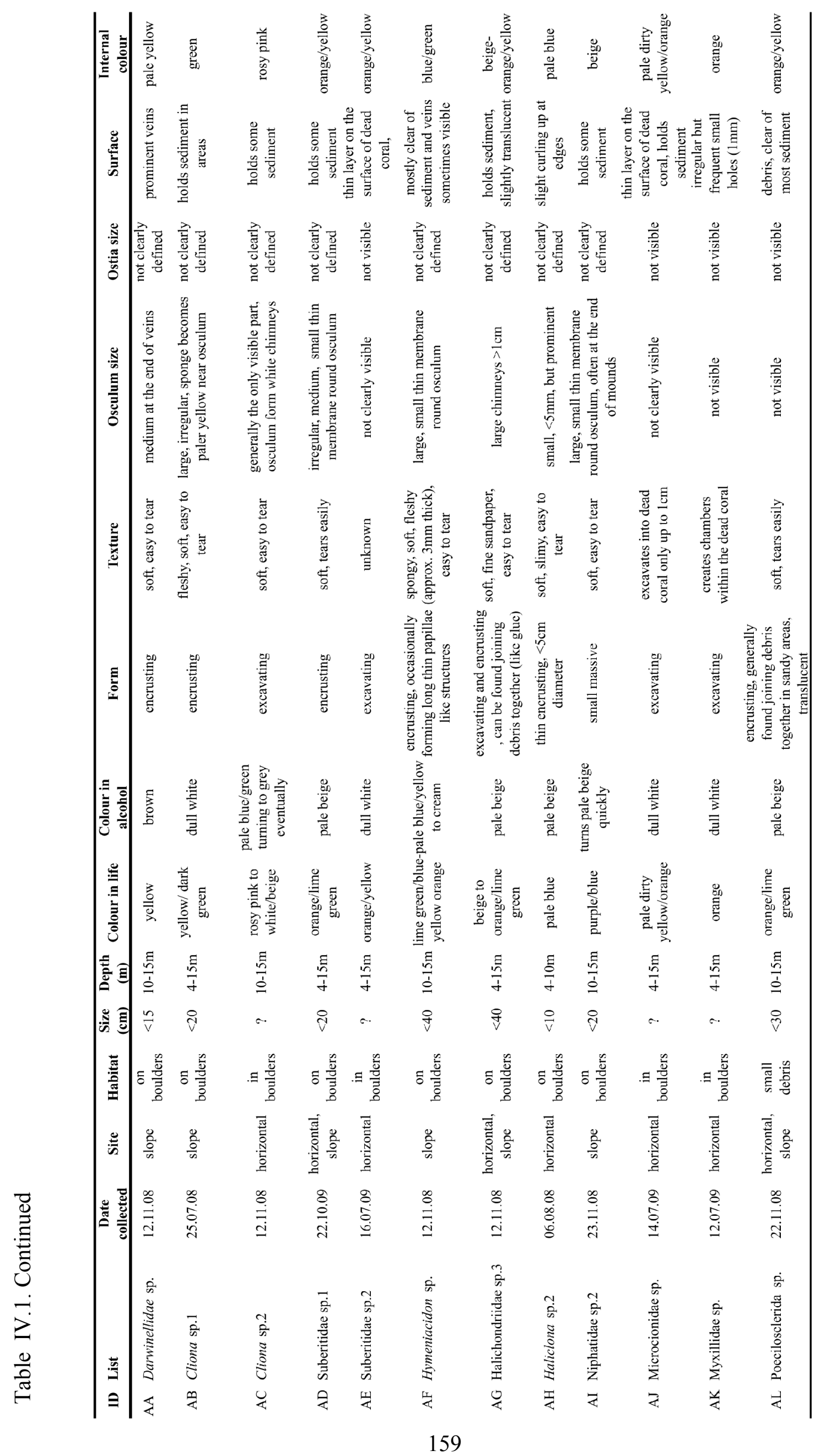




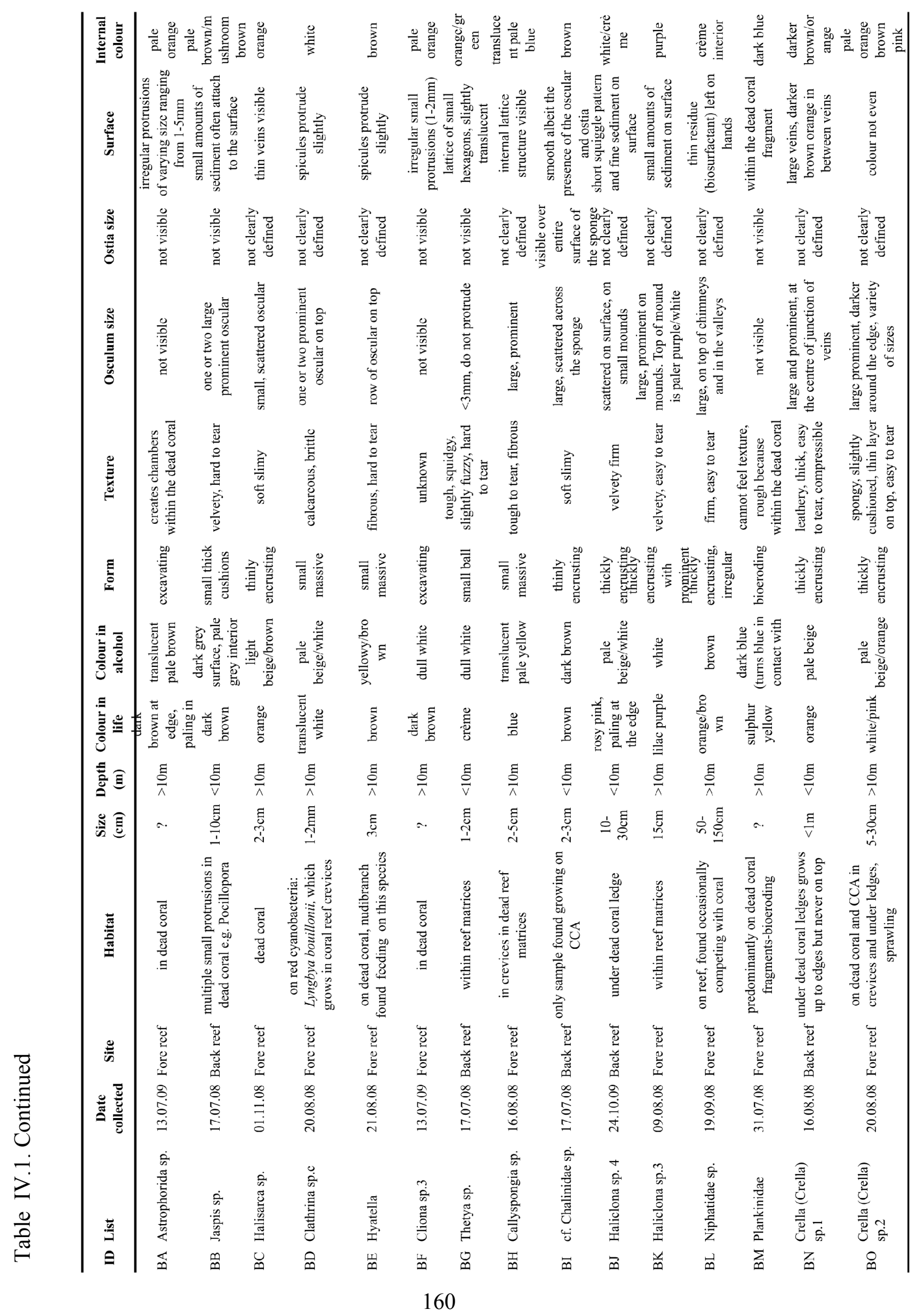




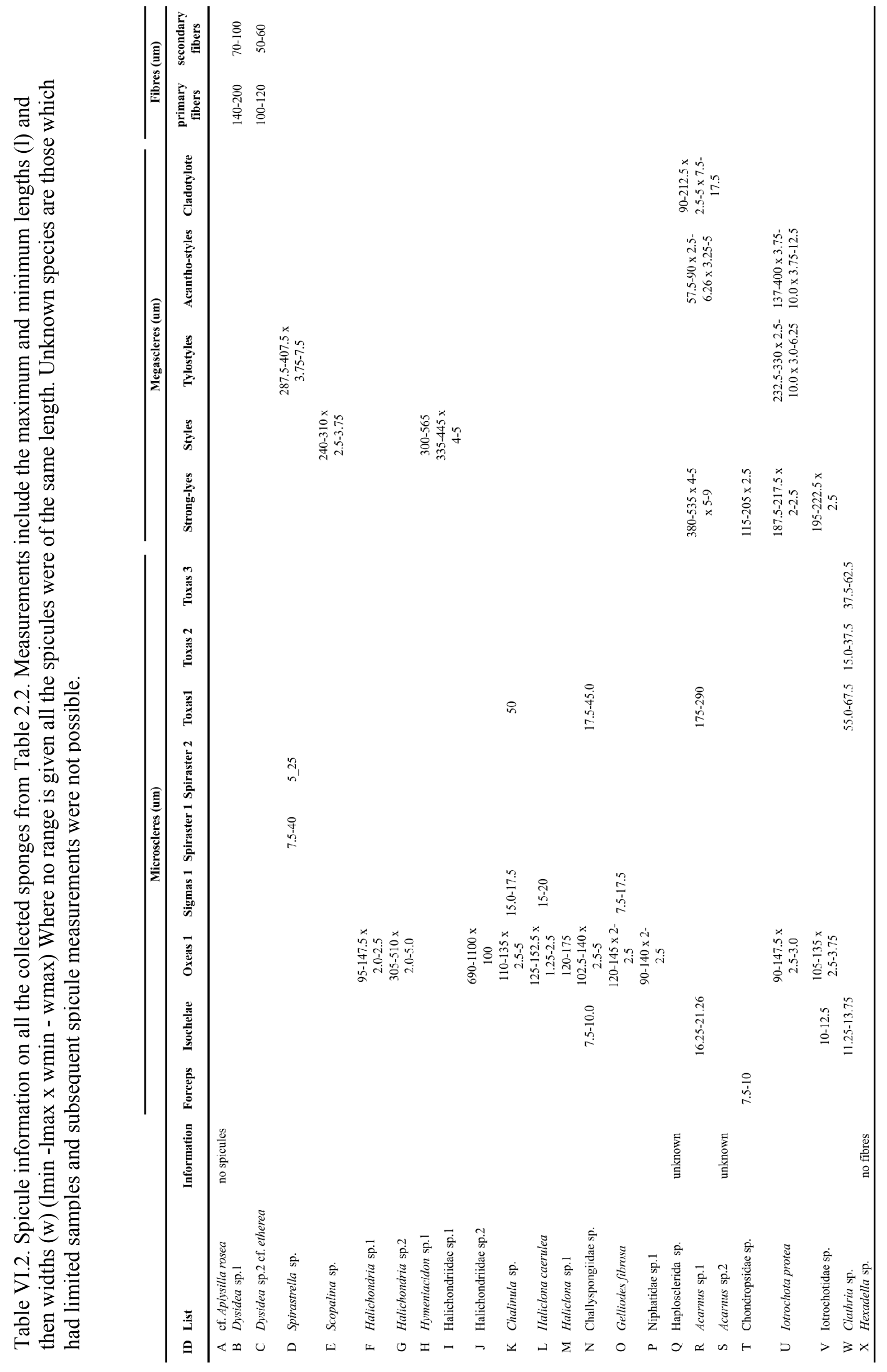




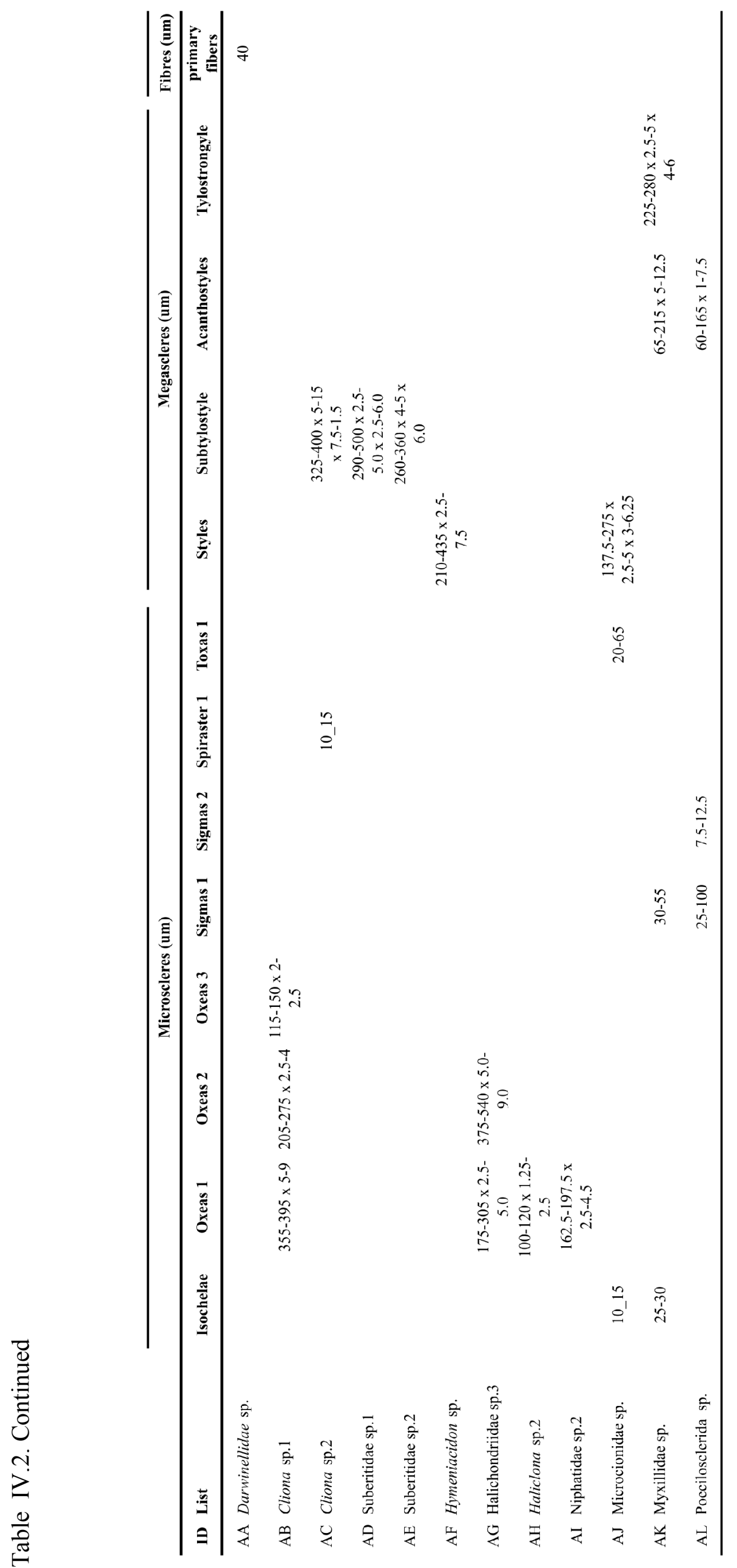




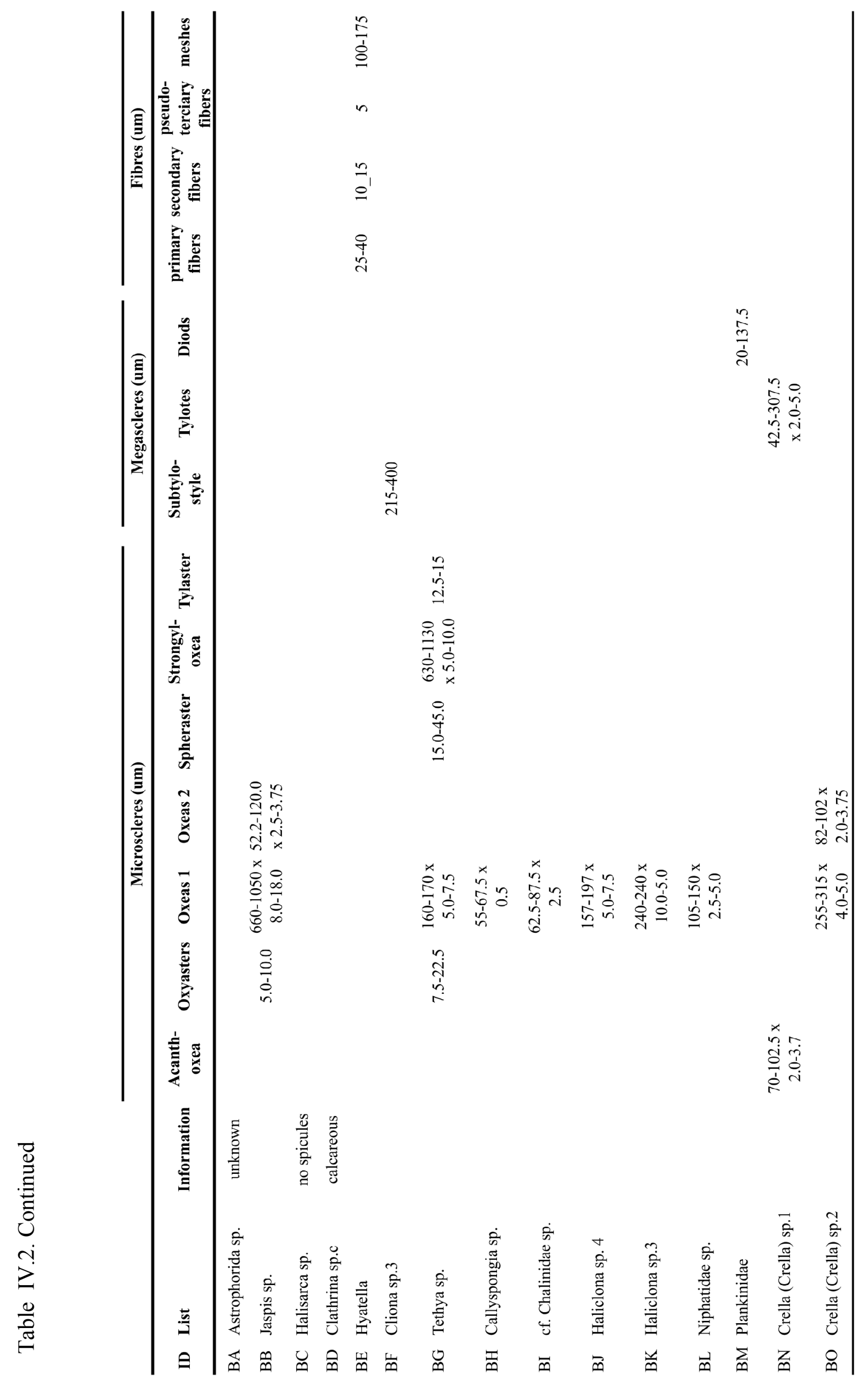




\section{Appendix V}

\section{Taxonomic histories of Gelliodes fibrosa (Wilson 1925) and Iotrochota protea (de Laubenfels, 1950)}

\section{Gelliodes fibrosa (Wilson, 1925) (accepted name)}

\section{Citation:}

Wilson, H.V.P (1925). Silicious and horny sponges collected by the U.S. Fisheries Steamer 'Albatross' during the Philippine Expedition,1907-10. pp. 273-532, pls 37-52. In: Contributions to the biology of the Philippine Archipelago and adjacent regions. Bulletin of the United States National Museum, 100 (2, part 4).

\section{Type specimen information:}

Original names: Gellius varius (Bowerbank, 1875), var. fibrosus, new variety and Gellius fibrosus.

Collection sites: (during Albatross Philippines expedition 1907-1910), station D5626 Kayoa, Indonesia; Togian Bay, Togian Island, Gulf of Tomini; Celebes (Sulawesi), Indonesia (identifications were made from 2 dried and 2 alcohol preserved specimens). Morphology: flattened or branching. Branches reach 30-40 $\mathrm{cm}$ and are cylindrical or flattened often terminating in pointed extremities. The sponge is firm but brittle (when dry).

Ectosome: Pores are uniformly distributed and close together, oscula are $2 \mathrm{~mm}$ in diameter, abundant and situated in well-defined depressions. Numerous small afferent canals $(\approx 0.5 \mathrm{~mm})$ extend radially from the surface of the sponge giving a porous appearance.

Endosome and skeleton: Consists of a renieroid reticulum and longitudinal polyspicular tracts. The tracts (often compact enough to be called fibres) are 20-100 $\mu \mathrm{m}$ in diameter and consist of closely packed spicules in approximately 3-12 rows which branch and anastomose obliquely forming a coarse and rather vague network with elongated meshes. The longitudinal tract distribution varies across the sponge. The remainder of the skeleton is made up of a renieroid reticulum with 3 or 4 sided meshes (one to two spicules long) made up of one to four spicules arranged into lines or fibres that are radial to the surface. Spongin is exiguous and only clearly apparent in the 
angles of the skeletal and dermal reticulum. Spicules can radiate outward from the nodes of the dermal reticulum. The tracts attach to the reticulum at nodes where several spicules converge.

Spicules: Oxea megascleres, which are smooth and slightly curved and taper evenly at both ends (160-180 $\mu \mathrm{m}$ long and 8-9 $\mu \mathrm{m}$ wide) and sigma microscleres (18-20 $\mu \mathrm{m}$ long), which are common in the interior and dermal membrane.

Notes: When dried the sponge may be light grey or light yellowish brown; in alcohol it can be reddish brown. Identifications were made from dried and preserved samples, therefore in situ descriptions were not provided.

\section{Recent published/unpublished records:}

Godwin, L. S. (2003). Hull fouling of maritime vessels as a pathway for marine species invasions to the Hawaiian Islands. Biofouling, 19(S1), 123-131.

Eldredge, L. G., \& Smith, C. M. (Eds.). (2001). A guidebook of introduced marine species in Hawaii. Bishop Museum and the University of Hawai'i.

Coles, S. L., DeFelice, R. C., Eldredge, L. G., \& Carlton, J. T. (1999). Historical and recent introductions of non-indigenous marine species into Pearl Harbor, Oahu, Hawaiian Islands. Marine Biology, 135(1), 147-158.

de Laubenfels, M. W. (1935). A collection of sponges from Puerto Galera, Mindoro, Philippine Islands. Philippine Journal of Science, 156(3), 327-336.

Iotrochota protea (de Laubenfels, 1950) (accepted name)

\section{Citation:}

de Laubenfels, M.W. (1950) The Sponges of Kaneohe Bay, Oahu. Pacific Science 4(1): $3-36$.

\section{Type specimen information:}

\section{Original name: Hiattrochota protea}

A new genus described as having smooth strongyles as special ectosomal spicules, smooth styles as endosomal megascleres, and birotulates or amphidiscs among the microscleres, without chelas. 
Collection sites: Coconut Island (Kaneohe Bay, Oahu), Kaalualu Bay (Oahu) and Honaunau (Kona, Hawaii)

Morphology: Massive, velvety black, somewhat elastic, not remarkable, smooth surface, oscula 1-3 mm and located on the summit of a rounded dome or lobe $(\approx 1 \mathrm{~cm}$ diameter and $0.5 \mathrm{~m}$ high)

Spicules: Smooth endosomal styles (135-180 $\mu \mathrm{m}$ long and 7-10 $\mu \mathrm{m}$ wide), smooth ectosomal strongyles (140-205 $\mu \mathrm{m}$ long and 3-6 $\mu \mathrm{m}$ wide) and amphidisc or birotulate microscleres (12-15 $\mu \mathrm{m}$ long) with greater than 4 clads at each end and a potentially spiny shaft.

Ectosome: Definite dermis over subdermal spaces, not very fleshy

Endosome and skeleton: Microcavernous with a skeleton similar to Isodictya species.

Few vague spicular tracts diameter $\approx 50-100 \mu \mathrm{m}$.

Notes: in preservative it retains its colour but stains the alcohol dark brown.

\section{Recent published/unpublished records:}

Smith, B. D., Donaldson, T. J., Schils, T., Reyes, A., Chop, K., \& Dugger, K. (2009). Marine Biological Survey of Inner Apra Harbor, Guam. University of Guam Marine Laboratory Technical Report, (126).

Van Soest, R. W. (2002). Family Iotrochotidae Dendy, 1922. In Systema Porifera (pp. 594-601). Springer US.

Dollar, S. J. (1979). WRRCTR No. 124 Ecological Response to Relaxation of Sewage Stress off Sand Island, O'ahu, Hawai'i. 


\section{Appendix VI}

\section{Fish predation trial experiment}

In order to examine whether fish predation could be maintaining the sponges in the lagoon I conducted a trial transplantation experiment where sponge species were taken from the lagoon and moved to the backreef to observe whether fish would predate on the sponges. Seven species of sponge $\left(\approx 5 \mathrm{~cm}^{2}\right)$ were collected from the lagoon and photographed next to a scale bar for later reference (Fig. VI.1). The seven species were (B) Dysidea sp.1, (D) Spirastrella sp., (F) Halichondria sp. 1, (L) Haliclona caerulea, (O) Gelliodes fibrosa, (U) Iotrochota protea and (W) Clathria sp. (ID letters taken from the species list in Table 2.2). The lagoon sponges were predominantly encrusting species and therefore if possible were collected on small rock fragments. All other organisms were removed from the rock fragments during the collection process in the lagoon. Removal of organisms only occurred if they could be taken off without damage. If this could not be achieved, the rock was replaced and another was selected. All material was returned to the site of collection after the experiment.

The sponges were then attached to a weighted PVC pipe (Fig. VI.1) using zipties threaded through pre-drilled holes (which were trimmed before placement on the reef) and placed in a container with seawater during transit to the reef. The water from the container was returned to the lagoon after the experiment. The experiments were set up in areas such as sand/shale patches or areas with dead coral all at backreef sites. If the trial was successful then the sponge samples would have been weighed on scales in a pre-tarred container of water before and after the fish predation experiment. However, for the trial the samples were not weighed as the aim of the trial was to observe whether any fish would consume the lagoon sponge species.

Preliminary trials were conducted 6 times at the backreef sites: Penguin Spit Inner, Middle (x2) and Outer Buoys, the Western Terrace and Tortugonas. These trials were conducted with diver and video surveillance to assure the quality of the experimental equipment. The experiment was in place for $1 \mathrm{~h}$ or theoretically for as long as it took for a considerable amount, but not all, of the sponge to be consumed. Predation generally occurs very rapidly on translocated sponges (Dunlap \& Pawlik 1996, Wulff 2000). During these trials divers remained at least $10 \mathrm{~m}$ away from the 
experiment but within visual range to observe fish feeding behaviour and intervene and remove the experiment if fragmentation occurred. The samples were encrusting or low lying massive species and therefore consumed by fish either by biting or scraping, not tearing (Dunlap \& Pawlik 1996). Fragmentation is unlikely, but all samples were handled with great care to avoid this as I did not want any chance of introducing any lagoon sponges to the reefs at Palmyra Atoll. Upon successful completion of the preliminary trials, the experiment would have been filmed with no divers present. It was believed that the presence of divers would not inhibit the fish feeding behaviour because they did not appear overly concerned by the presence of divers during the numerous dives prior to this trial.

All videos were watched afterwards despite divers observing the experiment throughout time of filming. The videos were double checked to ensure no fish predation occurred as the divers were in a different location to the camera. Unfortunately no fishes were observed predating on any of the lagoon sponges during theses trials, therefore the experiment was not taken any further.

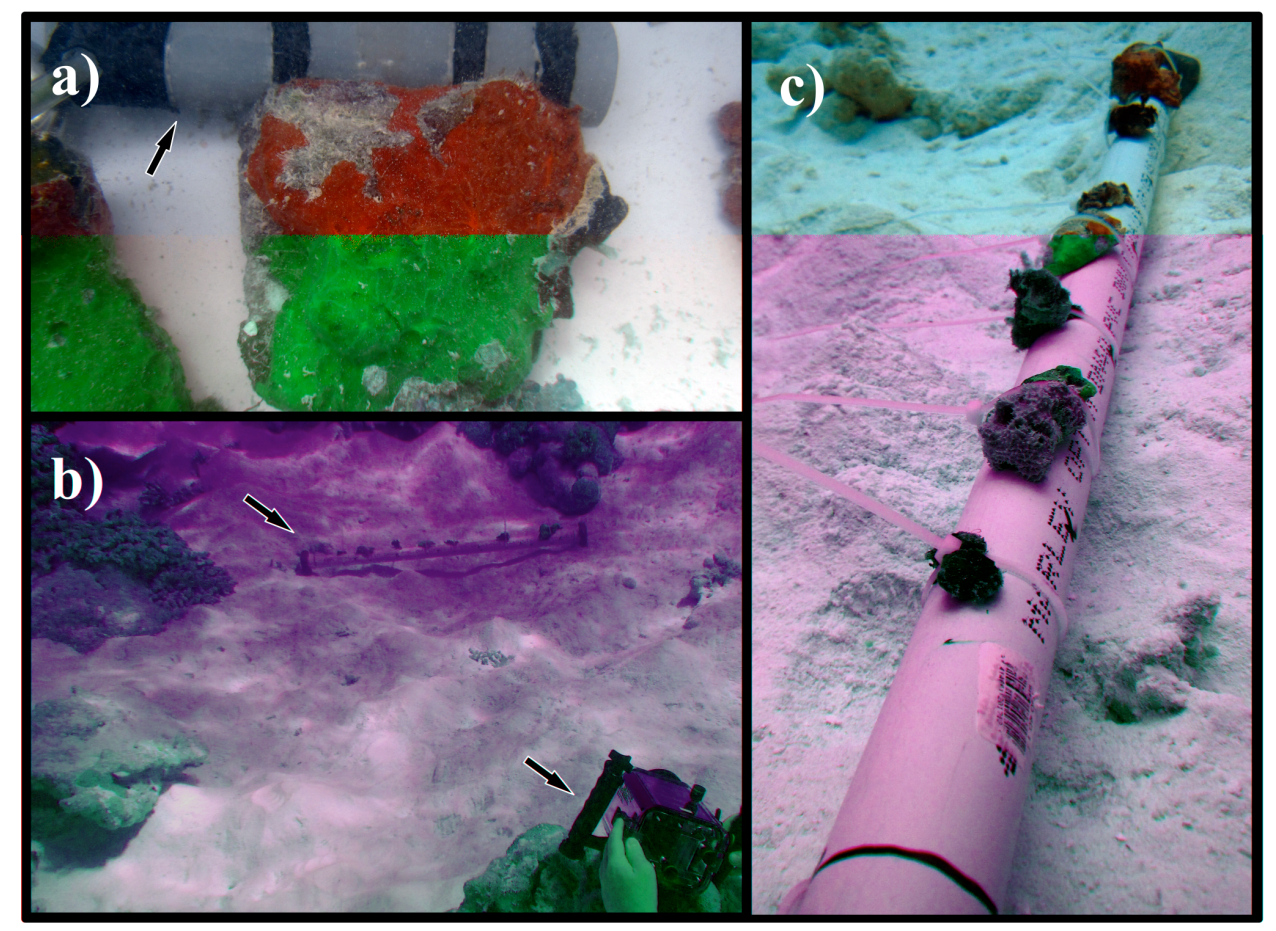

Figure VI.1. Fish predation trial setup with a) sponges photographed adjacent to a scale bar (see arrow) prior to deployment on the backreef, b) the placement of the weighted PVC pipe in a cleared area at Penguin Spit Inner Buoy with the video camera positioned nearby (see arrows) and c) the seven sponge species attached to the weighted PVC pipe with zip ties (untrimmed). 